\title{
CHARACTERIZATION OF AN ARYL HYDROCARBON RECEPTOR FROM A CETACEAN: AN APPROACH FOR ASSESSING CONTAMINANT SUSCEPTIBILITY IN PROTECTED SPECIES
}

\author{
by \\ Brenda Ann Jensen \\ B. S. Marine Science, Biology Track \\ Eckerd College, St Petersburg, Florida, 1994 \\ Submitted in partial fulfillment of the requirements for the degree of \\ Doctor of Philosophy \\ at the

\section{MASSACHUSETTS INSTITUTE OF TECHNOLOGY} \\ and the

\section{WOODS HOLE OCEANOGRAPHIC INSTITUTION}

September, 2000

(C2000 Brenda Jensen

All rights reserved.

The author hereby grants to MIT and WHOI permission to reproduce and to distribute publicly paper and electronic copies of this thesis document in whole or in part

Signature of author

Joint Program in Biological Oceanography

Massachusetts Institute of Technology/Woods Hole Oceanographic Institution

Certified by

Mark E. Hahn

Thesis Supervisor

Accepted by

Mark E. Hahn, Chair

Joint Committee for Biological Oceanography

Massachusetts Institute of Technology/Woods Hole Oceanographic Institution 


\title{
CHARACTERIZATION OF AN ARYL HYDROCARBON RECEPTOR FROM A CETACEAN: AN APPROACH FOR ASSESSING CONTAMINANT SUSCEPTIBILITY IN PROTECTED SPECIES
}

\author{
by \\ Brenda Ann Jensen \\ Submitted in partial fulfillment of the requirements for the degree of \\ Doctor of Philosophy
}

\begin{abstract}
Some cetaceans bioaccumulate substantial concentrations of halogenated aromatic hydrocarbons $(\mathrm{HAH})$ in their tissues, but little is known about the effects of such burdens on cetacean health. 2,3,7,8-Tetrachlorodibenzo-p-dioxin (TCDD) and related HAH cause toxicity via activation of the aryl hydrocarbon receptor (AHR), a member of the bHLHPAS family of transcription factors. Differences in AHR structure and function are known to contribute to species-specific differences in susceptibility to HAH toxicity, and targets for $\mathrm{HAH}$ toxicity are related to the tissue-specific expression of AHR. The goal of these studies was to ascertain the potential for HAH effects in cetaceans by characterizing the AHR from the beluga, Delphinapterus leucas. The beluga AHR was characterized by its molecular structure, capacity for ligand binding, structure-binding relationships with various classes of $\mathrm{HAH}$, as well as tissue-specific expression.
\end{abstract}

These results show that: 1) in an in vitro system, the beluga AHR possesses binding affinities similar to AHRs of other mammals that are considered sensitive to toxic effects of HAH, 2) Structure-activity relationships are consistent with a common mechanism of coplanar HAH action among cetaceans and rodent species, and 3) the AHR protein is expressed in many tissues of the beluga, and is present at high levels in lymphoid organs, liver and lung. Together, these data suggest that cetaceans can be considered sensitive to the action of coplanar HAH. Further, using in vitro expressed proteins is a promising approach for addressing molecular and biochemical questions about PHAH toxicity in endangered and protected species where logistical and ethical concerns preclude testing in live animals.

Thesis supervisor: Mark E. Hahn, Title: Associate Scientist, Biology Department, WHOI 


\section{Acknowledgements}

This thesis would not have been possible were it not for devoted support from a great number of people. First, a very sincere thanks to my advisor, Mark Hahn, who taught me far more than I was able to put into effective practice during my graduate work. I thank him for supporting me in all aspects of my education, including teaching, and especially field work. I admire him as a devoted and productive scientist, and look forward to being long time colleagues and friends.

My committee has been instrumental in so many ways, collectively and individually. I first came to Woods Hole as a summer fellow in John Stegeman's lab. Since that summer I have greatly appreciated his constructive comments on my work, and thank him for his tremendous support. From Michael Moore I learned that I could dare to do the science that I dreamed to do. I am forever indebted to him for including me in a right whale seeking expedition to the former whaling waters around South Georgia. The trip to the small island of few people and many penguins and pinnipeds proved to be a life-changing experience. I thank Peter Dedon for traveling down from MIT for every committee. Pete was generous with his encouragement and support, and taught a great course that was the first to teach me some toxicology fundamentals. I thank Judy McDowell for her endless support and enthusiasm for not only my thesis work, but also for any other issue I could question of her over the years. I thank Darlene Ketten not only for being a wonderful thesis defense chair, but also for being incredibly generous with her laboratory facilities, samples, time and support. I thank Neal Cornell, who was instrumental in the initial isolation of high quality beluga RNA. He always taught the art and value of both precision and compassion, and he is much missed in the Woods Hole community.

I thank the Joint Committee in Biological Oceanography and the WHOI Education Office for their generous support. A special thanks to John Farrington who went the extra mile when he arranged for me to have an MIT teacher's assistantship during my first year. Thanks also to Lauren Mullineaux for her advise and support over the years as Education Coordinator.

The beluga sampling trips would not have been possible without the support from the North Slope Borough Division of Wildlife and the town of Point Lay, Alaska, especially Robert Suydam, Todd O'Hara, Dave Ramey, Craig George, Victoria Woshner, Greg O'Corry-Crowe, Ray Tarpley, Mayor Kenny Towksjhea, Bill and Marie Tracey and all of the families of Point Lay. Thanks to Tracy Romano for sharing liquid nitrogen responsibilities and sampling paranoia, and for histologically identifying the elusive thymus.

Thanks to so many at WHOI, MBL, and MIT who helped me out at critical times: B.L. Owens, Dave MacDonald, Judy Kleindinst, Maggie Walden, Judy Fenwick, Tom Kleindinst, and Jim MacConnell, Lew Karchner, Tracey Crago, Maura Faggart, and Janice Chang.

I thank the Hahn and Stegelabs for great science and great times: Sibel Karchner, Diana Franks, Wade Powell, Connie Hart, Sue Bello, Eli Hestermann, Bruce Woodin, Renee White, Margie Oleksiak, Jennifer Schlezenger, Rachel Cox, Celine Godard (I'll 
never forget the trip to France!), Joanna Wilson, Carolyn Miller, Shannon Bard, Heather Handley, Brad Dooley, Rebeka Merson, Joy Laperitis, and Eric Montie. Bruce, thank you for being an incredibly fun presence in both of our labs, for always tolerating interruptions, for singing at my wedding, for great sailing trips, yummy pesto parties, and so much more. Eli, thanks for the science insight, for being the instigator for the Thesis Support Group (TSG- a tradition which I trust will live on long past our tenure here), for college football banter, and a great friendship.

I have been incredibly fortunate to share an office with Sibel Karchner and Diana Franks for most of my time here. We've all had something to contribute to the stress level in the office (!), but it sure brought us together. Sibel taught me all I know about molecular biology, and her incredible attention to detail made every discussion (about any topic) fruitful. Thanks so much for everything, Sibel.

Endless thanks to WHOI 94 for all the good times, and TSG for sticking together through all the not-so-fun. Both were incredibly essential for the complete grad school experience! Nicole, we've come a long way since our summer fellow days, and I thank you in particular for your constant support up to the very end. Liz, you've been with me through everything, and I thank you for always knowing what to say to get me out of a funk.

I thank my whole family for their patience and support through this whole process. My brothers, Brian and Brad, my in-laws Edie and Fred, Chris, Nicole, and Scotty, and my favorite out-laws Lorraine and Rudy. I am incredibly fortunate to have you all as my family.

Mom and dad, thanks for your unfaltering support and faith in me. Your strength is an inspiration to me, and I love you both incredibly.

Finally, I thank Erik for everything, and especially for his love.

This work was supported by NIH Grant No. ES06272, NOAA National Sea Grant College Program Grant Nos. NA46RG0470, (WHOI Sea Grant Project No. R/B-137), NA86RG0075 (WHOI Sea Grant Project No. R/B-151), NA86RG0075 (WHOI Sea Grant Project No. R/P-64) and the Ocean Ventures Fund. 


\section{TABLE OF CONTENTS}

$\begin{array}{ll}\text { Abstract } & 3\end{array}$

Acknowledgements $\quad 5$

$\begin{array}{ll}\text { List of Figures } & 9\end{array}$

$\begin{array}{ll}\text { List of Tables } & 12\end{array}$

Chapter 1: Introduction $\quad 13$

Chapter 2: Molecular cloning and functional characterization of an aryl 35

hydrocarbon receptor in the beluga

Introduction $\quad 36$

Materials and Methods $\quad 39$

Results $\quad 48$

Discussion $\quad 55$

Chapter 3: Structure-activity relationships and the derivation of relative 81 potencies for the binding of halogenated aromatic hydrocarbons to the beluga and mouse aryl hydrocarbon receptors

Introduction $\quad 82$

Materials and Methods $\quad 85$

Results $\quad 89$

Discussion $\quad 96$

Chapter 4: Tissue-specific expression of the aryl hydrocarbon receptor 111 in the beluga

Introduction $\quad 112$

Materials and Methods $\quad 115$

Results $\quad 126$

Discussion 133

Chapter 5: Summary, Conclusions and Future Directions 179

$\begin{array}{ll}\text { Bibliography } & 184\end{array}$ 


\section{LIST OF FIGURES}

Chapter 1:

Figure 1. Structures of halogenated aromatic hydrocarbons. 30

Figure 2. World beluga distribution. $\quad 31$

Figure 3. Malignant tumors in St. Lawrence belugas 1982-1998. 32

Figure 4. Functional domains of the mouse AHR. 33

Figure 5. AHR signal transduction pathway and CYP1A induction. 34

Chapter 2:

Figure 1. Strategy for the PCR amplification and sequencing of a beluga AHR cDNA.

Figure 2. Sequence coverage of beluga AHR cDNA.

Figure 3. Full length translation of a beluga AHR cDNA.

Figure 4. Alignment of beluga, human, and mouse AHRs.

Figure 5. Conservation in functional domains between beluga, mouse, and human AHRs.

Figure 6. Comparison of belAHR expression constructs under SP6 and $\mathrm{T} 7$ promoters

Figure 7. Autoradiogram and western blot of beluga, mouse, and human AHRs.

Figure 8 . Velocity sedimentation analysis of in vitro-expressed and 
cytosol-derived AHRs.

Figure 9. Total $\left[{ }^{3} \mathrm{H}\right] \mathrm{TCDD}$ binding and fraction of "free" relative to 73 protein dilution.

Figure 10. Saturation binding curves for beluga, mouse, and human AHR.

Figure 11. Scatchard analyses of saturation binding curves for beluga and mouse AHR binding to $\left[{ }^{3} \mathrm{H}\right]-\mathrm{TCDD}$.

Chapter 3:

Figure 1. Competitive binding assay with dextran-coated charcoal (DCC).

Figure 2. HAP assay timecourse and effects of sodium molybdate on specific binding of beluga, mouse, and human AHRs.

Figure 3. Competitive binding curves for mouse and beluga AHR for various $\mathrm{HAH}$

Figure 4. Inhibition constants $\left(\mathrm{K}_{\mathrm{i}}\right)$ of $\left[{ }^{3} \mathrm{H}\right]-\mathrm{TCDD}$ binding to beluga and mouse AHRs by various HAH.

Chapter 4:

Figure 1. Quality control check for total RNA isolated from various tissues from two individual belugas, 98-1 and 98-2.

Figure 2. Sequence and translation of partial beluga $\beta$-actin cDNA. 
Figure 3. Beluga $\beta$-actin primer design.

Figure 4. Parameter optimization for relative RT-PCR with beluga $\mathrm{AHR}$ and $\beta$-actin.

Figure 5. Specific ${ }^{3} \mathrm{H}-\mathrm{TCDD}$ binding in $98-1$ and $98-2$ belugas.

Figure 6. Structures of AHR and related proteins and antigens.

Figure 7. Western blots of 1998 beluga tissue cytosols.

Figure 8. Western blots of 1997 beluga tissue cytosols.

Figure 9. Western blots of 1997 beluga tissue cytosols (alternative view).

Figure 10. Western blots of 98-1 beluga tissues with SA-10 and BEAR2.

Figure 11. Overlay of Western blots from Figure 10.

Figure 12. Relative AHR expression patterns in 98-1 and 98-2 tissues using relative RT-PCR.

Figure 13. Summary of AHR mRNA expression as determined by relative RT-PCR.

Figure 14. RT-PCR signal does not arise from contaminating genomic DNA.

Figure 15. Full-length AHR transcripts are detected in all tissues using RT-PCR. 


\section{LIST OF TABLES}

Chapter 2:

Table 1. Summary of dissociation constants $\left(\mathrm{K}_{\mathrm{d}}\right)$ and maximal

binding $\left(\mathrm{B}_{\max }\right)$ determined for in vitro expressed AHRs.

Table 2. Dissociation constants $\left(\mathrm{K}_{\mathrm{d}}\right)$ reported in literature.

79

Chapter 3:

Table 1. Comparison of parameters used in competitive binding 105 assays using hydroxylapatite absorption.

Table 2. Summary of competitive binding experiments (HAP assay). 106

Table 3. Summary of IC50s, Ki, and relative potencies determined 108 for beluga and mouse.

Table 4. Relative potencies (REPs) for AHR binding and 109 mammalian Toxic Equivalency Factors (TEFs)

Chapter 4:

Table 1. Summary of tissue specific expression data for 98 belugas.

Table 2. Summary of tissue-specific expression data from the literature. 176 
Chapter 1:

Introduction 
Halogenated aromatic hydrocarbons $(H A H)$ in the environment

Halogenated aromatic hydrocarbons ( $\mathrm{HAH})$ are thermodynamically stable chemicals that elicit a number of biochemical and toxic responses. HAH include the dibenzo-p-dioxins (e.g. TCDD), dibenzofurans (e.g. TCDF), and polychlorinated biphenyls (PCBs)(Figure 1). Although most western countries banned new and open uses of PCBs in the 1970's, PCB influx into the environment continues. PCBs are still permitted for use in large transistors, capacitors, and hydraulics in the U.S. In developing countries, PCB use and disposal is not well documented (AMAP, 1998).

HAHs reach the marine environment from many sources. A major source of PCBs is disposal of PCB-containing machinery. Transistors, capacitors, and vacuum pumps are disposed in landfills, slow degradation allows PCBs to leech into ground water, and heat from waste decomposition causes PCBs to volatilize and distribute atmospherically (McClure, 1976). Chlorinated dioxins and furans reach the environment as minor components of other organochlorine mixtures as a byproduct of manufacture or formed during use or disposal. Processes such as paper bleaching and waste burning are common sources of chlorinated dioxins. Brominated dioxins and furans are formed by burning flame retardant substances, and though these are less persistent, they are potentially more toxic to freshwater fish embryos than the chlorinated species (Hornung et al., 1996).

Oceanic and atmospheric circulation are the likely modes by which HAHs are transported to regions where there is little human activity such as the Arctic, where organisms display surprisingly high concentrations of chlorinated hydrocarbons considering their remote location (Wade et al., 1997). Although legislation may limit 
HAH use in certain parts of the globe, the past and current use of organohalogens leave no marine environment pristine.

\section{Cetaceans are exposed to $H A H$}

Marine mammals accumulate large concentrations of HAH in tissue. As top predators in the coastal environment that depend morphologically and physiologically on huge lipid reserves, odontocete cetaceans are ideal reservoirs for hydrophobic and metabolically resistant $\mathrm{HAH}$. In certain populations, PCBs can reach very high concentrations. For example, PCBs as high as $500 \mu \mathrm{g} / \mathrm{g}, 50$-fold higher than what was observed as sufficient to cause reproductive and hormonal dysfunction in terrestrial mammals, have been observed in beluga adipose tissue (Martineau et al., 1987).

$\mathrm{HAH}$ accumulation in odontocetes is known to be sex and age-dependent. $\mathrm{HAH}$ patterns in 13 species of odontocetes show no sex difference in HAH accumulation rates among immature animals. However, HAH blubber burdens in females decrease dramatically after the first offspring, and fluctuate around a lower mean concentration during reproductive years, while males accumulate HAH throughout life (O'Shea, 1999). Exposure concentrations of persistent organic pollutants may be highest during fetal and neonatal development. Tanabe et al. estimated that a mother spinner dolphin (Stenella coeruleoalba) could transfer $4-10 \%$ of her PCB burden transplacentally (Tanabe \& Tatsukawa, 1992). Placental transfer appears to be structure-dependent. An examination of a neonate beluga and its mother showed preferential transfer of lower chlorinated PCBs and other organochlorines relative to more highly substituted congeners (Gauthier et al., 
1998). Measurements in fetal and neonatal pilot whales (Globicephala melas) indicate that the organochlorine pesticide DDT is more readily transferred across the placenta than PCBs. However, DDT and PCBs are transferred equally via lactation (Borrell et al., 1996). Lactation is clearly the more significant route of HAH transfer; Cockcroft et al. (1989) predicted that a mother bottlenose dolphin can transfer up to $80 \%$ of her PCB burden to her firstborn calf (Cockcroft et al., 1989). These data indicate not only that cetaceans are exposed during important developmental periods, but also reveal a mechanism for retaining a significant portion of $\mathrm{HAH}$ in the population by passing burdens on to subsequent generations.

\section{Evidence for contaminant-related health effects in cetaceans}

There is evidence from some cetacean populations suggesting that HAH burdens can increase susceptibility to disease. After a major morbillivirus epizootic that affected striped dolphins (Stenella coeruleoalba), the animals that succumbed to the virus had significantly higher PCB burdens in the blubber than did animals from the same stock that survived the mass mortality event (Aguilar \& Borrell, 1994; Borrell et al., 1996). In a study of harbor porpoise that inhabit the waters of the U.K., PCB burdens were significantly higher in animals that died from disease (stranded) compared to animals that died from trauma (bycatch) (Jepson et al., 1999).

Beluga that inhabit the St. Lawrence Estuary are an isolated stock of $\sim 500$ (Kingsley, 1998) that are heavily burdened with contaminants, including HAH (Martineau et al., 1987) (Figure 2). This population was severely decimated when it was believed that 
beluga competed with the fishermen for cod, and culling by the public was encouraged. Since culling was halted in the 1970's, the population has not recovered (Bailey \& Singer, 1995). Compared with High Arctic stocks, the St. Lawrence beluga suffer a low rate of reproduction and a high rate of disease. Within the diverse suite of pathologies observed in the St. Lawrence population, three categories of health problems have emerged to cause great concern. The first is a high incidence of tumors, and cancer in particular. At least 12 cases of malignant tumors have been reported since 1982 (Figure 3). These tumors originate in several tissue types, but these beluga seem particularly susceptible to cancer arising from the papilloma virus. Increased cancer susceptibility can be indicative of suppressed innate and cellular immunity, and/or higher exposure to carcinogens such as certain HAHs and polycyclic aromatic hydrocarbon metabolites. These beluga also appear to succumb easily to infections by bacteria that are considered to be only mildly pathogenic, including pneumonia, mammary mastitis, and other opportunitic infections that have accounted for organ failure and death in some individuals (Deguise et al., 1995; Martineau et al., 1994; Martineau et al., 1988). Also of serious concern is a very low rate of reproduction that is coincident with low pregancy rate, low ovarian activity, and dystocia (death during calving) (Bailey \& Singer, 1995).

Lahvis et al. (1995) determined that the partial loss of proliferative response of bottlenose dolphin (Tursiops truncatus) lymphocytes to mitogens was proportional to total PCB and DDT concentrations in the blood (Lahvis et al., 1995). Although no controlled study of immune dysfunction in cetaceans has been possible to date, a semi-field experiment on harbor seals has revealed a potentially significant cause and effect 
relationship between $\mathrm{HAH}$ and the immune system. One group of seals was fed herring from the highly contaminated Baltic Sea, and the control group was fed herring from the relatively uncontaminated North Atlantic. The seals fed Baltic fish exhibited a suppressed immune response relative to controls. The parameters measured included proliferative response to mitogens, natural killer cell activity assays, delayed-type hypersensitivity to ovalbumin following subdermal injection, and a lower titer of circulating ovalbumin antibodies (Deswart et al., 1995; DeSwart et al., 1994; Ross et al., 1995). The extent of these responses correlated inversely to projected dioxin equivalents measured in blubber biopsies of these seals. Since the $\mathrm{T}$ cell response is necessary in viral defense, these authors suggest that $\mathrm{HAH}$ exacerbated the outbreaks of morbillivirus in common seals of the Baltic Sea (Hall et al., 1992).

\section{The Aryl Hydrocarbon Receptor (AHR)}

\section{$A H R$ is required for toxic effects of $H A H$}

The growing list of HAH effects documented in terrestrial mammals include immunosuppression, hepatotoxicity, carcinogenesis, reproductive/ developmental toxicity, endocrine disruption, dermal toxicity, vitamin A depletion, wasting, and neural toxicity (Schmidt \& Bradfield, 1996). The discovery that these varied toxic effects were mediated by a single receptor came from several lines of evidence: inbred mice that varied in sensitivity to $\mathrm{HAH}$, structure-activity relationships for $\mathrm{HAH}$ binding to AHR compared to $\mathrm{HAH}$ induced effects, and finally, AHR knockout mice. 
The first clues indicating that toxicity of HAHs might be mediated by one locus were from studies with inbred mice. The capacity for TCDD induction of aryl hydrocarbon hydroxylase (CYP1A) activity varied according to mouse genotype; the "non-responsive" $\mathrm{DBA} / 2$ strain required at least 10 times the TCDD dose to elicit a response equivalent to that in the "responsive" C57BL/6 strain (Poland \& Glover, 1975). Crossing the two strains yielded a strain with intermediate responsiveness and backcrossing revealed that the ability to respond was dependent on one locus, named the Aryl Hydrocarbon responsiveness (Ah) locus (Thomas et al., 1972). Poland et al. characterized the putative gene product, a cytosolic protein that could bind to radiolabeled TCDD (Poland et al., 1976). That allelic variation could account for the responsive and nonresponsive strains was confirmed when Poland's group later characterized four mouse alleles, identifying the mutations that affected the ligand binding affinities of the AhRs (Poland et al., 1994).

Structure-activity relationships were also important for characterizing the role of the AHR in HAH effects. The relative binding affinities of various HAH in liver cytosol were in good agreement with the relative ability of $\mathrm{HAH}$ to induce aryl hydrocarbon hydroxylase (AHH) activity (Poland \& Knutson, 1982; Safe, 1994).

The quintessential piece of evidence that the AHR is necessary for TCDD toxicity came from the generation of knockout mice. A sensitive indicator of AHR activation is the induction of cytochrome P4501A (CYP1A). In three laboratories that generated AHR knockout mice independently, none of these mice were capable of induction of CYP1A1 activity in response to TCDD (Fernandez-Salguero et al., 1995; Schmidt et al., 1996; 
Shimizu et al., 2000). Furthermore, these mice lacking the $\mathrm{AHR}\left(\mathrm{AhR}^{-\alpha}\right)$ are resistant to $\mathrm{TCDD}$ induced toxicity at doses high enough to produce toxicity in wild type $\left(\mathrm{AhR}^{+/+)}\right.$ mice and heterozygote $\left(\mathrm{AhR}^{+/}\right)$mice. The toxic effects examined in these strains included thymic atrophy and hepatic abnormalities (Fernandez-Salguero et al., 1996) hydronephrosis, and cleft palate (Mimura et al., 1997)[Peters, 1999] \#5729]. AHR is a bHLH-PAS protein

Cloning of the AHR revealed that it is a member of the PAS (Per $\underline{A}$ RT $\underline{\text { Sim) }}$ family of proteins (Burbach et al., 1992; Ema et al., 1992). The PAS proteins are found in many different biochemical pathways whose common feature may be transduction of signals from the cellular or organismal environment. Several are important in proper cell timing and differentiation, including Drosophila Trachealess (Trh) in trachea differentiation, and Single-minded (SIM) in neuronal development (Nambu et al., 1991; Wilk et al., 1996). Mammalian SIM2 (homologous to Drosophila SIM) is expressed during embryonic development of the forebrain, and has been implicated in the expression of the Down Syndrome phenotype in humans (Fan et al., 1996). Drosophila Period is necessary for maintenance of the circadian clock (Jackson et al., 1986). Several other PAS proteins are indicators of specific extracellular cues such as oxygen tension (hypoxia-inducible factor-1 (HIF) and aryl hydrocarbon nuclear translocator (ARNT)), retinoic acid (steroid receptor coactivator-1), and xenobiotic compounds (AHR and ARNT) (Hoffman et al., 1991; Li et al., 1996; Yao et al., 1996). Murine ARNT can dimerize via its PAS domain with AHR, another ARNT, HIF, and Drosophila or mouse 
SIM in vitro (Probst et al., 1997; Swanson et al., 1995), suggesting a highly conserved structural motif and potential for signaling "cross-talk".

Conservation of molecular structure in these PAS family members has aided investigators in the classification of functional domains of these proteins (Gu et al., 2000). The AHR-specific roles of these functional domains were characterized by deletion analysis (Fukunaga et al., 1995) (Figure 4). The current model consists of a basic HelixLoop-Helix (bHLH) motif involved in HSP90 binding, dimerization with ARNT, and DNA binding. The PAS domain is approximately 300 amino acids in length with two degenerate repeats of approximately 50 amino acids, PAS A and PAS B. The PAS region is involved in ligand binding, HSP90 binding, and dimerization. The C terminus is important in transcriptional activation.

\section{AHR signaling pathway and molecular biology}

Much of our knowledge of AHR signaling has come from the examination of the induction of CYP1A1 (Figure 5)(for reviews, see (Whitlock, 1999; Wilson \& Safe, 1998)). The AhR complex at various stages of activation and inactivation is heteromeric with several proteins. Two hsp90 proteins are associated with the AhR; they aid in proper folding and maintaining conformation in the inactive state (Chen \& Perdew, 1994; Heid et al., 2000). Enan and Matsumura showed that c-Src, a tyrosine kinase and oncogene, is a component of the unliganded AhR complex in rodent liver and adipose tissue (Enan \& Matsumura, 1996). Three laboratories concurrently discovered an immunophilin-like protein: a $37 \mathrm{kD}$ protein cloned from a HeLa cDNA library (Ma \& Whitlock, 1997) and 
a 37-8 $\mathrm{kD}$ protein cloned from a B cell cDNA library (Carver \& Bradfield, 1997), now termed AHR Interacting Protein (AIP)(Meyer et al., 1998). These investigators suggest that AIP is involved in a nuclear targeting signal.

Upon ligand binding, the ligand-hsp90-AHR complex translocates to the nucleus and upon dimerization with ARNT, the AHR transforms to a DNA binding form; each phase is most likely regulated by kinase activity. Translocation of the activated complex to the nucleus depends on protein kinase C (Carrier et al., 1992; Chen \& Tukey, 1996). Dimerization with ARNT facilitates binding to particular enhancer sequences called Dioxin Responsive Elements (DRE). DREs are found in the promoter regions upstream of several of the AHR-inducible genes, including CYP1A1, CYP1B1, and glutathione Stransferase Ya subunit. Transcription of the these genes involved in metabolism of xenobiotic compounds completes the "adaptive response" (Schmidt \& Bradfield, 1996)

\section{AHR-dependent mechanisms of toxicity}

Unlike the induction of CYP1A1, the exact mechanisms of AHR-dependent signaling in bona fide toxic responses are not as well understood. As stated earlier, the AHR is a pleiotropic mediator of many dioxin-induced toxic endpoints. In this

discussion, I will attempt to summarize what is known about the role of the AHR and the specific targets in two types of HAH-induced toxicity that appear to be most relevant to cetaceans that are exposed to environmental contamination: cell cycle disruption and immunosuppression. These mechanisms are not necessarily mutually exclusive. 
Cell cycle disruption The phosphorylation cascades initiated by AhR activation by ligand appear to interfere with regulation of normal cell proliferation and differentiation. Several TCDD endpoints are related to these processes, including early eye opening, early incisor eruption, cleft palate, fatty liver, hyperkeratinization, and cancer (Huff et al., 1994; Matsumura, 1994). One interaction may be with the regulators of the cell cycle itself, since treatment with TCDD results in the upregulation or phosphorylation (activation) of cyclin dependent kinases (Devito et al., 1994; Ma \& Babish, 1993). This activation may be direct, or via the Mitogen Activated Protein (MAP) Kinase pathway. The MAP kinase pathway transduces signals from plasma receptors via protein phosphorylation events that ultimately induce transcription of the "immediate early gene" c-Fos and activate c-Jun, two components of AP-1, a transcription factor that regulates cell proliferation and differentiation via an unknown mechanism. TCDD and Epithelial Growth Factor (EGF) cause similar increases in phosphorylation activity and downregulation of EGF receptor, suggesting that TCDD acts directly or indirectly on the EGF receptor (Kawamoto et al., 1989). Some have hypothesized that the activation of the MAP kinase pathway begins with c-Src (an associate of cytosolic AHR), followed by activation and downregulation of the plasma receptors (Enan \& Matsumura, 1996). On the other hand, the interaction may be more direct. Early immunoprecipitation evidence suggests a direct interaction with TCDD activated AhR with MAPK, one of the kinases in the MAP pathway (Ma \& Whitlock, 1997). If the association between AHR and EGF signalling is proven, it is a mechanism 
that could explain a wide variety of $\mathrm{HAH}$ toxic effects that might occur independently of DRE binding.

Immunosuppression. The AHR is required for certain TCDD-induced immunotoxic endpoints. On the level of gross pathology, one of the most sensitive endpoints of TCDD is the substantial loss of leukocytes and overall organ mass, causing the condition termed thymic or splenic involution. Importantly, these effects are completely abolished in AHR knockout mice, unequivocally implicating the AHR in these effects (Fernandez-Salguero et al., 1996). Studies using radiation chimeras with AHR knockout mice has clarified that the most sensitive targets for TCDD toxicity are in fact the hematopoetic elements rather than the supporting tissues (Staples et al., 1998; Thurmond et al., 1999; Thurmond et al., 2000). Despite the fact that it is now known that hematopoetic cells in general are targets for PHAH toxicity, it is also of interest to consider which branches of immunity are affected, and which measurable endpoints might allow us to find clues among feral populations of marine mammals.

The most sensitive and classic assay used to test humoral (antibody) response is the hemolytic plaque assay, which depends on the ability of the mouse to secrete antibodies against sheep red blood cells (SRBC). It was noted early that mice with a high affinity AHR (strain C57BL/6) were much more sensitive to humoral suppression by $3,3^{\prime}, 4,4^{\prime}$ TCB than mice possessing low affinity AHR (DBA/2) (Silkworth \& Grabstein, 1982). The severity of the suppressive effect correlated with the specific binding affinity of the HAH to the AHR, supporting an AHR mediated mechanism. Such a relationship has been shown for various PCB congeners (Davis \& Safe, 1990) and polychlorinated 
dibenzofurans (Davis \& Safe, 1988; Dickerson et al., 1990). That the AHR antagonist alpha-napthoflavone can abrogate both CYP1A enzyme activity and suppression of hemolytic plaques formed is consistent with an AHR-mediated mechanism (Blank et al., 1987).

HAH may suppress the humoral response by interrupting the differentiation of proliferating B cells to antibody-secreting plasma cells. In order to dissect the potential targets of TCDD, Tucker et al. modified the hemolytic plaque forming assay to include mitogen stimulation of spleen cells before exposing B cells to SRBCs and complement (Tucker et al., 1986). Doubling TCDD dose did not modify the number of proliferating cells or enzyme activity associated with proliferation of leukemia cells, but did lower by half the number of plaques formed, thus showing that the differentiation step was affected. Further, of B cells incubated with TCDD and B cell mitogens, $50 \%$ fewer displayed plasma cell-specific (PC2) surface markers relative to control stimulated cells (Luster et al., 1992). Since tyrosine phosphorylation is important in normal differentiation of B lymphocytes, these authors also suggest and show partial evidence that disturbance of required tyrosine phosphorylation signals by TCDD may be the mechanism of toxicity (Clark et al., 1991).

Cell-mediated immunity is also a target of AHR-mediated suppression. Kerkvliet et al. showed that TCDD and hexachlorobiphenyls suppressed the tumor cell lysis activity of cytotoxic T cells to the extent predicted by their AhR binding affinities (Kerkvliet et al., 1990). AHR is present in both resting and activated T cells, but electromobility shift assays show that the AHR complex binds DNA only in activated, TCDD treated cells 
(Lawrence et al., 1996). Serum corticosterone levels also increased in a HAH structure dependent manner, but this response was later shown not to be part of the mechanism of suppression (Dekrey \& Kerkvliet, 1995). Further, TCDD does not appear to act via interruption of cyclooxygenase or prostaglandin, despite the presence of DRE in the promoters of cyclooxygenase genes and the immunoregulatory role of some prostaglandins (Lawrence \& Kerkvliet, 1997).

Possible molecular mechanisms for AHR-dependent immunosuppression. Recent studies have elucidated possible molecular roles of the AHR in immunosuppression and may further help define targets for $\mathrm{HAH}$ (immuno)toxicity. For example, cytokines are small proteins that play critical roles in immune cell-cell signaling during proliferation and differentiation. Several cytokines have DREs in their promoters (Lai et al., 1996), which suggests a direct mechanism for the AHR in the altered cytokine expression patterns observed after TCDD treatment (Lai et al., 1997). One of the many functions of cytokines is the timely induction of NF-kB, a transcription factor important in many cell types and signaling pathways (Ghosh et al., 1998). It was shown recently that the AHR can interact directly with relA, a subunit of NF-kB (Tian et al., 1999). Since one of the roles of NFkB is to inhibit apoptosis (Ghosh et al., 1998), occupation of NFkB with AHR may be a way that AHR activation may cause lymphoid tissue involution. Apoptosis is also observed in bone marrow pre-B cells upon treatment of dimethylbenzanthrazene (DMBA, a non-halogenated AHR ligand). This endpoint appears to be AHR and CYP1B1-dependent (Heidel et al., 1999; Mann et al., 1999). 
Evidence for AHR signal transduction in cetaceans

Consistent with its widespread occurrence in many terrestrial vertebrates, the CYP1A also occurs in cetaceans. Several laboratories have demonstrated both CYP1A activity and immunodetectable protein in microsomal fractions of various tissues (Watanabe et al., 1989; White et al., 1994; White et al., 2000). Further, a correlation between hepatic CYP1A content and blubber PCB concentrations suggests that this enzyme is inducible (White et al., 1994; White et al., 2000). The likely involvement of the AHR in this inducible response was supported when a putative beluga AHR was detected by photoaffinity labeling of beluga hepatic cytosol (Hahn et al., 1994). The detected protein had an apparent size similar to other mammalian forms of AHR. Using sucrose-gradient centrifugation of cultured bottlenose dolphin kidney cells, Carvan et al. also showed specific binding of a protein with a sedimentation coefficient expected for AHR (Carvan III et al., 1995). These results are strong, though not definitive evidence for the existence of a cetacean AhR.

\section{Rationale and approach for thesis research}

It is well documented that HAH accumulate in high quantities in the blubber of cetaceans, but the effects of these high levels of exposure are unknown. Toxic responses to the HAH in terrestrial mammals are mediated by the interaction of certain $\mathrm{HAH}$ with the AHR, a cytoplasmic, ligand-activated transcription factor. The goal of these studies was to ascertain the potential for HAH effects in cetaceans by characterizing the AHR from the beluga, Delphinapterus leucas. 
A fundamental problem with cetacean research is the inability to conduct controlled laboratory studies on live specimens. Moral and logistical factors prevent the invasive studies required to directly determine the sensitivity of cetaceans to HAHs and other compounds that act via the AHR. Because cetaceans are protected, sampling is opportunistic and tissue quality is often poor. Expressing the protein in vitro would alleviate the constant need for tissue from which to isolate the AHR, and allow molecular studies of AHR function. Chapter 2 describes the cloning and sequencing of a beluga AHR cDNA, and the generation of an expression vector for the in vitro expression of the beluga AHR.

AHR-mediated effects involve many proteins, and differences in vulnerability between species and strains within a species can be related to genetic variation at any stage of the AHR signal transduction pathway. In some animal models, these differences are known to be caused by allelic variation of the AHR itself. The molecular characterization of the cetacean AHR is a first step in determining how well the mode of AHR action in cetaceans is modeled by studies using laboratory rodents. Thus, in Chapter 2, the TCDD binding affinity of the beluga AHR was compared with the affinity of a mouse AHR (a relatively high affinity AHR), as well as that of a human AHR (a relatively low affinity allele).

Relative potencies (REPs) and toxic equivalency factors (TEFs), for AHR agonists are fractions that reflect the potential for an AHR agonist to elicit a TCDD-like response. TEFs are used by regulatory agencies for risk assessment of mixtures of compounds. The danger in using relative potencies to assess risk to marine mammals is that no relative 
potencies have been generated for or confirmed in any marine mammal species. Because contaminant-related health effects on wildlife are important conservation issues for endangered and protected stocks, there is a need for cetacean-based relative potencies for scientific and management purposes. In Chapter 3, inhibition of TCDD binding to the AHR by various structure classes of $\mathrm{HAH}$ is measured and relative potencies for beluga and mouse AHR binding are derived.

Finally, because the AHR is necessary for the toxic effects of $\mathrm{HAH}$, the relative expression of the AHR among tissues and organs may help predict tissue targets for $\mathrm{HAH}$ toxicity. Chapter 4 details the tissue-specific expression of AHR among various tissues of belugas from the Alaskan Arctic. 
<smiles>Clc1cc2c(cc1Cl)Oc1cc(Cl)c(Cl)cc1O2</smiles>

Dibenzo-p-dioxins (TCDD)

( 75 congeners)<smiles></smiles>

\section{Dibenzofurans (TCDF)}

(135 congeners)<smiles>Clc1ccc(-c2ccc(Cl)c(Cl)c2)cc1Cl</smiles>

Polychlorinated biphenyl (PCB) (209 congeners)

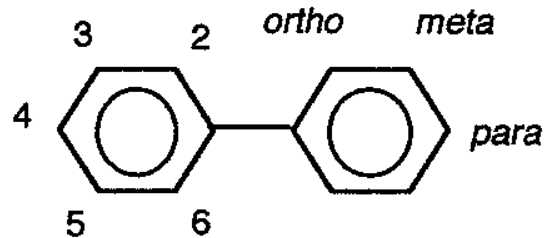

Figure 1. Structures of halogenated aromatic hydrocarbons. Examples of a chlorinated dibenzo-p-dioxin, a chlorinated dibenzofuran, and a polychlorinated biphenyl are shown with the number of congeners indicated. Numbering and ortho, meta, and para positions are shown on a PCB. 


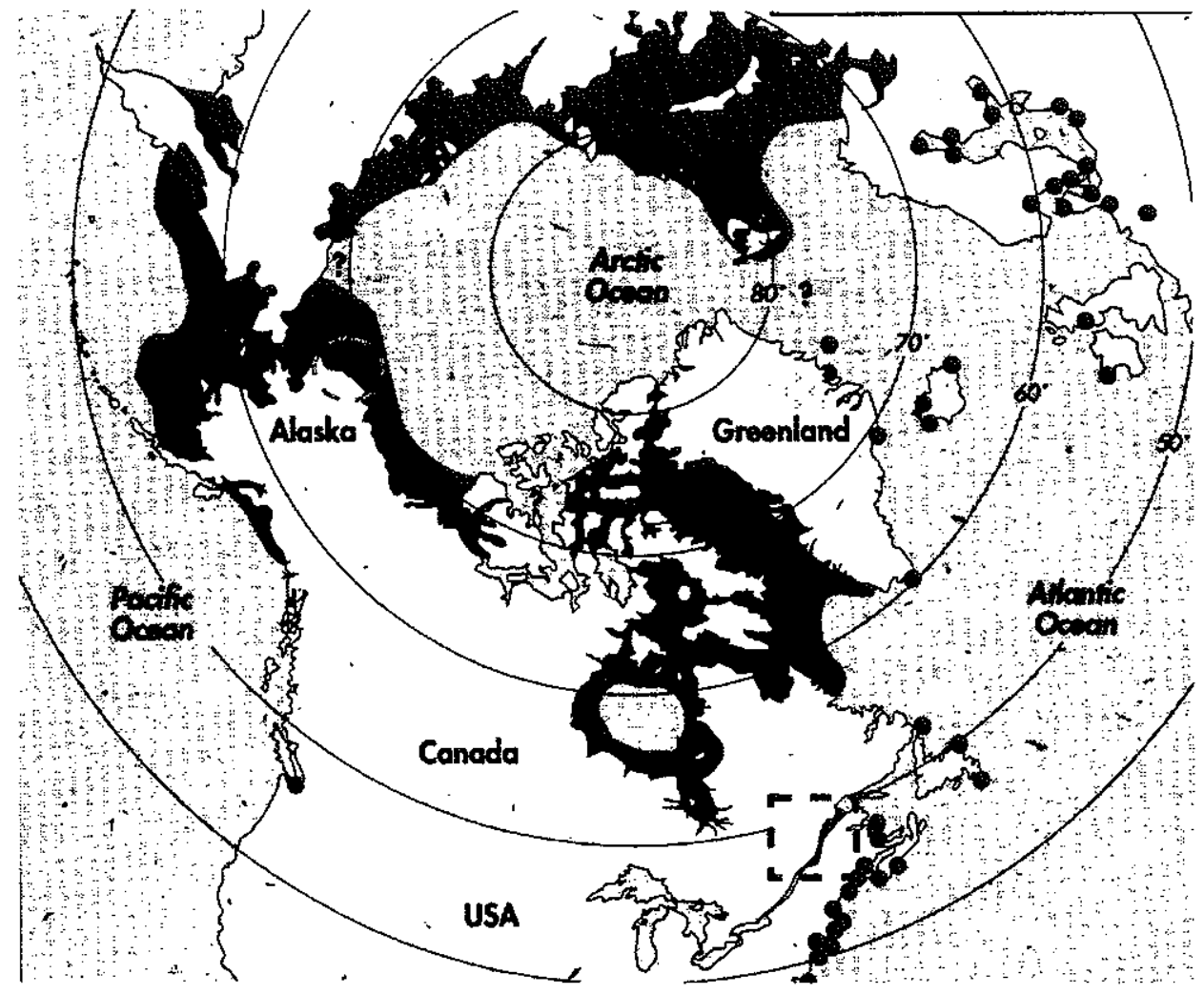

Figure 2. World beluga distribution. The black area indicates the worldwide range of beluga. Black dots are extralimital regions. The dashed shaded square indicates St. Lawrence estuary, a highly contaminated region that is the habitat of a small isolated population of beluga. The dashed and shaded circle indicates the Alaska origin of the beluga samples used in these studies. Beluga from the Chukchi Sea stock were harvested in Barrow or Point Lay, on the North Slope of Alaska. Map modified from the St. Lawrence Beluga Recovery Team (St. Lawrence Beluga Recovery Plan, 1995). 


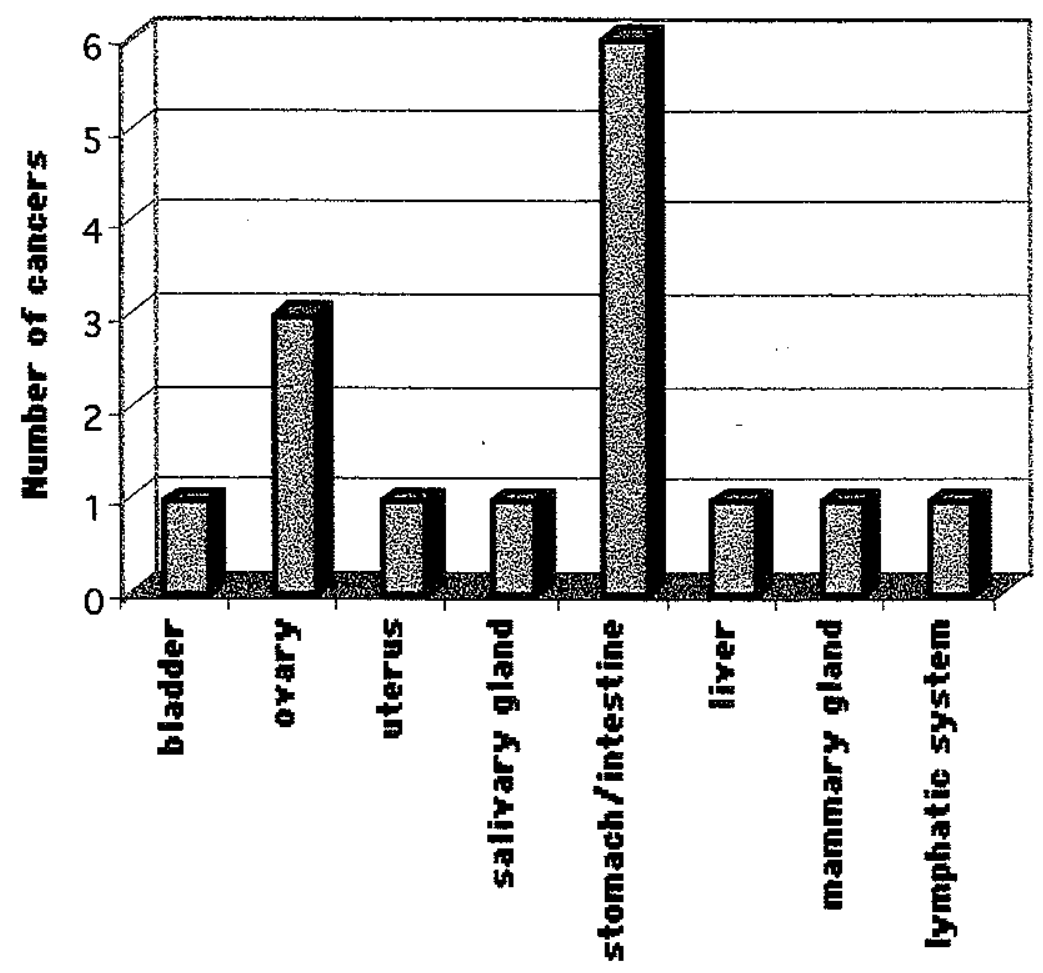

Figure 3. Malignant tumors in St. Lawrence belugas 1982-1998. Reports of malignant tumors occurring in St. Law rence beluga were compiled from the St. Lawrence Recovery Team (1995) and Lair et al. (1998). 


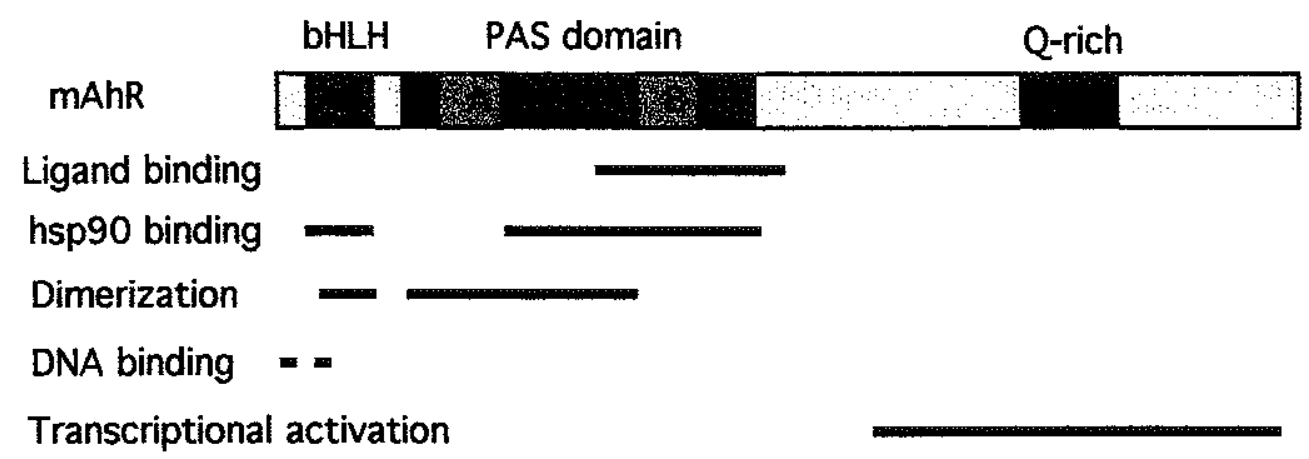

Figure 4. Functional domains of the mouse AHR. Regions critical for various AHR functions were determined by deletion analysis using the mouse AHR. From Fukunaga et al., (1995). 


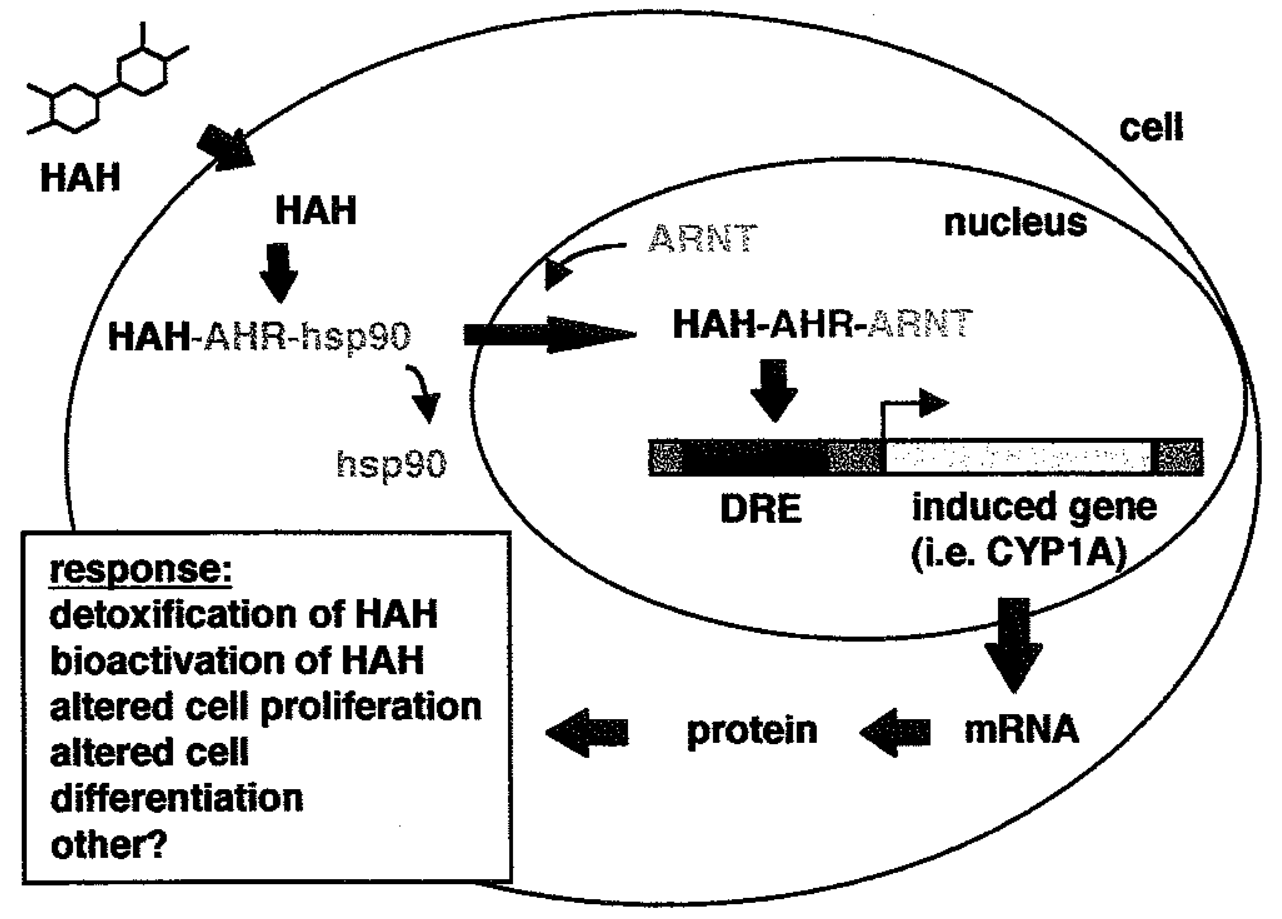

Figure 5. AHR signal transduction pathway and CYP1A induction. 


\section{Chapter 2:}

Molecular cloning and functional characterization of an aryl hydrocarbon receptor in the beluga 


\section{INTRODUCTION}

Persistent organic pollutants (POP) are ubiquitous in the marine environment. Sources of POPs include the use of pesticides (e.g. DDT), the breakdown of discarded electronics and heavy machinery (PCBs), and the incineration of waste (PCDDs). POPs are generally hydrophobic and resistant to metabolic and chemical degradation, and thus tend to partition to lipid-rich sediments, cellular compartments, and tissues. POPs that are not easily metabolized at low trophic levels bioaccumulate at higher trophic levels. This is particularly evident in top feeding marine mammals such as odontocete cetaceans, or toothed whales.

High levels of POP contamination have been documented in the beluga whale (Delphinapterus leucas, family Delphinidae). The beluga whales of the St. Lawrence have among the highest body burdens of PCBs ever documented in wildlife, which has raised concern about the potential health impacts. PCB concentrations as high as 500 $\mu \mathrm{g} / \mathrm{g}, 50$-fold higher than what was observed as sufficient to cause reproductive and hormonal dysfunction in terrestrial mammals, have been observed in beluga blubber (Beland et al., 1993; Martineau et al., 1987; Muir, 1990). Efficient transfer of maternal POP burdens via lactation suggests that exposure to these environmental contaminants may be highest during fetal and neonatal development of cetaceans (Cockcroft et al., 1989; Tanabe et al., 1988). High body burdens of POPs have long been suspected to play a direct role in the observed cancer and reduced rate of reproduction with the St. 
Lawrence beluga stock (Bailey \& Singer, 1995). However, very little is known about the effects of POPs in cetaceans and other marine animals.

A subset of the POPs are the planar halogenated aromatic hydrocarbons (PHAH) which include 2,3,7,8-tetrachlorodibenzo-p-dioxin (TCDD) and the planar representatives of the polychlorinated biphenyls (PCBs). PHAH cause a number of effects in laboratory rodents, including immunosuppression, endocrine dysfunction, enzyme induction, carcinogenesis, and reproductive/developmental toxicity (Schmidt \& Bradfield, 1996). PHAH toxicity occurs after direct binding to the aryl hydrocarbon receptor (AHR), a member of the bHLH-PAS family of transcription factors. Though many aspects of AHR signaling have been described, most notably the induction of the CYP1A gene (CYP1A1 in mammals), the mechanism(s) of toxicity are not well understood. However, the lack of toxic effects upon TCDD treatment of AHR knockout mice ( $\left.\mathrm{Ah} / \mathrm{Ah} h^{-}\right)$confirms that the AHR is necessary for TCDD toxicity (Fernandez-Salguero et al., 1996).

Beyond the mere presence or absence of the AHR, properties of the AHR also determine sensitivity to PHAH and other AHR ligands. The experimental system that led to the discovery and characterization of the AHR involved strains of mice that differed greatly in their sensitivity to planar aromatic hydrocarbons, and as such were labeled "Ah-responsive" (strain C57BL/6, $\mathrm{Ah}^{\mathrm{b}}$ alleles) and "Ah-non-responsive" (strain DBA/2, $\mathrm{Ah}^{\mathrm{d}}$ allele). Sequencing the AHR alleles revealed that the difference between the $\mathrm{Ah} \mathrm{h}^{\mathrm{b}-1}$ and $\mathrm{Ah}^{\mathrm{d}}$ alleles is a point mutation that causes one amino acid change $\left(\mathrm{A}_{375} \rightarrow \mathrm{V}_{375}\right)$ in the ligand binding region of the $\mathrm{Ah}^{\mathrm{d}}$ allele. Measurement of the binding affinities of the alleles in vitro revealed that the effect of that mutation was diminished ligand binding 
affiinity in the $\mathrm{Ah}^{\mathrm{d}}$ allele from the more resistant strain (Poland et al., 1994). Strainspecific differences in TCDD sensitivity in the rat may also be AHR-dependent. In a TCDD-resistant rat, a point mutation that does not affect ligand binding truncates the protein and may compromise its transactivation function (Pohjanvirta et al., 1998). In a comparison of several bird species, relative binding affinities of AHRs match the relative CYP1A inducibility and relative sensitivities to TCDD toxicity as assessed by an embryo assay (Sanderson \& Bellward, 1995). In humans it has recently been shown that an AHR polymorphism (and not a CYP1A1 polymorphism) is associated with higher relative CYP1A1 enzyme activity and protein in 3-methylcholanthrene-treated peripheral blood lymphocytes (Smart \& Daly, 2000). Taken together, this evidence suggests that confirming the presence of the AHR and characterizing the AHR are potentially important for evaluating PHAH sensitivity in any species.

Several laboratories have provided evidence for a functional AHR signal transduction pathway in cetaceans. Profiles of PCBs and PCB metabolites measured in cetacean blubber and in vitro measurement of hepatic microsomal enzyme activities are indicative of CYP1A activity (Tanabe et al., 1988; Watanabe et al., 1989). Microsomal activity indicative of CYP1A activity was first demonstrated in the minke whale (Balaenoptera acutorostrata) (Goksøyr et al., 1986). CYP1A expression in cetaceans was later confirmed by the direct measurement of CYP1A protein in the minke whale (Goksøyr et al., 1988), and beluga (White et al., 1994). The presence of a cetacean AHR that is capable of specific TCDD binding was confirmed using lysates from a dolphin kidney cell line (Carvan III et al., 1995) and beluga liver cytosol (Hahn et al., 1994). 
To further assess the potential susceptibility of cetaceans to PHAH, we are characterizing the AHR of the beluga. In this report, we describe the cloning, in vitro expression, and initial functional analysis of a beluga AHR. We compare this beluga

protein with a relatively high affinity AHR, the product of the mouse $\mathrm{Ah}^{\mathrm{b}-1}$ allele (Poland et al., 1994), and a human AHR (Dolwick et al., 1993). These studies focus on the beluga for several reasons: 1) the population in the St. Lawrence Estuary, Canada has long been suspected to be negatively affected by PHAH exposure; 2) distributions of stocks span a gradient of environmental contamination (Muir, 1990); 3) access to a captive population has allowed baseline health parameters to be determined; and 4) it has recently been proposed as a "model cetacean species" by a working group of marine mammal toxicologists convened by the Marine Mammal Commission (MMC, 1999). This is the first molecular characterization of an AHR in a marine mammal. We suggest that this is a promising approach for gathering species-specific data relevant to contaminant sensitivity when in vivo dosing experiments are ethically, legally, and logistically impossible.

\section{MATERIALS AND METHODS}

\section{Materials}

The mouse AHR plasmid (pSPORTmAHR) containing the $\mathrm{Ah}^{\mathrm{b}-1}$ allele and human HepG2 AHR (pSPORThAHR2) expression vectors were graciously provided by Dr. C. Bradfield (McArdle Center for Cancer Research, Madison WI)(Burbach et al., 1992; Dolwick et ál., 1993). 2,3,7,8-Tetrachloro[1,6- $\left.{ }^{3} \mathrm{H}\right]$ dibenzo- $p$-dioxin $(33 \mathrm{Ci} / \mathrm{mmol})$ was 
obtained from Chemsyn Science Laboratories (Lenexa, KS) and purified to $\geq 95 \%$ radiochemical purity by high performance liquid chromatography (Gasiewicz \& Neal, 1979). 2,3,7,8-Tetrachlorodibenzofuran (TCDF) was obtained from Ultra Scientific (Hope, RI). Methylated $\left[\right.$ methyl $\left.-{ }^{14} \mathrm{C}\right]$ ovalbumin was obtained from NEN Life Science Products, Inc. (Boston, MA). Methylated $\left[\right.$ methyl $\left.{ }^{14} \mathrm{C}\right]$ catalase was synthesized as described (Dottavio-Martin \& Ravel, 1978). The C57BL/6 mouse was provided by Dr. D. S. Sherr (Boston University School of Public Health, Boston, MA).

Tissue collection

Beluga liver was collected from Mackenzie Delta, NWT, Canada as described in White et al. (1994). Liver tissue was also collected from a subsistence hunt of Chukchi Sea beluga in Alaska during the summer of 1997. Liver tissue was snap frozen in liquid nitrogen approximately 3-4 hours after death. Tissues were maintained at liquid nitrogen temperatures throughout transport, storage, and powdering with mortar and pestle. The C57BL/6J mouse was killed by cervical dislocation and the liver was extracted from the animal and snap frozen minutes after death.

\section{RNA isolation}

Total RNA was isolated from liver tissue using the guanidinium isothiocyanate method (Clemens, 1984). Messenger RNA was isolated using oligo dT columns (Collaborative Research, Bedford MA) (Maniatis et al., 1982). The quality of the total 
and messenger RNA was confirmed by visualization on ethidium bromide-stained agarose minigels and quantity was determined by UV absorbance.

Oligonucleotide primers:

Primers were synthesized by National Biosciences, Life Technologies, or Integrated DNA Technologies. Degenerate primer sequences were: AHR-A1, AHR-A2, AHR-B1, AHRB2 (Hahn and Karchner, 1995). Gene-specific primers were: Dlb538: 5'TTC CTT TGG CAT CAC AAC CAG TAG-3'; Dlb467: 5'-CGG ATT TCA AGT ATG GAT GGT GG -3'; Dlf152: 5'- GGG CGT TAA ATC CTT CAC AGT GTC C-3'; Dlf258: 5'- GAA CTC TTC GTC TAT GGA AAG GTG C-3'; Dlf467: 5'-CCA CCA TCC ATA CTT GAA ATC CG-3', DIf538: 5'-CCT ACT GGT TGT GAT GCC AAA GGA A-3', DlExon9F: 5'-TGC AGT CGA ATG CAC GCT TAG-3'; DIUTRrev: 5'AAC CAA GAT GAA AAA TGG GCT TG-3'; 5nat-hind3: 5'-CCC AAG CTT GGG CAC CAT GAA CAG CAG C-3'; 5koz-hind3: 5'-CCC AAG CTT GGG CAC CAT GGA CAG CAG C -3'; xba1-utr: 5'-GCT CTA GAG CAA CCA AGA TGA AAA ATG GGC TTG-3'.

\section{Cloning and Sequencing of beluga AHR cDNA}

$R T / P C R$

Messenger RNA isolated from a beluga that stranded in the Mackenzie River Delta, Canada was made into cDNA using random hexamers. Degenerate primers AHRA2 and AHR-B2 containing inosines were used to amplify an internal beluga AHR 
fragment from the cDNA with the following PCR conditions: $94^{\circ} / 5: 00 ;\left(95 /: 15,45^{\circ} /: 30\right.$, $72 \% 1: 00$ ) for 45 cycles followed by a 7 minute final extension. The same primers were used in direct sequencing of the amplified fragment in both directions using the Sequenase Version 2 Kit (US Biochemical) with modifications for direct sequencing as described by Bachmann et al., (1990). Sequencing revealed 480 bp that shared high sequence identity with mammalian AHRs based on a BLAST search. Subsequent efforts to obtain a full-length clone using RACE techniques were unsuccessful. Suspecting that sample quality may have been compromised, we turned our efforts to beluga samples obtained in 1997 from Alaska.

Poly $\mathrm{A}^{+}$mRNA isolated from a beluga collected in 1997 in Alaska was used with a GeneAmp RT/PCR kit (Roche, Blanchberg, NJ) with the following conditions in the Perkin Elmer 2400 thermocycler: $94^{\circ} / 5: 00 ;\left(95^{\circ} /: 15,60 \%: 30,72 \% 1: 00\right)$ for 35 cycles. Degenerate primers AHR-A1 and AHR-B1 containing inosines amplified a 648 base pair fragment that was sequenced with a Licor 4000 automated sequencing system using Excel II cycle sequencing kit. The sequence matched the $480 \mathrm{bp}$ fragment that was sequenced previously.

Gene-specific primers were then designed for 5' and 3' RACE. The 5' genespecific primers Dlb538 and Dlb467 and the 3' gene-specific primers Dlf152, Dlf258, Dlf467, Dlf538 were used with the Marathon gene amplification kit (Clontech, Palo Alto, CA). "Touchdown" PCR was used for all RACE reactions: $94^{\circ}: 30 ;\left(94^{\circ} \%: 05,72^{\circ} 2: 00\right)$ ( 5 cycles), $\left(94^{\circ} \%: 05,70^{\circ} / 2: 00\right)$ ( 5 cycles), $\left(94^{\circ} \%: 05,68^{\circ} 2: 00\right)$ ( 25 cycles). Nested $5^{\prime}$ RACE was carried out on the b538 product using DIb467. All four of the 3' RACE reactions 
yielded a product of approximately $2 \mathrm{~kb}$. The Dlf258 and Dlf538 primer products were sequenced, and both were AHR. The 3' fragment was too large to obtain a complete sequence, so two more primers were designed internal to F538 and the adapter primer and "primer walked" with DLExon9F and DIUTR1rev with conditions 95\%5:00; $95^{\circ} \%: 30,56^{\circ} / 30,72^{\circ} \%: 30$ ( 35 cycles); $72^{\circ} / 7: 00$ extension in order to obtain the entire sequence of the 3' RACE clone. All sequencing was done on the Licor4000 automated sequencing system using Excel II cycle sequencing kit.

Once sequencing revealed the start and stop codons of the coding region, primers were designed to amplify the full-length cDNA. Two 5' primers were designed, one with the native sequence (5nat-hind3) and the other with a Kozak sequence (5koz-hind3) (A$>$ G switch at +4) (Kozak, 1987). Both contained HindIII restriction sites outside of the coding region. The full length beluga AHR was amplified using Klentaq (a mixture of taq polymerase and proofreading polymerase) of the Advantage cDNA PCR kit (Clontech, Palo Alto, CA). Primer pairs 5nat-hind3/ xba1-utr and 5koz-hind3-/xba1-utr were used in touchdown PCR: 94\% 1:00; 94\%:05, 70²:00 (5 cycles); 94\%:05,68\% $/ 2: 00$ (5 cycles); $94^{\circ} \%: 05,66^{\circ} 2: 00$ ( 25 cycles $) ; 68^{\circ} / 7: 00$.

\section{Expression vector construction}

The the full-length AHR products derived from primer pairs 5nat-hind3/xba1-utr and 5koz-hind3-/xba1-utr were cut with HindIII and Xbal (Promega, Madison, WI) and cloned into HindIII and Xbal sites of pcDNA3.0 (Invitrogen) and pSP64 Poly(A) vector (Promega, Madison WI). This generated a native and a Kozak 5' end under both the T7 
(pcDNAbelAHRnat and pcDNAbelAHRkoz) and SP6 (pSP64belAHRnat and pSP64belAHRkoz) promoters. Minipreps of all constructs were digested with HindIII, Xba, Pst1 and BamH1. Preps that contained expected digest patterns were observed for pcDNAbelAHRnat, pSP64belAHRnat, and pcDNAbelAHRkoz, so these constructs were tested for expression efficiency. The constructs were cleaned and purified using the Qiafilter Maxi Plasmid Purification kit (Qiagen, Santa Clarita, CA). Proteins were synthesized using the TNT Quick Coupled Transcription and Translation system (Promega) for T7 or SP6 promoters in the presence of $\left[{ }^{35} \mathrm{~S}\right]$-methionine. The pSP64belAHRnat construct under the SP6 promoter expressed 2-3 fold higher levels of protein compared to the pcDNA constructs, and the native belAHR sequence was expressed at levels similar to the SP6 positive control. To ensure that the pSP64belAHRnat expression plasmid (hereafter referred to as pSP64belAHR) was free of PCR errors, the vector was digested with Hindm/BamH1, Pst1/Sac1, and Cla1/Xba and subcloned into pBluescript into the same sites. Each subclone was completely sequenced and was confirmed to match the belAHR consensus sequence.

\section{Cytosol preparation}

Liver cytosol was prepared as described in Hahn et al. (1994). Cryo-preserved liver was first powdered while under liquid nitrogen, then homogenized in MEEDGM (35mM MOPS, 1mM EDTA, $5 \mathrm{mM}$ EGTA, 0.02\% $\mathrm{NaN}_{3}, 20 \mathrm{mM} \mathrm{Na}_{2} \mathrm{MoO}_{4}, 10 \%$ (v:v) glycerol, 1mM DTT, pH 7.5 containing protease inhibitors and PMSF). After serial 
centrifugations of $750 \mathrm{~g}, 12,000 \mathrm{~g}$, and $100,000 \mathrm{~g}$, the supernatants were frozen in liquid nitrogen until analysis.

\section{In vitro protein synthesis}

Beluga, mouse and human AHR proteins were synthesized using the TNT Quick coupled Reticulocyte Lysate Systems (Promega) in the presence or absence of ${ }^{35} \mathrm{~S}$ labeled methionine. Size of the proteins was confirmed by SDS-PAGE with $5 \mu$ l of reaction containing ${ }^{35} \mathrm{~S}$-labeled AHR, followed by fluorography and autoradiography.

\section{Western blotting}

$2 \mu \mathrm{l}$ of mouse, human, and beluga TNT reaction, and 100 $\mathrm{g}$ beluga liver cytosol were loaded onto a tris-acetate gel (Novex). The gel was blotted onto $0.22 \mu \mathrm{m}$ PVDF membrane, and probed with SA-210 rabbit anti-mouse AHR polyclonal antibody (Biomol) and secondary goat anti-rabbit antibody (Schleicher \& Schuell). Bands were visualized with CSPD chemiluminescent substrate (Tropix).

\section{Velocity sedimentation}

The beluga, mouse, and human AHR constructs and the empty pSP64polyA vector were used in in vitro transcription and translation reactions and the resulting proteins were analyzed by velocity sedimentation on sucrose gradients in a vertical tube rotor (Tsui \& Okey, 1981). For each AHR, two identical TNT reactions (100 $\mu \mathrm{I}$ total) were combined, diluted 1:2 with MEEDMG buffer (25 mM MOPS , pH $7.5 @ 20^{\circ} \mathrm{C}$, 
containing $1 \mathrm{mM}$ dithiothreitol, $1 \mathrm{mM}$ EDTA, $5 \mathrm{mM}$ EGTA, $0.02 \% \mathrm{NaN}_{3}, 20 \mathrm{mM}$ $\mathrm{Na}_{2} \mathrm{MoO}_{4}, 10 \%$ (v:v) glycerol plus a mixture of protease inhibitors: aprotinin (100

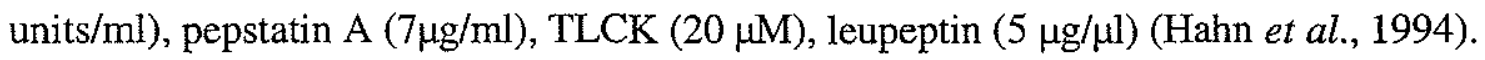
Each sample was split into two $150-\mu$ aliquots and incubated with $\left[{ }^{3} \mathrm{H}\right] \mathrm{TCDD}(2 \mathrm{nM}) \pm$ $\mathrm{TCDF}(400 \mathrm{nM})$ for $8 \mathrm{hr}$ at $4^{\circ} \mathrm{C}$ in glass tubes. Following incubation, the in vitro expressed proteins were treated with dextran-coated charcoal (DCC) (charcoal:dextran $10: 1 \mathrm{w}: \mathrm{w})$. In a polypropylene tube, $110 \mu \mathrm{l}$ of the incubation were mixed $1: 1$ with $7 \mathrm{mg} / \mathrm{ml} \mathrm{DCC}$ in MEEDMG buffer, followed by vortexing and centrifugation. Cytosols were diluted in MEEDMG buffer to $5 \mathrm{mg} / \mathrm{ml}$ and incubated under the same conditions as the expressed proteins, except that they were not treated with DCC. The $\left[{ }^{3} \mathrm{H}\right] \mathrm{TCDD}$ concentration was verified by sampling each tube for total counts. $200 \mu \mathrm{l}$ of the TNT incubation and 230 $\mu \mathrm{l}$ of cytosol incubations were applied to $10-30 \%$ sucrose gradients that were prepared in MEEDMG buffer (Coombs \& Watts, 1985). The gradients were spun for $140 \mathrm{~min}$ at $60,000 \mathrm{rpm}$ at $4^{\circ} \mathrm{C}$ in a VTi 65.2 rotor, after which $150 \mu \mathrm{l}$ fractions were counted using a Beckman LS5000TD Scintillation counter. Specific binding is defined as the difference between total binding (incubations containing $\left[{ }^{3} \mathrm{H}\right] \mathrm{TCDD}$ ) and nonspecific binding (incubations containing $\left[{ }^{3} \mathrm{H}\right] \mathrm{TCDD}$ plus a 200 -fold excess of TCDF). $\left[{ }^{14} \mathrm{C}\right]$-Ovalbumin $(3.6 S)$ and $\left[{ }^{14} \mathrm{C}\right]$-catalase $(11.3 S)$ were added as internal sedimentation markers; they eluted in fractions $\sim 5-6$ and $\sim 18-19$, respectively. Sedimentation coefficients of AHR proteins were also determined (Martin \& Ames, 1961). 


\section{Saturation binding}

The saturation binding assay with in vitro expressed AHRs is a modification of the binding assay of $\left[{ }^{3} \mathrm{H}\right] \mathrm{TCDD}$ to hepatic cytosol (Poland \& Glover, 1976). A major difference in the assay used here is the use of unprogrammed TNT lysate to determine non-specific binding. In tissue preparations as described above, specific binding is determined from the difference between total $\left[{ }^{3} \mathrm{H}\right] \mathrm{TCDD}$ binding by cytosol and the $\left[{ }^{3} \mathrm{H}\right] \mathrm{TCDD}$ binding measured when excess cold ligand is used to block specific binding sites. With in vitro expressed proteins, the specific binding sites are synthesized. Therefore, the lysate provides a convenient means for measuring non-specific binding without the need for duplicate tubes for each species tested. The beluga, mouse, and human AHR constructs were synthesized by in vitro transcription and translation as for the velocity sedimentation assay. The reactions were then diluted 1:8 in MEEDGM with protease inhibitors. Diluted TNT -expressed proteins were incubated in a $16 \times 100 \mathrm{~mm}$ glass tube for 7-8 hours with one of nine concentrations $\left(0-8 \mathrm{nM}\right.$ nominal) of $\left[{ }^{3} \mathrm{H}\right] \mathrm{TCDD}$

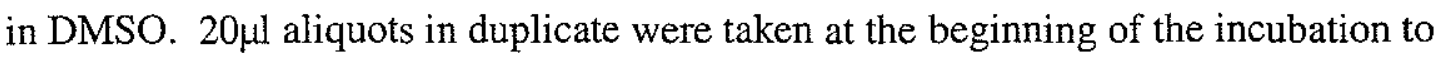
measure the actual concentrations of $\left[{ }^{3} \mathrm{H}\right] \mathrm{TCDD}$ in each tube. After the incubation, $30 \mu \mathrm{l}$ were transferred in triplicate aliquots to standard $1.5 \mathrm{ml}$ polypropylene tubes containing $30 \mu \mathrm{l}$ of $2.3 \mathrm{mg} \mathrm{DCC} / \mathrm{ml}$ MEEDGM. Tubes were vortexed for 5 seconds 3 times, with a 5 minute incubation on ice between each vortexing. Tubes were then spun at $7000 \mathrm{~g}$ for 3 $\min .40 \mu l$ of the supernatant was counted to measure bound $\left[{ }^{3} \mathrm{H}\right] \mathrm{TCDD}$. Total counts and total binding were measured on a Beckman 5000 scintillation counter. 
All curves were plotted as "free" $\left[{ }^{3} \mathrm{H}\right] \mathrm{TCDD}(\mathrm{nM})$ vs. bound $\left[{ }^{3} \mathrm{H}\right] \mathrm{TCDD}$ (DPM). Bound TCDD was determined directly from measured DPM. Free $\left[{ }^{3} \mathrm{H}\right] \mathrm{TCDD}$ was determined by subtracting the bound DPM from the total counts for each tube, and converting this difference to nM. The unprogrammed lysate data (non-specific binding) was fit to a linear model, and the slope was used to calculate the non-specific binding that corresponded to total binding at each concentration of free TCDD. The difference between the actual total binding and the calculated non-specific binding was the specific binding. The specific binding points were fit to the equation: $B=\frac{B_{\max }[L]}{[L]+K_{d}}$ where $\mathrm{B}$ is bound $\left[^{3} \mathrm{H}\right] \mathrm{TCDD}, \mathrm{B}_{\max }$ is maximum bound receptor (DPM), $\mathrm{L}$ is concentration of free ligand, and $\mathrm{K}_{\mathrm{d}}$ is the dissociation constant. The $\mathrm{K}_{\mathrm{d}}$ values from 3 experiments each for beluga, mouse, and human AHRs were compared using unpaired Students t-test. Curve fits and statistics were done with SigmaPlot 5.0 for the Macintosh (Jandel Scientific).

\section{RESULTS}

\section{Beluga AHR cloning}

A beluga AHR cDNA was isolated from liver of belugas collected from Canada and Alaska (Figure 1). The initial attempts utilized a beluga that stranded in the Mackenzie River Delta, Canada. This individual was among those for which PCB levels were measured and CYP1A was successfully identified by immunoblotting (White et al., 1994) and AHR was identified by photoaffinity labeling (Hahn et al., 1994). Using degenenerate primers designed based on previously published mammalian AHR 
sequences (Hahn \& Karchner, 1995) we isolated the AHR-A2/AHR-B2 fragment after using low stringency conditions (see Methods). Efforts to isolate the full-length beluga AHR cDNA using the Mackenzie River Delta beluga sample were not successful, so subsequent efforts utilized a beluga liver sample collected in Alaska in 1997. From freshly prepared mRNA, a 648 bp AHR-A1/AHR-B1 fragment was isolated that encompassed the AHR-A2/AHR-B2 fragment and matched its sequence exactly.

The remaining beluga AHR sequence was obtained with 5' and 3' RACE. Together the RACE fragments and original PCR products spanned a $3.2 \mathrm{~kb} \mathrm{cDNA}$ that contained a 2535 bp open reading frame, $29 \mathrm{bp}$ of 5'UTR, and $699 \mathrm{bp}$ of 3' UTR. No poly A tail was detected, despite the fact that the cDNA was primed with oligo dT. This might be explained by cleavage of the end of the 3'UTR before the kit adapters were ligated to the cDNA ends, or by priming of the adapter primer AP1 upstream of the poly A tail. The consensus sequence was based on 44 sequences; 38 were obtained by cycle sequencing of 21 separate clones and 6 sequences were from direct sequencing of $\mathrm{PCR}$ products in forward and reverse directions. The ORF encoded an 845 amino acid protein with predicted size $95.5 \mathrm{kDa}$. The minimum number of sequences that were used to form a consensus at each base was 4 within the coding region, and 2 in the UTR (Figure 2). The translated consensus sequence is shown in Figure 3.

The alignment with mouse $\mathrm{AHR}^{\mathrm{b}-1}$ allele (Burbach et al., 1992) and the human AHR (Dolwick et al., 1993) is shown in Figure 4. Among published mammalian AHR sequences, the beluga AHR shares the highest (85\%) overall amino acid sequence 
identity with the human AHR. The amino acid sequence identity of the beluga AHR shared with the mouse AHR is $75 \%$.

The AHR has functional regions whose boundaries have been elegantly determined for the mouse AHR (Burbach et al., 1992; Dolwick et al., 1993; Fukunaga et al., 1995; Poland et al., 1994). In brief, the bHLH is involved in DNA binding, the PAS domain is involved in ligand binding, dimerization with ARNT, and hsp90 binding, and the $\mathrm{C}$-terminus is believed to function mainly in transcriptional activation. When the homologous regions of the beluga AHR were compared to mouse and human AHR genes, the beluga AHR again shared the greatest sequence identity and similarity with the human AHR (Figure 5). As in other bHLH/PAS proteins, the N-terminus is much more highly conserved between species as compared to the C-terminus. Clusters of glutamine residues appear among amino acids 598-775 of the beluga AHR, 20 in total (27\%)(Figure 4). In the same region, mouse AHR is $28 \%$ glutamine, and human AHR is $29 \%$ glutamine. This "Q-rich" domain, which has been shown to contribute to transcriptional activation in other transcription factors, is suggested to have also have a role in transcriptional activation in the AHR (Burbach et al., 1992).

Certain amino acid changes in the AHR confer dramatic changes in AHR function. One of these is the amino acid 375 of the mouse AHR; an alanine at this position in the $\mathrm{Ah}^{\mathrm{b}-1}$ allele confers about four to five-fold greater binding affinity compared to the $\mathrm{Ah}^{\mathrm{d}}$ allele, where the residue is a valine (Ema et al., 1994; Poland et al., 1994). Like the high affinity mouse allele, the beluga AHR has an alanine at the analogous residue 380. Another notable mutation is found in AHR of Hepa-1 cells (D 
mutant strain) at residue 216 of the mouse $\mathrm{Ah}^{\mathrm{b}-1}$ allele, between the PAS-A and PAS-B domains. A point mutation that changed this residue from cysteine to tryptophan conferred a complete loss of DNA binding by the AHR-ARNT heterodimer (Sun et al., 1997). As with the human AHR and the wild type mouse $\mathrm{Ah}^{\mathrm{b}-1}$ allele, the beluga AHR has the conserved cysteine at analogous residue 221 (222 in human AHR).

\section{Characterization of beluga AHR synthesized in vitro}

The beluga AHR protein was expressed in a rabbit reticulocyte lysate system under control of the SP6 and T7 promoters, with and without modification to create Kozak sequences near the start codon. An autoradiogram of a polyacrylamide gel containing the proteins made with $\left[{ }^{35} \mathrm{~S}\right]$-methionine revealed that the native AHR sequence under the SP6 promoter was the most efficiently expressed construct (Figure 6). The apparent size was $\sim 110 \mathrm{kDa}, 15 \%$ different from its predicted size of $95.5 \mathrm{kDa}$, but consistent with its apparent size as observed by photoaffinity labeling (Hahn et al., 1994). All functional assays of in vitro expressed protein were henceforth conducted using the pSP64belAHR plasmid.

The fluorogram in Figure 7a shows the expressed beluga, human, and mouse proteins synthesized in the presence of $\left[{ }^{35} \mathrm{~S}\right]$. The relative sizes are consistent with the relative sizes of their predicted molecular weights of $95.5,90.6$, and $96.0 \mathrm{kDa}$ for pSP64belAHR, pSPORTmoAHR, and pSPORThuAHR products, respectively. Figure

$7 \mathrm{~b}$ is a Western blot probed with an anti-mouse AHR polyclonal antibody. This antibody clearly recognizes the in vitro-expressed beluga AHR, along with the expressed mouse 
and human AHR expression products. The blot also shows a band in beluga liver cytosol that was equivalent in size to the expressed beluga AHR. Likewise, the size of the band detected in mouse liver cytosol was the same as the expressed mouse AHR.

We next determined the ability of the in vitro-expressed beluga AHR to bind $\left.{ }^{3} \mathrm{H}\right] \mathrm{TCDD}$. The beluga, mouse, and human AHR TNT products all showed a clear peak of binding that was eliminated upon incubation with 200 -fold excess TCDF, which indicated that the $\left[{ }^{3} \mathrm{H}\right] \mathrm{TCDD}$ binding was specific. The concentrations and sedimentation coefficients of AHR from representative experiments are shown in Figure 8. The expressed beluga and human AHR sedimented with a peak at $10.5 \mathrm{~S}$, and the mouse AHR peak was at $10 \mathrm{~S}$. The mouse TNT reaction produces the highest concentration of binding AHR ( $111 \mathrm{fmol}$ AHR/50 $\mu \mathrm{l}$ reaction), followed by beluga ( $69 \mathrm{fmol} /$ reaction) and human ( $24 \mathrm{fmol} /$ reaction). No specific binding was observed with the unprogrammed lysate, confirming that all detectable specific binding was from the expression products alone, and not from lysate proteins.

The peaks of specific binding in mouse and beluga cytosol were centered at $9.5 \mathrm{~S}$. In contrast with the high levels of binding observed for TNT expressed AHRs, specific binding in C57BL/6 mouse liver cytosol was $24 \mathrm{fmol} \mathrm{AHR/mg} \mathrm{cytosol} \mathrm{protein,} \mathrm{and} \mathrm{that}$ in beluga liver cytosol was $7 \mathrm{fmol} / \mathrm{mg}$. When the beluga liver cytosol was treated with as little as $0.025-2 \mathrm{mg} \mathrm{DCC} / \mathrm{mg}$ protein to adsorb free $\left[{ }^{3} \mathrm{H}\right]-\mathrm{TCDD}$, a significant amount of specific binding was lost (not shown). Sensitivity of cytosolic AHR to charcoal treatment has also been observed in human tissues (Manchester et al., 1987) and in fish cells (Lorenzen \& Okey, 1990). We did not observe this sensitivity to charcoal with TNT- 
expressed proteins. Overall, these results show that beluga AHR binds $\left[{ }^{3} \mathrm{H}\right]-\mathrm{TCDD}$ in a highly specific manner, and that in vitro expression is a suitable way to generate large amounts of AHR protein without the need to collect and process large amounts of difficult to obtain tissue.

\section{Relative binding affinities of beluga, mouse, and human AHRs}

Having established the ability of the beluga AHR to specifically bind $\left[{ }^{3} \mathrm{H}\right]-\mathrm{TCDD}$, we next sought to compare the TCDD binding affinity $\left(\mathrm{K}_{d}\right)$ of the in vitro expressed beluga AHR with $\mathrm{K}_{d} \mathrm{~s}$ of expressed mouse and human AHRs. The saturation binding assay with in vitro expressed AHRs is a modification of the cytosolic binding assay described by Poland et al. (Poland et al., 1976). Critical to these experiments is the achievement of an abundance of "free" ligand relative to bound ligand so that the $\left[{ }^{3} \mathrm{H}\right]-$ TCDD concentrations used to measure the dissociation constant are not overly distorted by associations with lower affinity binding sites. A satisfactory balance of detectable specific binding ( $\geq 500$ disintegrations per minute) and fraction of "free" $\left[{ }^{3} \mathrm{H}\right]-\mathrm{TCDD}(\geq$ 80) for the beluga AHR was determined to be around a 10-fold dilution of the lysate (Figure 9). A 9-fold dilution was used for all subsequent $\mathrm{K}_{\mathrm{d}}$ determinations.

Bound $\left[{ }^{3} \mathrm{H}\right]-\mathrm{TCDD}$ was separated from "free" $\left[{ }^{3} \mathrm{H}\right]-\mathrm{TCDD}$ with the use of dextran-coated charcoal, and the mean of 3 replicates per concentration of $\left[{ }^{3} \mathrm{H}\right] \mathrm{TCDD}$ was plotted as total bound $\left[^{3} \mathrm{H}\right] \mathrm{TCDD}$. As shown in Figure 8 (panel F), unprogrammed lysate (UPL) does not bind $\left[{ }^{3} \mathrm{H}\right]-\mathrm{TCDD}$ specifically, so UPL was used to determine the amount of non-specific binding. This eliminated the need for a second set of tubes that 
are incubated in parallel with $\left[{ }^{3} \mathrm{H}\right]-\mathrm{TCDD}$, plus excess unlabeled competitor. Binding to UPL increased linearly with increasing amount of $\left[{ }^{3} \mathrm{H}\right]-\mathrm{TCDD}$ in the concentration range used, consistent with the theoretical notion that non-specific binding sites are high capacity and not saturable. Specific binding was then calculated as the difference between the total binding points and the linear non-specific binding curve. Specific binding was fit to the Langmuir binding isotherm to determine the binding affinity $\mathrm{K}_{\mathrm{d}}$ and the theoretical maximum binding $\left(\mathrm{B}_{\max }\right)$. A representative set of experiments is shown in Figure 10, and data from 3 independent experiments is summarized in Table 1. The beluga AHR exhibited high affinity for $\left[{ }^{3} \mathrm{H}\right]$-TCDD that was not significantly different from that of the mouse AHR, and both the beluga and mouse AHRs had binding affinities that were significantly greater than that of the human AHR.

The curves in Figure 10 are plotted as Scatchard plots in Figure 11. For the human $A H R$, the $\mathrm{K}_{\mathrm{d}}$ calculated using the Scatchard analysis was within 1 standard deviation of the $K_{d}$ predicted by the curve fit method, but the $K_{d}$ for mouse (within 5 SD) and beluga (within $2 \mathrm{SD}$ ) were not as close. The data transformation in the Scatchard analysis causes two problems: 1 ) it requires a correlation between $\mathrm{X}$ and $\mathrm{Y}$ values for which $\mathrm{X}$ is dependent on $\mathrm{Y}$, and 2) it "compresses" data at the high and low ends of the curve (Kenakin, 1999). Both of these conditions exacerbates error at the ends of the data. In this system, the low $\left[{ }^{3} \mathrm{H}\right] \mathrm{TCDD}$ concentrations are subject to the highest error because of scintillation counting limitations. The high ends of the curve are also difficult to obtain because of the very low solubility of TCDD. Since curve-fitting does not depend on transformed data, estimates obtained from direct curve fitting are more accurate. 


\section{DISCUSSION}

The objective of these studies is to assess the potential impact of a persistent and toxic class of environmental contaminants, the $\mathrm{PHAH}$, on the health of cetaceans. The toxicity of PHAH has been clearly established in other mammalian species. For this reason, $\mathrm{PHAH}$, among other contaminants and factors related to environmental degradation, have been implicated in apparent increases in marine mammal disease and mortality. However, species-specific variability in sensitivity to PHAH confounds and limits broad speculation on the toxicological significance of the high tissue burdens that are observed in marine mammals.

One way of assessing whether effects by PHAH might be significant in a given species is to examine proteins involved in the mechanism of toxicity. We chose to examine the AHR, a protein known to interact directly with PHAH and play an important role in PHAH toxicity. However, biochemical examination requires intact proteins from high quality tissue samples, which are difficult to collect for marine mammals. We cloned and expressed a beluga AHR in vitro, which circumvented the problems inherent in both marine mammal tissue sampling (autolysis before tissues can be collected, rare sampling opportunities) and working with AHR (low abundance, labile protein). The results presented here show that PHAH are likely to cause effects via the AHR and thus have the potential to affect cetacean health.

Beluga AHR shares high sequence identity with other mammalian AHRs 
Cloning and sequence analysis of a full-length cetacean AHR confirms and extends earlier observations of a protein in cytosols from beluga liver and a dolphin cell line that binds dioxin specifically (Carvan III et al., 1995; Hahn et al., 1994). The beluga AHR possesses major functional domains that are characteristic of AHRs, including the bHLH, PAS A, PAS B, and glutamine-rich regions (Figure 4). Like other AHRs, the Nterminus is highly conserved and the $\mathrm{C}$-terminus is much less conserved, and might be termed "hypervariable" as by others (Dolwick et al., 1993). Overall, the beluga AHR sequence is most identical to human AHR (Dolwick et al., 1993). It differs by only 3 amino acids in total length of the coding region and shares $85 \%$ identity with human $\mathrm{AHR}$ and $75 \%$ identity with the $\mathrm{Ah}^{\mathrm{b}-1}$ allele expressed in the C57BL/6 mouse strain and wild-type Hepa-1c1c7 cell line (Burbach et al., 1992). Within the bHLH and PAS domains (as defined by homology to the mouse AHR), this identity is much higher (Figure 5).

Despite the high degree of sequence identity among mammalian AHRs, subtle changes in the amino acid sequence can cause remarkable changes in AHR function. A much greater understanding of the AHR structure-function relationship is required before function may be deduced accurately from AHR sequence data. For this reason, we characterized the in vitro binding affinity for the beluga AHR.

\section{Beluga AHR is a high affinity AHR}

In order to conduct a comparison of the beluga AHR with AHRs from terrestrial mammals that have been reasonably well characterized, we chose a relatively "high 
affinity" and a relatively "low affinity" AHR to use alongside the beluga AHR in our experimental system to determine TCDD binding affinities. The "high affinity" AHR was the mouse $\mathrm{AHR}$ allele $\mathrm{Ah}^{\mathrm{b}-1}$ (Burbach et al., 1992). In vitro, the $\mathrm{Ah}^{\mathrm{b}-1}$ protein has a 4-5 fold greater binding affinity than the mouse $\mathrm{Ah}^{\mathrm{d}}$ protein (Ema et al., 1994; Poland et al., 1994). The representative "low affinity" AHR that we used was a human AHR that was cloned from the hepatic carcinoma cell line Hep G2 (Dolwick et al., 1993). In vitro, the Hep G2 AHR has a 4-5 fold lower affinity for TCDD than the mouse $A h^{b-1}$ allele, comparable to the binding affinity of the $\mathrm{Ah}^{\mathrm{d}}$ allele (Ema et al., 1994).

Determination of the $K_{d} s$ of in vitro expressed beluga, mouse and human AHRs by saturation binding showed that the beluga AHR is a high affinity AHR. In this system, the belAHR has a $\mathrm{K}_{\mathrm{d}}$ of $\sim 0.43 \mathrm{nM}$, the mouse $\mathrm{Ah}^{\mathrm{b}-1} \mathrm{AHR}$ has a $\mathrm{K}_{\mathrm{d}}$ of 0.68 , and the human AHR has a $\mathrm{K}_{\mathrm{d}}$ of $\sim 1.63 \mathrm{nM}$. Absolute binding affinities are highly dependent on the protein concentrations used in the incubations, with apparent binding affinities decreasing with increasing protein concentrations (Bradfield et al., 1988). Therefore, $\mathrm{K}_{\mathrm{d}} \mathrm{s}$ are best used to describe relative binding affinities that are determined under similar experimental conditions and protein concentrations. Some experiments and within-lab data sets within which $\mathrm{K}_{\mathrm{d}} \mathrm{s}$ can be compared are compiled in Table 2. Despite the protein concentration caveat, the relative binding affinities observed for the mouse and human AHRs in my studies are in reasonable agreement with observations from other laboratories, and in some cases, the relative and absolute $\mathrm{K}_{\mathrm{d}} \mathrm{s}$ are in very close agreement (see data from (Ema et al., 1994)). 
Two conclusions can be drawn from these data that are potentially important for understanding the susceptibility of beluga to PHAH. First, the beluga AHR has a binding affinity that is statistically no different than that of the mouse $\left(\mathrm{Ah}^{\mathrm{b}-\mathrm{l}}\right)$ AHR. Second, the beluga AHR has a $\left[{ }^{3} \mathrm{H}\right]-\mathrm{TCDD}$ binding affinity that is $\sim 4$-fold greater than the binding affinity of the human AHR (Figure 9, Table 1). In the case of inbred mice, a single alanine to valine switch at residue number 375 is responsible for a $4-5$ fold difference in the in vitro ligand binding affinities observed between the $\mathrm{Ah}^{\mathrm{b}-1}$ allele and the $\mathrm{Ah}^{\mathrm{d}}$ alleles (Ema et al., 1994; Poland et al., 1994). At the homologous residues in the beluga and human AHRs, the beluga AHR possesses an alanine ( $\mathrm{Ala}^{380}$, similar to the $\mathrm{Ah}^{\mathrm{b}-1}$ allele), while the human $\mathrm{AHR}$ has a valine $\left(\mathrm{Val}^{381}\right.$, similar to the $\mathrm{Ah}^{\mathrm{d}}$ allele). This alternate residue might also contribute to the 4-fold difference in binding affinity between the beluga and human AHRs observed here. In vivo studies using congenic mice, the homozygous $\mathrm{Ah}^{\mathrm{b}-1}$ mouse strain shows $8-24$ fold higher sensitivity to toxic effects compared to the homozygous $\mathrm{Ah}^{\mathrm{d}} \operatorname{strain}($ Birnbaum et al., 1990). Thus, in the case of mouse strains, the AHR binding affinity phenotype can predict the PHAH sensitivity phenotype. If the same is true for the beluga AHR phenotype, then the beluga may be particularly sensitive to $\mathrm{PHAH}$.

Significance of a high affinity AHR in cetaceans

Some diseases and pathologies are prevalent in cetacean populations that carry high contaminant burdens in their tissues, suggesting a potential link between contaminants and immunosuppression (Aguilar \& Borrell, 1994; Borrell et al., 1996; 
Jepson et al., 1999). In particular, the contaminant-burdened St. Lawrence population of beluga have exhibited susceptibility to mild pathogens, and have an high occurrence (approaching rates in humans) of metastatic cancers (Beland et al., 1993; Martineau et al., 1988). Among other possibilities, this may indicate a reduced capacity for cellular and/or the innate immune response in this population (Deguise et al., 1995).

Establishing a cause and effect relationship between contaminant burdens in marine mammals and disease is a difficult challenge. Because controlled dosing experiments in cetaceans are impossible, others have suggested a "weight of evidence" approach for addressing questions regarding contaminant effects in marine mammals (Ross, 2000). Thus, the evidence in favor of a role of contaminants, and in particular the PHAH, in cetacean disease is the following. 1) Certain populations of cetaceans are highly exposed to POPs, as evidenced by very high levels detected in blubber and tissues (Kannan et al., 1993; Martineau et al., 1987; Ross et al., 2000) 2) There is a correlation between high POP burdens in cetaceans and death by disease (Aguilar \& Borrell, 1994; Jepson et al., 1999). 3) Suppression of both the humoral and cellular branches of the immune system, as well as metastatic cancers such as those observed in cetaceans can be induced by TCDD in laboratory rodents (Huff et al., 1994; Kerkvliet et al., 1990; Kerkvliet et al., 1990; Schwarz et al., 2000; Staples et al., 1998). 4) The observation of CYP1A induction in belugas and the observed correlation with PCB levels suggests that the AHR is activated by low levels of contaminants in feral cetaceans (White et al., 1994). 
This study contributes further to the weight of evidence by showing the following. 5) Beluga possess an AHR that sharès a high degree of sequence identity with other mammalian AHRs. 6) Finally, the beluga AHR binds TCDD with an affinity that is at least as high as a "high affinity" mouse AHR. The finding of a high affinity AHR in a cetacean is consistent with a role for the AHR and PHAH in the toxic effects observed in environmentally exposed cetaceans. Future work will focus on verifying this apparent connection between toxicant exposure and toxic effect in other systems and with other AHR agonists. 


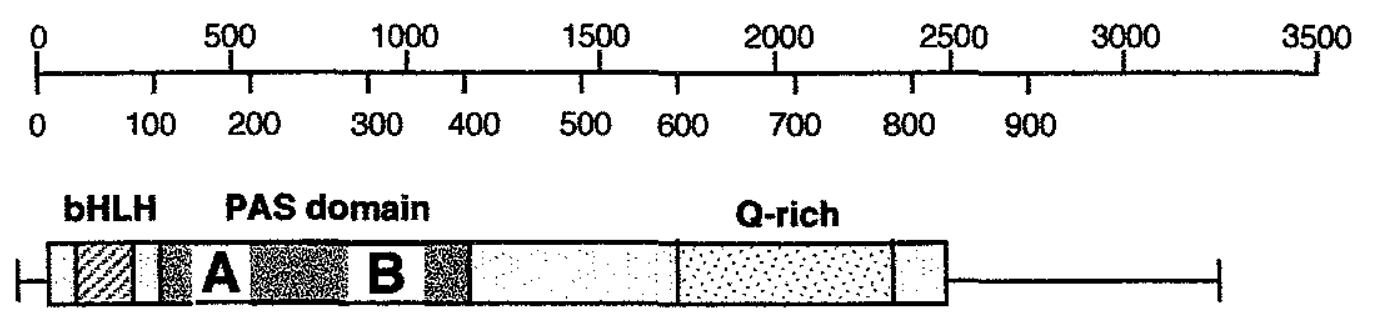

\section{5' RACE product}

A1-B1 PCR product

3' RACE product

Figure 1. Strategy for the PCR amplification and sequencing of a beluga AHR cDNA. The sequence of the full length cDNA was derived from an internal PCR fragment isolated with degenerate primers, a 5' RACE product, and a 3' RACE product, and a bridging internal PCR product isolated with specific primers. Sequence was from each region was derived from a minimum of 2 minipreps and 2 independent reactions. The $3.3 \mathrm{~kb}$ cDNA contained a $2535 \mathrm{bp}$ open reading frame that encoded an 845 amino acid protein with a predicted size of $95.5 \mathrm{kDa}$. 


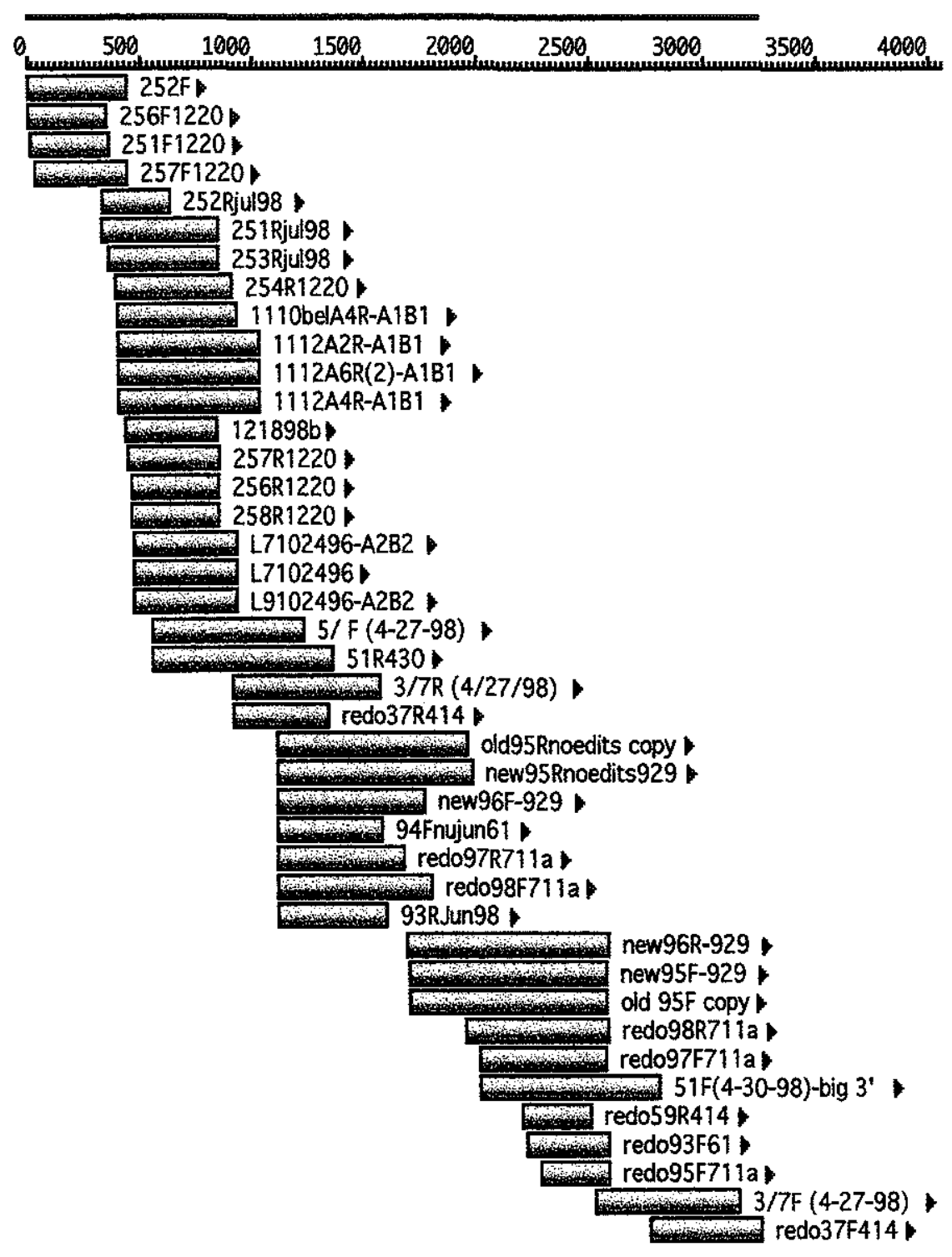

Figure 2. Sequence coverage of beluga AHR cDNA. A minimum of 4 sequences were used to determine the consensus sequence of the beluga AHR open reading frame, and at least 2 sequences were used to determine the consensus sequence of the UTR. Almost all sequencing was done on the Licor 4000 automated sequencing system (see text for details). 


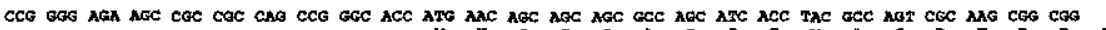

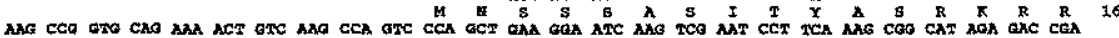

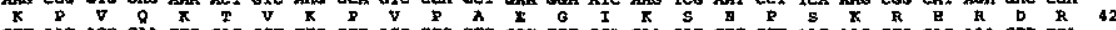

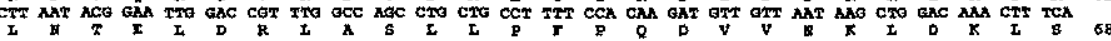
OTT CI2 AOG CTC AGT GTC AGT TAT CTA AGA OCC NAG AGC TTC TTST GAT OTT GCA ITA AAG TCC ACC CEA GCT GAC AOA

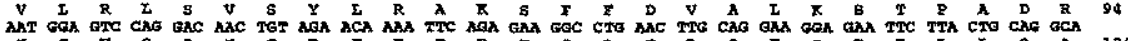

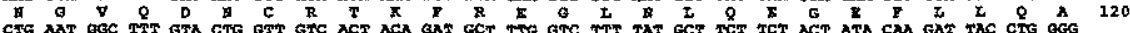

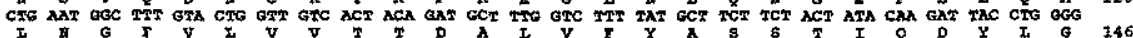

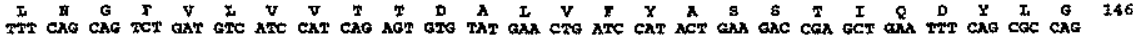

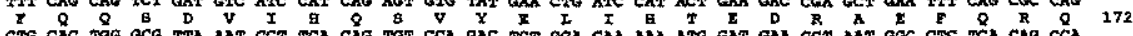

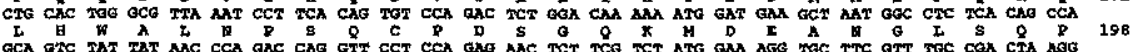

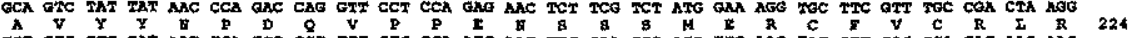

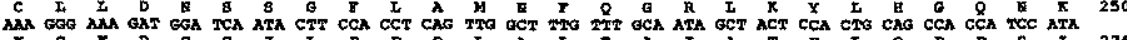

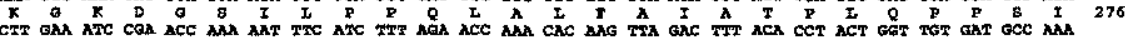

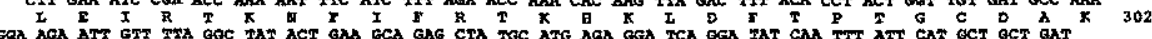

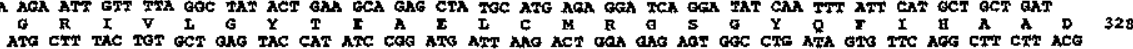

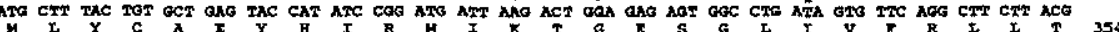

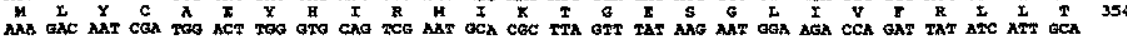

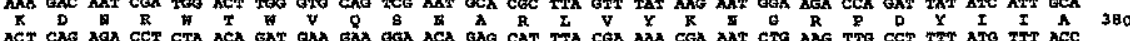

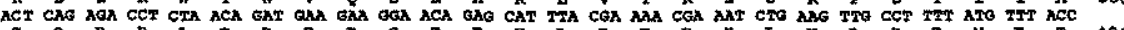

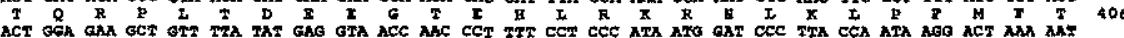
$T$ G $\quad I$ A

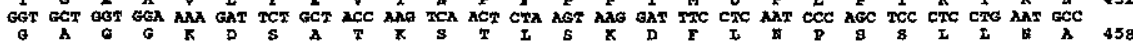

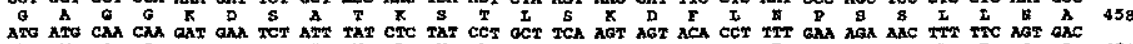

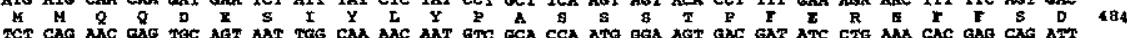

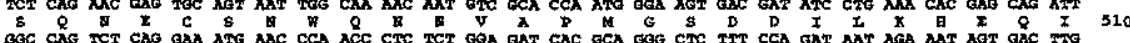

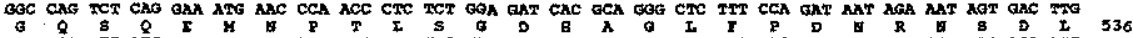

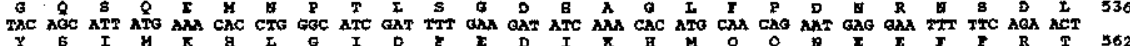

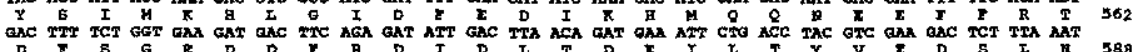

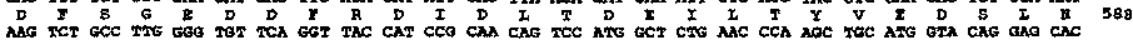

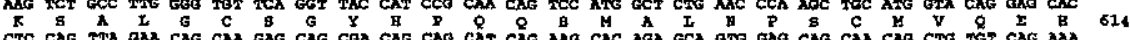

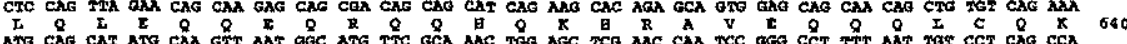

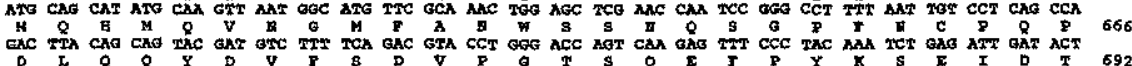

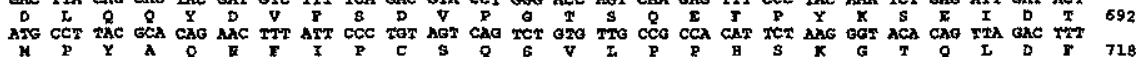

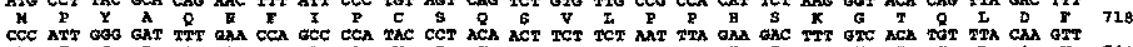

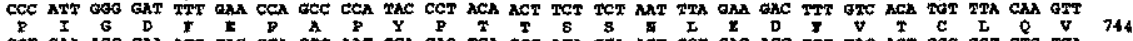

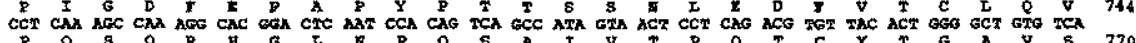

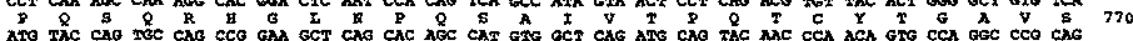
ATO TAC CAO TEC CAB CCG GAA GCT CAG CAC AGC CAT GAE OCI CAG ATS CAO TAC NAC CCA ACA GTG CCA GGC CCO CAG

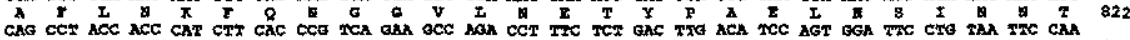

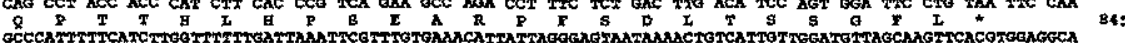

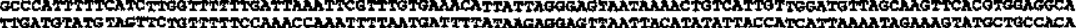

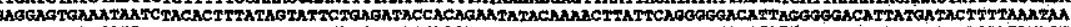

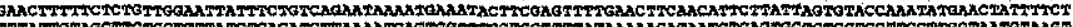

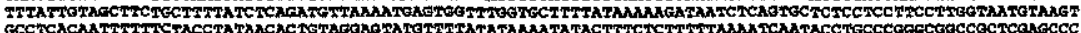

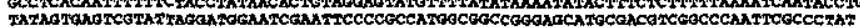

Figure 3. Full length translation of a beluga AHR cDNA. The full-length consensus sequence of a beluga AHR is shown. Bases are numbered on the left, starting with 1 at the start codon ATG, and encoded amino acids are numbered on the right. The untranslated sequence is the UTR, and the stop codon is denoted with an *. 
Figure 4. Alignment of beluga, human, and mouse AHRs. The Clustal algorithm, with slight adjustments by eye, was used to align the full-length beluga, human, and mouse cDNAs. The functional domains labeled were identified by homology to other mammalian AHRs (Mimura et al., 1994; Schmidt et al., 1993; Bennett et al., 1996). Identical amino acids are shaded dark, similar amino acids are shaded light and boxed, and gaps are indicated by dashes. 
basic 1

basic 2

Helix

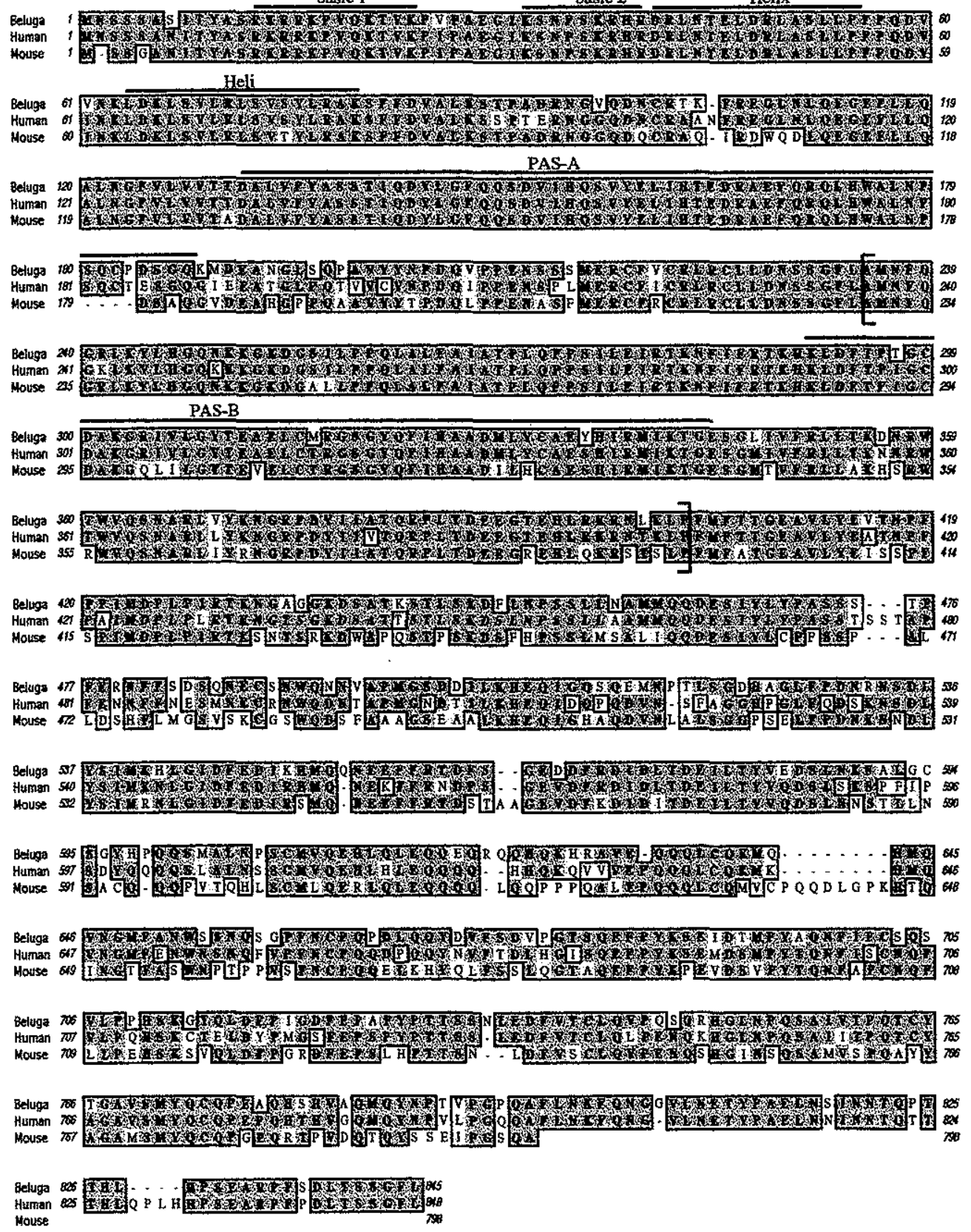




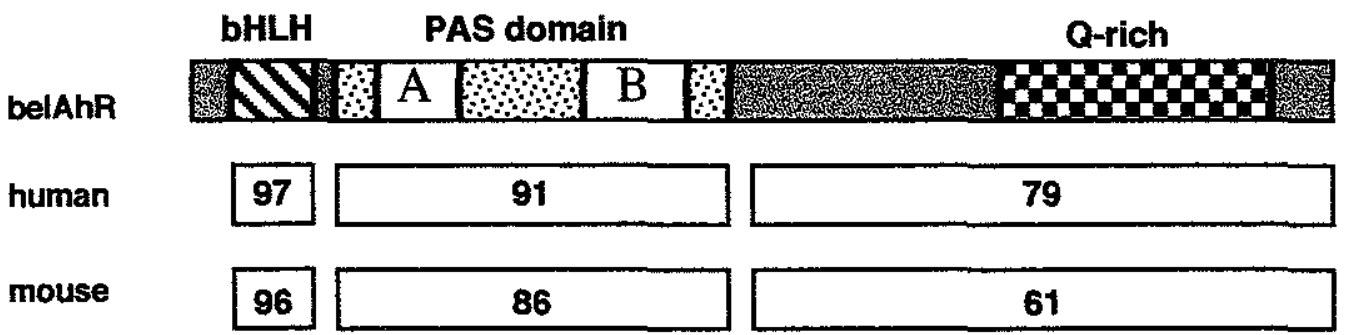

Figure 5. Conservation in functional domains between beluga, mouse, and human AHRs. MacVector was used to generate pairwise alignments of the functional domains. The boxed numbers represent percent amino acid identity within the region spanned by the box. As with most bHLH/PAS proteins, the first nine exons that contain the bHLH and PAS domains are highly conserved, while the C-terminus is more variable. 

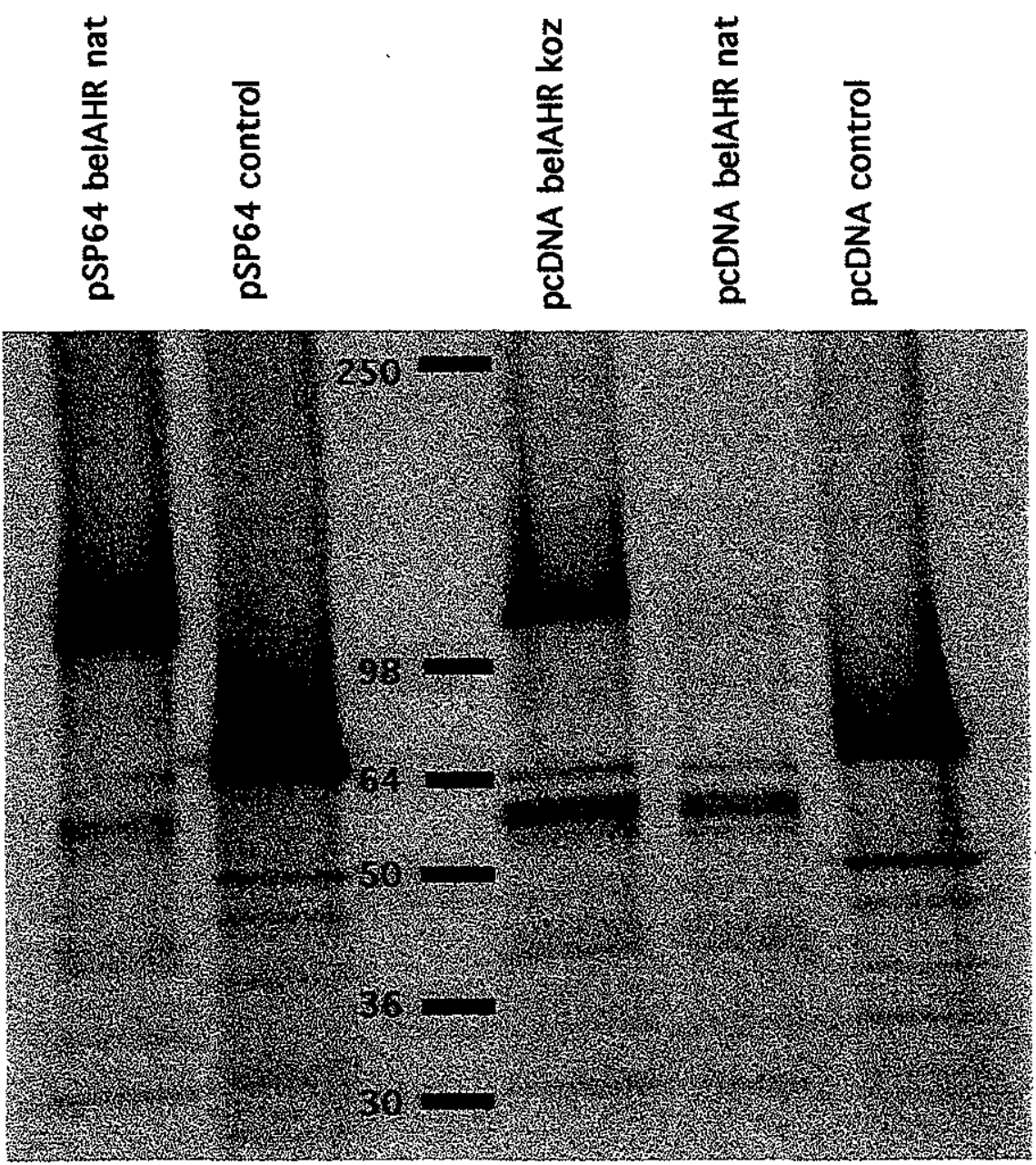

Figure 6. Comparison of belAHR expression constructs under SP6 and T7 promoters. The belAHR was cloned into expression vectors under the SP6 (pSP64polyA) and T7 (pcDNA3.1) promoters. The pcDNA constructs were constructed with and without Kozak sequences, and only the native sequence was used to generate pSP64belAHR(nat). Proteins were expressed in the SP6 or T7 Quick TNT (Transcription and Translation) kits (Promega). The positive control was luciferase $(\sim 62 \mathrm{kDa})$ that came with kits. 

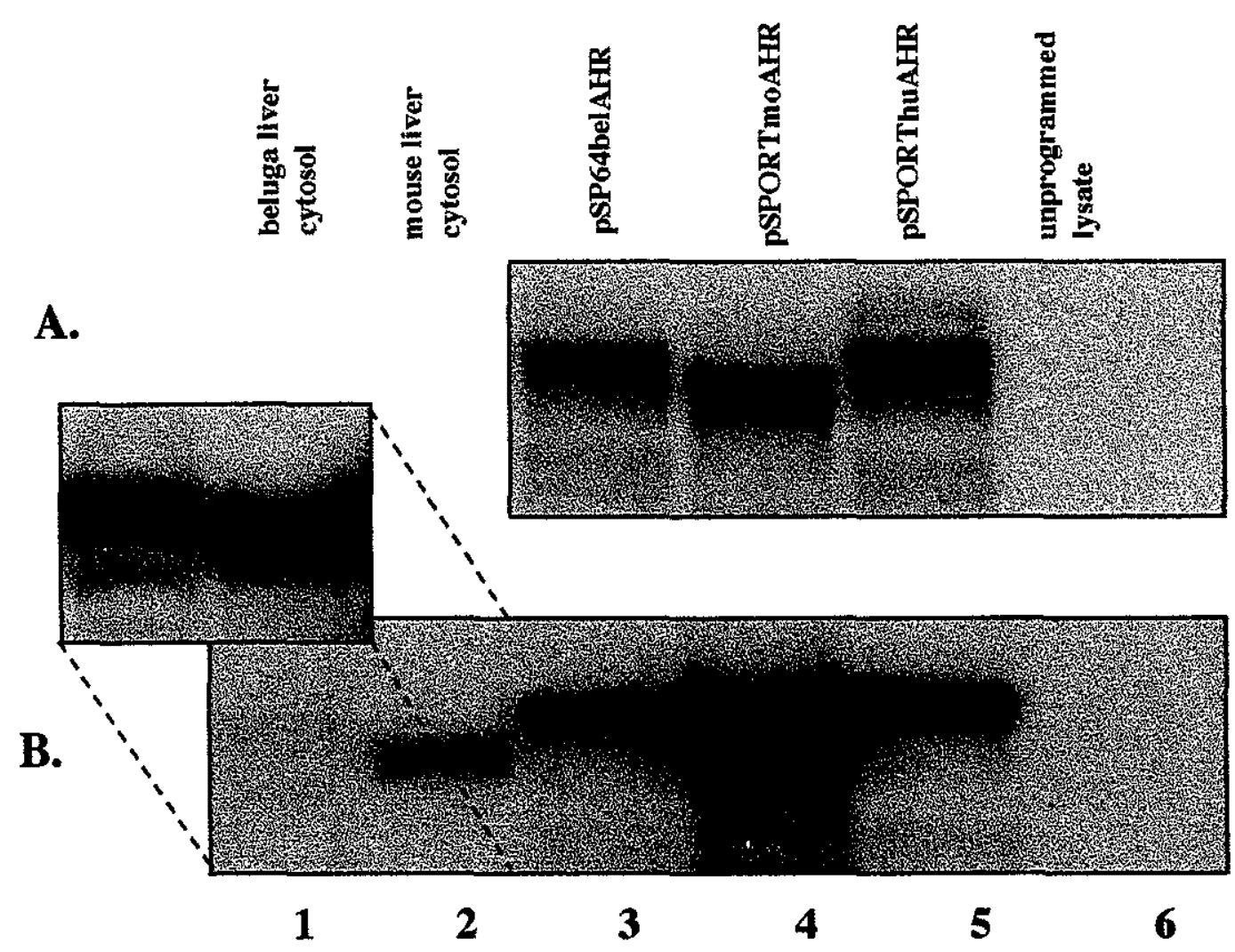

Figure 7. Autoradiogram and western blot of beluga, mouse, and human AHRs. TNT reactions that were conducted in the presence of ${ }^{35} \mathrm{~S}$ and $100 \mu \mathrm{g}$ cytosol protein were run on a $7 \%$ gel. A. The gel was dried and exposed to Kodak X-OMAT film 6 hours or 12 hours (inset lanes 1 and 2). B. Proteins were transfered to $0.2 \mu$ PVDF membrane and probed with SA-210 anti-moAHR polyclonal Ab, followed by APconjugated $2^{\circ} \mathrm{Ab}$, and exposed X-OMAT film for 15min. Lane 1: 100 $\mu \mathrm{g}$ beluga liver cytosol protein. Lane 2: 100 $\mu \mathrm{g} \mathrm{C57/B6} \mathrm{mouse} \mathrm{liver} \mathrm{cytosol} \mathrm{protein.} \mathrm{Lane} \mathrm{3:} 5 \mu 1$ pSP64 belAHR. Lane 4: 5 $\mu \mathrm{l}$ pSPORT moAHR. Lane 5: 5 $\mu 1$ pSPORT huAHR. Lane 6: $5 \mu 1 \mathrm{TNT}$ reaction programmed with empty pSP64 vector. 
Figure 8. Velocity sedimentation analysis of in vitro-expressed and cytosol-derived AHRs. Beluga, mouse and human AHRs were expressed in vitro and beluga and C57BL/6 liver cytosols were incubated with 3H-TCDD, with or without 200 -fold excess cold TCDF. Total bound $\left[{ }^{3} \mathrm{H}\right] \mathrm{TCDD}(\mathrm{DPM})$ are indicated by the solid boxes, and nonspecific binding $\left(\left[{ }^{3} \mathrm{H}\right] \mathrm{TCDD}\right.$ that is not displaced by 200 -fold excess cold TCDF) is indicated by the hollow boxes. The specific binding detected was as follows: (A) pSP64belAHR $115 \mathrm{fmol} / \mathrm{mg}$, (B) pSPORTmoAHR $185 \mathrm{fmol} / \mathrm{mg}$, (C) pSPORThuAHR 41 $\mathrm{fmol} / \mathrm{mg}$, (D) beluga liver cytosol $7.2 \mathrm{fmol} / \mathrm{mg}$, and (E) C57BL/6 mouse liver cytosol 24 fmol/mg. No specific binding was detected in TNT lysate programmed with empty pSP64polyA vector (F). 
A.

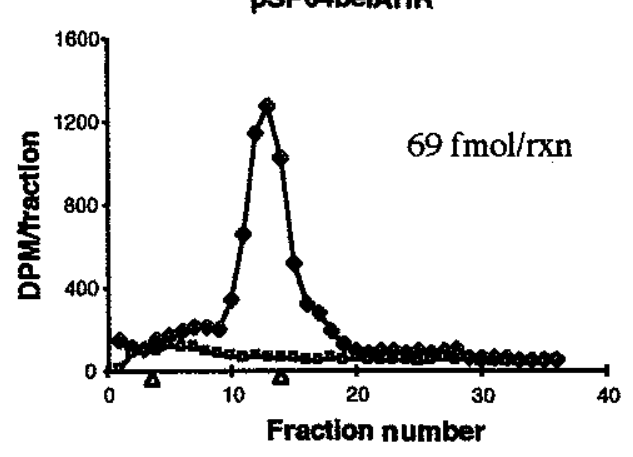

B.

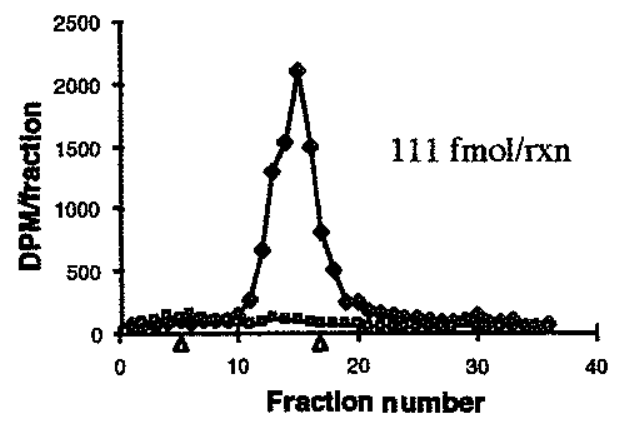

C.

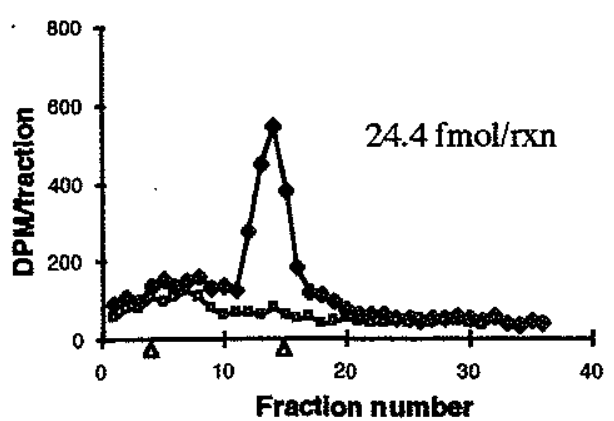

D. Beluga Llver Cytosol

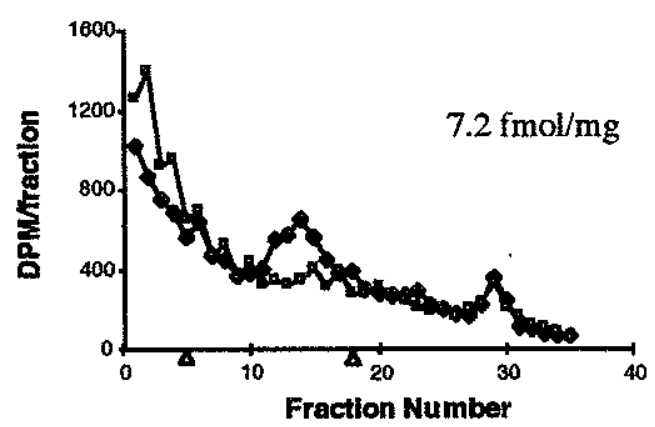

E.

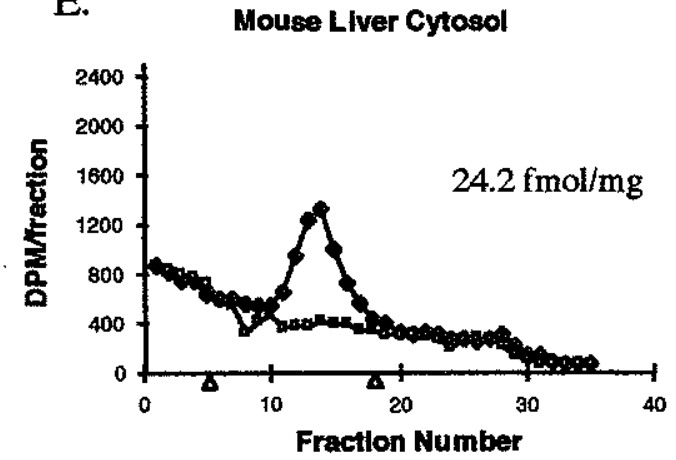

F. Unprogrammed Lysate

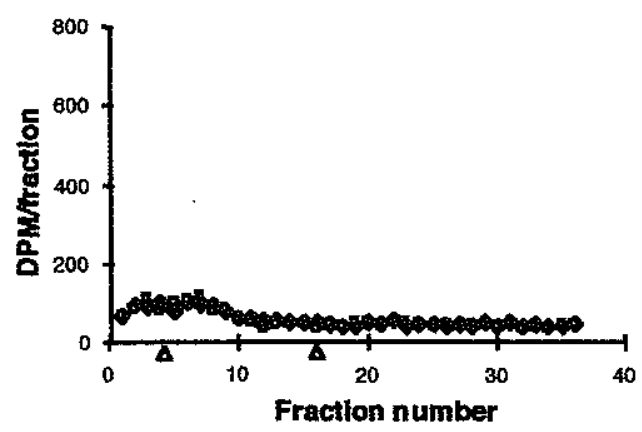




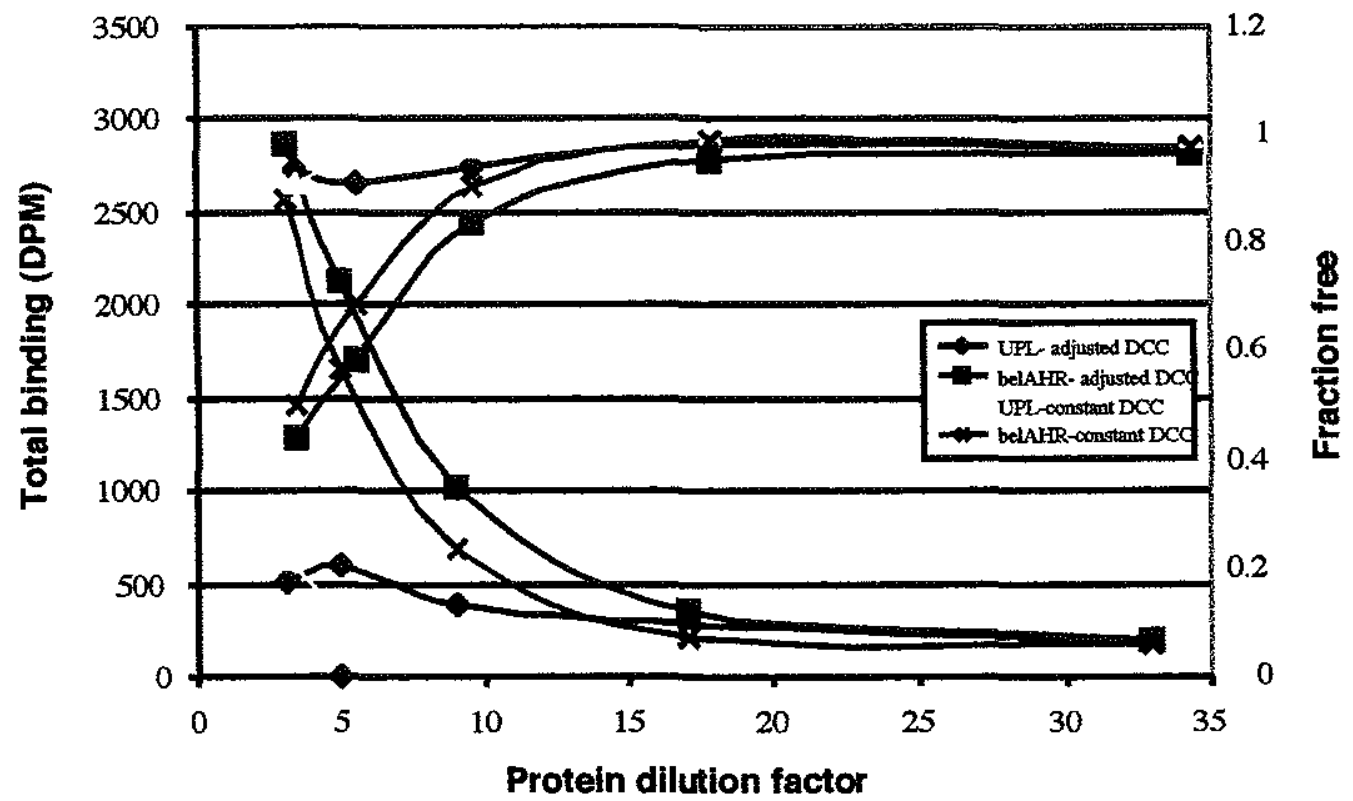

Figure 9. Total $\left[{ }^{3} \mathrm{H}\right] \mathrm{TCDD}$ binding and fraction of "free" relative to protein dilution. Total binding was measured in TNT lysate programmed with pSP64belAHR (squares and x's), and in unprogrammed lysate (diamonds and triangles) at different protein dilutions. BelAHR and UPL dilutions was either treated with the same DCC concentration at all dilution points $(3.5 \mathrm{mg} / \mathrm{ml})$ or the $\mathrm{DCC}$ was adjusted at each point to maintain the same DCC/protein ratio at all dilutions. The yellow shaded region reflects the ideal dilution above which the fraction "free" is ideal, and the shaded green region is the dilution for which measuring total $\left[{ }^{3} \mathrm{H}\right]-\mathrm{TCDD}$ binding is ideal. The unshaded region of plot reflects protein dilution that best satisfies the need for maximal fraction of "free" $\left[{ }^{3} \mathrm{H}\right] \mathrm{TCDD}$ and for maximal detection of total binding. 
Figure 10. Saturation binding curves for beluga, mouse, and human AHR. Binding curves for A. pSP64 belAHR, B. pSPORTmoAHR, and C. pSPORThuAHR. Nine concentrations of ${ }^{3} \mathrm{H}$-TCDD were incubated with TNT reaction diluted in AHR buffer as described. Diamonds represent total binding, squares represent non-specific binding using an empty pSP64 vector treated the same. Triangles represent specific binding determined by subtracting the non-specific binding from the total binding. The curve fitting the specific binding points was determined by a simultaneous fit of the binding equations as described in the text. 

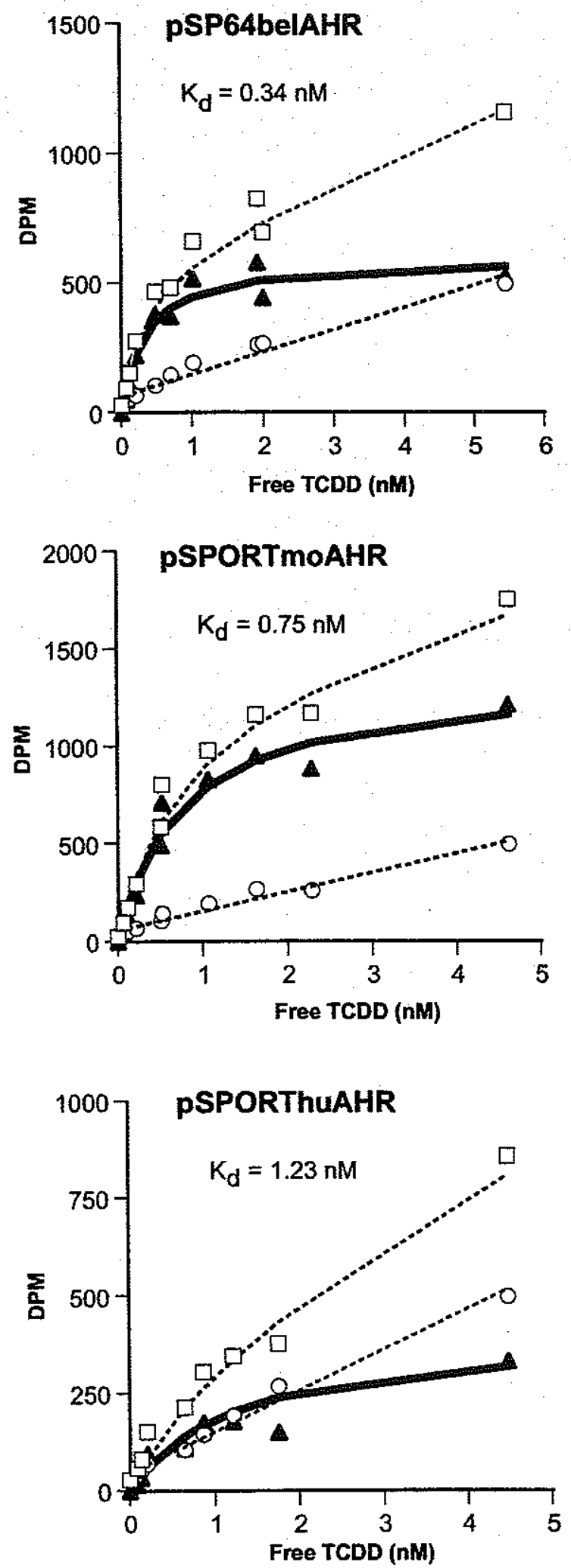
Figure 11. Scatchard analyses of saturation binding curves for beluga and mouse AHR binding to $\left[{ }^{3} \mathrm{H}\right]-\mathrm{TCDD}$.

Data from Figure 10 were transformed and fitted to the linear equation:

$\frac{\text { Bound }}{\text { Free }}=\frac{\text { Bound }}{K_{d}}+\frac{B_{\max }}{K_{d}} \cdot \mathrm{K}_{d} \mathrm{~s}$ were determined by taking the inverse of the slope of the fitted line. 

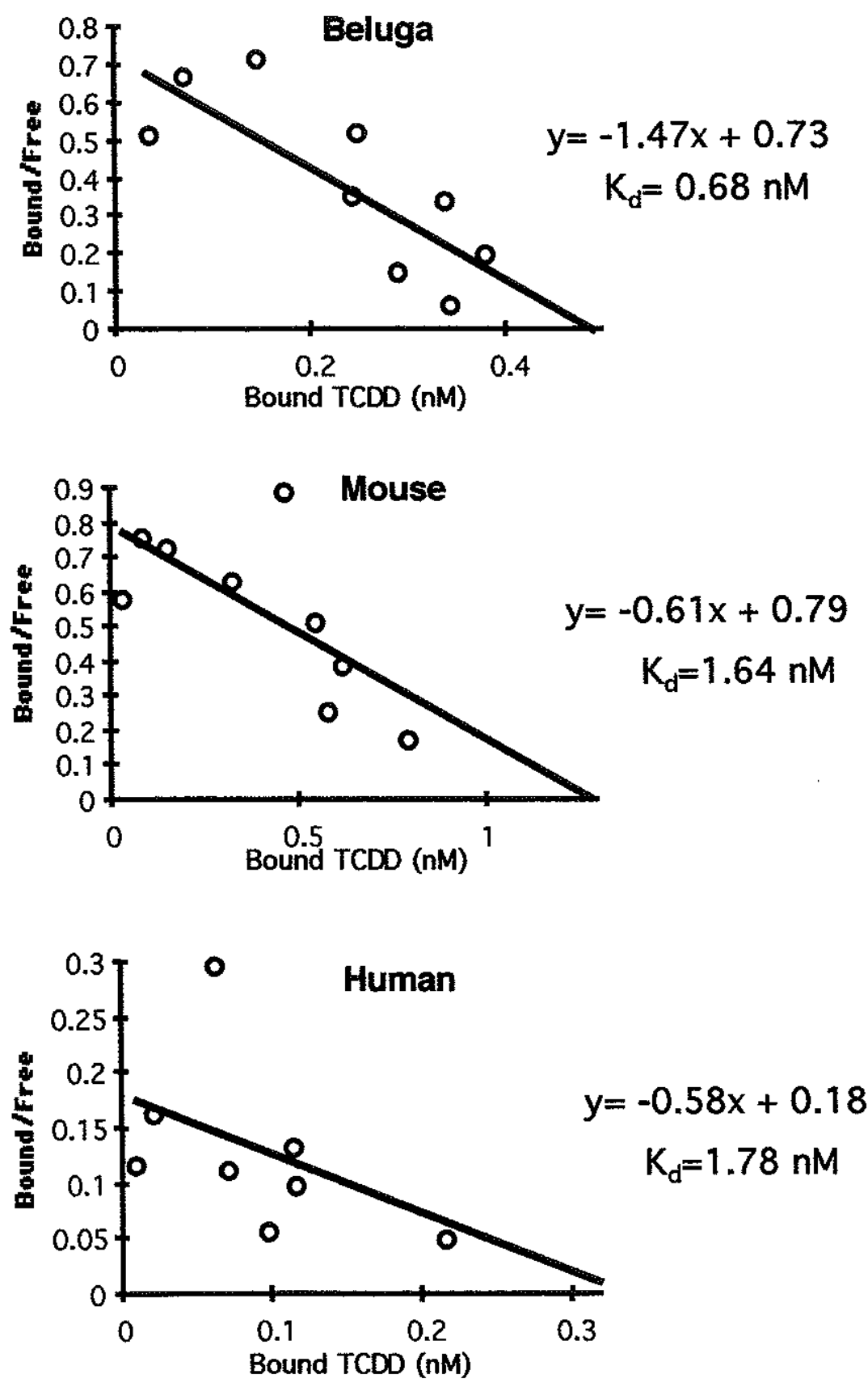
Table 1. Summary of dissociation constants $\left(K_{d}\right)$ and maximal binding $\left(B_{\max }\right)$ determined for in vitro expressed AHRs. $\mathrm{K}_{d} \mathrm{~s}$ of AHRs were compared using paired Student's $\mathrm{T}$ tests.

\begin{tabular}{lccrcc}
\hline & $\mathrm{n}$ & $\begin{array}{c}\text { Mean } \mathrm{K}_{\mathrm{d}} \pm \mathrm{SD} \\
(\mathrm{nM})\end{array}$ & $\begin{array}{c}\mathrm{B}_{\max } \pm \mathrm{SD} \\
(\mathrm{DPM})\end{array}$ & $\begin{array}{c}\text { T-test with } \\
\text { moAHR } \mathrm{K}_{\mathrm{d}} \\
(\mathrm{p})\end{array}$ & $\begin{array}{c}\text { T-test with } \\
\text { humAHR } \mathrm{K}_{\mathrm{d}} \\
(\mathrm{p})\end{array}$ \\
\hline belAHR & 3 & $0.43 \pm 0.16$ & $857 \pm 252$ & 0.122 & 0.010 \\
moAHR & 3 & $0.68 \pm 0.23$ & $1322 \pm 466$ & - & 0.031 \\
huAHR & 3 & $1.63 \pm 0.64$ & $503 \pm 106$ & - & - \\
\hline
\end{tabular}


Table 2. Dissociation constants $\left(\mathrm{K}_{\mathrm{d}}\right)$ reported in literature. Data are grouped in columns by lab. $\mathrm{K}_{\mathrm{d}} \mathrm{s}$ reflect $\left.{ }^{3} \mathrm{H}\right]-\mathrm{TCDD}$ binding with the exception of data from Poland et al., 1994, which were derived using 2-[ $\left.{ }^{125} I\right]$ iodo-7,8dibromodibenzo-p-dioxin.

\begin{tabular}{|c|c|c|c|c|c|c|c|}
\hline AHR source & \multirow{2}{*}{$\frac{\text { Species }}{\text { beluga }}$} & \multirow{2}{*}{$\begin{array}{l}\text { Allele/line/tissue } \\
\text { pPSP64belAHR } \\
\text { (liver) }\end{array}$} & \multicolumn{5}{|c|}{$\mathbf{K}_{d}(\mathbf{n M})$} \\
\hline $\begin{array}{c}\text { Translation } \\
\text { products }\end{array}$ & & & 0.43 & & (2) & & \\
\hline & mouse & $A h^{b-1}$ & 0.68 & 0.010 & 0.27 & & \\
\hline & & $\overline{\mathrm{Ah}^{\mathrm{b}-2}}$ & & & & & \\
\hline & & $\mathrm{Ah}^{\mathrm{d}}$ & & 0.037 & 1.66 & & \\
\hline & human & $\begin{array}{l}\text { phuAHR } \\
\text { (iiver Hep G2) }\end{array}$ & 1.63 & & 1.58 & & \\
\hline & & $\begin{array}{l}\text { pSR } \alpha \text {-hAHR } \\
\text { (Hep G2 short variant) }\end{array}$ & & & 0.89 & & \\
\hline $\begin{array}{l}\text { Tissue } \\
\text { cytosols }\end{array}$ & mouse & $\begin{array}{l}\text { C57BL6 liver cytosol } \\
\left(\mathrm{Ah}^{\mathrm{b}-1} / \mathrm{Ah}^{\mathrm{b}-1}\right)\end{array}$ & & 0.034 & & 0.29 & $1-3^{d, e}$ \\
\hline & & $\begin{array}{l}\text { DBA } / 2 \text { liver } \\
\text { cytosol }\left(\mathrm{Ah}^{d} / \mathrm{Ah}^{d}\right)\end{array}$ & & $\begin{array}{l}0.09- \\
0.15\end{array}$ & & $\begin{array}{l}\text { Not } \\
\text { measur- } \\
\text { able }\end{array}$ & $16^{\mathrm{e}}$ \\
\hline Cell & human & placenta & & & & & $5-8^{d}$ \\
\hline & mouse & $\begin{array}{l}\text { Hepalc1c7 } \\
\text { (liver hepatoma) }\end{array}$ & & & & & $1.0^{f}$ \\
\hline & human & $\begin{array}{l}\text { liver Hep G2 } \\
\text { (liver hepatoma) }\end{array}$ & & & & & $9.0^{f}$ \\
\hline & & $\begin{array}{l}\text { LS180 } \\
\text { (colon carcinoma) }\end{array}$ & & & & & $5.6^{\mathrm{g}}$ \\
\hline & & $\begin{array}{l}\text { A431 (squamous cell } \\
\text { carcinoma) }\end{array}$ & & & & & $10^{f}$ \\
\hline & & $\begin{array}{l}\text { BCR-5 } \\
\text { (B lymphoblastoma) }\end{array}$ & & & & & $5^{i}$ \\
\hline Reference & & & $\begin{array}{l}\text { this } \\
\text { study }\end{array}$ & a & b & c & $\mathrm{d}, \mathrm{e}, \mathrm{f}, \mathrm{g}, \mathrm{h}, \mathrm{i}$ \\
\hline
\end{tabular}

a (Poland et al., 1994)

b (Ema et al., 1994)

c (Gasiewicz \& Rucci, 1984)

d (Manchester et al., 1987)

e (Okey et al., 1989)

f (Roberts et al., 1990)

$\mathrm{g}$ (Harper et al., 1991)

h (Harper et al., 1988)

i (Waithe et al., 1991) 


\section{Chapter 3:}

Structure-activity relationships and the derivation of relative potencies for the

binding of halogenated aromatic hydrocarbons to the beluga and mouse aryl hydrocarbon receptors 


\section{INTRODUCTION}

Halogenated aromatic hydrocarbons (HAH) that can achieve a planar conformation exert their toxic effects via the aryl hydrocarbon receptor (AHR) (Schmidt \& Bradfield, 1996). Mechanistic studies of AHR-dependent toxicity have focused predominantly on 2,3,7,8-tetrachlorodibenzo- $p$-dioxin (TCDD) because it is the most potent AHR agonist. However, TCDD is not the most prevalent $\mathrm{HAH}$ in the environment by far. HAHs include the polychlorinated dibenzo-p-dioxins (PCDD), polychlorinated dibenzofurans (PCDF), and polychlorinated biphenyls (PCB), among others. Many of these are introduced to the environment by industrial effluents, waste incineration, or dump seepage. Despite the curtailing of widespread manufacture of HAHs in most parts of the world, these persistent compounds still bioaccumulate in marine organisms, particularly in top-feeding marine mammals (AMAP, 1998).

Hundreds of $\mathrm{HAH}$ isomers and congeners are possible, and these differ in toxic potency by orders of magnitude. Consequently, assessing the risk associated with exposure to mixtures of $\mathrm{HAH}$ is confounding. Toxic Equivalency is a means of simplifying the toxicity estimates for mixtures of $\mathrm{HAH}$ that bind to and cause toxicity via the AHR. Because TCDD is the most toxic AHR agonist in all species examined, the potency of other AHR-binding compounds can be expressed as fractions of dioxin potencies, or Toxic Equivalency Factors (TEFs). TEFs are then used to adjust actual concentrations of HAH to an expression of TCDD toxic equivalents, or TEQ (Safe, 1990). The World Health Organization (WHO) and affiliates have taken on the task of estimating the consensus TEFs of AHR agonists for humans and wildlife. These TEFs 
are order of magnitude estimates of a compounds toxic potency relative to the toxic potency of TCDD, and are derived from a large database of toxicity and biochemistry data evaluated by experts. In order for a compound to be assigned a TEF, several criteria must be met. The compound must: 1) be structurally related to TCDD, 2) be persistent and bioaccumulate in the environment, 3) bind to the AHR, 4) cause bona fide toxicity in an organism, and 5) exert additive (rather than synergystic or antagonistic) effects (van den Berg et al., 1998).

Recently, separate sets of TEFs were derived for birds, fish, and mammals (van den Berg et al., 1998). However, an important weakness of TEFs is the lack of ability to account for species-specific differences in sensitivities to particular AHR agonists. TEFs for mammals (including humans) have been derived almost exclusively from studies in laboratory rodents. The primary limitation in the application of the TEF approach is perhaps not the approach itself, but rather the lack of data that confirm the approach in a wide variety of species and provide a reasonable estimate of error (Starr et al., 1999).

Relative potencies (REP) are toxic or biochemical responses expressed in terms of dioxin potency. REPs can be from a single study or set of studies, and must reflect an AHR-dependent response, though it need not be a bona fide toxic effect. The most common effects used to determine REPs are CYP1A activity (EROD activity) and ligand binding to the AHR. REPs can contribute to the WHO derivation of TEFs according to the type of endpoint measured and its assessed relevance to whole-animal toxicity. Though caution must used to avoid overinterpreting findings, REPs generated by measuring AHR-dependent, non-toxic endpoints tend to correlate highly with REPs for 
toxic endpoints, thus supporting the TEQ concept (Safe, 1990). Compared to the number of rodent studies, there have been very few determinations of REPs for toxicity endpoints in feral species, though there are some notable exceptions in birds (Sanderson et al., 1994; Sanderson et al., 1994), fish (Mizell et al., 1996) and mammals (Deswart et al., 1995; Hochstein et al., 1998).

As the TEF concept becomes more familiar and accepted by the scientific community, more investigators are expressing marine mammal contaminant burdens in terms of TEQ. In one example, total PCB burdens expressed as TEQ were shown to be higher in striped dolphins that died during a morbillivirus epizootic compared to the burdens in dolphins that survived (Borrell et al., 1996). In the absence of apparent disease, some investigators have used calculated TEQ to suggest that certain populations of cetaceans are at risk for toxic effects (Berggrena et al., 1999; Finklea et al., 2000; Ross et al., 2000). If TEFs are to be a part of the standard language for assessing risk to cetacean populations, it would be desirable, at minimum, to have relative potency data that supports the use of the TEF concept for cetaceans.

The aim of this study is to determine REP for HAH binding to the beluga AHR. A competitive binding assay was optimized for beluga and mouse TNT-expressed proteins, and Ki values were determined for HAH inhibition of $\left[{ }^{3} \mathrm{H}\right] \mathrm{TCDD}$ binding to the AHRs. The Ki values were used to determine the REPs for HAH binding to beluga and mouse AHRs. This is the first determination of REPs for a cetacean. These data contribute to the validation of mammalian TEFs for assessing impacts in cetaceans. 


\section{MATERIALS AND METHODS}

\section{Chemicals}

2,3,7,8-Tetrachloro[1,6- $\left.{ }^{3} \mathrm{H}\right]$ dibenzo-p-dioxin (specific activity was $33.3 \mathrm{Ci} / \mathrm{mmol}$ and purity $>97 \%$ ) was purchased from Chemsyn Science Laboratories (Lenexa, KS). The unlabeled TCDD, TCDF and PCBs (IUPAC numbers 126, 169, 77, 81, 105, 118, 156, and 128) were purchased from Ultra Scientific (purity $>98 \%$ ). Serial dilutions of the TCDD, TCDF, and PCBs were made in dimethylsulfoxide (DMSO) as described previously (Hahn et al., 1996).

In vitro expression of $A H R$

The mouse AHR expression construct (pSPORTmoAHR, $\mathrm{Ah}^{\mathrm{b}-1}$ allele) and human AHR expression construct (pSPORThuAHR) were gifts from Dr. Christopher Bradfield (Burbach et al., 1992; Dolwick et al., 1993). The beluga AHR expression vector (pSP64belAHR) is described in Chapter 2.

AHR proteins were expressed using the SP6 Quick Transcription/Translation system (Promega) per the supplier's instructions, with $2 \mu \mathrm{g}$ DNA/reaction. A TNT reaction programmed with empty pSP64polyA vector ("unprogrammed lysate" or UPL) was used to determine non-specific binding. For competitive binding assays, the volumes were scaled up to $2 \mathrm{ml}$ ( 40 reactions), then diluted with 8 parts MEEMDG buffer ( $35 \mathrm{mM}$ MOPS, $1 \mathrm{mM}$ EDTA, $5 \mathrm{mM}$ EGTA, $0.02 \% \mathrm{NaN}_{3}, 20 \mathrm{mM} \mathrm{Na}_{2} \mathrm{MoO}_{4}, 10 \%$ (v:v) glycerol, $1 \mathrm{mM}$ DTT, $\mathrm{pH} 7.5$ containing protease inhibitors). Aliquots were snap frozen in liquid 
nitrogen and stored at $-80^{\circ} \mathrm{C}$ until use, which was usually within days. Aliquots of expressed proteins were stored no longer than 1 month.

Competitive binding assay using dextran-coated charcoal (DCC)

The conditions for the competitive binding assay were designed to mimic the conditions of the saturation binding assay in Chapter 2 as much as possible. The diluted TNT reactions $(150 \mu \mathrm{l})$ were incubated with $1 \mathrm{nM}\left[{ }^{3} \mathrm{H}\right]-\mathrm{TCDD}$ (nominal) and $1 \mu \mathrm{l}$ of one of nine concentrations $(0-133 \mu \mathrm{M})$ of PHAH competitor in $16 \times 100 \mathrm{~mm}$ glass tubes. The final DMSO concentration was always $1 \%$. For these experiments, $1 \mathrm{nM}\left[{ }^{3} \mathrm{H}\right]$-TCDD was chosen because it two to three times the $\mathrm{Kd}$ for both of the beluga and mouse binding curves. At the start of the incubation, two $20 \mu \mathrm{l}$ aliquots were taken to measure the total $\left[{ }^{3} \mathrm{H}\right]-\mathrm{TCDD}$. After a 16 hour incubation on ice, the contents of each tube were transferred in triplicate $30 \mu \mathrm{l}$ aliquots to standard $1.5 \mathrm{ml}$ polypropylene tubes containing $30 \mu \mathrm{l}$ of 2 $\mathrm{mg} \mathrm{DCC} / \mathrm{ml}$ MEEDGM (and sometimes $20 \mathrm{mg} / \mathrm{ml}$ ). Tubes were vortexed for 5 seconds 3 times, with a five minute incubation on ice between each vortexing step. Tubes were spun at $7000 \mathrm{~g}$ for 3 minutes, then $40 \mu \mathrm{l}$ of each supernatant was counted on a Beckman LS5000TD scintillation counter.

Competitive binding assay using hydroxylapatite (HAP)

The HAP assay procedure was adapted from the methods of Gasiewicz and Neal (1982), Schneider et al. (1995), and Coumailleau et al., (1995). Diluted TNT reactions $(150 \mu \mathrm{l})$ were added to $16 \times 100$ glass tubes containing $\left[{ }^{3} \mathrm{H}\right] \mathrm{TCDD}(1$ or $2 \mathrm{nM}$ nominal) and one of 10 concentrations of unlabeled competitor $(0-133 \mu \mathrm{M})$. DMSO was $1 \%$ of the 
final volume. Incubations were vortexed thoroughly and kept on ice for 16 hours (set 1 ) or 8 hours (sets 2 and 3 ).

Following the incubation on ice, tubes were vortexed again, and $25 \mu \mathrm{l}$ were taken for total counts. $150 \mu \mathrm{l}$ of $10 \%$ DNA grade HAP(Biorad) in MEEDMG (kept in suspension by stirring) were distributed to $13 \times 100$ glass culture tubes. $50 \mu l$ of the contents of each incubation tube were added to duplicate HAP tubes and mixed by gently vortexing until the HAP pellet was fully resuspended. Tubes were placed on ice for 30 min, with resuspension by vortexing every 10 minutes. After adding $500 \mu$ of wash solution (MEEDMG with $0.1 \%$ Tween 20 ) the tube was vortexed and spun at $1000 \mathrm{rpm}$ (approx. $300 \mathrm{~g}$ ) for $5 \mathrm{~min}$ at room temperature. The supernatant was removed by aspiration, and the pellet was washed two more times as above. After the last wash, the pellet was resuspended in $500 \mu$ of $95 \%$ ethanol and transferred to a $7 \mathrm{ml}$ scintillation vial. $4 \mathrm{ml}$ Scintiverse II was added, and the disintegrations per minute (DPM) were counted on a Beckman LS5000TD liquid scintillation counter.

\section{Data analysis}

With some exceptions (as reported in the Results), measured DPM were converted to fractional specific $\left[{ }^{3} \mathrm{H}\right]$-TCDD binding:

$$
\text { Fraction }=\frac{(D P M-N S B)}{(M A X-N S B)}
$$

Maximum specific binding (MAX) was defined as the binding observed when the AHR was incubated with $\left[{ }^{3} \mathrm{H}\right] \mathrm{TCDD}$ and DMSO with no competitor. Non-specific binding 
(NSB) was defined as the DPM obtained from unprogrammed TNT lysate incubated with $\left[{ }^{3} \mathrm{H}\right] \mathrm{TCDD}$ and treated with HAP as above. The binding detected using UPL was the same as the minimum levels of binding detected when excess unlabeled TCDF is used.

The fraction of maximum specific binding points were fitted using the following model for one-site competition:

$$
Y=\text { Bottom }+\frac{(\text { Top }- \text { Bottom })}{1+10^{X-\text { LoglCSO }}}
$$

where Top is the fraction of $\left[{ }^{3} \mathrm{H}\right] \mathrm{TCDD}$ binding in the absence of competitor (fixed to $1.0)$, Bottom is the fraction of $\left[{ }^{3} \mathrm{H}\right] \mathrm{TCDD}$ binding observed when specific binding sites are occupied with unlabeled competitor, $\mathrm{X}$ is the $\log$ of the concentration of competitor in $\mathrm{nM}$, and $\mathrm{Y}$ is the fraction of specific binding at each competitor concentration. Fits were carried out using the mean $\mathrm{Y}$ value at each point, and points were not weighted. The $\mathrm{K}_{\mathrm{i}}$ for each competitor was calculated from the IC50 and the $\mathrm{K}_{\mathrm{d}}$ of $\left[{ }^{3} \mathrm{H}\right]$-TCDD binding using the method of Cheng and Prusoff (Cheng \& Prusoff, 1973):

$$
K_{i}=\frac{E C_{50}}{1+\frac{[\text { ligand }]}{K_{d}}} .
$$

The $\mathrm{K}_{d}$ s for the beluga, mouse, and human AHR TNT were derived in Chapter 2: 0.43 $\mathrm{nM}$ (beluga), and $0.68 \mathrm{nM}$ (mouse). All curve fitting analyses were carried out using Prism version 2.0 for the Macintosh (GraphPad Software, San Diego). 


\section{RESULTS}

\section{Development of a competitive binding assay for in vitro-expressed AHRs}

When determining inhibition constants for competitor binding to receptors, it is desirable that the competition assay be as similar as possible to the assay used to determine the dissociation constant $(\mathrm{Kd})$ for the compound that is to be inhibited (Motulsky, 1999). Thus, the first approach for the development of a competitive binding assay for in vitro expressed AHRs was to adapt the saturation binding assay with dextrancoated charcoal (DCC) used to determine $\mathrm{K}_{d} \mathrm{~s}$ for the beluga, mouse and human AHRs (Chapter 2). All parameters were kept the same except that the radioligand $\left(\left[{ }^{3} \mathrm{H}\right]-\mathrm{TCDD}\right)$ was kept constant and various concentrations of unlabeled competitors were added in the incubation. During the optimization of the saturation binding assay for Kd determination, it was observed that the beluga and human constructs lost notable amounts of specific binding when the concentrations of DCC were in excess of $1 \mathrm{mg} / \mathrm{ml}$ (not shown). Consequently, the amount of DCC that might be required to absorb unbound TCDD plus excess unbound competitor was a concern for the adaptation of this assay.

An example of an experminent using belAHR and TCDF as a competitor is shown in Figure 1. When $1 \mathrm{mg} / \mathrm{ml}$ DCC was used, TCDF competition for specific binding sites appears to be $100 \%$ at approximately $80 \mathrm{nM}$ TCDF. However, at higher concentrations of TCDF, the total binding plots show that binding in fact increased, rather than decreased in the belAHR tubes as well as the UPL tubes. There are at least two possible explanations for the apparent increased binding at higher concentrations of TCDF. First, the effect could be related to solubility. Total binding would appear to be 
higher if the competitor is not dissolved in the solution. However, this does not explain why more than $100 \%$ binding is observed in the UPL, which lacks AHR, at the highest concentrations of TCDF. Second, apparent binding could increase when the concentration of competitor exceeds the binding capacity of the DCC. The results from this experiment support this idea, since a 10-fold increase in DCC shifts the apparent increase in binding to the right by approximately 10 -fold.

Though the higher concentration of DCC appears to absorb a higher proportion of excess ligand at the higher concentrations of TCDF competitor, the higher concentrations of DCC clearly decreases the significant binding of the AHR, in agreement with earlier observations. Taking all of these factors together, it was apparent that the competitive binding assay using DCC was not a viable assay to use with these AHRs. Consequently, other options were considered.

HAP is a well-established method for measuring AHR binding in rodent liver cytosols (Gasiewicz \& Neal, 1982; Gasiewicz \& Rucci, 1984; Petrulis \& Bunce, 2000; Schneider et al., 1995) and has also been used with in vitro-expressed (TNT) proteins (Coumailleau et al., 1995). These assays were modified for use with TNT-expressed beluga proteins. HAP is a basic calcium phosphate mineral that interacts with positively charged functional groups. Because the success of the assay depends on efficient binding of AHR to HAP, the time of incubation and the presence of molybdate in the dilution buffer were important factors to revisit. Upon ligand binding, the AHR "transforms" into a DNA-binding form. All of the steps involved in transformation are not known, but the cytosolic rat receptor gradually $\left(2-20\right.$ hours at $\left.20^{\circ} \mathrm{C}\right)$ changes into a form that is less 
negative and has a greater affinity for DNA (Gasiewicz \& Bauman, 1987). It was suggested recently that the term "conversion" be used to differentiate the early stages of the AHR-ligand interaction, where the complex changes to an essentially irreversiblybound form, from the nuclear-localized "transformed" AHR that can interact with DNA (Petrulis \& Bunce, 2000). (Note that a "converted" form was not identified by Bradfield et al. (Bradfield et al., 1988).)Therefore, the ability of the TNT-expressed, ligand-bound AHRs to interact with HAP may require a time, temperature, and/or species-dependent conversion. Thus, in the current scenario where competition experiments are to be carried out using beluga, mouse and human AHRs side-by-side, conducting experiments on ice, rather than room temperature (slowing conversion?) would seem to favor opportunity for competition to reach equilibrium.

The molybdate ion stabilizes the AHR in a species-specific manner. Molybdate is particularly necessary for stabilizing the human AHR and the low affinity mouse $\left(\mathrm{Ah}^{\mathrm{d}}\right)$ AHR so they it may be characterized in binding studies (Manchester et al., 1987) (Golas et al., 1990; Okey et al., 1989; Roberts et al., 1990). In contrast, molybdate contributes to destabilization of the rat AHR (Kester \& Gasiewicz, 1987). Stabilization by molybdate allowed the successful analysis of the $\mathrm{Kd}$ of beluga, mouse, and human AHRs by saturation binding when DCC was used to separate bound ligand from free ligand (Chapter 2). However, molybdate also inhibits AHR transformation at the level of ARNT dimerization by stabilizing the AHR-hsp90 association at a threshold concentration around $20 \mathrm{mM}$ (Heid et al., 2000). Since the biochemical changes that lead to hsp90 dissociation, and the physiochemical requirements for AHR-HAP association 
are not known, it was unclear whether molybdate would inhibit AHR association with HAP.

Figure 2 shows the time course and effect of molybdate on specific binding of beluga, mouse and human AHRs at two concentrations of $\left[{ }^{3} \mathrm{H}\right]-\mathrm{TCDD}$ and 200 -fold excess TCDF. Molybdate increased detectable specific binding in all AHRs, not just the human AHR. In most cases, maximal specific binding was reached at 8 hours. Despite the benefits of molybdate, the specific binding observed for the human AHR was very low relative to mouse and beluga binding. Non-specific binding, as determined by competition with 200 -fold excess TCDF, varied only with $\left[{ }^{3} \mathrm{H}\right]-\mathrm{TCDD}$ concentration, and not with AHR species origin, molybdate presence, or time. A summary of parameters used in this HAP assay alongside parameters published in other studies is in Table 1.

\section{Competitive inhibition studies with beluga and mouse AHRs}

The HAP assay described above was used in competitive inhibition studies on the beluga, mouse, and human AHRs for the purpose of deriving structure-activity relationships using various $\mathrm{HAH}$ compounds. Five different structure classes of HAH were represented: TCDD (PCDD), TCDF (PCDF), IUPAC 126, 169, 77, and 81 (nonortho PCBs), IUPAC 105, 118, 156 (mono-ortho PCBs), and IUPAC 128 (di-ortho PCBs). Three sets of competitive inhibition curves were generated. One set was obtained with selected members of each $\mathrm{HAH}$ structure class listed above at $1 \mathrm{nM}\left[{ }^{3} \mathrm{H}\right]-\mathrm{TCDD}$ with no molybdate in the dilution buffer. Two sets were carried out at $2 \mathrm{nM}\left[{ }^{3} \mathrm{H}\right]-\mathrm{TCDD}$ with molybdate in the dilution buffer (Table 2). 
Representative competitive inhibition curves generated for beluga and mouse AHRs are shown in Figure 3. The data were fit to a one-site competition model (Equation 2 ), and the curves were derived by fixing the values of the tops and bottoms of the model to $100 \%$ and $0 \%$ specific binding. The rationale for fixing the parameters of the curve fit is as follows. Because the data points are expressed as fractional specific binding, the only way that a one-site competition model can be correct is if the actual minimum of the curve is $0 \%$. In practice, the actual concentration of competitor needed to displace $>95 \%$ of $\left[{ }^{3} \mathrm{H}\right]-\mathrm{TCDD}$ specific binding may be greater than the highest concentrations tested, and perhaps beyond the limits of solubility. By allowing the model to fit the data points assuming that $100 \%$ inhibition is possible, the equation is able to predict an IC50 that is based on the data points yet is not underestimated because of solubility limitations and false minima.

Table 2 lists the IC50s for curves fit to the data with fixing the top and bottom of the curves to $100 \%$ and $0 \%$ specific binding (column 1) and without fixing these parameters (column 2). Also listed in Table 2 are the model-fitted lower plateaus of the curves (Column 5), as well as the lowest fraction of specific binding measured in each experiment (Column 4). Comparing these values for each compound shows that, in general, the derived IC50s from both sets of curve fitting parameters were in close agreement for compounds that compete well for AHR binding (e.g. TCDD,126, 81). For compounds that did not compete as well for $\left[{ }^{3} \mathrm{H}\right]-\mathrm{TCDD}$ binding (e.g. 105, 118) the fitted curve minimum (column 5) was far from $0 \%$, and the IC50s calculated from the "fixed" 
fits (column 1) tended to be higher than those estimated from the "unfixed"fits (column 2).

The IC50s spanned 5 orders of magnitude, and the rank order of the IC50s for beluga AHR binding was: TCDD $<$ TCDF $<126<169<77<81<<<156 \sim 128<105<118$. The rank order of IC50s for the mouse AHR binding was TCDD $<\mathrm{TCDF}<$ $126<169<81<77<156<<128 \sim 105 \sim 118$.

Inhibition constants $(\mathrm{Ki})$ were generated based on the IC50s from the curves with fixed tops and bottoms (column 1), the $\mathrm{K}_{\mathrm{d}} \mathrm{s}$ for the beluga and mouse AHRs (Chapter 2), and the $\left[{ }^{3} \mathrm{H}\right]-\mathrm{TCDD}$ incubation concentration. $\mathrm{K}_{\mathrm{i}} \mathrm{s}$ are unique to a specific receptor and compound, and should independent of radioligand incubation concentrations. Therefore, $\mathrm{K}_{\mathrm{i}} \mathrm{s}$ can be compared across experiments, assuming the experiments were conducted under similar conditions. The individual $\log \mathrm{K}_{\mathrm{i}} \mathrm{s}$ for each compound and for each species are plotted in Figure 4, and summarized numerically as Ki in Table 3. TCDD was the competitor with the highest affinity for both AHRs. The average Ki for TCDD in beluga was $0.1 \mathrm{nM}$, and for mouse the mean $\mathrm{Ki}$ for TCDD was 0.36 . These are in close agreement with the Kds determined for TCDD binding using a saturation binding assay, $0.43 \mathrm{nM}$ for beluga AHR, and $0.68 \mathrm{nM}$ for mouse AHR. TCDF also had a very high affinity for both AHRs. As a group, the binding affinities of the non-ortho substituted PCBs spanned an order of magnitude in beluga (1.6-19 nM), and slightly more for the mouse AHR (4.6-94 $\mathrm{nM}$ ). All of the non-ortho PCBs had a binding affinity that was less than TCDD and TCDF, but greater than the mono or di-ortho PCBs. Of these 4 non-ortho 
PCBs, PCB126 clearly had the highest affinity for both AHRs. PCB77, 169, and 81 all had very similar $\mathrm{Ki}$ values for both AHRs that ranged a few fold.

Among the mono-ortho PCBs, PCB 156 had the highest affinity for both AHRs. PCB 105 and 118 had higher Ki values than PCB 156. The Ki values for 105 and 118 were very similar to each other in either species. The $\mathrm{Ki}$ for the mono-ortho were one or two orders of magnitude higher than the non-ortho PCBs. The one di-ortho PCB that was tested, PCB128, had an affinity for the beluga AHR that was very similar to that of PCB156. In the mouse, the affinity of PCB128 was very similar to those of PCBs 105 and 118. Attempts to use another di-ortho PCB (PCB 170) in the competitive binding assay failed because of insolubility.

Relative potencies for AHR binding were determined from the mean $\mathrm{Ki}$ values for each HAH (Table 3). The REPs span 5 orders of magnitude in the beluga (1-0.00007), and 4 orders of magnitude for the mouse (1-0.0002). The compound with the lowest REP for beluga for mouse was mono-ortho PCB118.

The HAP competitive binding assay was also used in attempts to derive $\mathrm{HAH} \mathrm{Ki}$ values for the in vitro-expressed human AHR. Despite several repeats and trials with alternate conditions, data were scattered and uninterpretable. This is consistent with other investigators' inability to obtain data using the HAP assay with human placenta (Nakai \& Bunce, 1995). Because the TNT products generated binding curves that were sufficient for the derivation of $\mathrm{K}_{\mathrm{d}} \mathrm{s}$ (Chapter 2), it seems probable that the difficulty lies in the association of the human AHR with the HAP, rather than instability of the human AHR protein under these conditions. 


\section{DISCUSSION}

Since PCBs were discovered at very high concentrations in marine mammals in the 1970 s, there has been concern about the possible effects on marine mammal health. A growing number of observations suggests that contaminant burdens can have negative effects on cetacean health. Cetaceans and seals that succumb to disease tend to have significantly higher contaminant body burdens compared to animals that survive epizootics or die from incidental take (Aguilar \& Borrell, 1994; Hall et al., 1992; Jepson et al., 1999). Despite lack of proof of AHR-mediated toxicity in marine mammals, the tendency to express marine mammal contaminant burdens as TEQ is on the rise. Thus, in order to further the characterization of the beluga AHR and begin to establish an experimental basis for the application of the TEF concept to cetaceans, competitive inhibition studies were conducted to measure binding affinities of and derive REPs for HAH binding to the beluga AHR. For comparison, the well-studied mouse $\mathrm{Ah}^{\mathrm{b}-1}$ allele was included in the analysis. This is the first determination of relative potencies of any kind for a marine mammal, and the most comprehensive set of relative potencies derived for HAH binding in vitro to mouse AHR.

\section{Determination of relative potencies for beluga and mouse AHR}

A HAP assay was modified for use with beluga and mouse TNT products to determine structure-binding relationships for various representative classes of HAH: the polychlorinated dibenzo-p-dioxins (PCDD), the polychlorinated dibenzofurans (PCDF), 
non-ortho PCBs, mono-ortho PCBs, and di-ortho PCBs. All of these HAH structure classes are found in the environment and detected in marine mammal tissues, including beluga (Martineau et al., 1987). Competitive binding curves show that all of the HAHs tested were able to displace $\left[{ }^{3} \mathrm{H}\right]$-TCDD for AHR binding (Figure 3). The Ki values calculated for $\mathrm{HAH}$ inhibition of $\left[{ }^{3} \mathrm{H}\right]-\mathrm{TCDD}$ binding to beluga and mouse AHRs shared a very similar rank order overall and within HAH structure groups (Table 3). These in turn were very similar to the rank order of IC50 values determined for inhibition in rat hepatic cytosol (Bandiera et al., 1982). The similarity of the structure-binding relationships of the beluga AHR compared with those of rodent AHRs suggests that the structure requirements for high affinity ligand binding are very similar among these AHRs.

For the beluga and mouse AHRs, the three mono-ortho and the single di-ortho PCBs examined had similar affinities that were had much lower than the affinities of the coplanar HAHs. It was somewhat surprising to observe that the di-ortho PCB128 had a binding affinity that was similar to or greater than some of the mono-ortho PCBs. Binding studies with rat cytosols have shown that di-ortho PCBs tend to have IC50s that are one to two orders of magnitude greater than the mono-ortho congeners (Bandiera $e t$ al., 1982). In contrast, PCB 128 binds to a fish AHR with the same affinity as PCB105 and 118 (Hestermann et al., 2000). In this study, the ability of PCB 128 to inhibit $\left[{ }^{3} \mathrm{H}\right]-$ TCDD binding was not an artifact of curve fitting to few points, since PCB 128 competition reached $90 \%$ for beluga AHR and $80 \%$ for mouse AHR. Also, the curves 
generated by the one-site competition model (with the exception of one mouse experiment) fit the data very well.

The high affinity binding by PCB 128 to the beluga and mouse AHRs may not be a contradiction given that receptor binding does not always result in receptor activation. The ability of a compound to cause an effect beyond receptor binding is referred to as the efficacy of a compound. Tissue-specific contributions to the mediation of the AHRgenerated signal is called "coupling" (Kenakin, 1999). The validity of the TEF concept depends on high efficacy of AHR ligands. Rodent data suggest that in general, di-ortho PCBs bind to the AHR with low affinity but do not elicit in vivo toxic or biochemical effects (Goldstein \& Safe, 1989). In the past, very low TEFs (0.0001-0.00001) were assigned to di-ortho PCBs by the WHO (Ahlborg et al., 1994). The most recent WHO report withdrew TEFs for di-ortho PCBs because of a lack of AHR-dependent toxicity data (van den Berg et al., 1998). More recent studies have shown that di-ortho PCBs can elicit competitive antagonism of ligand binding and downstream responses of more potent AHR agonists (Hestermann et al., 2000; Petrulis \& Bunce, 2000). Further, some antagonistic effects by di-ortho PCBs may be species-specific (Aarts et al., 1995).

The WHO-98 TEFs are presented alongside REPs for beluga AHR binding, mouse AHR binding, and rat AHR binding (Table 4). Comparing the REPs with the TEFs in this table demonstrate that for the most potent AHR agonists, REPs reflect TEFs quite well. For mono- and di-ortho PCBs, however, REPs display species specificity and may not correspond as well to the suggested mammalian TEF. 
Overall, the structure-activity relationships observed by HAH binding to the beluga AHR support a similar mechanism of toxicity to that observed in the mouse. The $\mathrm{Ki}$ values and REPs calculated for the binding of HAH to the beluga AHR are consistent with the ability of coplanar PCBs to activate the beluga AHR and cause downstream responses such as toxicity and CYP1A induction. There are cetacean field data to support this assertion. A number of investigators have reported relative depletion of coplanar HAH among the suite of HAH detected in cetacean tissues, and all have suggested that this is indicative of a high capacity for CYP1A-dependent metabolism in cetaceans (Boon et al., 1997; Kannan et al., 1989; Norstrom et al., 1992; Tanabe et al., 1988). The occurrence of CYP1A has been confirmed in cetaceans, including minke (Goksøyr et al., 1988) and beluga (White et al., 1994). In the beluga study, CYP1A protein levels correlated well with the concentrations of non and mono-ortho PCBs in these animals. This observation for feral beluga, along with the observations of high affinity binding of $\mathrm{HAH}$ with beluga $\mathrm{AHR}$, suggest that coplanar HAH display high potency for binding that is coupled with efficacy for downstream effects in the beluga. This supports the application of mammalian TEFs for these compounds to cetaceans.

An important factor that can be easily overlooked in discussions of speciesspecific relative potencies is absolute differences in sensitivity. Beyond structure activity relationships, another potentially important observation is that the absolute binding affinities of HAH for the beluga AHR were consistently several fold higher than those of the mouse. This is especially true for TCDD and PCBs $126,77,81$, and 128 , for which the $95 \%$ confidence intervals for the binding $\mathrm{Ki}$ do not overlap those of mouse AHR. An 
exception to this pattern was PCB 156, which had nearly identical Ki values in both species. Thus, the beluga AHR has a higher affinity than mouse AHR for most of the HAHs tested; this is consistent with the $\sim 2$-fold higher beluga AHR $\left[{ }^{3} \mathrm{H}\right]-\mathrm{TCDD}$ binding affinity determined by saturation binding. Differences in absolute TCDD binding affinities among mouse AHR alleles in vitro correspond with differences in overall strain sensitivity in the homozygous mice (Poland et al., 1994). Thus, for two species that differ in overall sensitivity to AHR ligands, the same TEQ measured in two different species might be an order of magnitude more potent in one compared to the other.

In summary, a competitive binding assay was used to determine the ability of several structure classes of HAH to inhibit binding to the beluga and mouse AHRs. The inhibition coefficients indicated high affinity HAH binding by both receptors, particularly for the coplanar $\mathrm{HAH}$. Together with available field and in vitro data, these results suggest that the beluga AHR has a high affinity for coplanar HAH that is coupled with an efficient CYP1A metabolic response. Thus the application of the TEF for coplanar HAH to cetaceans seems valid. The advice of the WHO-98 to revoke TEFs for di-ortho PCBs should be upheld until toxicity data for cetaceans becomes available. These results also demonstrate the value of molecular and in vitro approaches for addressing toxicological questions in protected species for which dosing is impossible. 


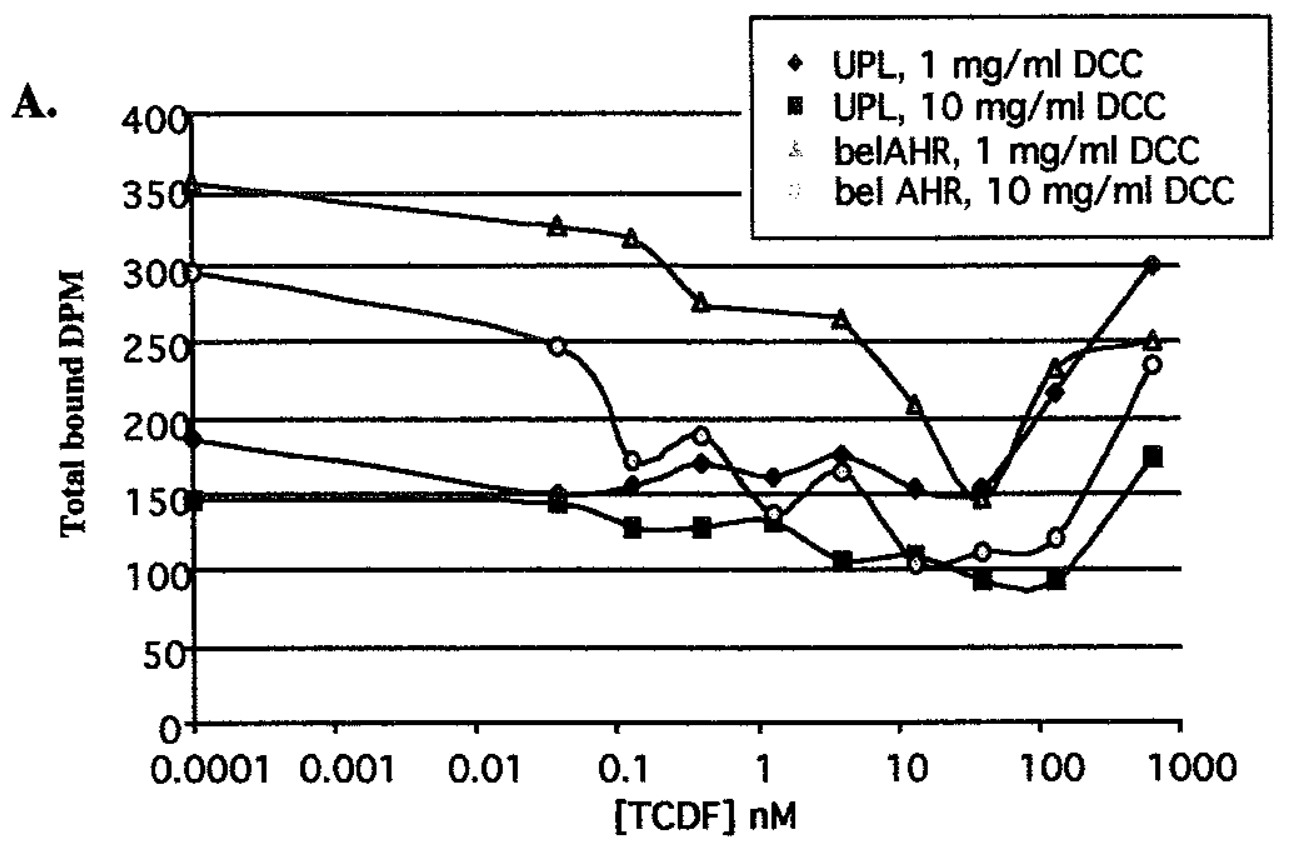

B.

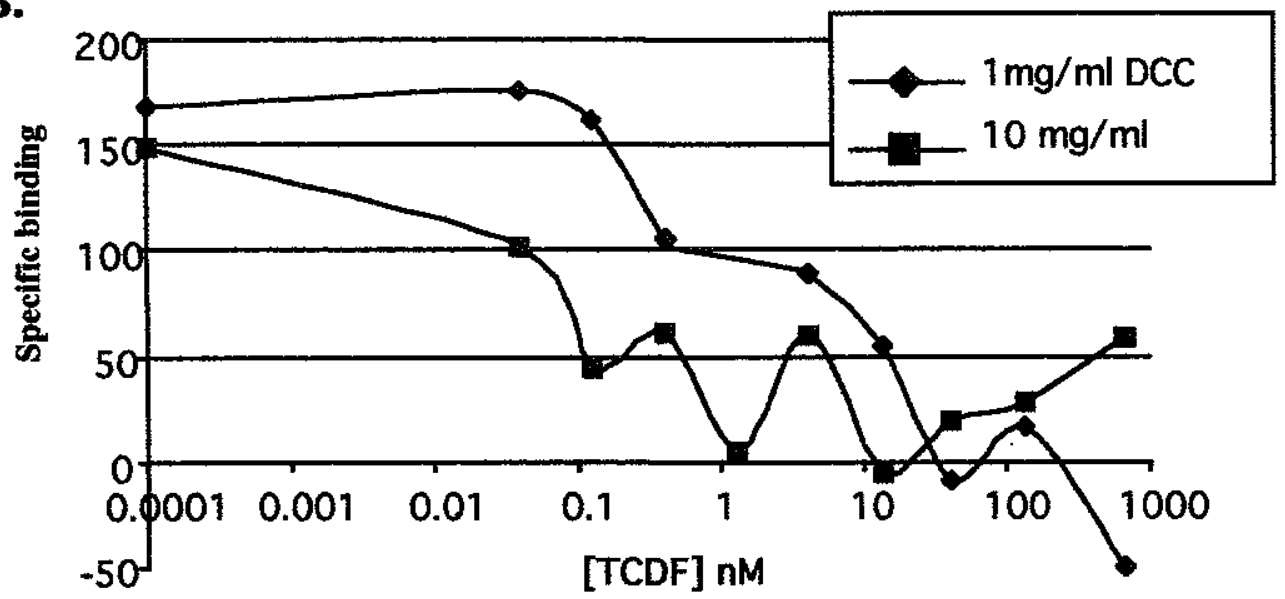

Figure 1. Competitive binding assay with dextran-coated charcoal (DCC). Incubations with TNT-expressed beluga AHR (belAHR) and unprogrammed lysate (UPL) diluted in buffer were carried out in $1 \mathrm{nM}\left[{ }^{3} \mathrm{H}\right]-\mathrm{TCDD}$ and various concentrations of TCDF. The incubations were treated with $1 \mathrm{mg} / \mathrm{ml}$ or $10 \mathrm{mg} / \mathrm{ml} \mathrm{DCC}$, centrifuged, and the DPM of the supernatants were counted. A. Total binding for belAHR and upl. B. Specific binding of belAHR, determined by the difference between the belAHR total binding and the Upl curve at both charcoal concentrations. 

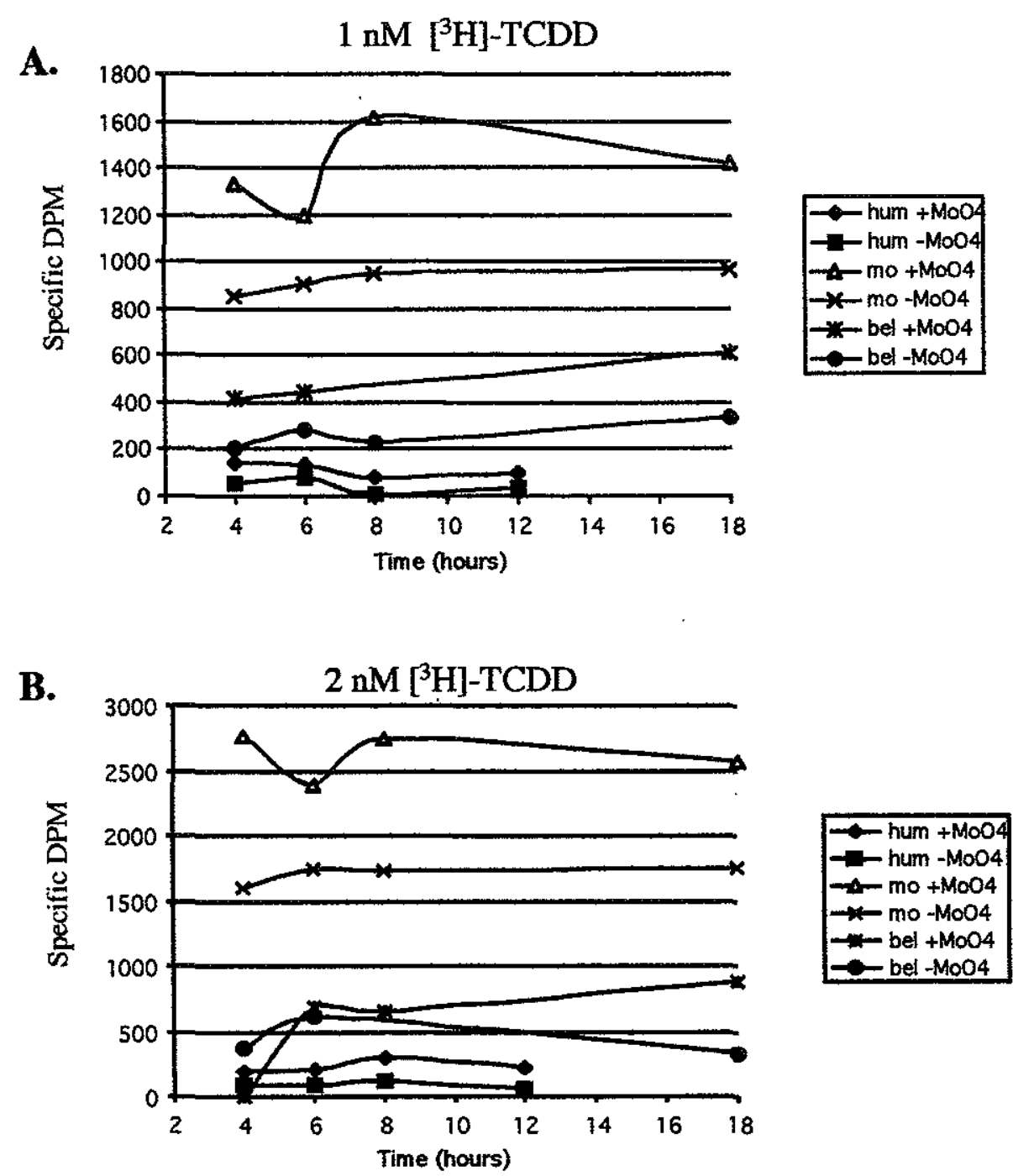

Figure 2. HAP assay timecourse and effects of sodium molybdate on specific binding of beluga, mouse, and human AHRs. In vitro-expressed proteins were incubated with $1 \mathrm{nM}$ or $2 \mathrm{nM}$ [3H]-TCDD, with or without $17 \mathrm{mM}$ NaMoO4. Non-specific binding was subtracted from total binding and the resulting DPM were plotted. The non-specific binding was determined with 200 -fold excess TCDF, and varied only with [3H]-TCDD concentration, and not with AHR species origin, molybdate, or time. 
A. Beluga competitive binding

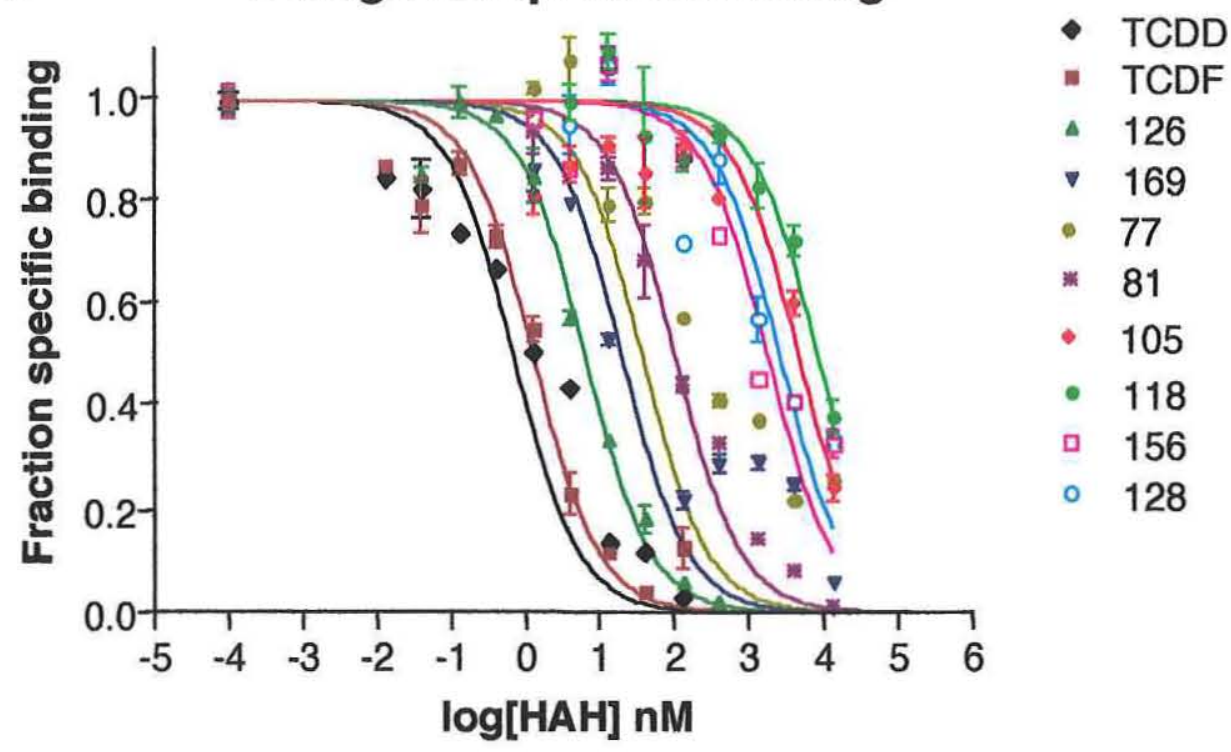

B. Mouse competitive binding

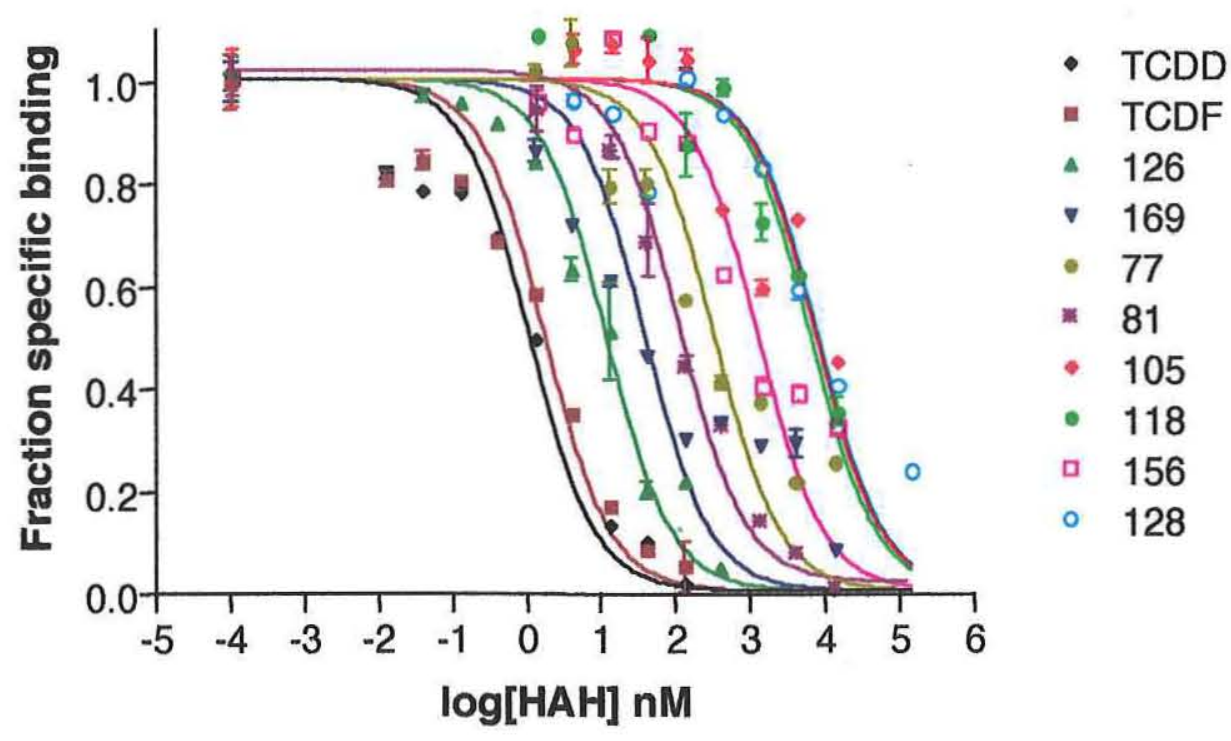

Figure 3. Competitive binding curves for mouse and beluga AHR for various HAH. Inhibition of binding of $2 \mathrm{nM}\left[{ }^{3} \mathrm{H}\right]-\mathrm{TCDD}$ to beluga and mouse AHRs by various HAH was measured by the HAP assay. Curve maxima and minima were fixed to $100 \%$ and $0 \%$ and fit to a one-site competition model using non-linear curve fitting. IC50s were calculated for TCDD, TCDF, and PCBs (IUPAC numbers 126, 169, 77, 81, 105, 118, 156, 128). Error bars represent $1 \mathrm{SD}$. 


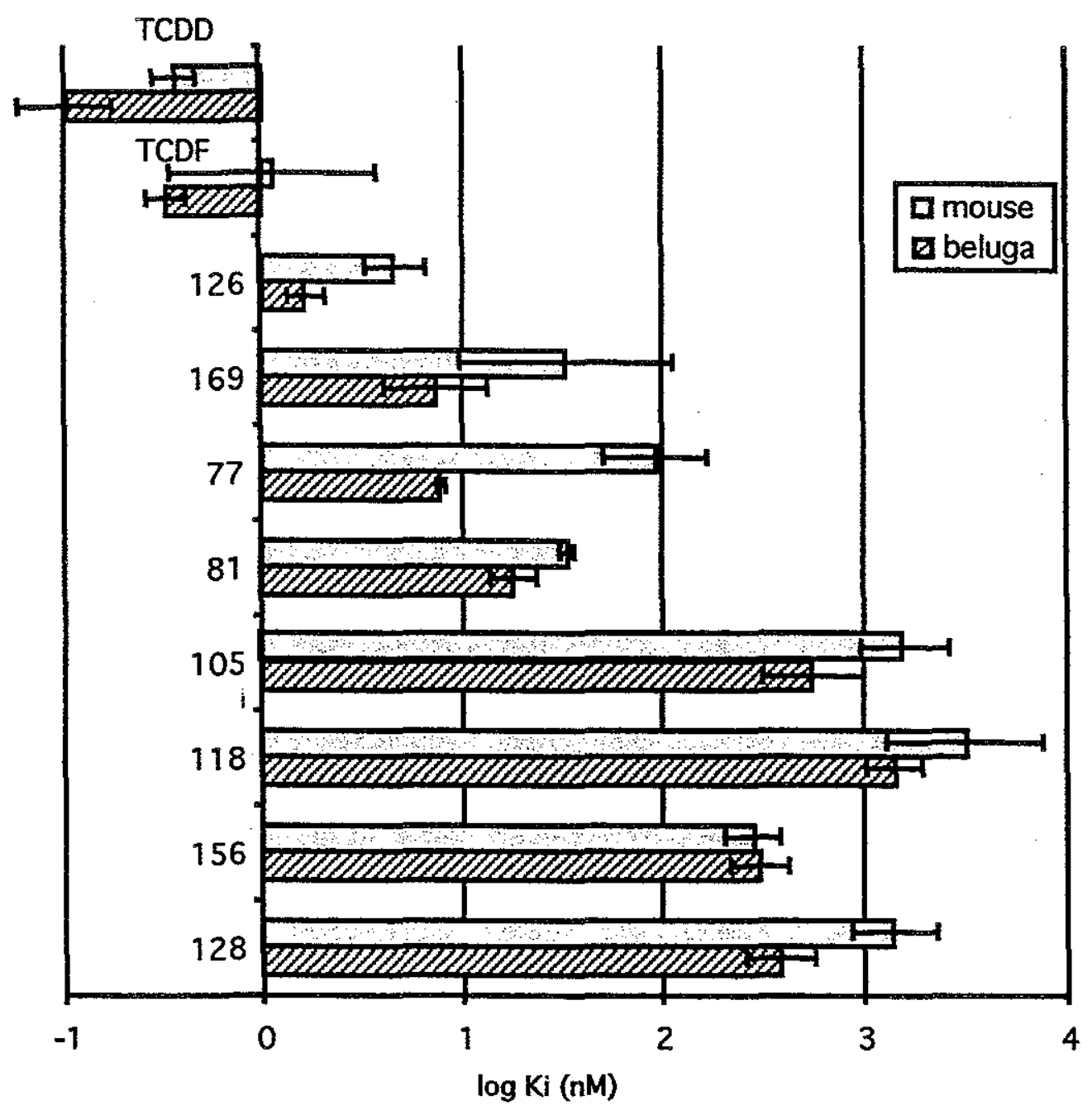

Figure 4. Inhibition constants $\left(\mathrm{K}_{1}\right)$ of $\left[{ }^{3} \mathrm{H}\right]-\mathrm{TCDD}$ binding to beluga and mouse AHRs by various HAH. IC50s were determined from the non-linear curve fit to a one-site competition model, and $\mathrm{K}_{\mathrm{i}}$ values were determined by the method of Cheng and Prusoff. Bars represent means of $\log \mathrm{K}_{\mathrm{i}}$ determinations for beluga AHR (hatched), or mouse AHR (solid). Whiskers indicate 1 standard deviation. 
Table 1. Comparison of parameters used in competitive binding assays using hydroxylapatite absorption.

\begin{tabular}{|c|c|c|c|c|}
\hline Parameter & this assay & $\begin{array}{c}\text { Coumailleau et al. } \\
1995\end{array}$ & $\begin{array}{c}\text { Schneider et al, } \\
1995\end{array}$ & $\begin{array}{c}\text { Gasiewicz and } \\
\text { Neal, } 1984\end{array}$ \\
\hline sample type & TNT products & TNT products & liver cytosols & liver cytosols \\
\hline non-specific binding & UPL & 250-fold excess TCDF & 200-fold excess TCDF & 200-fold excess TCDF \\
\hline protein concentration in incubation & $1.3 \mathrm{mg} / \mathrm{ml}$ & $\sim 3 \mathrm{mg} / \mathrm{ml}$ & not reported & $1.5-2.5 \mathrm{mg} / \mathrm{ml}$ \\
\hline buffer & MEEDMG & TEG & HEDG & HEDG \\
\hline [AHR] in incubation & $<.05 \mathrm{nM}$ & not reported & $<0.2 \mathrm{nM}$ & $\sim 0.05-0.12 \mathrm{nM}$ \\
\hline$[3 \mathrm{H}]-\mathrm{TCDD}$ in incubation & $0.9-1.6 \mathrm{nM}$ & $0.2-2.5 \mathrm{nM}$ & $1 \mathrm{nM}$ & $0.3 \mathrm{nM}$ \\
\hline$[3 \mathrm{H}]-\mathrm{TCDD}$ specific activity & $33 \mathrm{Ci} / \mathrm{mmol}$ & $28 \mathrm{Ci} / \mathrm{mmol}$ & $37 \mathrm{Ci} / \mathrm{mmol}$ & $50.5 \mathrm{Ci} / \mathrm{mmol}$ \\
\hline$\%$ solvent in incubation & $1 \%$ DMSO & not reported & $2 \%$ DMSO & $0.5 \%$ dioxane \\
\hline incubation time & 8-16 hours & 90 minutes & 1 hour & 2 hours \\
\hline incubation temperature & $0-4^{\circ} \mathrm{C}$ & RT & RT & $20^{\circ} \mathrm{C}$ \\
\hline detergent in HAP wash & $0.1 \%$ Tween 20 & $0.1 \%$ Tween 20 & $1 \%$ Triton $X-100$ & $1 \%$ Tween 80 \\
\hline number washes of HAP & 3 & 4 & 4 & 4 \\
\hline DCC adsorption step & none & $70 \mathrm{mg} / \mathrm{ml}$ & none & none \\
\hline volume wash:vol incubation in $\mathrm{HAP}$ & 30 & $3 \mathrm{mg} / \mathrm{ml}$ & 20 & 20 \\
\hline
\end{tabular}

MEEDGM: 35mM MOPS, 1mM EDTA, 5 mM EGTA, 0.02\% NaN3, 20mM Na2MoO4, 10\% glycerol, (pH 7.5),

$1 \mathrm{mM}$ dithiothreitol, plus protease inhibitors

TEG: $20 \mathrm{mM}$ Tris-HCl pH 7.4, $1 \mathrm{mM}$ EDTA, $10 \%$ glycerol, $1 \mathrm{mM}$ dithiothreitol

HEDG: 25 mM Hepes pH 7.4, 1.5 mM EDTA, $10 \%$ glycerol, $1 \mathrm{mM}$ dithiothreitol 
Table 2. Summary of competitive binding experiments (HAP assay).

\begin{tabular}{|c|c|c|c|c|c|c|c|c|c|c|c|c|c|c|}
\hline & & & & BELUGA & & & & & & & MOUSE & & & \\
\hline & & & & & & & SET 1: [3H & $\mathrm{A}] \mathrm{TCDD}=0.9 \mathrm{nM}$ & & & & & & \\
\hline HAH: & $\log 1 \mathrm{C} 50_{1}$ & $\log \mid \mathrm{C} 5 \mathrm{O}_{2}$ & $\begin{array}{c}\mathrm{Ki} \\
(n M)_{3}\end{array}$ & $\begin{array}{c}\text { lowest } \\
\text { data pt } 4\end{array}$ & $\begin{array}{c}\text { fitted } \\
\text { curve min s }\end{array}$ & $R^{\wedge} 2$ 。 & $\begin{array}{c}\text { Runs Test } \\
\text { (p) ? }\end{array}$ & $\log 1 \mathrm{C} 50$ & $\log 1 \mathrm{C} 50_{2}$ & $\begin{array}{c}\mathrm{Ki} \\
(\mathrm{nM})_{8}\end{array}$ & $\begin{array}{l}\text { lowest } \\
\text { data pt }\end{array}$ & $\begin{array}{c}\text { fitted } \\
\text { curve } \min 5\end{array}$ & $R \wedge 2_{e}$ & $\begin{array}{c}\text { Runs Test } \\
(p) \text {, }\end{array}$ \\
\hline$T C D D$ & - & - & - & - & - & - & - & - & - & - & - & - & - & - \\
\hline TCDF & 0.09 & 0.09 & 0.39 & 0.00 & 0.31 & 0.98 & 0.71 & 0.78 & 0.62 & 2.6 & 0.12 & 0.08 & 0.95 & 0.14 \\
\hline 126 & 0.53 & 0.53 & 1.5 & 0.01 & 0.10 & 0.95 & 0.88 & 1.2 & 1.1 & 6.4 & 0.10 & 0.09 & 0.96 & 0.64 \\
\hline 169 & 1.6 & 1.1 & 14 & 0.26 & 0.23 & 0.66 & 0.25 & 2.5 & 1.1 & 122 & 0.47 & 0.47 & -0.24 & 0.07 \\
\hline 77 & 1.4 & 1.2 & 7.3 & 0.01 & 0.11 & 0.94 & 0.37 & 2.6 & 2 & 172 & 0.31 & 0.29 & 0.87 & 0.07 \\
\hline 81 & - & - & - & - & - & - & - & - & - & - & - & - & - & $\cdot$ \\
\hline 105 & 3 & 3 & 315 & 0.27 & 0.08 & 0.73 & 0.11 & 3.7 & 3.3 & 2175 & 0.37 & 0.27 & 0.94 & 0.64 \\
\hline 118 & 3.7 & 2.9 & 1595 & 0.37 & 0.39 & 0.8 & 0.25 & 4.3 & 3.9 & 8873 & 0.53 & 0.12 & 0.24 & 0.2 \\
\hline 156 & & & & & & & & - & - & - & - & : & - & - \\
\hline 128 & 2.9 & 3.1 & 258 & 0.05 & -0.03 & 0.93 & 0.28 & 3.3 & 0.05 & 858 & 0.31 & 0.55 & -1.2 & 0.83 \\
\hline & & & & & & & SET 2: [3H] & $\mathrm{JTCDD}=1.6 \mathrm{nN}$ & & & & & & \\
\hline & $\log \mid C 5 O_{1}$ & $\log I C 5 O_{2}$ & $\begin{array}{c}\mathrm{Ki} \\
(\mathrm{nM})_{s}\end{array}$ & $\begin{array}{c}\text { lowest } \\
\text { data pt }{ }_{4}\end{array}$ & $\begin{array}{c}\text { fitted } \\
\text { curve min } 3\end{array}$ & RA2。 & $\begin{array}{l}\text { Runs Test } \\
\text { (p) } 7\end{array}$ & $\log \mathrm{IC} 50$ & $\log \mid \mathrm{C} 50=$ & $\begin{array}{c}\mathrm{Ki} \\
(\mathrm{nM})\end{array}$ & $\begin{array}{c}\text { lowest } \\
\text { data pt }\end{array}$ & $\begin{array}{c}\text { fitted } \\
\text { curve } \min 5\end{array}$ & $R \wedge 2_{5}$ & $\begin{array}{l}\text { Runs Test } \\
\text { (p) } 7\end{array}$ \\
\hline TCDD & -0.15 & -0.16 & 0.15 & 0.10 & 0.11 & 0.93 & 0.07 & 0.16 & 0.3 & 0.43 & 0.03 & 0.06 & 0.88 & 0.04 \\
\hline TCDF & 0.13 & 0.17 & 0.28 & 0.04 & 0.05 & 0.95 & 0.19 & 0.21 & 0.33 & 0.49 & 0.06 & 0.05 & 0.92 & 0.01 \\
\hline 126 & 0.82 & 0.82 & 1.4 & 0.02 & 0.02 & 0.98 & 1 & 1 & 0.94 & 3.2 & 0.05 & 0.09 & 0.97 & 0.4 \\
\hline 169 & 1.3 & 1 & 4.3 & 0.06 & 0.21 & 0.75 & 0.11 & 1.6 & 1.1 & 10.8 & 0.09 & 0.25 & 0.62 & 0.05 \\
\hline 77 & 1.6 & 1.2 & 8 & 0.18 & 0.22 & 0.71 & 0.01 & 2.2 & 1.7 & 52.7 & 0.21 & 0.27 & 0.78 & 0.05 \\
\hline 81 & 1.9 & 1.8 & 15.4 & 0.08 & 0.07 & 0.98 & 0.29 & 2 & 1.9 & 32 & 0.06 & 0.11 & 0.89 & 0.22 \\
\hline 105 & 3.7 & 4.1 & 1016 & 0.23 & -0.42 & 0.78 & 0.58 & 3.5 & 3.2 & 917 & 0.34 & 0.27 & 0.77 & 0.08 \\
\hline 118 & 3.9 & 4 & 1842 & 0.38 & -0.13 & 0.93 & 0.88 & 3.8 & 3.8 & 2051 & 0.35 & 0.01 & 0.89 & 0.79 \\
\hline 156 & 3.3 & 2.8 & 388 & 0.33 & 0.29 & 0.84 & 0.5 & 2.9 & 2.6 & 229 & 0.28 & 0.26 & 0.62 & 0.05 \\
\hline 128 & 3.4 & 2.9 & 567 & 0.34 & 0.29 & 0.83 & 0.79 & 3.7 & 3.1 & 1496 & 0.43 & 0.38 & 0.87 & 0.63 \\
\hline
\end{tabular}




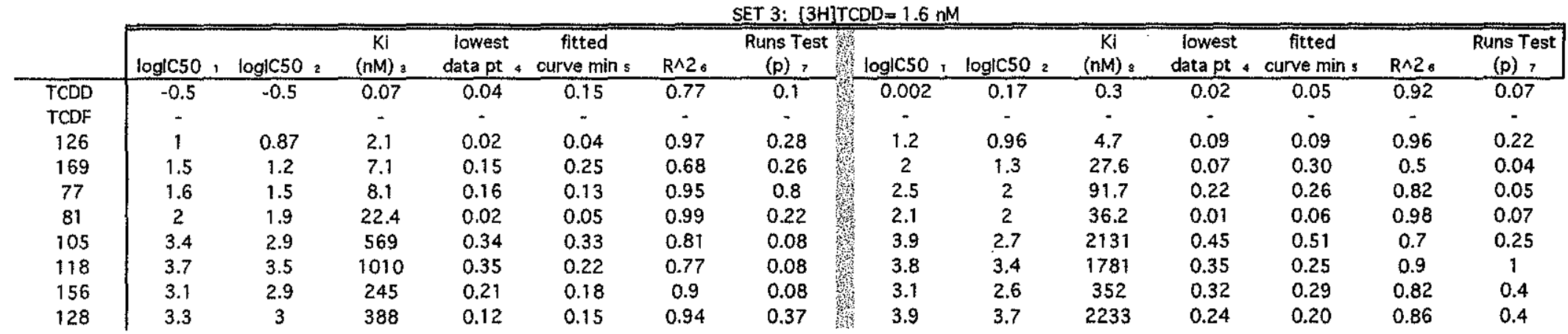

1. logIC50 (1): determined by non-linear curve fitting to a one-site model for competition, with the values for top and bottom of the curves fixed at $100 \%$ and $0 \%$, respectively.

2. $\log \mid \mathrm{C} 50$ (2): determined by non-linear curve fitting to a one-site model for competition, and the model fitted values for the maximum and minimum fractional specific binding

3. Ki (nM): determined by the method of Cheng and Prusoff from the logiC50 (1).

4. Lowest data point: the lowest average fractional specific binding point determined for this curve

5. Fitted curve min: lowest fractional specific binding as determined by one-site competition model without fixing top and bottom values

6. R^2: R-square for the one-site competition model used to determine loglc50(1)

7. Runs test: a reflection of how well the model fits the data based on how many consecutive data points run above or below the fitted curve, regardless of R-square. If $p<.05$, then significant chance a different model would better fit the data. 
Table 3. Summary of IC50s, $\mathrm{Ki}$, and relative potencies determined for beluga and mouse.

Mean IC50 is the average of the two experiments conducted at $1.6 \mathrm{nM}$, and Mean $\mathrm{Ki}$ is determined from all three data sets.

\begin{tabular}{|c|c|c|c|c|c|c|c|c|c|}
\hline \multirow[b]{2}{*}{ HAH } & \multirow[b]{2}{*}{ |Chlorination pattern } & \multicolumn{4}{|c|}{. Beluga } & \multicolumn{4}{|c|}{ Mouse } \\
\hline & & $\begin{array}{l}\text { Mean IC50 } \\
(\mathrm{nM})\end{array}$ & $\begin{array}{l}\text { Mean Ki } \\
(\mathrm{nM})\end{array}$ & $\begin{array}{c}95 \% \text { confidence } \\
\text { interval for } \mathrm{Ki}\end{array}$ & $\begin{array}{l}\text { Relative potency } \\
\text { (from mean } \mathrm{Ki} \text { ) }\end{array}$ & $\begin{array}{l}\text { Mean IC50 } \\
(\mathrm{nM})\end{array}$ & $\begin{array}{c}\text { Mean Ki } \\
(\mathrm{nM})\end{array}$ & $\begin{array}{l}95 \% \text { confidence } \\
\text { interval for } \mathrm{Ki}\end{array}$ & $\begin{array}{l}\text { Relative potency } \\
\text { (from mean } \mathrm{Ki} \text { ) }\end{array}$ \\
\hline$\overline{T C D D}$ & $2,3,7,8$ & 0.47 & 0.10 & $0.05-0.22$ & 1.00 & 1.21 & 0.36 & $0.25-0.51$ & 1.00 \\
\hline TCDF & $2,3,7,8$ & 1.35 & 0.33 & $0.24-0.46$ & 0.31 & 1.62 & 1.1 & $0.21-5.8$ & 0.32 \\
\hline 126 & $3,3^{\prime}, 4,4^{\prime}, 5$ & 8.1 & 1.6 & $1.3-2.1$ & 0.063 & 12.6 & 4.6 & $3.1-6.8$ & 0.078 \\
\hline 169 & $3,3^{\prime}, 4,4^{\prime}, 5,5^{\prime}$ & 25.1 & 7.5 & $3.9-14.7$ & 0.014 & 63.1 & 33 & $8.3-132$ & 0.011 \\
\hline 77 & $3,3^{\prime}, 4,4^{\prime}$ & 35.5 & 7.8 & $7.3-8.3$ & 0.013 & 224 & 94 & $47.6-185.1$ & 0.0038 \\
\hline 81 & $3,4,4,5$ & 89.1 & 19 & $12.9-26.8$ & 0.0055 & 112 & 34 & $30-38$ & 0.011 \\
\hline 105 & $2,3,3^{\prime}, 4,4^{\prime}$ & 3548 & 567 & $292-1099$ & 0.00018 & 5012 & 1620 & $927-2829$ & 0.00022 \\
\hline 118 & $2,3^{\prime}, 4,4^{\prime}, 5$ & 6310 & 1437 & $930-2219$ & 0.000071 & 6310 & 3188 & $930-10934$ & 0.00011 \\
\hline 156 & $2,3,3^{\prime}, 4,4^{\prime}, 5$ & 1585 & 309 & $196-485$ & 0.00033 & 1000 & 284 & $186-433$ & 0.0013 \\
\hline 128 & $2,2^{\prime}, 3,3^{\prime}, 4,4^{\prime}$ & 2239 & 384 & $246-600$ & 0.00027 & 6310 & 1421 & $826-2445$ & 0.00025 \\
\hline
\end{tabular}


Table 4. Relative potencies (REPs) for AHR binding and mammalian Toxic Equivalency Factors (TEFs)

\begin{tabular}{|c|c|c|c|c|c|}
\hline $\mathrm{HAH}$ & $\begin{array}{l}\text { Chlorination } \\
\text { pattern }\end{array}$ & $\begin{array}{l}\text { beluga REPs for } \\
\text { AHR binding }\end{array}$ & $\begin{array}{c}\text { mouse REPs for } \\
\text { AHR binding }\end{array}$ & $\begin{array}{l}\text { rat REPs for } \\
\text { AHR binding }\end{array}$ & $\begin{array}{l}98 \text { WHO TEFs for } \\
\text { wildife/humans } 2\end{array}$ \\
\hline TCDD & $2,3,7,8$ & 1.00 & 1.00 & 1.0 & 1 \\
\hline TCDF & $2,3,7,8$ & 0.31 & 0.32 & & 0.1 \\
\hline 126 & $3,3^{\prime}, 4,4^{\prime}, 5$ & 0.063 & 0.078 & 0.08 & 0.1 \\
\hline 169 & $3,3^{\prime}, 4,4^{\prime}, 5,5^{\prime}$ & 0.014 & 0.011 & insoluble & 0.01 \\
\hline 77 & $3,3^{\prime}, 4,4^{\prime}$ & 0.013 & 0.0038 & 0.01 & 0.0001 \\
\hline 81 & $3,4,4^{\prime}, 5$ & 0.0055 & 0.011 & 0.0004 & 0.0001 \\
\hline 105 & $2,3,3^{\prime}, 4,4^{\prime}$ & 0.00018 & 0.00022 & 0.0023 & 0.0001 \\
\hline 118 & $2,3^{\prime}, 4,4^{\prime}, 5$ & 0.000071 & 0.00011 & 0.0011 & 0.0001 \\
\hline 156 & $2,3,3^{\prime}, 4,4^{\prime}, 5$ & 0.00033 & 0.0013 & 0.0014 & 0.0005 \\
\hline 128 & $2,2^{\prime}, 3,3^{\prime}, 4,4^{\prime}$ & 0.00027 & 0.00025 & - & - \\
\hline
\end{tabular}

1 calculated from IC50 reported in Bandiera et al., 1982

$z$ van den Berg et al., 1998 


\section{Chapter 4:}

Tissue-specific expression of the aryl hydrocarbon receptor in the beluga 


\section{INTRODUCTION}

Dioxins and related planar halogenated aromatic hydrocarbons (PHAH) are known to cause a variety of toxic effects in terrestrial mammals, including immunosuppression, thymic atrophy, reproductive toxicity, cancer, epithelial hyperplasia, enzyme induction, and wasting syndrome (Schmidt \& Bradfield, 1996). Studies using mice that that do not express the AHR have shown that the AHR is necessary for these toxic effects to occur (Fernandez-Salguero et al., 1996; Hundeiker et al., 1999).

High body burdens of contaminants in marine mammals correlate with episodes of disease and low rates of reproduction in certain cetacean populations (reviewed in Chapter 1). This has raised questions regarding the possible health effects of contaminants in cetaceans. However, a mechanistic link remains to be established between contaminant exposure and observed effects in feral cetacean populations.

The AHR is very likely to be an important protein in this mechanistic link. Chapters 2 and 3 describe the isolation and characterization of a beluga AHR, and the expressed AHR protein was used to compare relative binding affinities among species and to determine structure-binding relationships for different PHAH. These results showed that the beluga AHR binds to PHAH with the same structure-activity relationships that have been established for other mammals, but the overall affinity for the compounds is greater. In this chapter, another factor involved in establishing the link between cetacean disease and PHAH exposure is addressed by examining the tissuespecific expression of AHR in beluga tissues. 
There is theoretical and experimental support for the argument that relative AHR expression can predict sensitivity to AHR agonists. For example, Kenakin (1999) noted that "The number of units (receptors) capable of producing stimuli in the organ clearly is a factor in the total stimulus imparted by any concentration of agonist...Therefore, the higher the number of drug receptors $\left[R_{t}\right]$ is, the larger the receptor stimulus"(Kenakin, 1999).

The radiation chimeric mouse is an elegant model that shows the importance of tissue and cell-specific AHR expression for determining PHAH toxicity. Irradiated $\mathrm{Ah}^{+} / \mathrm{Ah}^{+}$mice were reconstituted with $\mathrm{Ah} / \mathrm{Ah}^{-}$bone marrow stem cells, and the reciprocal case was also done. Mice that were reconsituted with $\mathrm{Ah}^{-} / \mathrm{Ah}^{-}$hematopoetic stem cells, regardless of background phenotype of the stromal cells, were resistant to TCDD-induced thymic atrophy and suppression of the B-cell maturation process (Staples et al., 1998; Thurmond et al., 2000). Though the mechanism is not known, it appears to involve the disruption of signaling events during proper proliferation and differentiation stages, and growing evidence is implicating the involvement of the transcription factor NFkB (Puga et al., 2000; Tian et al., 1999). Pre-B cells in the bone marrow are also targets of another pathway of AHR-mediated toxicity. 7,12-Dimethylbenzanthrazene causes pre-B cells to undergo apoptosis following a signal generated from bone marrow stromal cells. The "death signal" is dependent on AHR induction of CYP1B1, thus implicating a CYP1B1 metabolite (Heidel et al., 1999; Mann et al., 1999).

Other mechanisms likely occur in other tissues and cell types. For example, planar representatives of the polyaromatic hydrocarbons $(\mathrm{PAH})$ such as benzo[a]pyrene 
(B[a]P) bind to the AHR and induce CYP1A1 and CYP1B1 that metabolize PAH.

Certain of these metabolites, particularly B[a]P-7,8-diol-9,10 epoxide (BPDE), are highly genotoxic, and are implicated in cancer initiation in many tissues, including liver and lung (Phillips, 1983). It was shown recently that $\mathrm{B}[\mathrm{a}] \mathrm{P}$ induced carcinogenicity is strictly AHR-dependent, which confirms exclusive roles for CYP1A1 in producing genotoxic B[a]P metabolites, and reconfirms the AHR in the induction of CYP1A1 (Shimizu et al., 2000). Though TCDD is not a tumor initiator (a genotoxin), it is known to be an extremely potent tumor promoter (Huff et al., 1994; Pitot et al., 1980). Furthermore, it was recently shown that a genotoxic class of PAH metabolites (planar PAH o-quinones) can bind the AHR and be translocated into the nucleus, thereby using the AHR as a "shuttle" for nuclear targeting by carcinogens (Burczynski \& Penning, 2000). Thus, it is clear that certain organs and cells are sensitive targets of $\mathrm{PHAH}$, planar $\mathrm{PAH}$, and certain PAH metabolites, and the sensitivity is AHR-dependent.

Pathologies similar to those observed in rodents treated with AHR agonists occur in beluga of the St. Lawrence Estuary. Cancer has been reported in many of the small beluga population of the St. Lawrence Estuary, Canada. Tumors were detected in $40 \%$ of the 45 belugas necropsied (Beland et al., 1993). Of these, 9 malignant cancers occurred in bladder, ovary ( 2 animals), salivary gland ( 2 animals), stomach, intestine ( 2 animals), and liver. This is coincident with $\mathrm{B}[\mathrm{a}] \mathrm{P}$ adducts detected in $90 \%$ of the animals tested (Martineau et al., 1994). This high incidence of cancer, along with high frequencies of viral and bacterial infections suggest that St. Lawrence beluga may also suffer from immunosuppression (Deguise et al., 1995). All of these pathologies are coincident with 
high chemical burdens in beluga tissues, of which PHAH are represented (Martineau et al., 1987). Thus, the targets for PHAH and other AHR ligands in beluga might be similar to targets in rodents.

In order to begin to assess potential sites for AHR-mediated toxic effects in cetaceans, the tissue-specific expression of AHR was examined in the beluga. Several tissues were collected from 5 male beluga from the Alaskan Arctic. Three methods were used to measure AHR expression: 1) ligand binding in cytosols, 2) presence of immunodetectable AHR protein in cytosols, and 3) messenger RNA expression. These results provide insights about AHR regulation and implicate potential targets for PHAH toxicity in the beluga.

\section{MATERIALS AND METHODS:}

Sample collection

The beluga tissues were collected during and after subsistence hunts by native American Inupiaq. The first collection was after an opportunistic take in Barrow, AK in July 1997, after the organized annual hunt in Point Lay, AK was spoiled by unfavorable ice conditions. After the blubber (maq taq) and meat were taken by the hunters, most of the inner viscera from 3 male belugas were bagged in plastic and kept outside (temperature $0-5^{\circ} \mathrm{C}$ ) until sampling began about 3 hours later. 97-1 was sampled first, followed by $97-2$ and $97-3$. The last frozen samples were taken about 2 hours after sampling began, approximately 5 hours post-mortem. 
The second sampling opportunity occurred during the organized annual hunt in Point Lay in July, 1998. The belugas were killed by bullet fired into the rear of the cranium at close range. After the belugas were towed ashore and pulled up onto the beach, two of the youngest looking animals (as judged by their color) were chosen for sampling. $98-1$ had the most grey character (indicating that it may be 1 year old or less) followed by $98-2$. The time post mortem before sampling began on 98-1 was 1.5-2 hours. The approximate order for tissue sampling in 98-1 was liver, lung, heart, thymus, spleen, lymph node, testis, thyroid. Beluga 98-2 was sampled immediately after 98-1, about 1 hour later, 2.5-3 hours post mortem. The approximate order of sampling was liver, lung, heart, spleen, kidney, adrenal, testis, thyroid. Again, sampling took approximately one hour. Tissues were cut into small slices, placed in pre-labeled $2 \mathrm{ml}$ cryo vials, and snap frozen in liquid nitrogen until further processing.

\section{Cytosol preparation}

Liver cytosol was prepared as described in Hahn et al (1994). Cryo-preserved liver was first powdered under liquid nitrogen temperatures, then homogenized in MEEDGM (35mM MOPS, 1mM EDTA, 5 mM EGTA, $0.02 \% \mathrm{NaN}_{3}, 20 \mathrm{mM} \mathrm{Na}_{2} \mathrm{MoO}_{4}$, $10 \%$ (v:v) glycerol, 1mM DTT, pH 7.5 containing protease inhibitors and PMSF) with at least 20 passes of a teflon pestle, keeping the sample cool with a beaker of ice. After serial centrifugations of $750 \mathrm{~g}, 12,000 \mathrm{~g}$, and $100,000 \mathrm{~g}$, the supernatants were snap frozen and stored in liquid nitrogen until analysis. Protein concentrations were determined by the method of Lorenzen and Kennedy (Lorenzen \& Kennedy, 1993). Bovine serum 
albumin standards and samples were read in triplicate and MEEDGM was used as the blank.

In vitro expression

The beluga AHR (pSP64belAHR) was constructed as described in Chapter 2. The mouse AHR (pSPORTmoAHR) was a gift from Dr. C. A. Bradfield (Burbach et al., 1992). The mouse AHR repressor construct was a gift from Dr. Y. Fujii-Kuriyama (Mimura et al., 1999). Proteins were expressed from ultrapure vector in a rabbit reticulocyte lysate: TNT T7 or SP6 Quick Coupled Transcription and Translation Kit (Promega, Madison, WI)

\section{Velocity sedimentation}

The velocity sedimentation procedure follows the vertical tube rotor method of Tsui and Okey (Tsui \& Okey, 1981). 2,3,7,8-Tetrachloro[1,6- $\left.{ }^{3} \mathrm{H}\right]$ dibenzo-p-dioxin, specific activity $27 \mathrm{Ci} / \mathrm{mmol}\left(\left[^{3} \mathrm{H}\right]-\mathrm{TCDD}\right)$ was purchased from Chemsyn Science Laboratories (Lenexa, KS). $\left[{ }^{3} \mathrm{H}\right]-\mathrm{TCDD}$ in DMSO, plus either DMSO or $80 \mu \mathrm{M}$ TCDF in DMSO were added to $300 \mu \mathrm{l}$ of undiluted chipped cytosols (1.2-2.9 $\mathrm{mg}$ protein), to final concentrations of $2 \mathrm{nM}\left[{ }^{3} \mathrm{H}\right]-\mathrm{TCDD} \pm 400 \mathrm{nM}$ TCDF and $1 \%$ DMSO in $13 \times 100$ glass culture tubes. A $50 \mu \mathrm{l}$ (1.2 mg protein) pSP64belAHR TNT reaction diluted in 2 parts MEEDGM and incubated with the same final concentrations of $\left[{ }^{3} \mathrm{H}\right]-\mathrm{TCDD}$ and TCDF. Tubes were parafilmed, vortexed, and placed on ice. After 2 hours, $25 \mu$ were taken for total counts, and the remainder of the reaction was transferred to a polypropylene $1.5 \mathrm{ml}$ 
microcentrifge tube, vortexed for 10 seconds, and tap spun. $275 \mu \mathrm{l}$ of cytosol incubations and $125 \mu \mathrm{l}$ TNT incubations were applied to $10-30 \%$ sucrose gradients that were prepared in MEEDMG buffer using the method of Coombs and Watts (1985) in Beckman polypropylene centrifuge tubes. $5 \mu$ of a mixture of $\left[{ }^{14} \mathrm{C}\right]-O v a l b u m i n(3.6 S)$ and $\left[{ }^{14} \mathrm{C}\right]-$ catalase $(11.3 S)$ were loaded on the gradient as internal sedimentation markers. The gradients were spun for $140 \mathrm{~min}$ at $60,000 \mathrm{rpm}$ at $4^{\circ} \mathrm{C}$ in a VTi 65.2 rotor. The gradients were separated into $150 \mu \mathrm{l}$ fractions were collected using a tube piercing apparatus and an automatic fraction collector, with 50\% sucrose in MEEMG as chasing solution. 3.5 ml Scintiverse II (Fisher Scientific) were added to each fraction, and disintegrations per minute (DPM)were counted using a Beckman LS5000TD Scintillation counter. Specific binding is defined as the difference between total binding (incubations containing $\left[{ }^{3} \mathrm{H}\right] \mathrm{TCDD}$ ) and nonspecific binding (incubations containing $\left[{ }^{3} \mathrm{H}\right] \mathrm{TCDD}$ plus a 200 -fold excess of TCDF).

\section{Western Blotting}

SDS-PAGE was accomplished using the NuPAGE system of pre-cast gels and reagents: $7 \%$ tris-acetate SDS-PAGE gels, Running Buffer, Sample treatment buffer, Antioxidant, and Sample Reducing Agent (Invitrogen, Carlsbad, CA). $100 \mu \mathrm{g}$ cytosol protein, $12 \mu \mathrm{g}$ pSPORTmoAHR TNT product, and 30 $\mu \mathrm{g}$ pSP64belAHR TNT product, and $8 \mu \mathrm{l}$ of resuspended High Molecular Weight Marker (Sigma, St. Louis, MO) were run at 117 volts constant, $29-45$ mamps. Gels were transferred onto $0.20 \mu \mathrm{m}$ PVDF membrane (Invitrogen) in NuPAGE Transfer Buffer (500mM Bicine, $500 \mathrm{mM}$ Bis-Tris, 
20 mM EDTA, pH 7.2, plus 10\% methanol and $0.1 \%$ NuPAGE Sample Antioxidant, recipe supplied by Invitrogen). Transfer conditions were 250 mamps constant, 55-65 volts, 2 hours in Hoeffer Scientific mini transfer module.

The membrane was blocked in 1\% Rad-Free Blocking Powder (Schleider and Schuell) in tris-buffered saline (TBS: $20 \mathrm{mM}$ Tris, $500 \mathrm{mM} \mathrm{NaCl}, \mathrm{pH} 7.5$ ). Two primary antibodies were used. SA-210 is a rabbit polyclonal antibody directed to amino acids 1402 of the mouse $\mathrm{Ah}^{\mathrm{b}-1}$ allele (Biomol). BEAR2 is a rabbit polyclonal antibody directed to amino acids $1-415$ of the mouse $\mathrm{Ah}^{\mathrm{b}-1}$ allele, and it was a generous gift from $\mathrm{Dr}$. Richard Pollenz. Membranes were probed with SA-210 ( $0.6 \mu \mathrm{g} / \mathrm{ml}$ in blocking solution) or Bear $2(1 \mu \mathrm{g} / \mathrm{ml}$ in blocking solution) for 1.5 hours, flipping once. Membranes washed and then probed with secondary antibody, Goat-Anti-Rabbit Rad-Free Alkaline Phosphatase Conjugate (Schleicher and Shuell) 1:10,000 in blocking solution. After each antibody incubation, membranes were washed 3 times in water, and 3 times in TBS. The membrane was then soaked in TBS, $\mathrm{pH} 9.5$, then bathed in $3 \mathrm{ml} \mathrm{CSPD} \mathrm{Ready-To-Use}$ (Tropix, Bedford, MA) for 5-7 minutes. Membranes were heat-sealed in plastic, and chemiluminescence was visualized on X-OMAT film (Kodak) after exposure times of 45-minutes-5 hours. Efficiency of transfer, and size marker visualization was determined by staining gels with Coomassie Blue.

\section{Total RNA Isolation}

Total RNA was prepared using RNAqueous-Midi Kit (Ambion, Austin, TX) with slight modifications to the manufacturer's protocol that were required to accommodate 
the fibrous and DNA-rich nature of most of the whale tissues. Tissue powders $(0.17-$ $0.55 \mathrm{~g}$ ) were homogenized in $7 \mathrm{ml}$ of the guanidinium isothiocyanate-based buffer with over 20 passes with a teflon pestle, until the solution appeared clear of debris. The temperature of the solution was kept cool during homogenization by keeping a beaker of ice outside of the tube. The homogenate was vigorously passed through a disposable 10 $\mathrm{ml}$ syringe attached to an $18 \mathrm{~g}$ needle 10 times to shear any precipitated genomic DNA. The genomic DNA significantly increased the viscosity of the sample in the spleen, thymus, and lymph node samples even before precipitating with ethanol. The sheared homogenates were transferred to a $15 \mathrm{ml}$ Corex tube, then spun at $7650 \mathrm{~g}$ ( $8000 \mathrm{rpm}$ in Beckman JA-20 rotor) for 15 minutes at $4^{\circ} \mathrm{C}$. Using a sterile pipet and taking care to avoid any debris at the surface as well as the pellet on the bottom, the supernatant (about $6 \mathrm{ml}$ ) was transferred to a sterile, disposable $50 \mathrm{ml}$ conical vial. The DNA was sheared again as described above. $6 \mathrm{ml}$ of $64 \%$ ethanol was added and the solution was mixed by inversion. The DNA was sheared again as above until there was no notable viscous quality to the sample. The sample was then passed though the glass filter and washed per the manufacturer's instructions. The RNA was eluted from the filter by passing 3 aliquots of $333 \mu \mathrm{l}$ of kit-provided Elution buffer $\left(100^{\circ} \mathrm{C}\right)$ using a $3 \mathrm{ml}$ sterile syringe.

The sample quality was determined by running $10 \mu \mathrm{l}$ on a formaldehyde gel, which revealed significant amounts of DNA contamination running above the $28 \mathrm{~S}$ ribosomal RNA fragment. Furthermore, spectrophotometric quantition revealed low concentrations for most of the samples, spurring further concentration and purification. $300 \mu$ l of the total RNA sample was concentrated to less than $100 \mu \mathrm{l}$ on a speedvac 
centrifuge equipped with a condenser. Half volumes of Lithium Chloride precipitation solution (provided with the RNAqueous Midi kit) were added, and the samples precipitated overnight. After spinning for $15 \mathrm{~min}$ at $14,000 \mathrm{rpm}$ at room temperature in an Eppendorf microcentrifuge, visible pellets were observed. The pellets were washed with

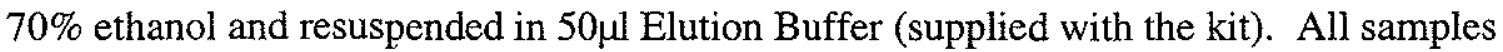
were then treated with $1 \mathrm{x}$ RNAsecure (Ambion) and stored at $-80^{\circ} \mathrm{C}$. The final quality of the RNA was verified by visualization on an agarose-formaldehyde gel (Figure 1).

\section{Relative RT-PCR}

\section{Sequencing beluga $\beta$-actin cDNA}

$\beta$-actin is the non-muscle actin isoform that is highly conserved and involved in cell motility, structure, and integrity (Vandekerckhove \& Weber, 1978). Its ubiquitous presence in cells (a "housekeeping gene") has made it an ideal candidate for control for messenger RNA studies. It is prudent to obtain species-specific actin sequence.

Although $\beta$-actin amino acid sequences are $100 \%$ conserved in mammals examined so far, the nucleotide sequences have evolved with silent mutations that occurred very recently and at a faster rate than likely divergence times would predict (Alonso et al., 1986). In order to generate species-specific primers for $\beta$-actin, the majority of a beluga $\beta$-actin cDNA was amplified, cloned, and sequenced. Beluga liver poly A+ mRNA was isolated as described in Chapter 2. One $\mu$ g poly A+RNA was reverse transcribed with random hexamers using the GeneAmp RNA PCR Core Kit (Perkin-Elmer, Branchburg, NJ). Degenerate $\beta$-actin primers which amplify amino acids $18-351$ of the vertebrate actin 
gene were a gift from Hillary Morrison (Marine Biological Laboratory): 5' actin: 5'GAATTCTGCAGACAACGGYTCSGGTATGTGC-3', 3' actin: 5'CTCGAGGATCCGAAGCAYTTGCGRTGWACRAT-3'. $50 \mathrm{ng}$ of each primer was used with AmpliTaq Gold Polymerase (Perkin-Elmer) the following conditions in the Perkin Elmer 2400 thermocycler: $95 \% 10: 00 ; 94 \%: 15,50 \%: 30$ for 35 cycles, $72 \% 11: 00$. The product was separated in a $1 \%$ agarose gel, cut out, and the DNA was extracted from the agarose with GeneClean (Bio101). The DNA was ligated into pGEMT-Easy (Promega, Madison, WI), transfected into JM109 high efficiency competent cells (Promega), plated, and white colonies were selected for analysis. Three minipreps that revealed expected size fragments upon EcoR1 digest were grown up to larger scale and the plasmid was purified by QIAprep Spin Miniprep Kit (Qiagen). The purified DNA was sequenced from the $\mathrm{T} 3$ and $\mathrm{T} 7$ vector sites by the University of Maine Sequencing Facility (Orono, ME). The consensus sequence was derived from forward and reverse sequences from 3 clones that overlapped completely with no discrepancies in the sequences. The translated sequence is shown in Figure 2, which corresponds to amino acids $17-351$, or $94 \%$ of the protein sequence.

\section{Design of primers for RT-PCR}

Primers for RT-PCR were designed to avoid amplification of genomic DNA. The complete nucleotide sequence of the beluga AHR cDNA is known (Chapter 2, Figure 2). The intron/exon structures for the mouse AHR (Burbach et al., 1992), human AHR (Bennett et al., 1996), and most of the fish AHR1 (Karchner et al., 1999) are known and are identical. Therefore, it was presumed that the gene structure would be conserved in 
beluga as well. Primers were designed spanning the presumed exon junctions 6-7(ex67forw (28-mer): 5'- GCTGGATAATTCATCTGGTTTTCTGGCA -3') and 8-9 (ex89back (28-mer): 5'- GGCCACTCTCTCCAGTCTTAATCATCCG -3') to amplify a 362 base pair fragment (Figure 3). Using a relatively small product for the PCR minimizes differences in product formation that may be a result of differential RNA degradation. The actin primers were designed such that they would 1) amplify a product similar in size to the AHR product, 2) have similar optimal annealing temperatures so that they could be used in the same polymerase chain reaction run (albeit in different tubes), 3) be discernable from the beluga product on a $2 \%$ agarose gel, and 4) span a sizable intron so that amplification of genomic DNA would be easily detected. The $\beta$-actin intron/exon structure and $\beta$-actin intron sequences are highly conserved in vertebrates (NakajimaIijima et al., 1985). Primers dlactforw ( 20 mer: 5'-AGAGCAAGAGAGGCATCCTG -3') and dlactback (19-mer: 5' - TAGATAGGCACGTGTGGG -3') were designed to amplify a $322 \mathrm{bp}$ fragment spanning the presumed exons $2-4$ of the beluga actin sequence (Figure 3). This region spans the largest intron among those that interrupt the coding region of the $\beta$-actin gene, a $>400$ bp intron between exons 2 and 3 , thereby facilitating identification of PCR products derived from contaminating genomic sequence.

\section{cDNA synthesis from total RNA}

Two $\mu \mathrm{g}$ of total RNA from 10 different tissues from 2 individual belugas , 8 tissues from each (98-1: liver, heart, lung, testis, spleen, thyroid, thymus, lymph node; 98-2: liver, heart, lung, testis, thyroid, spleen, kidney, adrenal) were reverse transcribed into cDNA üsing Omniscript Reverse Transcriptase (Qiagen) with random hexamers 
(Perkin-Elmer) in the presence of 12 units Rnasin (Promega). Another set of reactions (one sample from each 98-1 tissue, plus kidney and adrenal from 98-2) was prepared without the reverse transcriptase to serve as a control for PCR products derived from genomic DNA.

\section{Determination of optimized conditions for relative RT-PCR}

Initial screen. In order to determine which tissue(s) express AHR, an initial screen of the CDNA was carried out with the actin and AHR primers under the following conditions: $2 \mathrm{mM} \mathrm{MgCl}, 1 \mu \mathrm{M}$ final primer concentration with Taq gold PCR system (Perkin Elmer) $95^{\circ} / 10: 00 ; 95^{\circ} \%: 15,60 \%$ (35 cycles); $72^{\circ} / 7: 00$ in a Thermocycler 9700 (Perkin Elmer). A band of expected size was observed in all tissues, but because the liver was among the tissues with the highest apparent expression levels, we carried out subsequent optimization steps on liver cDNA from both animals and tested cDNA detection levels using 98-1 liver cDNA.

Cycle optimization. To determine what cycles are within the linear range of detection for transcripts, $100 \mu \mathrm{l}$ reactions were set up as described above, using beluga liver cDNA from 98-1 and 98-2, $4 \mu \mathrm{l} \mathrm{cDNA}$ per $100 \mu \mathrm{l}$ PCR. Aliquots were taken from the tube during the annealing step of cycles $21,24,26$, and 29 for AHR, and 20,22, 25, $28,29,31$ for $\beta$-actin. Figure 3 shows that the upper limit of the linear range for both AHR and actin detection in liver for both individuals is between 29 and 32 cycles (Figure 4a). 28 cycles was chosen for further experimentation. By choosing a cycle near the upper limit of the linear range for a tissue expressing high amounts of AHR message, it 
was reasoned that it would increase the likelihood that all tissues, including those with less AHR message, will fall within the linear range of optical density.

cDNA test. To ensure that the chosen cycle number of 28 would allow detection of variable amounts of transcript, the liver cDNA from beluga 98-1 was used in a dilution series that varied 8 -fold $(1 \mu \mathrm{l}-8 \mu \mathrm{l})$. Figure $4 \mathrm{~b}$ shows that, as expected based on the choice of cycle number, not much resolution is possible above $4 \mu$ liver cDNA. However, signal from AHR template is linear over at least 4-fold range (1-4 $\mu \mathrm{l} \mathrm{cDNA})$. Actin was apparently linear over only a 2 -fold range, though no points were taken between 2 and $4 \mu \mathrm{l}$ cDNA. Nevertheless, this was deemed acceptable, since actin message was expected to vary much less than AHR message.

\section{Relative RT-PCR from multiple tissues}

Complementary DNA from all tissues was used in $25 \mu \mathrm{l} \mathrm{PCR} \mathrm{reactions} \mathrm{with} \mathrm{the}$ following conditions: $2 \mathrm{mM} \mathrm{MgCl}, 1 \mu \mathrm{M}$ final primer concentration with AmpliTaqGold PCR system (Perkin Elmer) 95\% $/ 10: 00 ; 95^{\circ} \%: 15,60^{\circ} \%: 30$ (28 cycles); $72^{\circ} / 7: 00$ in a Thermocycler 9700 (Perkin Elmer). Control cDNA reactions (minus RT) were performed under the same conditions. $10 \mu \mathrm{l}$ of each reaction was separated on a $2 \%$ agarose gel, then soaked in $0.5 \%$ Ethidium bromide solution for 1 hour. The stained gel was visualized using ChemiImager 4000 Low Light Imaging System (Alpha Innotech Corp.). Bands were quantified using the accompanying SpotDenso densitometry software. 


\section{RT-PCR of full length AHR from beluga tissues}

$1 \mu \mathrm{cDNA}$ was amplified using Hind3nat and XBA-UTR primers that amplify the full-length beluga AHR using Touchdown PCR as previously described (Chapter 2).

\section{RESULTS}

\section{Detection of specific TCDD binding in tissue cytosols}

Sucrose density gradient centrifugation was used to compare the ability of cytosols prepared from various tissues to specifically bind $\left[{ }^{3} \mathrm{H}\right]$-TCDD. A clear peak of specific binding ( $7 \mathrm{fmol} / \mathrm{mg}$ ) was detected in fractions 11-19 of liver cytosol from beluga 98-1( Figure 5 panel A). This peak shares the same sedimentation coefficient $(9.5 \mathrm{~S})$ as the in vitro expressed belAHR and mouse liver cytosol (Chapter 2, Figure 5). The experiment was repeated for other tissues collected from the 1998 belugas: $98-1$ heart, lung, spleen, thymus, and lymph node (Figure 5 panels B-F) and 98-2 liver, lung, and spleen (Figure 5, panels H-J). Small peaks of specific binding were detected in 98-1 lung and spleen $(3.3,3.7 \mathrm{fmol} / \mathrm{mg}$, respectively). Very small specific binding peaks were observed in $98-1$ heart, and thymus, $(1.5$, and $0.87 \mathrm{fmol} / \mathrm{mg}$ respectively). No specific binding was evident in the 98-2 samples. In each extrahepatic tissue, the detectable binding very low relative to the positive control (Figure 5, panel G; Table 1).

The peaks for the $\left[{ }^{14} \mathrm{C}\right]$-labeled $3.6 \mathrm{~S}$ catalase and $11.3 \mathrm{~S}$ ovalbumin, standards were detected in fractions 4-6 and 15-17, respectively. This indicated good consistency between experiments and between gradients within experiments. The peaks of $\left[{ }^{3} \mathrm{H}\right] \mathrm{TCDD}$ specific binding between the positive control, liver, and lung samples were all 
detected at $9.5 \mathrm{~S}$. The very small peaks detected in heart, spleen, and thymus were detected at $11 S$, indicating that the specific binding, if real, could have a slightly higher sedimentation coefficient than the complex detected in liver and lung.

\section{Immunodetection of AHR in tissue cytosols.}

Western blotting was used to assess levels of cytosolic AHR in 5 individual beluga sampled in 1998 and 1997. SA-210 is a commercially-available polyclonal antibody against the $\mathrm{N}$-terminal 402 amino acids of the mouse AHR b-1 allele (Figure 6). It is known to detect AHR in mouse and rat liver, and does not cross-react with ARNT. In Chapter 2 we showed that SA-210 cross-reacts with beluga AHR (107 kDa) by showing that it recognized the $\left[{ }^{35}\right] S$-labeled protein band that resulted from TNT expression of pSP64belAHR. In the present experiments, while detecting single bands

of the expected size for the belAHR and moAHR TNT products $(107 \mathrm{kDa}$ and $95 \mathrm{kDa}$, respectively), SA-210 detected more than one band in cytosol from almost every extrahepatic tissue examined (Figure 6a). For the 98-1 cytosols, a band the same size as the in vitro expressed beluga liver AHR (107 kDa) was observed in all tissues except heart (Figure 7). In the order of decreasing prominence, this band was observed in lung, lymph node, spleen, thymus, liver, testis, and thyroid. No $107 \mathrm{kDa}$ band was detected in heart. However, in spleen, thymus, and lymph node, a very prominent band was also detected that appeared to be slightly smaller than the moAHR $(<95 \mathrm{kDa})$. This band was also observed in lung, but was much less prominent. The only visible band in $98-1$ heart 
cytosol was slightly smaller still $(<90 \mathrm{kDa})$. A band of this apparent size was also observed in the liver.

The pattern of immunodetected bands in the second beluga sampled in 1998 (982) was fairly different from that observed for the first animal. In the $98-2$ samples, no $107 \mathrm{kDa}$ (belAHR-sized) bands were outstanding, and the only band of belAHR size was detected in the lung only after prolonged exposure. The most prominent band among all of the 98-2 samples was a band in spleen that corresponded to the smaller, more prominent band detected in 98-1 spleen. Note that thymus and lymph node were not available in the 98-2 samples. The single 98-1 heart band that was smaller than moAHR was also observed in the 98-2 heart cytosol. The only liver band observed in the 98-2 sample was the same size as the $98-2$ heart band, which was equivalent in size to the very minor band in the 98-1 liver. A very faint band was observed in 98-2 kidney, this protein ran at a size in between the spleen and heart/liver bands.

The 1997 samples were presumed to be of lesser quality than the 1998 samples because the time between death and tissue sampling was several hours longer. Therefore, it was not necessarily expected that the findings would match the 98 sample set because of possible sample degradation. The bands will be described relative to the bands detected in the 98 samples. The 97 western blots with SA-210 are shown in Figures 8 and 9. Figure 8 shows the unmanipulated image with the TNT-expressed mouse and beluga AHRs on each as a size reference. Figure 9 is an alternative view of Figure 8 with the 3 beluga tissues sets separated for ease of comparison between animals and tissues, and all relative sizes were maintained during the image adjustment. In the 97 animals, 
the only band that was the same size as the in vitro expressed belAHR was detected in 2 of 4 lymph nodes sampled. The smaller of the two spleen bands was detected in both spleens of 97 animals for which spleens were sampled. The smaller of the 2 liver bands was detected in all three samples. The same size band was detected in 1 of 3 kidney samples, and all kidneys revealed a band that was slightly smaller yet. The only tissue sampled in 97 that was not represented in the 98 samples was muscle: both muscle cytosols revealed a band that was closest in size to the small spleen band. No band was detected in two testes samples.

In addition to the expected $95 \mathrm{kDa}$ protein detected in the moAHR TNT lysate, a $70 \mathrm{kDa}$ band as well as a $<30 \mathrm{kDa}$ band were less prominent, but visible on all blots. The identity of the $70 \mathrm{kDa}$ peptide is might be a product of proteolysis by a very fast acting, $\mathrm{Ca}^{2+}$-dependent protease such as that which has been characterized in the Hepa 1 cell line and liver cytosols from the C57 mouse (Poland \& Glover, 1988). Similar sized bands are not evident in the belAHR TNT lanes.

In a further attempt to characterize the bands detected by SA-210, we obtained a second antibody, Bear 2, which was a gift from Dr. R. S. Pollenz. Bear 2 is also a polyclonal antibody against the mouse AHR b-1 allele, but to the expressed $\mathrm{N}$-terminal 415 amino acids of the protein (Figure 6). Figure 10 shows two Western blots of gels run with identical selected 98-1 cytosol samples under identical conditions except that one was probed with the SA-210 antibody (Figure 10a), and one was probed with the BEAR2 antibody (Figure 10b). By comparing the TNT-expressed belAHR in both blots, it is evident that Bear 2 does not recognize the full length pSP64belAHR expression product 
as well as does SA-210. It is therefore not surprising that bands of equivalent size to belAHR are extremely faint in liver and lung lanes of the Bear 2 blot, while they are very evident in the SA-210 blot. The larger bands in spleen and thymus were not detected, and no bands were detected in heart. Surprisingly, a very strong band was detected in spleen. Overlaying the 2 exposures revealed that the spleen band detected by BEAR2 is smaller than the bands detected by SA-210 in spleen, thymus and lymph node (Figure 11). All other faint bands detected by BEAR 2 correspond to the bands of expected size detected by SA-210. This suggests that the bands recognized by both antibodies are AHR, or both antibodies are capable of recognizing the same non-specific protein.

A possible explanation for the multiple bands observed in samples probed with SA-210 is that this antibody is recognizing proteins that are related to the AHR. The AHR repressor is a recently discovered protein that is a member of the bHLH-PAS protein family that shares homology with the AHR, particularly at the $\mathrm{N}$-terminus (Mimura et al., 1999). Figure 9 shows that SA-210 cross reacts readily with the in vitro expressed mouse AHRR protein, which has a predicted size of $78 \mathrm{kDa}$, and an apparent size of $\sim 84 \mathrm{kDa}$. Intriguingly, this is similar in size to the $\sim 90 \mathrm{kDa}$ bands detected in heart and liver of beluga 98-1 and 98-2, and the smallest band ( $82 \mathrm{kDa})$ detected in $98-1$ liver. In contrast, BEAR2 detects mouse AHRR only weakly. Neither antibody detects human ARNT.

Curiously, a less intense but readily visible band of $95 \mathrm{kDa}$ was recognized by SA-210 in the mo AHRR and huARNT TNT lanes (Figure 10). In previous experiments, this band has been observed in unprogrammed lysate, but only after 
overexposure of the blot. Since the band was detected in rabbit cell lysate using a polyclonal primary antibody and anti-rabbit secondary antibody, in the past we have regarded it as non-specific. However, with the batch of TNT lysate used in this experiment, this $95 \mathrm{kDa}$ band is obvious and is the same size as the smaller bands in liver, lung, spleen, thymus, and lymph node. The cloned rabbit AHR when expressed in a rabbit reticulocyte lysate in the presence of $\left[{ }^{35}\right] \mathrm{S}$ methionine has an apparent size of 94 $\mathrm{kDa}$ (Takahashi et al., 1996), the same size as the band observed here. Further, when a gel with TNT lysate, liver and lung cytosol was stained with Coomassie blue instead of transferred to a membrane, there were no outstanding bands in the size range in question that might implicate non-specific interactions from overloaded protein (data not shown). Therefore, the band detected in the TNT lysate might be AHR, as discussed below.

\section{Detection of AHR transcripts from total RNA from various tissues}

Relative RT-PCR was used to detect AHR transcripts in several tissues of beluga sampled in 1998. The AHR mRNA expression was normalized to $\beta$-actin and compared to results obtained by velocity sedimentation and western blotting, as well as to results obtained by other investigators in other species. Figure 12 shows results of a representative experiment in which AHR and $\beta$-actin transcripts were measured using the optimized conditions arrived at as described in the Methods: 28 cycles using $4 \mu \mathrm{cDNA}$ per $100 \mu$ reaction. Beluga AHR transcripts are clearly expressed in all tissues. Normalizing to actin and repeating the experiment did not reveal any differences in tissue-specific AHR expression that were observed consistently between experiments or 
between animals (Figure 13). However, the expression levels in liver were consistently no less than $90 \%$ of the maximum. Because expression levels so close to liver were not expected, and because liver was used to optimize the assay, the experiment was repeated with fewer cycles to see if the conditions might show greater resolution of relative expression among tissues. When 25 cycles was used, liver clearly expressed the highest levels of AHR in both animals. When normalized to the maximum amount of expression, 25 cycles exposes lower relative expression in the heart and testis of both animals, and lower expression in spleen of $98-2$, but not in $98-1$. Figure 14 shows that no bands were observed in tubes where reverse transcriptase was not present, indicating that all PCR bands are derived from RNA message, and not contaminating genomic DNA. Taken together, the overall expression trends indicate that the tissues exhibiting the highest AHR mRNA expression are liver, lung, and kidney, tissues expressing high levels are thyroid, spleen, thymus, lymph node, and adrenal, and relatively low amounts of AHR mRNA was detected in heart and testis.

\section{Detection of full length belAHR transcripts in tissues}

As a means of probing for transcripts of alternative lengths, and to support further the relative RT-PCR results, the full-length AHR was amplified from one sample of each tissue from the 1998 belugas. The primers were the same primers derived from 5' and 3' RACE products that successfully amplified the full AHR coding region from beluga liver (Chapter 2). A product of expected size $(2.5 \mathrm{~kb})$ was detected in all tissues tested. Again, liver produced the most prominent band, which had an optical density 2 -fold 
greater than that from lymph node. Lung, spleen, thymus, and adrenal were all amplified to similar degrees, and only slightly less signal was observed in heart, testis, thyroid and kidney. The conditions for the full-length amplification were not optimized for comparisons of relative expression.

\section{DISCUSSION}

In order to further characterize the cetacean AHR and understand the potential for AHR-dependent toxic effects in cetaceans, the tissue-specific expression of the AHR was examined in the beluga. Three methods were employed to quantitate AHR, and each measured different properties of the AHR: sucrose gradients measured the AHR ligand binding, western blotting measured protein occurrence in the cytosol, and RT-PCR measured AHR transcription. These results show that 1) AHR mRNA is expressed in all tissues examined, 2) AHR protein is prevalent in lung, liver, and lymphoid organs, but is not as prevalent in heart, testis, and adrenal, and 3) the minimal detection of AHR binding by extrahepatic tissues could be indicative of low AHR expression in these tissues, but in light of the AHR mRNA and AHR protein data, inadequate sample quality is a more likely reason. Taken together, these results are consistent with tissue-specific pathologies observed in cetaceans and suggest that the AHR and its ligands could play an important role in cetacean disease.

AHR message is expressed in many beluga tissues 
RT-PCR was used to assess the relative expression of AHR in eight tissues from 2 individual adult male belugas. The relative RT-PCR protocol, which was shown to have a linear range of detection of at least a 4 fold difference in cDNA (Figure 4b), detected reverse transcribed mRNA in all tissues examined (Figure 12). This is consistent with results of other investigators who have measured AHR mRNA expression in human, mice, and rats (Carver et al., 1994; Dolwick et al., 1993; Li et al., 1994). The beluga tissues with the highest expression relative to actin were liver, lung, and kidney, followed by spleen, thymus, lymph node and thyroid. (Table 1). Table 2 summarizes results of studies in other mammals and displays the relative abundance of AHR detected in each tissue, as well as the species and method used. For the AHR RNA detection methods listed, all investigators observed very high expression of AHR in the lung. Although substantial expression in the lung was seen here, the highest levels of expression were consistently observed in the liver (Figures 12-14). The patterns of beluga RNA expression follow more closely the pattern of the rat, with high RNA expression observed in liver, thymus, and kidney (Carver et al., 1994). These trends differed from the patterns for human, for which high AHR mRNA expression was found in heart and placenta (Dolwick et al., 1993).

The goal for these experiments was to assess patterns of tissue-specific expression in beluga, and observe where AHR mRNA tissue-expression patterns might differ from those of other mammalian species. Such differences were not observed. Thus, the observation that AHR message is readily detected in all tissues examined from 2 healthy beluga suggests that AHR protein may normally be expressed in all tissues of beluga. 
AHR protein is immunodetected in many tissues

In beluga $98-1$, a band of $\sim 107 \mathrm{kDa}$ was observed in almost all tissues. The same sized band was detected in the lung of $98-2$. This was the same size as the in vitro expressed beluga AHR that was confirmed to be AHR in previous chapters. Therefore, we conclude that the $107 \mathrm{kDa}$ band is beluga cytosols is the AHR. The relative expression pattern of this $\mathrm{AHR}$ is lung $>$ liver=spleen=thymus=lymph node $>>$ testis $=$ thyroid; no protein of this size was immunodetected in the heart. However, smaller bands $(\sim 80-95 \mathrm{kDa})$ were detected in the liver, heart, lung, spleen, thymus, and lymph node of 98-1, and liver, heart, spleen, kidney, and adrenal gland of 98-2. Non-specific binding is always a possibility when polyclonal antibodies are used, since a number of different epitopes may be recognized, thus increasing the odds for non-specific interactions. Interpretation was further hampered by the limited ability of BEAR2 to detect beluga AHR. In light of what is known about the physiochemical properties, regulation, and evolution of the mammalian AHR, the presence of the smaller immunodetected bands could reflect: 1) products of proteolysis during autolysis, 2) post-translational modification of AHR, 3) an AHR-related protein, 4) an alternative splice product of the AHR, or 5) an altemative AHR allele or gene.

Possible interpretations for multiple bands

Proteolysis occurs in tissues via targeted, necrotic, or autolytic pathways. Proteolysis as a result of autolysis is an especially important concern for these beluga 
samples because it was logistically impossible to sample the tissues immediately after death. Most AHR studies have been conducted in laboratory rodents that can be conveniently sampled immediately post-mortem. However, even in rapidly preserved samples the AHR is well known to be very sensitive to post-mortem degradation. For example, the mouse AHR ( $\mathrm{Ah}^{\mathrm{b}-1}$ allele) is degraded by a calcium-dependent protease that generates a $70 \mathrm{kDa}$ peptide that retains its binding properties (Poland \& Glover, 1988). The degradation was so rapid that only perfusion of the mouse liver with EDTAcontaining buffer before homogenization could minimize its occurrence. A similar-sized band was observed here in a 90 minute mouse AHR TNT reaction, although whether this band is a proteolytic product was not tested. (Figures $8,9,10$ ). Further, it has been shown that other mouse alleles (such as the mouse AHR b-2, b-3 and d alleles are even more labile than the b-1 allele in vitro (Poland \& Glover, 1990; Poland et al., 1994). In another study, these same authors also note "two to three other peptides" in mouse liver cytosol with molecular masses between 70 and $95 \mathrm{kDa}$ which also bind to ligand specificially (Poland et al., 1986). In a study that monitored the disappearance of AHR after nuclear translocation, the investigators observed bands of slightly smaller molecular weight than the AHR in rat spleen, thymus, and lung (Pollenz et al., 1998). The authors described these bands as non-specific. However, since the intensity of the smaller bands appear to correlate with the intensity of the AHR band, it seems possible that these bands are proteolytic products of an $\mathrm{N}$ or $\mathrm{C}$-terminal amino peptidase that does not affect critical epitopes. Huska et al. (1998) found multiple bands, including a very prominent $50 \mathrm{kDa}$ band, that were immunodetected during the developmental stages of mouse mammary 
epithelium. These authors interpreted these as proteolytic fragements despite their use of protease inhibitors in buffers (Hushka et al., 1998). Thus, the beluga AHR as well may be especially sensitive to proteolysis.

The reason for the rapid autolysis of AHR may be related to its mechanism of regulation. A growing number of studies are revealing that targeted proteolysis of the AHR is important for ligand-dependent regulation of the AHR (Davarinos \& Pollenz, 1999; Lees \& Whitelaw, 1999; Pollenz, 1996; Pollenz et al., 1998; Roberts \& Whitelaw, 1999). After translocation to the nucleus and gene induction, the AHR is exported back to the cytosol, ubiquinated, and degraded by a proteosome complex (Roberts \& Whitelaw, 1999). Therefore, the fragments observed in cytosols of laboratory rodents and beluga may reflect breakdown of the proteosome complex during post mortem autolysis, which could account for the rapid, yet incomplete AHR degradation.

The degree of proteolysis should increase with time lapsed between death and sampling. The disappearance of the belAHR $107 \mathrm{kDa}$ band and smaller bands seems to reflect this trend: as the post-mortem sampling delay increases as represented by $98-1$ (freshest, about 60-90 min post-portem time to sampling), 98-2 (about 3-4 hours) , 97-1 (4-5 hours), 97-2 (5-6 hours), and 97-3 (6-8 hours, longest post mortem-sampling delay), the larger bands in each respective tissue cytosol disappear (Figures 7-8).

The BEAR2 and SA-210 antibodies dectected major bands in spleen that were distinct in size. One of the bands recognized by SA-210 was the full-length AHR. The single small band recognized in spleen by each antibody is distinct in size from one another. This is intriguing, particularly since Bear 2 does not recognize the full-length 
beluga AHR well relative to the mouse AHR. To presume that either band is nonspecific binding seems improbable. One interpretation is that different proteolytic fragments could differ in their recognition by different antibodies, and particularly those raised against truncated proteins (instead of full-length proteins). If proteolysis exposes an epitope that is conserved among species, it is conceivable (though improbable) that a peptide fragment of a whale AHR could be detected more easily than the full length whale AHR by an antibody raised against mouse AHR. A satisfactory interpretation for these results is not forthcoming.

The second possibility for the multiple bands detected in the western is that the prominent $\sim 95 \mathrm{kDa}$ is a product of post-translational modification. The TNT reactions used for the mouse AHRR and the human ARNT proteins (Figures 7-11) are accomplished in lysate that is derived from rabbit reticulocytes, presumably harvested from the blood or spleen, a secondary site of hematopoeisis in rodents. Reticulocytes are immature erythrocytes that have recently expelled a nucleus and are poised to lose mitochondria and ribosomes, at which point they are mature erythrocytes (Kuby, 1998). Studies with chimeric AHR knockout mice show that AHR-dependent TCDD toxicity occurs in hematopoetic precursor cells in bone marrow (Staples et al., 1998). A high proportion of the spleen, thymus, and lymph node tissues are lymphocytes. Since these and reticulocytes are derived from a common precursor cell, the detected band in the TNT may be related to the second, smaller band detected in beluga spleen, thymus, and lymph node. The cloned rabbit AHR when expressed in a rabbit reticulocyte lysate in the presence of $\left[{ }^{35} \mathrm{~S}\right]$-methionine has an apparent size of $94 \mathrm{kDa}$ (Takahashi et al., 1996), the 
same size as the band observed here. The rabbit AHR is 847 amino acids in length, which is very similar to the beluga AHR (845 aa) and the human AHR (848 aa). The predicted sizes of these proteins are $96.1,95.5$, and $94.4 \mathrm{kDa}$ for human, beluga, and rabbit AHRs, respectively. The sizes of the AHRs as determined by photoaffinity labeling is $\sim 110 \mathrm{kDa}$ for both human HeLa cytosol and the TNT-expressed huAHR clone (Dolwick et al., 1993), $\sim 110 \mathrm{kDa}$ for beluga cytosolic liver AHR (Hahn et al., 1994), and $104 \mathrm{kDa}$ for rabbit cytosolic liver AHR (Poland \& Glover, 1987). In contrast, using the TNT expression system, apparent sizes of human and beluga AHRs are equal, $\sim 107 \mathrm{kDa}$ (human AHR data not shown) and the rabbit AHR is $94 \mathrm{kDa}$ (Takahashi et al., 1996). It is possible that some post-translational modification may be occurring for the rabbit in the conspecific rabbit reticulocyte lysate environment that is not occuring with the in vitro expressed beluga and human AHRs, but is occurring in the beluga cytosols, particularly the lymphatic tissue cytosols. Not much is known about post-translational modification of the AHR, and it is interesting to consider the possibility that the $107 \mathrm{kDa}$ and $95 \mathrm{kDa}$ bands represent latent and activated forms that contribute to tissue-specific susceptibility to AHR ligands. This is pure speculation, however, since deviations from predicted molecular weights are common, and there is no evidence of post-translational modification of AHR size in any other system examined thus far.

Another possibility for the identity of the alternate bands detected in the western blots is that they are AHR-related proteins that are cross-reacting with the SA-210 antibody. The antibody SA-210 recognizes belAHR better than does BEAR2 (Figure 10), which may be because the epitopes recognized by SA-210 are more highly 
conserved than those of BEAR2. Because the $\mathrm{N}$-terminus of the AHR includes the conserved bHLH and PAS domains (Figure 6), it seemed possible that SA-210 might be recognizing epitopes that are conserved among related proteins as they are conserved across species. To test this, we included an in vitro expressed mouse AHR repressor, and an in vitro expressed human ARNT protein on gels that were blotted with both antibodies.

AHRR is a newly discovered PAS protein that is induced by AHR activation and blocks AHR binding with ARNT. The potential for 3- methylcholanthrene (3MC) induction is tissue-specific, with the highest AHRR mRNA levels detected in mouse heart and lung (Mimura et al., 1999). The AHR repressor shares high sequence identity with the moAHR, as high as $81 \%$ in the bHLH domain and $60 \%$ in the PAS-A domain. The PAS-B characteristics are absent, and the C-terminus shares only $19 \%$ amino acid identity with AHR (Mimura et al., 1999). ARNT is the nuclear dimerization partner for the AHR, which shares about $19 \%$ amino acid identity with AHR in the bHLH-PAS domain (Gu et al., 2000). We noted earlier that the SA-210 antibody does not cross-react with rodent ARNT, and as expected, SA-210 did not reveal a human ARNT band (Figure 10). This suggests that none of the cross-reacting bands are beluga ARNT. However, SA-210 (but not BEAR2) detected the mouse AHR repressor (AHRR). Intriguingly, the only band detected in heart and the smallest band detected in liver are similar in size to the mouse AHRR. Despite this interesting possibility, we must interpret with caution, since we know nothing about the existence, size structure, or regulation of a beluga AHRR. 
Another possible reason for the multiple bands is the occurrence of splice variants. Many splice variants have been identified in AHR and in other PAS proteins. We screened for particular types of splice variants by using the primers designed to amplify the full length $\mathrm{AHR}$ in beluga liver. A product that corresponded to the complete beluga AHR coding region was amplified in all tissue types (Figure 13). This allowed us to rule out the occurrence of any splice variant that utilizes the same start and stop codons, unless the splicing event results in a transcript of exactly the same size. This includes most types of splice variants, including an optional exon, an optional intron, mutually exclusive exons and internal spice sites, since in most cases these splicing events produce a final transcript of a different size. Examples of alternate splicing events have been described for AHRs in several species. For example, a rare variant in the Sprague-Dawley rat has a 699 bp deletion spanning exons 5-8 (Carver et al., 1994). The TCDD-resistant Han/Wistar rat has a mutation in a splice site that causes the random use of cryptic splice sites. This results in 3 discernable transcripts, 2 with insertions and 1 with a deletion (Pohjanvirta et al., 1998). Similar splicing events in beluga would have been detected using these primers, since the original stop codon (though not used in the translated products in the $\mathrm{H} / \mathrm{W}$ rat) was still present in the transcripts.

This full-length PCR test could not, however, detect splice products that arise from an alternative use of $5^{\prime}$ start sites or 3' termini, for which there are many examples among PAS proteins. The only AHR example is the Fundulus AHR1 $\beta$, which exhibits a rare alternate 3'coding region with a unique stop codon and UTR (Karchner et al., 1999). Similarly, apparent alternate splice products of rainbow trout ARNT (rtARNTa and 
rtARNTb) have unique carboxy-termini (Pollenz et al., 1996). Hif-1 $\alpha$ undergoes splicing to accomplish two dominant forms with alternative exons 1 (Wenger et al., 1997). When such products are the result of regulated alternative splicing, then different products often have tissue-specific or condition-specific patterns of mRNA expression. When the alternative splicing is consitutive, both products are expressed, but may be regulated at the protein level (Alberts et al., 1994). These examples and others suggest that constitutive and regulated alternative use of 5' and 3' ends are a common theme in PAS proteins. Therefore we cannot confirm nor rule out the possibility that the bands detected by western blotting arise from alternative splicing events without further study.

Another interesting possibility is that the SA-210 antibody is recognizing products from different genes or alleles. There are many examples of strain-specific alleles as well as multiple gene isoforms in the PAS protein family. For example, there are at least four, well-characterized AHR alleles in various mouse strains that represent 2 different sized proteins (Poland et al., 1994). Two alleles have been well characterized in rat strains, and these also are very different in size (Pohjanvirta et al., 1999; Poland \& Glover, 1987). At least 3 alleles occur in humans, though all result in single amino acid changes ( 1 in exon 2 and 2 in exon 10) and do not appear to change the protein length (Kawajiri et al., 1995; Smart \& Daly, 2000). Most PAS proteins to date are shown to exist as paralog groups (e.g. SIM1 and SIM2). Paralog groups are generally believed to arise from a gene duplication event, though alternative scenarios have been suggested (Hahn et al., 1997). In the case of the AHR, both members of the paralog group (AHR1 and AHR2) have been identified in the mummichug (Karchner et al., 1999), while the 
non-mammal-like isoform (AHR2) has been found in zebrafish (Tanguay et al., 1999) and rainbow trout (Abnet $e t$ al., 1999). The second isoform, which appears to be the more ubiquitous form in fish, has not been identified in mammals despite extensive effort. The observation that two predominant bands were detected in lung, spleen, thymus, lymph node, and possibly liver, is intriguing in this light. The validity of these speculations may be clarified with further study.

Lack of substantial TCDD Binding in extrahepatic tissues

Velocity sedimentation on sucrose gradients was not particularly useful for comparing AHR in these beluga tissues. The low or undetectable specific binding in extrahepatic tissues could be because 1) the AHR protein was degraded, 2) the AHR protein has minimal or no binding function, and/or 3) the concentration of AHR was too low to detect in these samples. These possibilities are not mutually exclusive. From the western blot data, we favor the interpretation that proteolysis has, at least in part, affected the detectable AHR protein pool and these effects become more significant as the postmortem time before sampling increases. The observation that minimal to no specific $\left[{ }^{3} \mathrm{H}\right]-$ TCDD binding was observed in tissues other than the $98-1$ liver is in accordance with this interpretation, since it was the very first tissue sampled from this animal. Alternatively, some or all of the AHR protein in certain cytosols may be non-functional. An example of an AHR with compromised binding function is the $\mathrm{Ah}^{\mathrm{d}}$ allele. After no specific binding was detected for any tissue in an $\mathrm{Ah}^{\mathrm{d}} / \mathrm{Ah}^{\mathrm{d}}$ mouse (Mason \& Okey, 1982), it was later shown that this was because the product of the $\mathrm{Ah}^{\mathrm{d}}$ protein has a lower binding affinity compared to the $\mathrm{Ah}^{b}$ alleles (Poland et al., 1994). Alternatively, the pool of AHR that 
binds $\left[{ }^{3} \mathrm{H}\right]-\mathrm{TCDD}$ may be a subset of the total cytosolic AHR, and these ratios could be post-translationally regulated and tissue-specific. For example, phosphorylation is involved at several points along the AHR signal transduction pathway. Protein kinase C activity is required for transcriptional activation of the AHR-ARNT-DRE complex (Carrier et al., 1992; Long et al., 1998). Phosphorylation of the AHR occurs upon TCDD binding, suggesting a requirement for phosphorylation in AHR activation (Enan \& Matsumura, 1995). Gradin et al. demonstrated that blocking a tyrosine phosphorylation site within the ligand-binding domain of the AHR inhibited ligand-activated dissociation of Hsp90, but apparently not ligand binding (Gradin et al., 1994). A phosphorylation requirement has not been demonstrated for ligand binding, but it remains a possibility and a reminder of the myriad of modifications that occur in the cell's native environment. If modification that affects TCDD binding does occur in beluga tissues, this would explain the ability to detect AHR by immunoblot despite very low levels of specific binding. At the same time, the fact that specific binding was observed in lung, heart, thymus, and spleen strengthens the argument that the bands detected by western blot for those respective tissues are AHR, and a functional AHR pool exists in these tissues. This is particularly interesting for the heart; since no band of $107 \mathrm{kDa}$ was detected, this suggests that the $\sim 90 \mathrm{kDa}$ band not only may be AHR, but may be TCDD-binding AHR.

To summarize, the most critical data presented in this chapter is the western blot of beluga 98-1 tissues. With support from immunoblots of four other belugas, relative RT-PCR, and specific binding data, we conclude that lymphoid tissues (thymus, spleen, and lymph node) and lung express the highest levels of AHR protein. AHR is expressed 
in moderate to high amounts in liver, and kidney, and low amounts are expressed in testis, thyroid and heart. Given the data in hand, the most likely explanations for the detection of the 107 and $95 \mathrm{kDa}$ proteins in certain cytosols are either proteolysis during early autolysis, or post-translational modification. The evidence from these five beluga shows that the most likely targets for PHAH action via the AHR are the lymphoid organs, lung, liver, and kidney.

\section{Conclusions}

These studies show that the AHR, a factor that is necessary for the toxicity of planar halogenated aromatic hydrocarbons, is ubiquitously expressed at the level of mRNA. Protein levels are relatively high in the lymphoid organs, liver, and lung, implying that these may be targets for toxicity of PHAH and other AHR ligands. These results are consistent with a role for the AHR in apparent immunosuppression in cetaceans with high body burdens of PHAH. Furthermore, relating in vitro and molecular data to field observations is a productive approach for assessing the sensitivity of a species for which dosing studies are logistically and ethically impossible. 


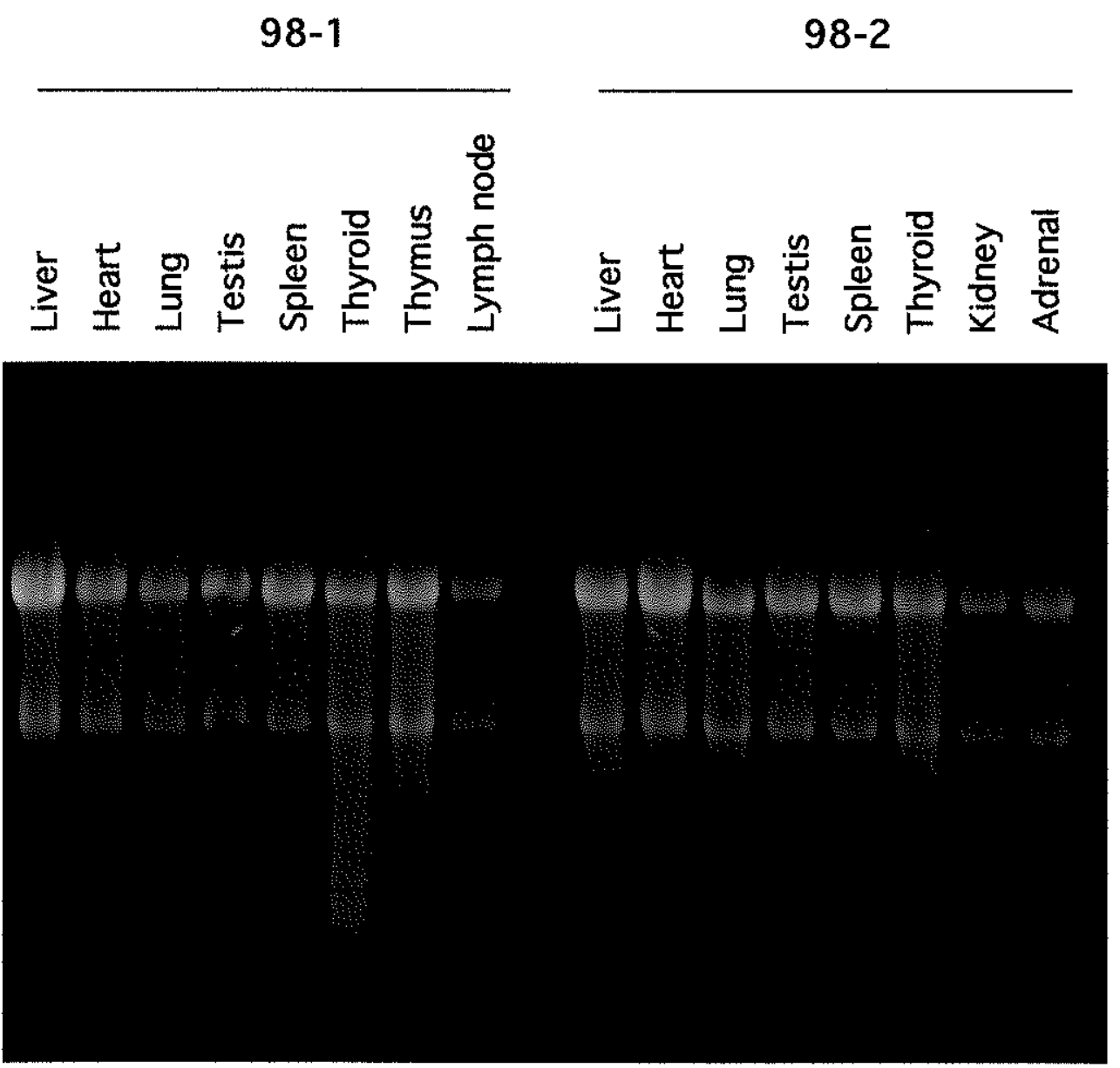

Figure 1. Quality control check for total RNA isolated from various tissues from two individual belugas, 98-1 and 98-2. $5 \mu \mathrm{g}$ RNA (as measured by $\mathrm{OD}_{260}$ ' was loaded in each lane and resolved with electrophoresis on an agarose-formaldehyde gel. 


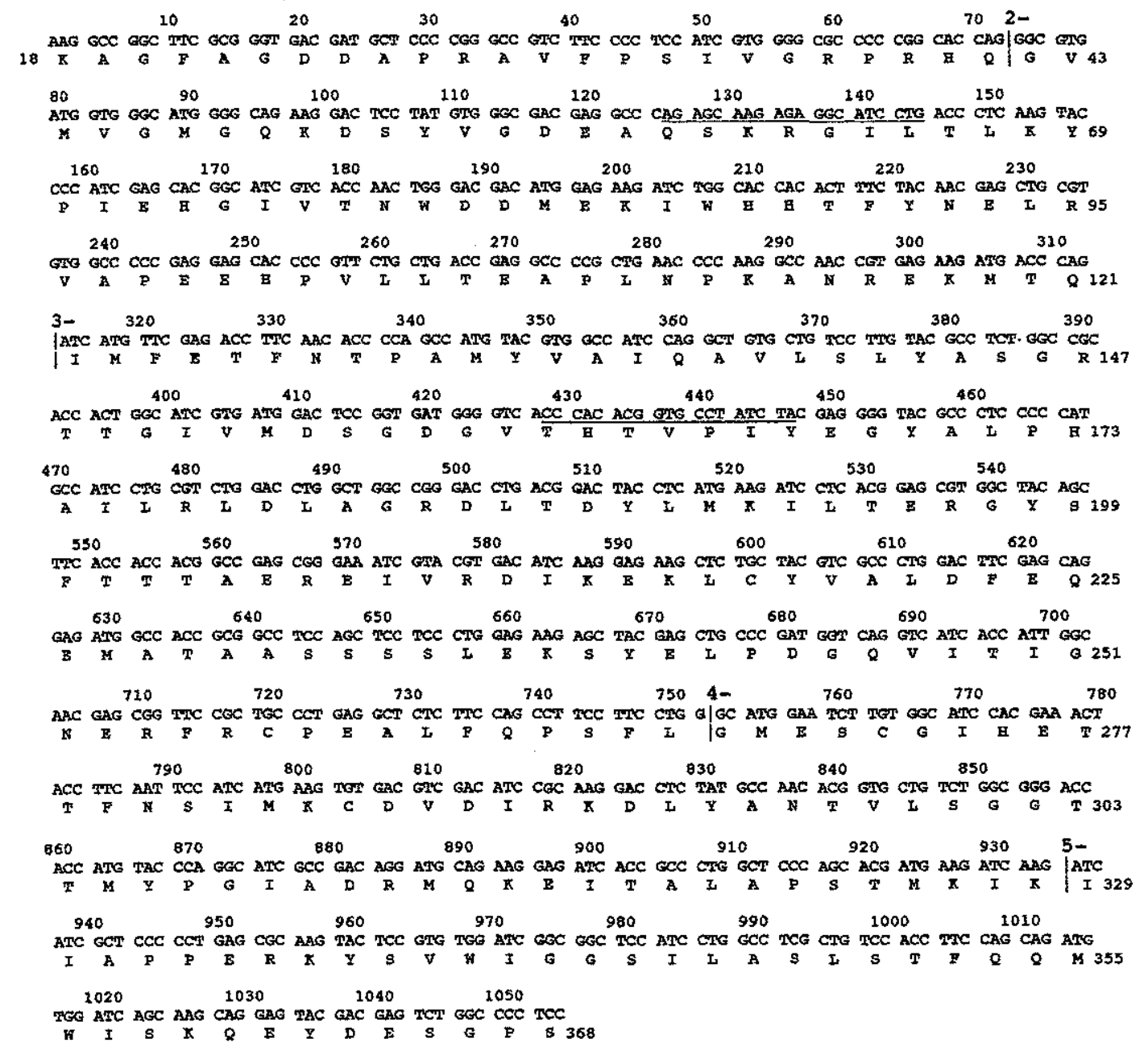

Figure 2. Sequence and translation of partial beluga $\beta$-actin cDNA. Beluga liver mRNA was reverse transcribed to cDNA and amplified using degenerate primers designed to vertebrate $\beta$-actin. Probable exon junctions based on mammalian $\beta$-actins are numbered. Nucleotide numbers correspond to the numbers of the partial sequence, and residue numbers correspond to 375 amino acid mammalian actin sequence. 
A.
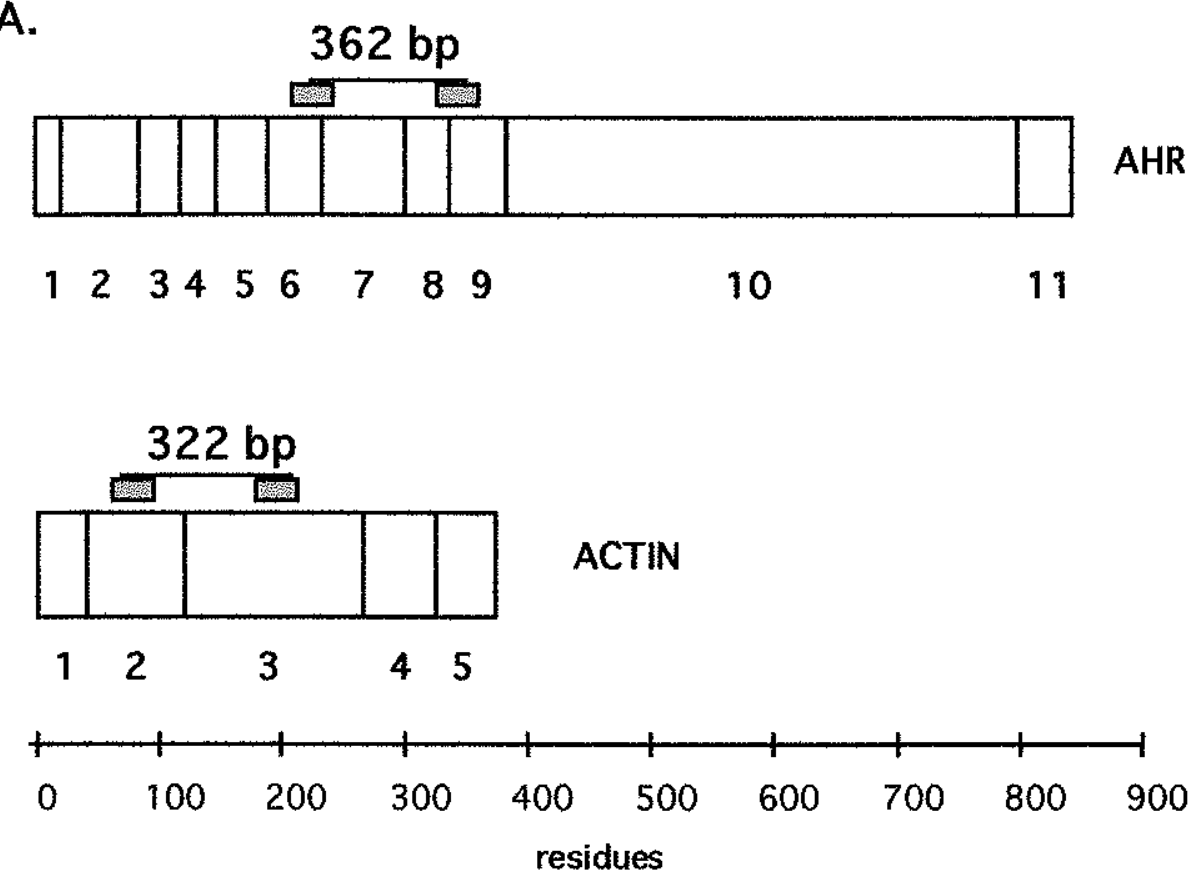

B.

Primer 1: Dlactforw: $\quad$ Primer 2: Dlactback:

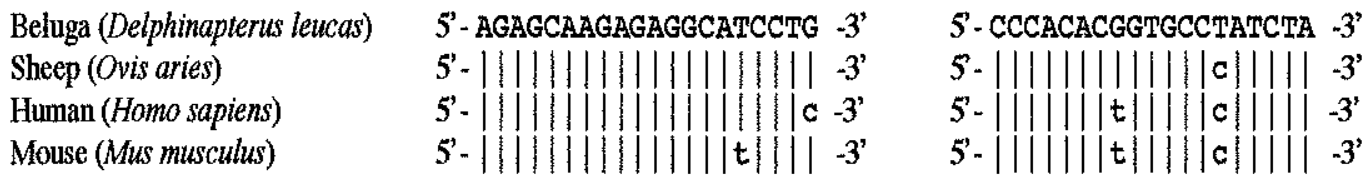

Figure 3. Beluga $\beta$-actin primer design. (A) Schematic of full length AHR and $\beta$ actin cDNAs. Numbers refer to exons deduced from vertebrate sequences. Dark boxes above represent location of target sequences (not to scale). Labeled lines above primers indicate predicted product size. (B) Conservation of nucleotides within primer region for select mammals. 
Figure 4. Parameter optimization for relative RT-PCR with beluga AHR and $\beta$-actin. (A) AHR and actin cycle number optimization. PCR was run with 98-1 and 98-2 beluga liver cDNA derived from total RNA. Reaction with AHR primers were run for $21,24,26,29$, and 35 cycles, and the reaction with $\beta$-actin was run for $20,22,25,28,31,32$, and 35 cycles. $10 \mu \mathrm{l}$ was electrophoresed on a $2 \%$ agarose gel and stained with ethidium bromide. Visualization and densitometry was done using the ChemImager 4000 system. The $Y$ axis represents optical density units measured, minus background. (B) cDNA dilution test. 98-1 liver cDNA was diluted in water up to 8-fold and run with 28 cycles with AHR and $\beta$-actin primers in separate tubes but in the same machine run. Yaxis represents OD units from $10 \mu \mathrm{l}$ as in $\mathrm{A}$. 

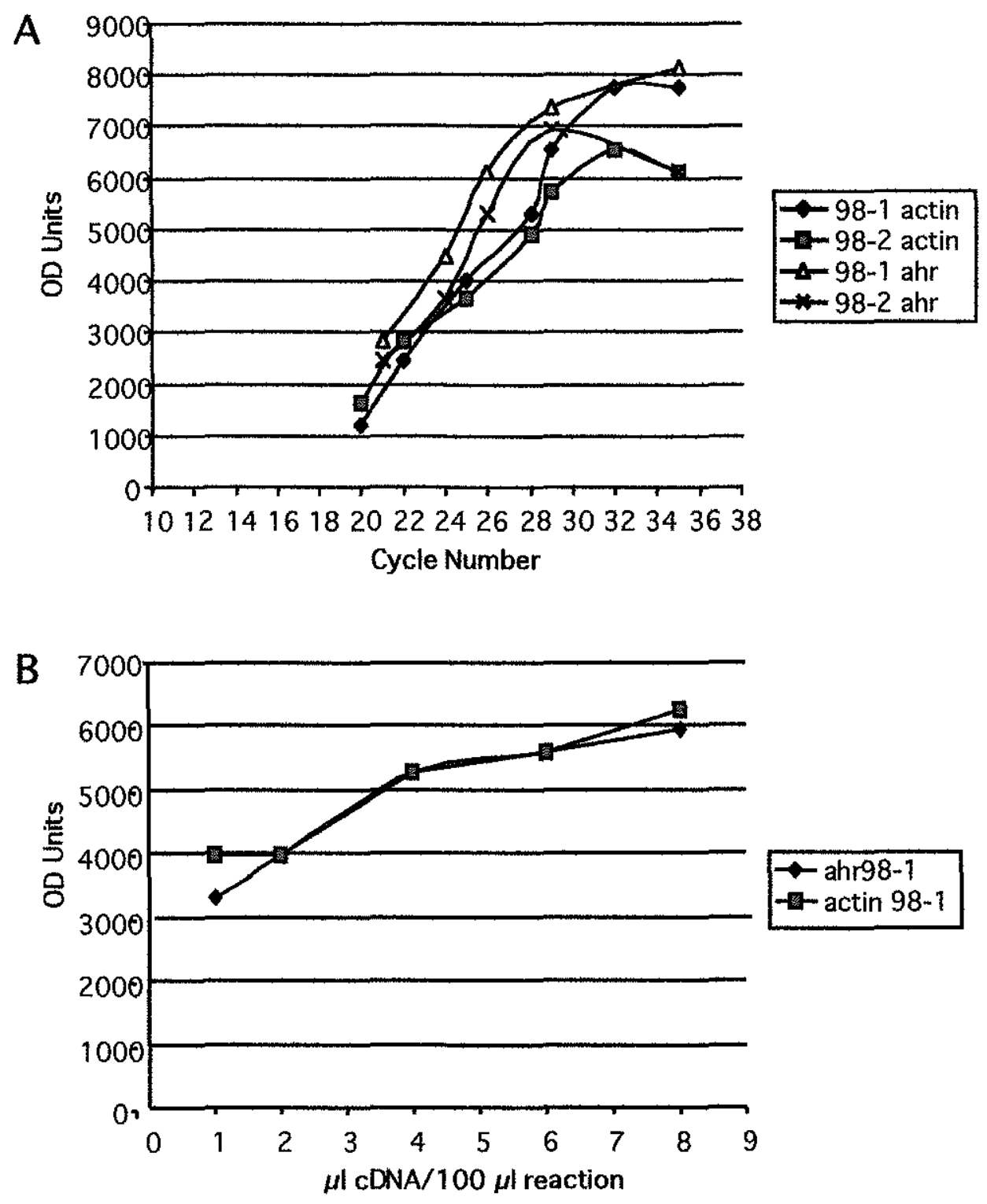

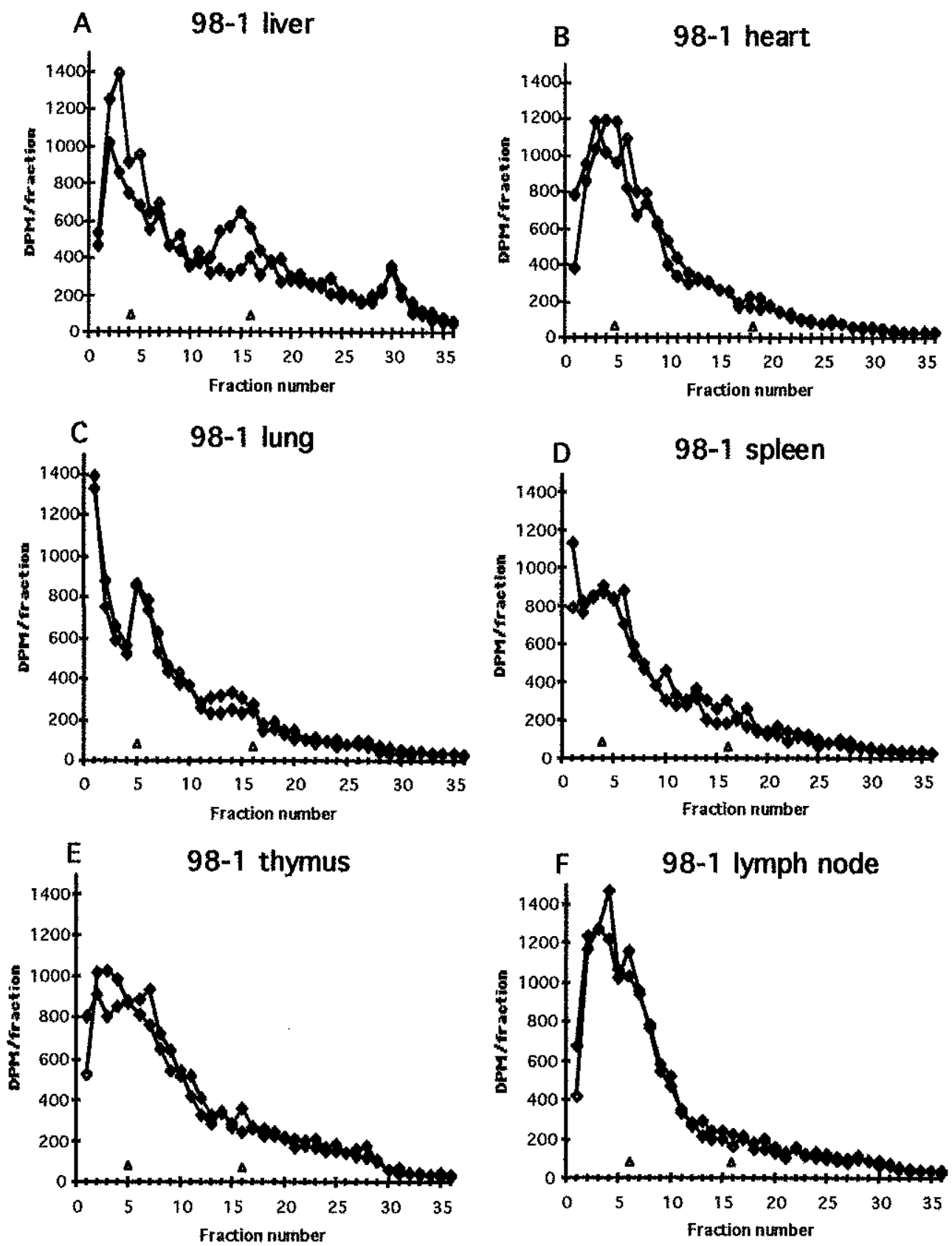

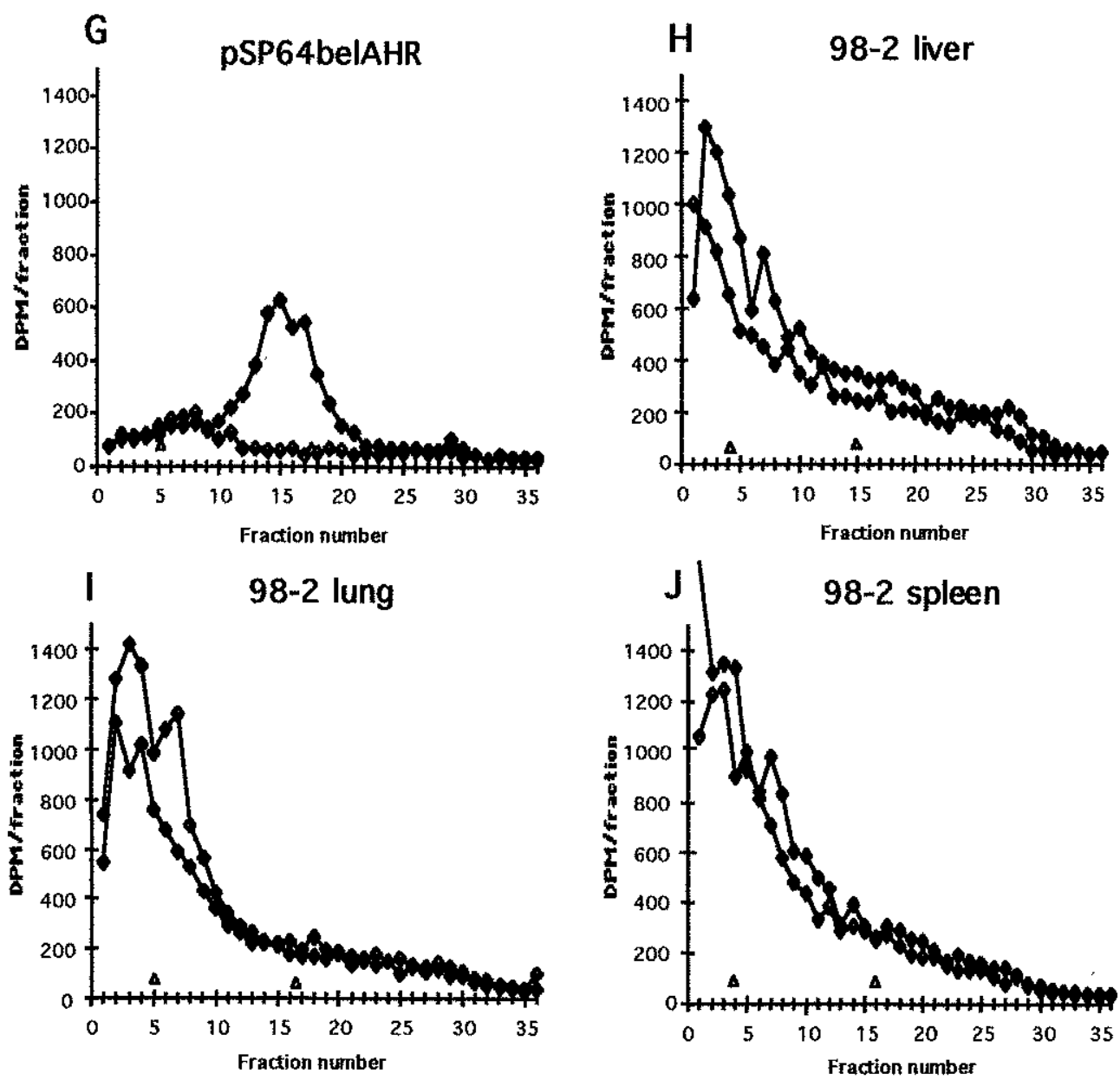

Figure 5. Specific ${ }^{3}$ H-TCDD binding in 98-1 and 98-2 belugas. Cytosols were incubated with 3H-TCDD, plus DMSO or 200-fold excess TCDF, applied to a sucrose gradient and sedimented. Solid diamonds represent total binding disintegrations per minute (DPM) per fraction, hollow diamonds are non-specific binding DPM/fraction. Small triangles indicate peak of ${ }^{14} \mathrm{C}$ labeled $3.6 \mathrm{~S}$ and $11.3 \mathrm{~S}$ protein size standards. Specific binding ( $\mathrm{fmol} / \mathrm{mg}$ ) and sedimentation coefficients are indicated. Panels (A) through (F) show 98-1 tissue cytosols. Panels $(\mathrm{H})$ through $(\mathrm{J})$ show binding in tissue cytosols from beluga 98-2. Panel (G) shows binding of TNT expressed beluga AHR, used as a positive control run for samples in panels (D) through $(\mathrm{J})$. 
154 

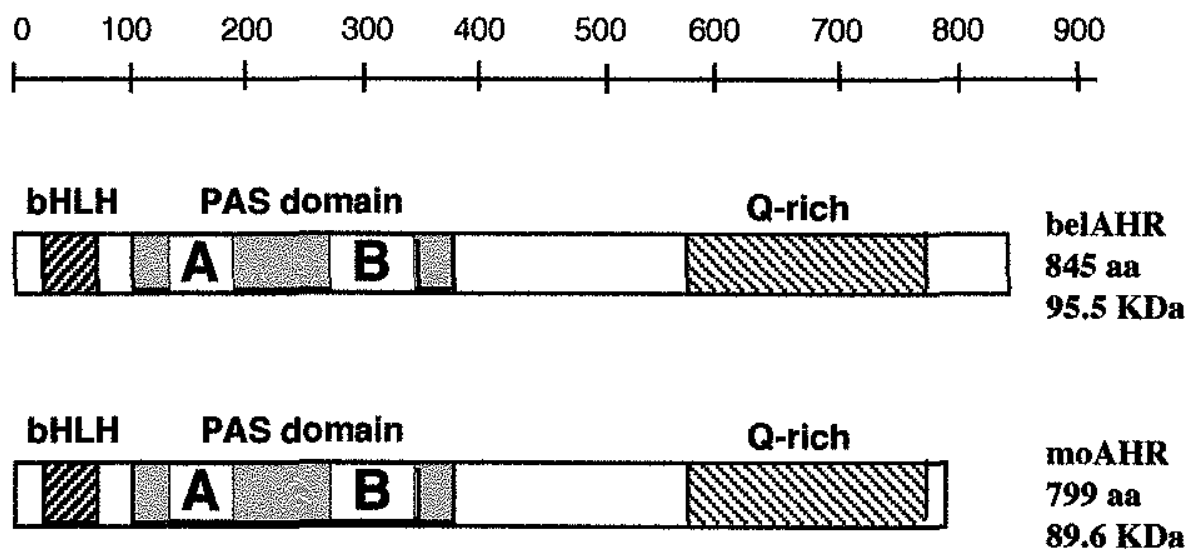

bHLH PAS domain

WEA

SA-210 antigen

402 as

45.7 KDa

bHLH PAS domain

W

BEAR2 antigen

415 aa

$47.5 \mathrm{KDa}$

bHLH PAS domain

MOAHRR

W] A

701 aa

$77.8 \mathrm{KDa}$

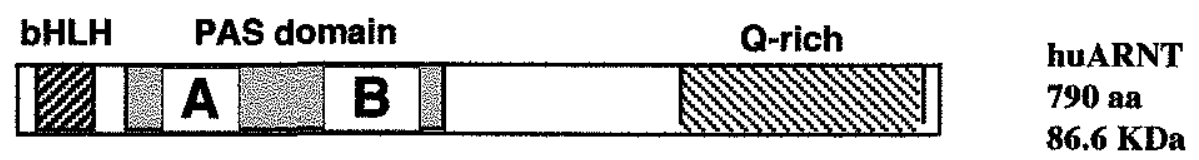

Figure 6. Structures of AHR and related proteins and antigens. General structure and major domains of proteins that were in vitro expressed and used in Western blots as indicated in the text. The protein fragments that were used by others to generate polyclonal antibodies SA-210 and BEAR2 are also shown. 
Figure 7. Western blots of 1998 beluga tissue cytosols. $100 \mu \mathrm{g}$ cytosol protein was separated on a $7 \%$ tris acetate gel, transferred to PVDF membrane and probed with SA-210 rabbit-anti-mouse AHR polyclonal antibody (Biomol). Alkaline phosphatase conjugated goat anti-rabbit ( $\& \& S$ ) was the secondary antibody, and visualization was with Tropix CSPD (Tropix) and exposure to Kodak X-Omat film. The plasmids pSP64belAHR and pSPORTmoAHR were used in a rabbit reticulocyte lysate transcription/translation system (non-radioactive) to serve as positive controls and for size comparisons. (A) shows cytosols from beluga 98-1, and (B) shows cytosols from 98-2. 


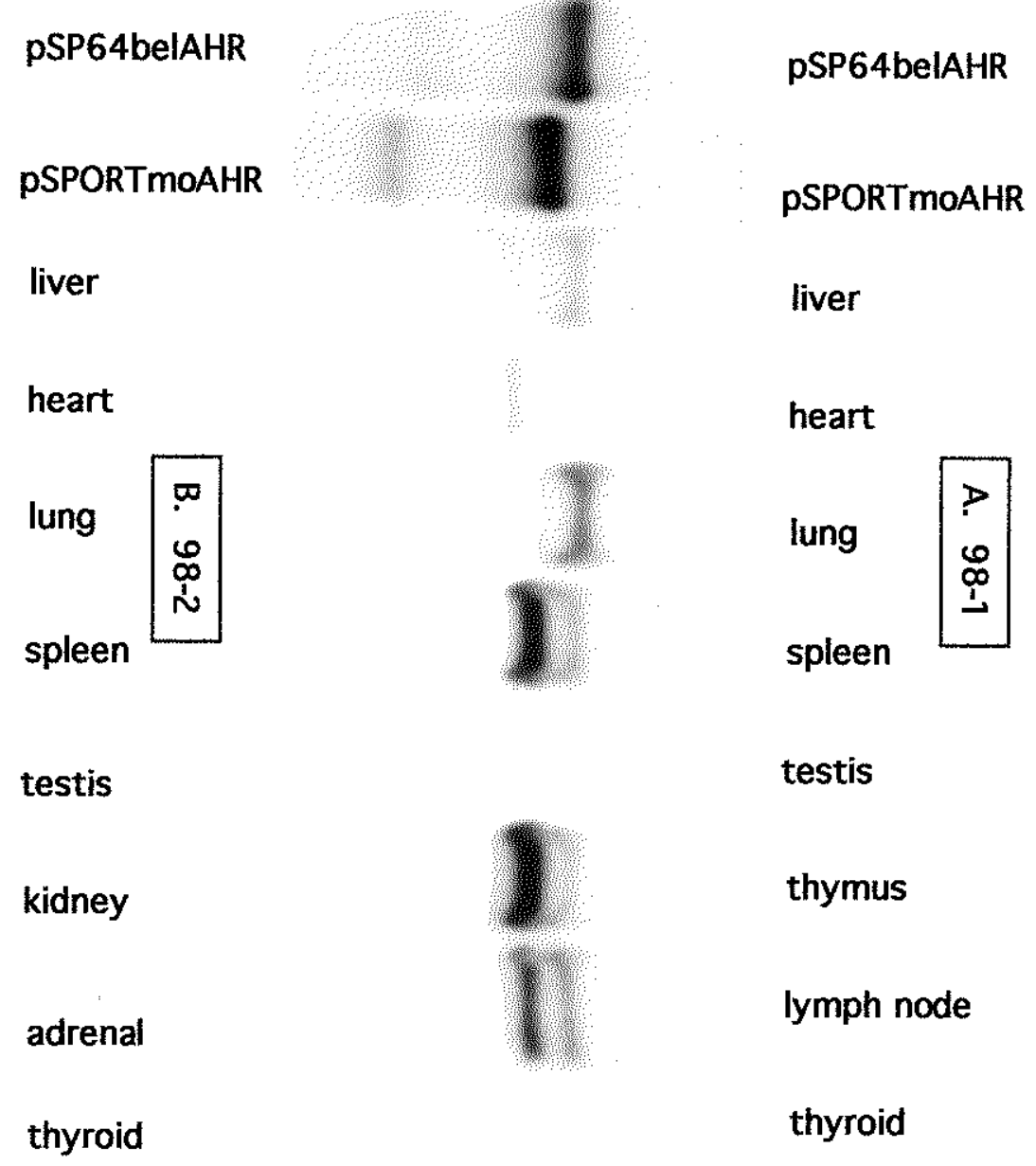


Figure 8. Western blots of $\mathbf{1 9 9 7}$ beluga tissue cytosols. Tissue cytosols were run as in Figure 7, but with cytosols prepared from belugas 97-1, 97-2, and 97-3 as indicated. 


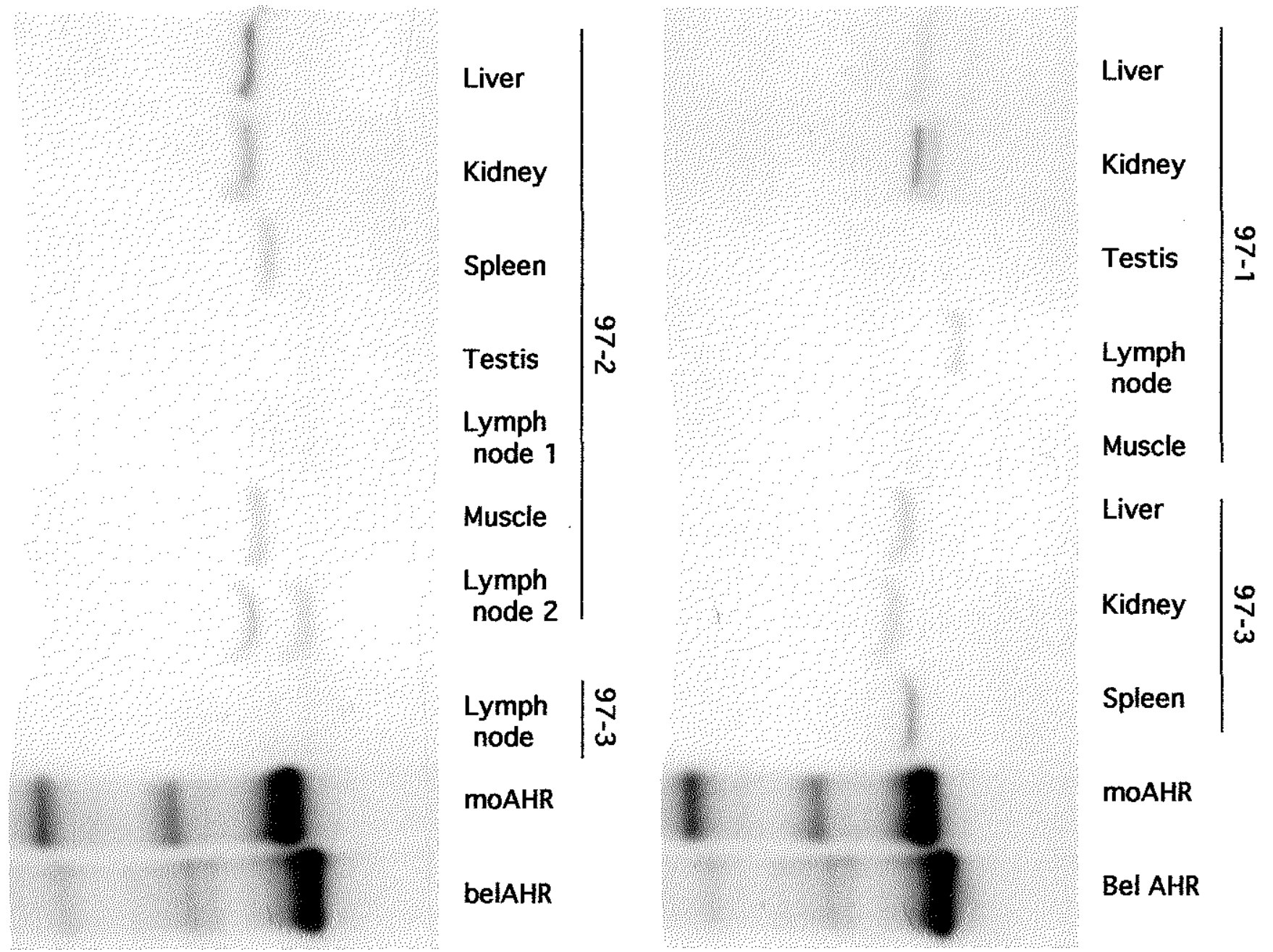


Figure 9. Western blots of 1997 beluga tissue cytosols (alternative view).

Alternative view of Figure 8, with tissues shown in columns for ease of tissue and animal comparison. Relative positions were maintained during manipulation of the image. (A) 97-1 cytosols. (B) 97-2 cytosols. C. 97-3 cytosols. 


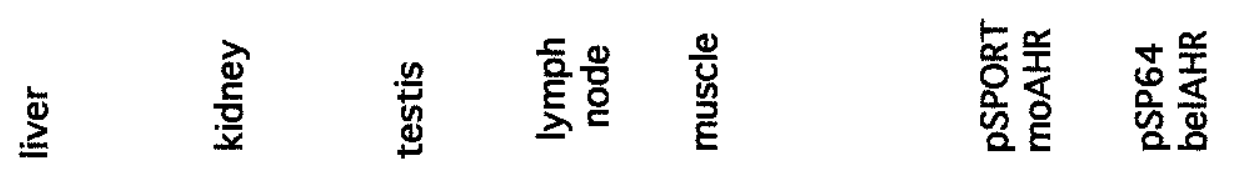
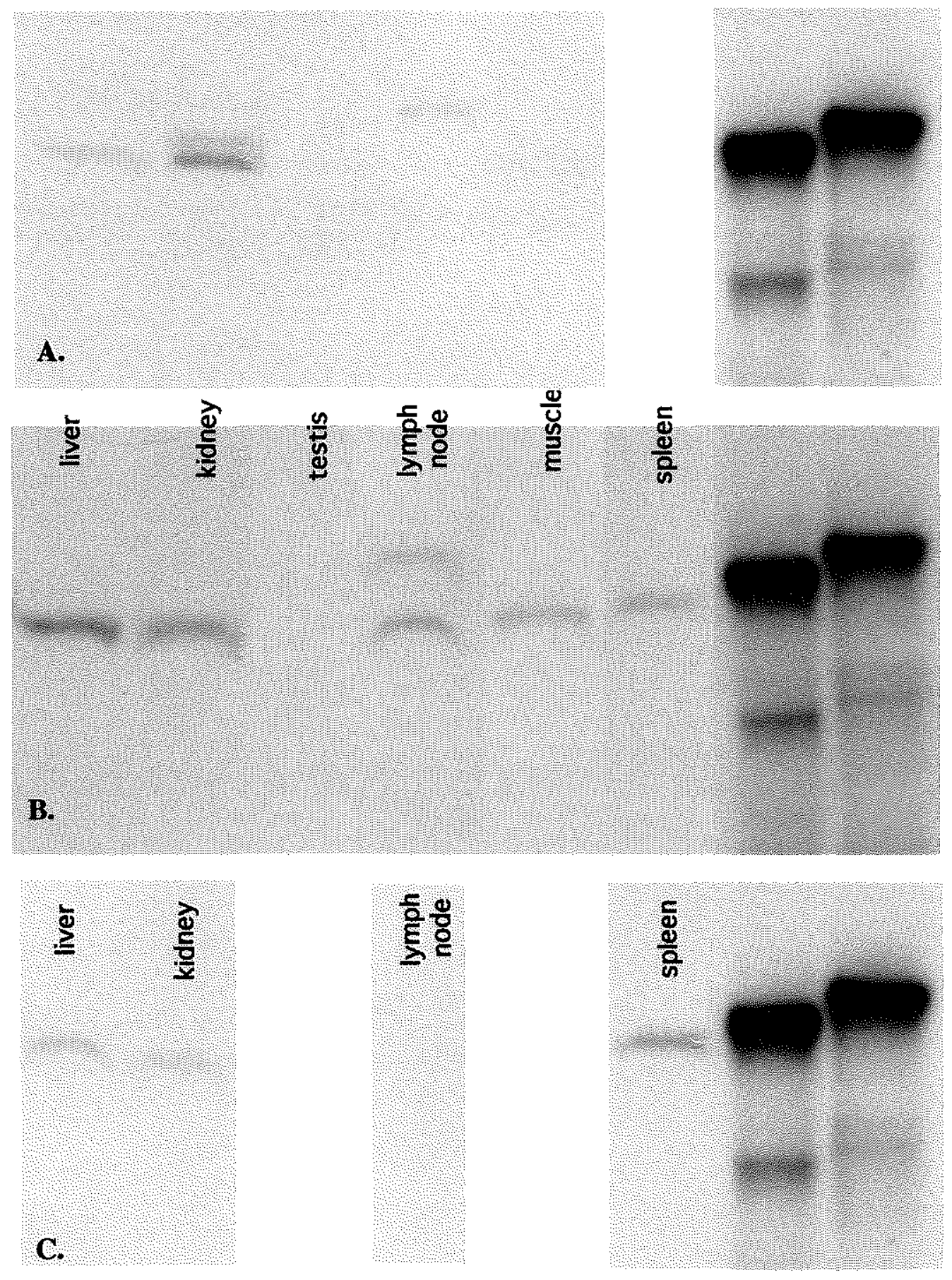
Figure 10. Western blots of 98-1 beluga tissues with SA-10 and BEAR2. Select cytosols from beluga 98-1, plus TNT products of plasmids containing beluga AHR, mouse AHR, mouse AHR repressor, and human ARNT were probed with (A) SA-210 as in Figure 7, or (B) with the same conditions but with BEAR2 primary antibody. 


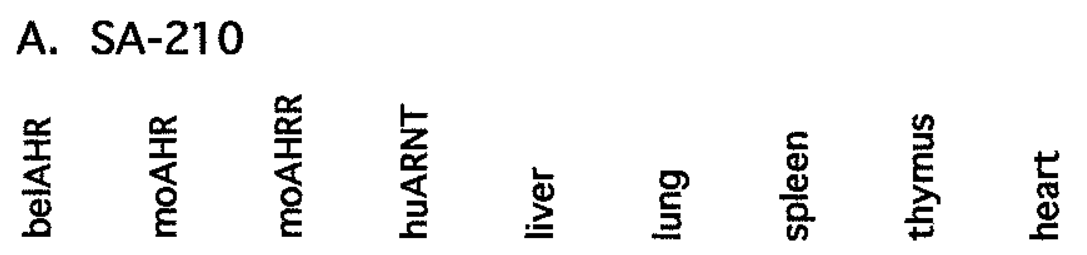

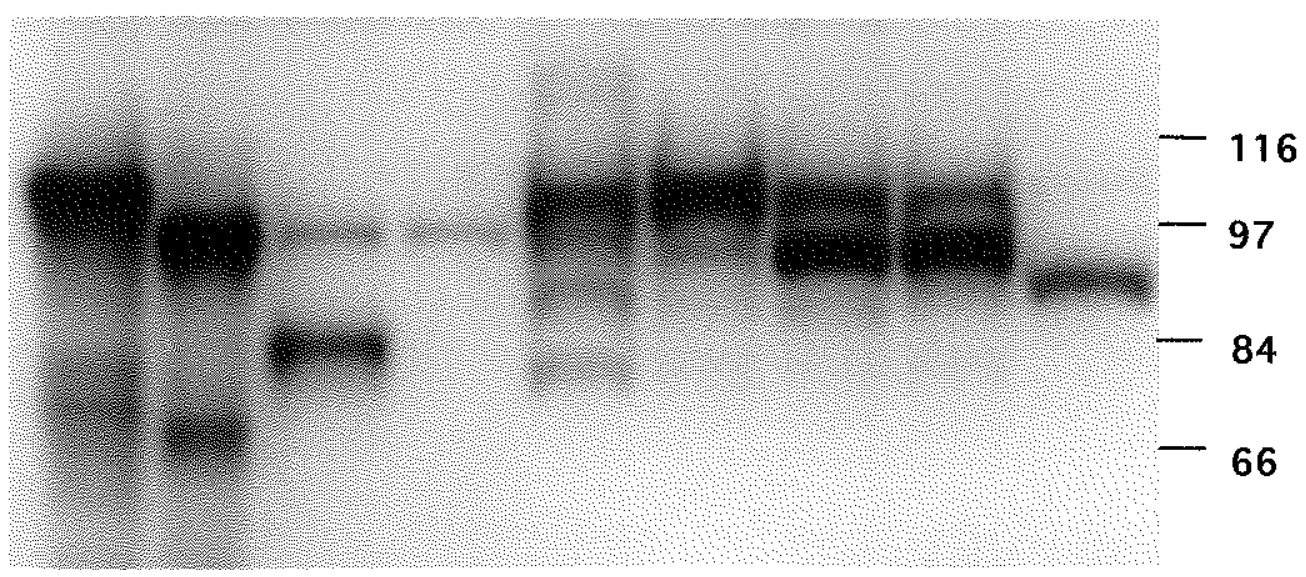

B. BEAR2

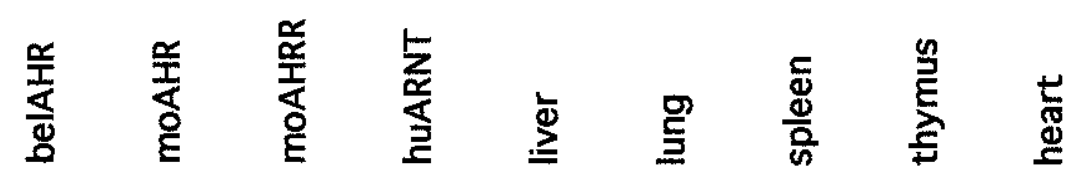

$-116$

$-97$

$-84$

$-66$ 


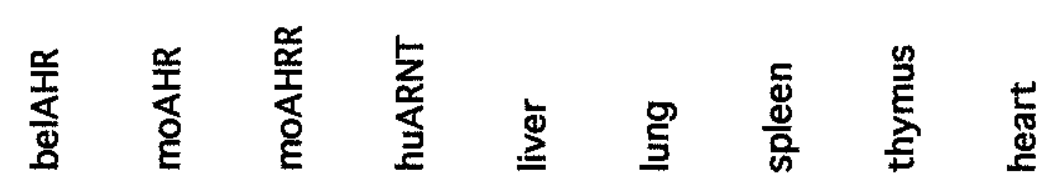

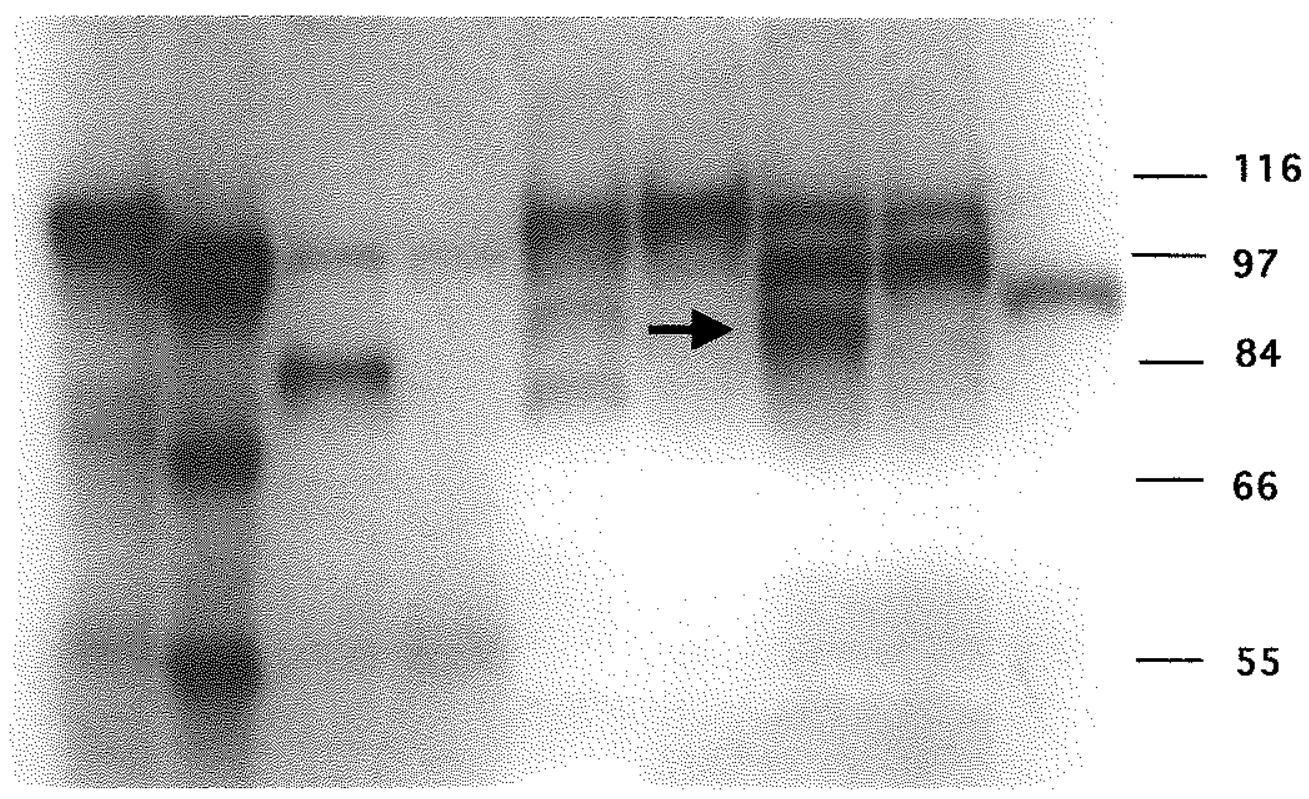

Figure 11. Overlay of Western blots from Figure 10. The films from Figure 10 were overlayed to show that the bands detected with BEAR2 are the same as those detected with SA-210, with the exception of the $\sim 90 \mathrm{kDa}$ band in spleen detected by BEAR2 (indicated by arrow). 
Figure 12. Relative AHR expression patterns in 98-1 and 98-2 tissues using relative RT-PCR. Total RNA was reverse transcribed to CDNA and PCR was performed under optimized conditions as determined in the Methods: 28 cycles with $4 \mu \mathrm{l} \mathrm{cDNA} / 100 \mu \mathrm{l}$ reaction. (A) $10 \mu \mathrm{l}$ of the PCR was separated on a $2 \%$ agarose gel, then stained with ethidium bromide. (B) Optical density was determined for each band, background was subtracted, then signal from each tissue was plotted as a ratio of AHR/actin. 


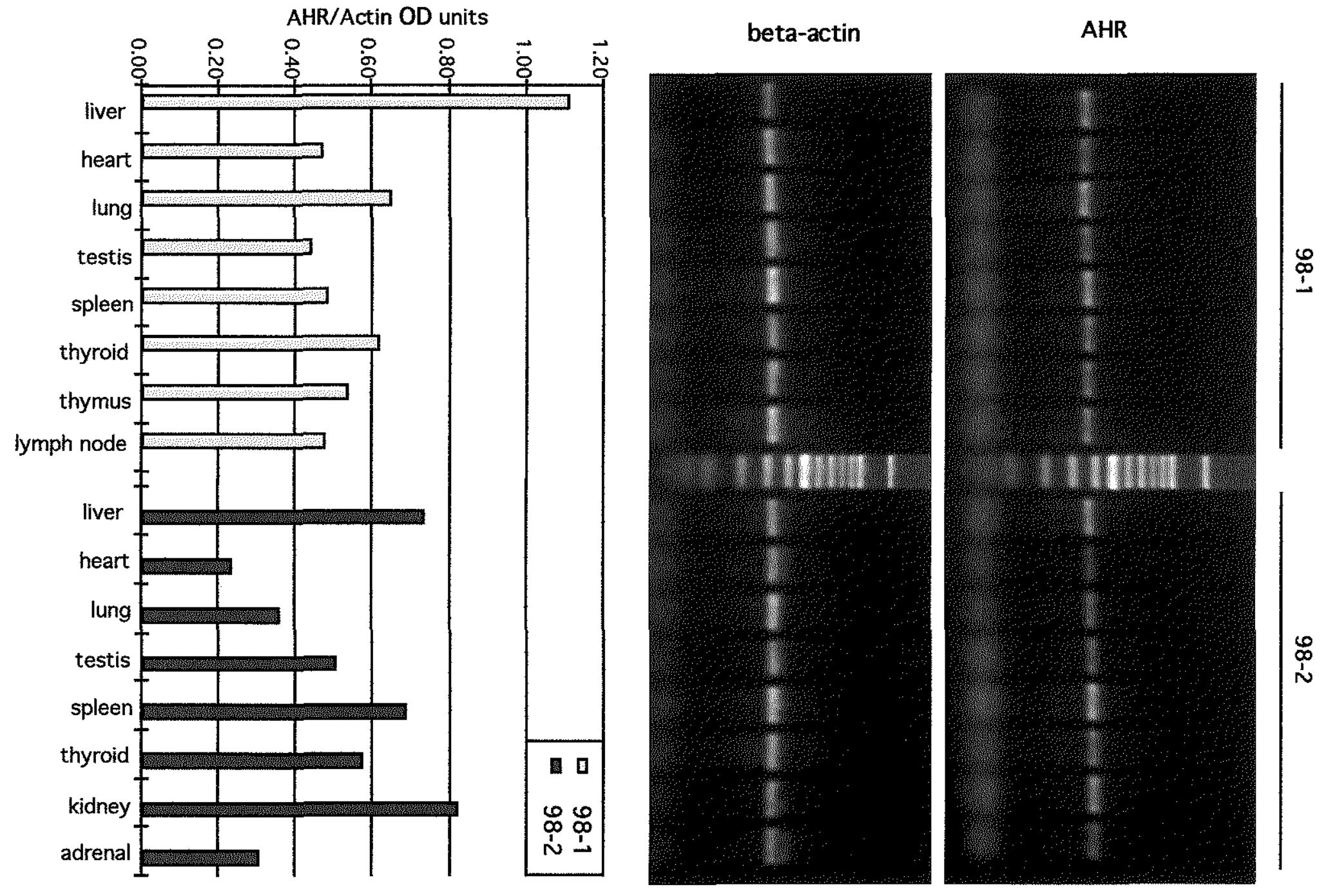


Figure 13. Summary of AHR mRNA expression as determined by relative RT-PCR. Four experiments are summarized. For ease of comparison, each tissue is plotted as a fraction of the tissue that showed the maximum AHR/actin OD ratio for each animal. A. Three experiments were carried out using 28 cycles, as in Figure 12. In all trials with 98-1, the maximum expression was in liver. For 98-2, maximal expression was observed in liver, lung, or kidney. Bars indicate standard deviation. B. Additional experiment run under identical conditions as in A, except 25 cycles were used, for reasons detailed in the text. 
A. Summary of relative RT-PCR, 28 cycles

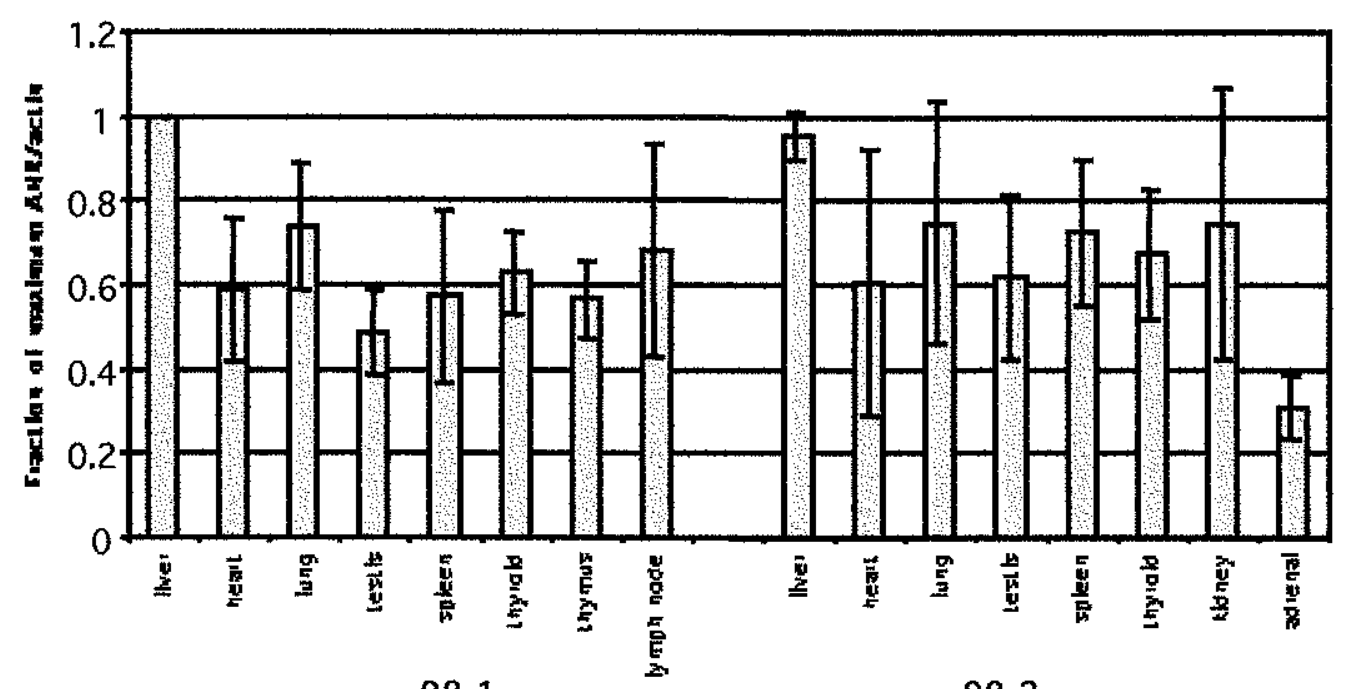

98-1

98-2

B Relative RT-PCR with 25 cycles

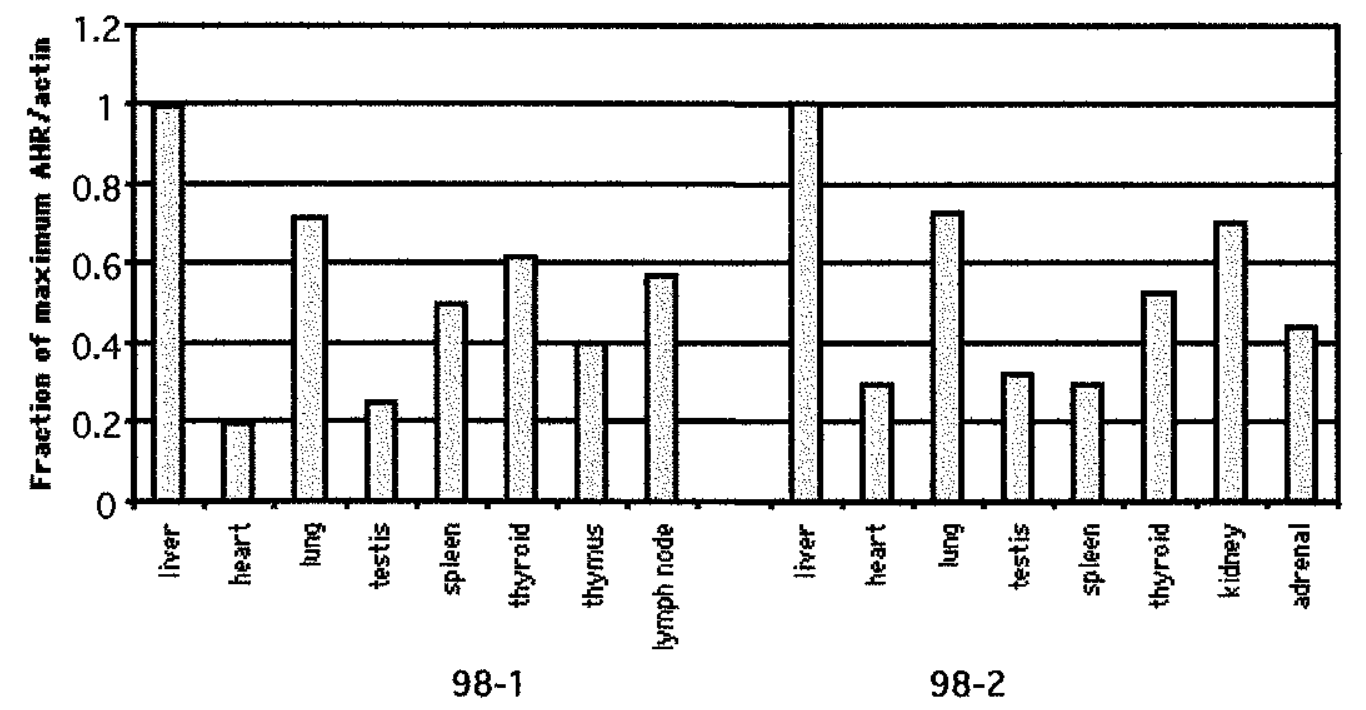


Figure 14. RT-PCR signal does not arise from contaminating genomic DNA. Two approaches were used to minimize signal from genomic DNA contamination: 1) The RNA was $\mathrm{LiCl}$ precipitated, which excludes large DNA and very small RNA, and 2) AHR primers were designed to span splice junctions and actin primers were designed to exons flanking a large intron. A separate set of cDNA, synthesis reactions were carried out without reverse transcriptase enzyme. In two additional tubes containing liver and spleen total RNA, reverse transcriptase was added last to serve as a positive control for the master mix and the RNA handling. All control cDNA tubes were amplified and visualized as in Figure 12. 
Actin -RT

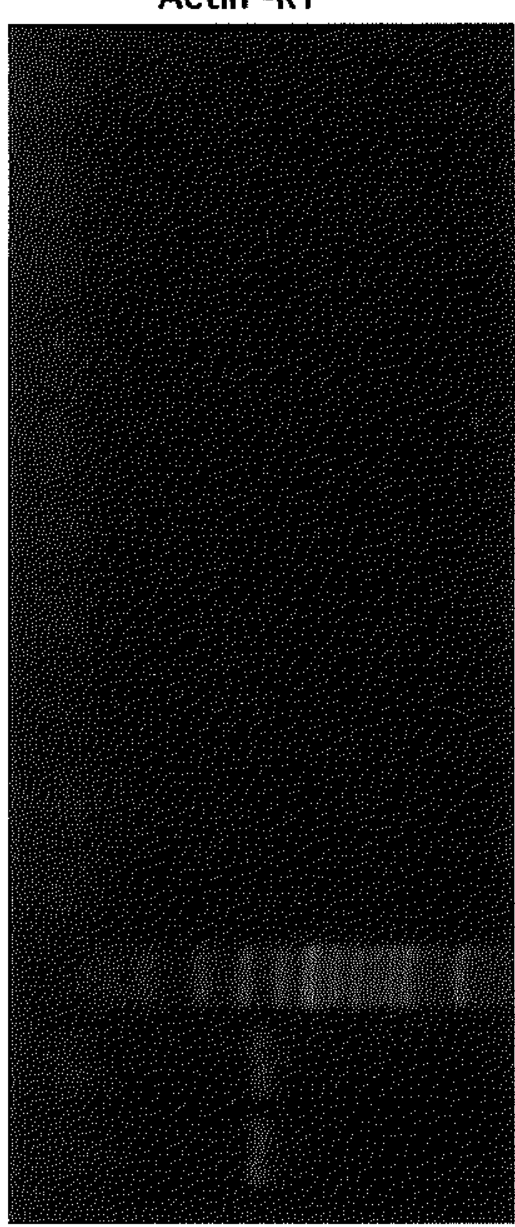

AHR - RT

Liver

Heart

Lung

Testis

Spleen

Thyroid

Thymus

Lymph node

Kidney

Adrenal

Liver (+RT)

Spleen (+RT)

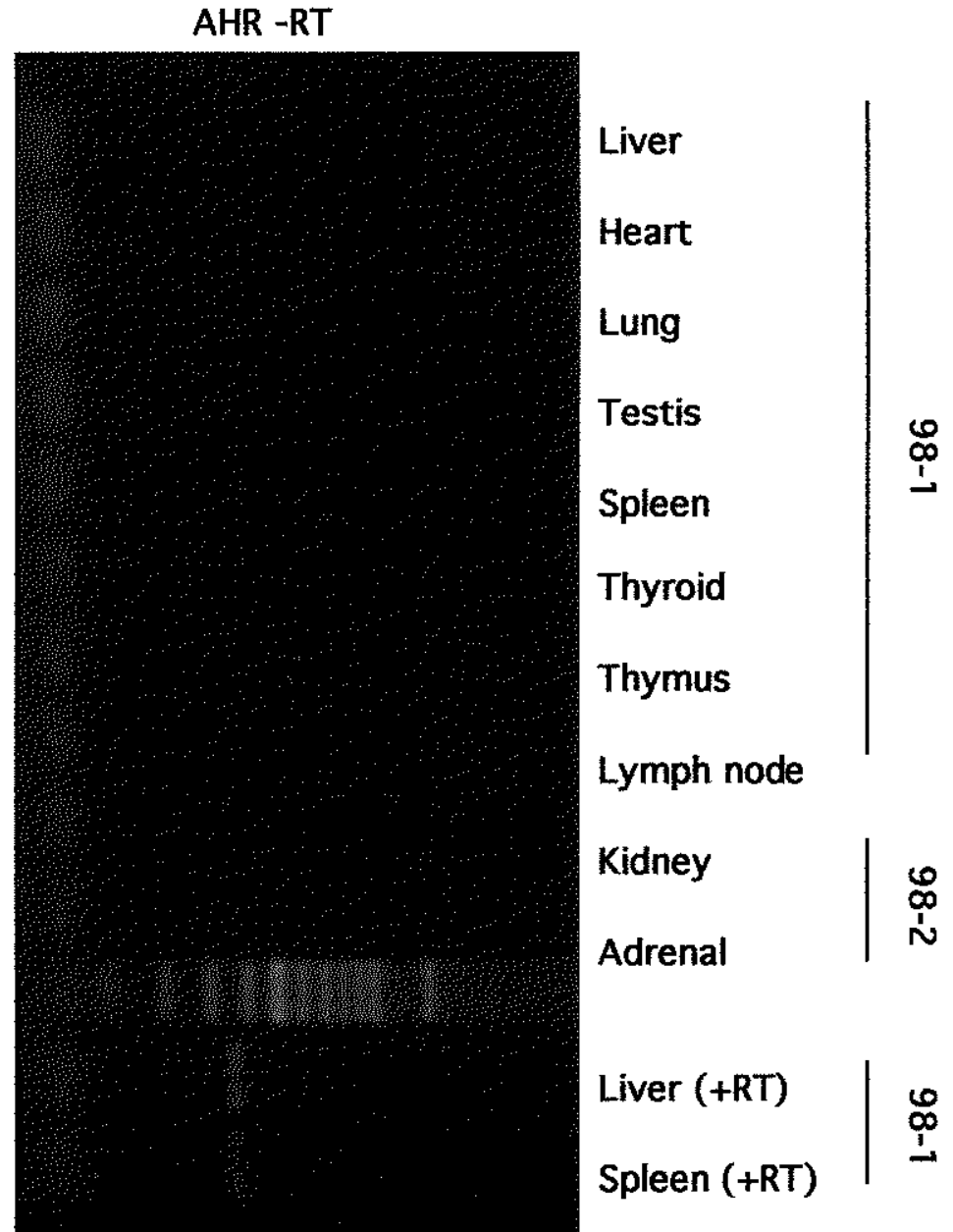


Figure 15. Full-length AHR transcripts are detected in all tissues using RTPCR. Full length beluga AHR transcripts were amplified using primers designed to regions overlapping the start codon, and just downstream of the stop codon; as described in Chapter 2. Touchdown PCR and 35 cycles were used to maximize specificity and detection. 
AHR OD units

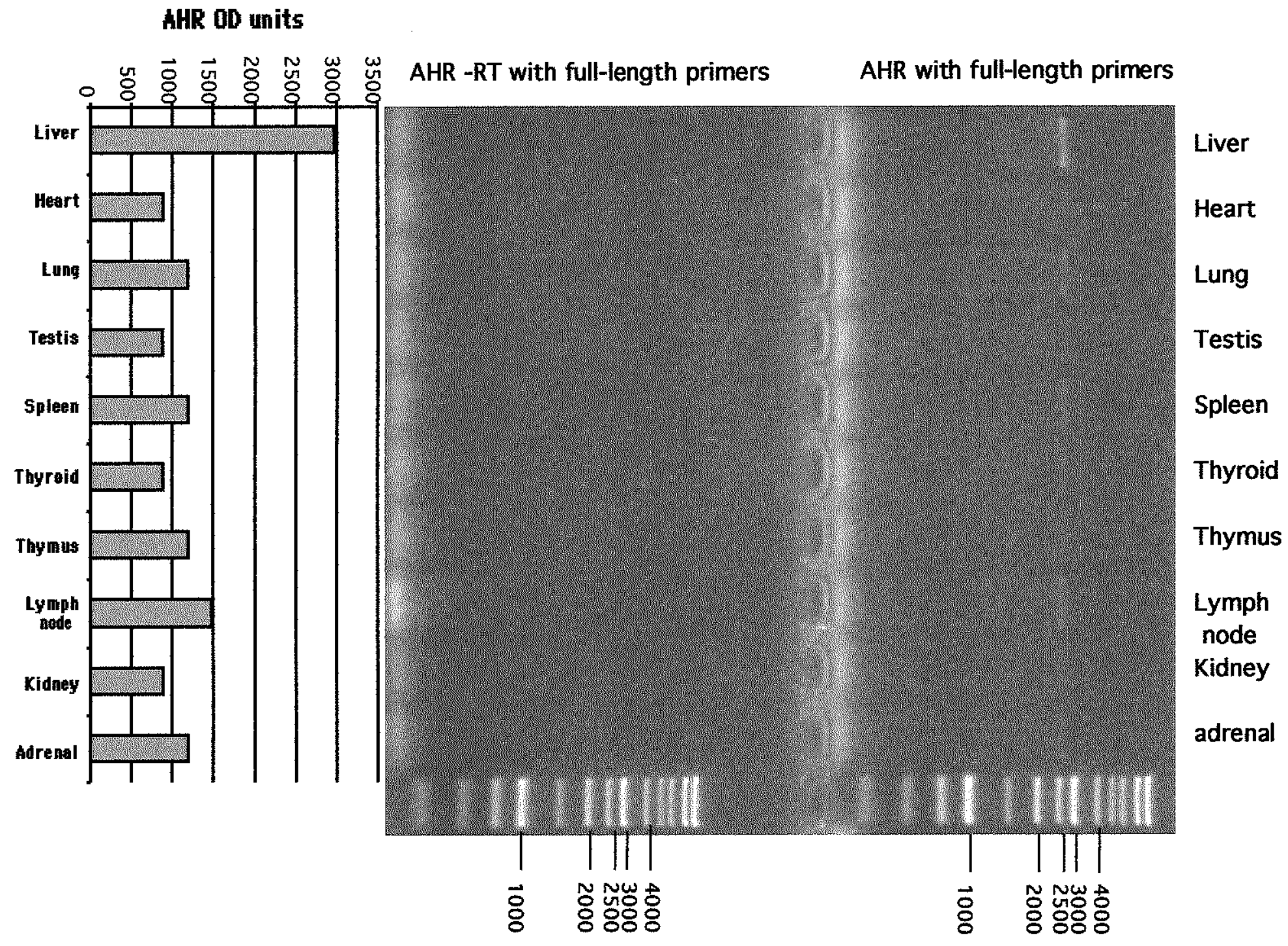


Table 1. Summary of tissue specific expression data for 98 belugas. Based on 98-1 tissues plus kidney and adrenal from 98-2:

\begin{tabular}{|c|c|c|c|c|c|}
\hline method & $\begin{array}{l}\text { Highest } \\
(++++)\end{array}$ & $\begin{array}{l}\text { High } \\
(+++)\end{array}$ & $\begin{array}{l}\text { Medium } \\
(++)\end{array}$ & $\begin{array}{l}\text { Low } \\
(+)\end{array}$ & $\begin{array}{l}\text { None } \\
\text { detected }\end{array}$ \\
\hline $\begin{array}{l}\text { SDG } \\
\text { Liver } \\
\text { Heart } \\
\text { Lung } \\
\text { Testis } \\
\text { Thyroid } \\
\text { Spleen } \\
\text { Thymus } \\
\text { Lymph node } \\
\text { Kidney } \\
\text { Adrenal } \\
\text { WESTERNS } \\
\text { Liver } \\
\text { Heart } \\
\text { Lung } \\
\text { Testis } \\
\text { Thyroid } \\
\text { Spleen } \\
\text { Thymus } \\
\text { Lymph node } \\
\text { Kidney } \\
\text { Adrenal } \\
\\
\text { RT-PCR } \\
\text { Liver } \\
\text { Heart } \\
\text { Lung } \\
\text { Testis } \\
\text { Thyroid } \\
\text { Spleen } \\
\text { Thymus } \\
\text { Lymph node } \\
\text { Kidney } \\
\text { Adrenal }\end{array}$ & $\begin{array}{l}\mathrm{x} \\
\mathrm{x} \\
\mathrm{x}\end{array}$ & $\begin{array}{l}\mathrm{x} \\
\mathrm{x} \\
\mathrm{x} \\
\mathrm{x}\end{array}$ & $\begin{array}{l}x \\
x\end{array}$ & $\begin{array}{l}x \\
x\end{array}$ & $\mathrm{x}$ \\
\hline
\end{tabular}


Table 2. Summary of tissue-specific expression data from the literature.

\begin{tabular}{|c|c|c|c|c|c|c|c|c|}
\hline Species & Method & Liver & Heart & Lung & Testis & Spleen & Thymus & Kidney \\
\hline $\begin{array}{c}\mathrm{C} 57 \mathrm{BL} / 6 \mathrm{~J} \\
\text { mouse }\end{array}$ & $\overline{\mathrm{SDG} a}$ & $++++t$ & - & ++++ & - & & ++ & ++ \\
\hline $\begin{array}{c}\mathrm{C} 57 \mathrm{BL} / 6 \mathrm{~J} \\
\text { mouse }\end{array}$ & SDG b & $+++t$ & & & & & +++ & \\
\hline $\begin{array}{l}\text { DBA-2J } \\
\text { mouse }\end{array}$ & SDG a & - & - & - & & & - & - \\
\hline Guinea pig & SDG b & $+++t$ & ++ & +++++ & ++++ & ++ & ++++ & +++ \\
\hline Hamster & SDG D & ++++ & - & +++ & - & + & + & ++ \\
\hline$S-D$ rat & SDG a & +++++ & - & +++++ & - & & +++++ & + \\
\hline S-D rat & $S D G_{b}$ & ++++ & & ++++ & & & ++++++ & \\
\hline S-D rat & $\mathrm{HAP}_{\mathrm{c}}$ & ++++ & & +++ & & & +++++ & \\
\hline S-D rat & $\begin{array}{l}\text { Isoelectric } \\
\text { focusing o }\end{array}$ & ++++ & & +++++ & + & & +++++ & $++t+$ \\
\hline Human & SDGe & $+++!$ & & +++ & & & & \\
\hline S-D rat & Western f & ++ & & +++ & & ++++ & +++ & \\
\hline $\mathrm{C} 57 \mathrm{BL} / 6$ & $\begin{array}{l}\text { Photoaffinity/ } \\
\text { Immunoppt g }\end{array}$ & $+++t$ & ++ & +++++ & & $+++t$ & +++ & $+t$ \\
\hline Human & Northem h & ++ & ++++ & ++++ & & & & ++ \\
\hline S-D rat & $\operatorname{RPA}_{i}$ & $+++t$ & + & +++++ & & + & $+++t$ & ++++ \\
\hline $\begin{array}{l}\text { C57BL } \\
\text { mouse }\end{array}$ & $\begin{array}{c}\text { Competitive } \\
\text { RT-PCR }\end{array}$ & ++ & + & +++++ & & + & ++ & + \\
\hline Rabbit & S-1 mapping $k$, & +++ & + & ++++ & & ++ & & $++t$ \\
\hline
\end{tabular}

aason \& Okey, 1982

b Gasiewicz \& Rucci, 1984

c Poellinger et al., 1985

d Carlstedt-Duke, 1979

- Harper et al., 1988; Harper et al., 1991; Manchester et al., 1987; Roberts et al., 1986; Roberts et al, 1990

$f$ Poflenz et al., 1998

goland et al., 1991

h Dolwick et al., 1993

i Carver et al., 1994

j Li et al., 1994

k Takahashi et al., 1996

$m=$ cell line

$n=$ no values were reported from this paper, so this interpretation was based on the apparent relative optical densities in Figure 4, and the authors' report that AHR was detected in every tissue (e.g. where l could see no signal, a "+" was inserted in the table). 


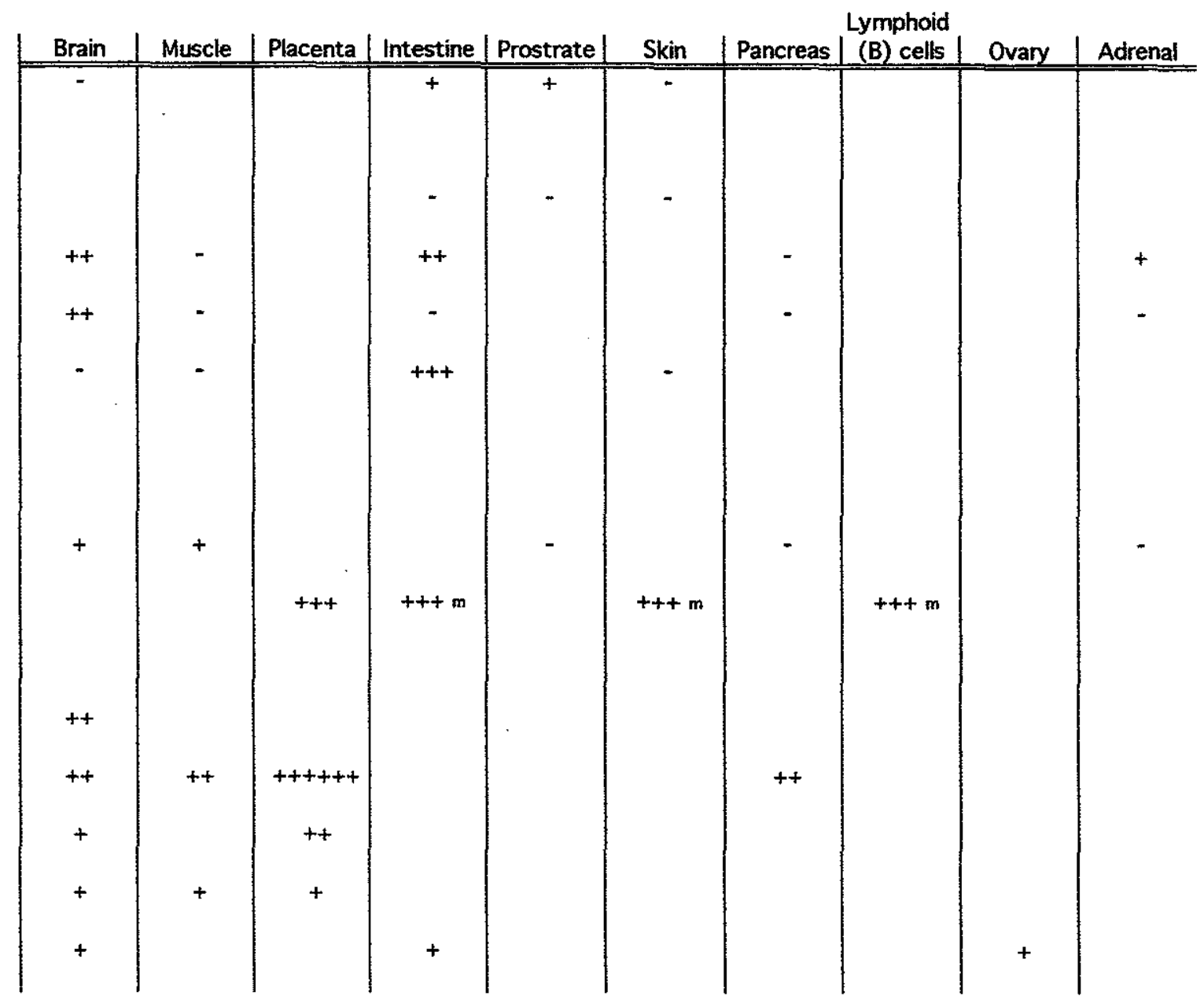




\section{Chapter 5:}

Summary, Conclusions and Future Directions 
Marine mammals are known to accumulate high levels of persistent contaminants in their tissues. However, the effects of high burdens of contaminants on marine mammal health are largely unknown. Because of ethical, legal, and logistical obstacles, direct toxicity studies in marine mammals are usually impossible. This thesis demonstrates an approach that circumvents these difficulties by conducting in vitro studies and examining a protein known to be necessary for the toxicity of a class of potent environmental contaminants, the planar halogenated aromatic hydrocarbons. Specifically, I examined the molecular and functional properties, as well as tissue distribution of the aryl hydrocarbon receptor from the beluga, an odontocete cetacean.

The major findings of this thesis were:

- The beluga AHR shares high sequence identity with other mammalian AHRs, especially with the human AHR (85\%)

- The beluga AHR has similar (or greater) TCDD binding affinity compared to that of the $\mathrm{Ah}^{\mathrm{b}-1}$ mouse allele, a classic "high-affinity" mouse AHR.

- Relative potencies for AHR binding suggest that structure-binding relationships are similar in beluga and rodents, and thus support the use of TEFs for cetaceans.

- High AHR protein expression was found in lymphoid tissues (thymus, spleen, lymph node, liver, and lung).

The AHR from beluga liver was isolated, cloned, and sequenced. The $3.2 \mathrm{~kb}$ cDNA encoded an 845 amino acid protein with a predicted size of $95.5 \mathrm{kDa}$. Overall the beluga AHR shared $85 \%$ amino acid sequence identity with the human AHR and $75 \%$ identity with the mouse AHR $\mathrm{Ah}^{\mathrm{b}-1}$ allele. Beluga AHR protein synthesized in a rabbit 
reticulocyte lysate system demonstrated specific, high affinity $\left[{ }^{3} \mathrm{H}\right]-\mathrm{TCDD}$ binding. In a charcoal-dextran binding assay with varying concentrations of $\left[{ }^{3} \mathrm{H}\right]-\mathrm{TCDD}$, the binding affinity of the beluga AHR was compared to that of an AHR from a dioxin-sensitive mouse strain (product of the $\mathrm{Ah}^{\mathrm{b}-1}$ allele) and with the human AHR. In this comparison, the beluga AHR bound ligand with an affinity $\left(\mathrm{K}_{\mathrm{d}}=0.43 \pm 0.16\right)$ that was at least as high as that of the mouse AHR $\left(\mathrm{K}_{\mathrm{d}}=0.68 \pm 0.23\right)$, and significantly greater than that of the human AHR $\left(\mathrm{K}_{\mathrm{d}}=1.63 \pm 0.64\right)$.

In order to further the characterization of the beluga AHR and begin to establish an experimental basis for the application of Toxic Equivalency Factors to cetaceans, competitive inhibition studies were conducted to measure binding affinities of different structure classes of HAH. From these binding studies, relative potencies (factors that describe potency for a compound relative to the potency of TCDD) were derived for HAH binding to the in vitro-expressed beluga AHR. In order to again compare with a well-characterized $\mathrm{AHR}$, the high-affinity mouse $\mathrm{Ah}^{\mathrm{b}-1}$ allele was included in all in vitro analyses. Overall affinities of $\mathrm{HAH}$ for the beluga AHR were higher than were the $\mathrm{HAH}$ affinities for the mouse AHR. Structure-binding relationships were very similar between the beluga and mouse AHRs and within the different structure classes of HAH tested. Relative potencies calculated for the coplanar HAH were correlated with Toxic Equivalency Factors (TEFs) determined for humans and mammals. Thus, these data support the use of rodent-derived TEFs for PCBs for cetaceans. However, since REPs and TEFs do not correlate as well for the mono and di-ortho PCBs, and because no data exist showing efficacy of the mono-ortho PCBs, TEFs for mono-ortho PCBs should be 
used with caution, and TEFs for di-ortho PCBs are not likely to be valid. This was the first determination of relative potencies of any kind for a marine mammal, and the most comprehensive set of relative potencies derived for $\mathrm{HAH}$ binding to in vitro mouse AHR.

To determine potential targets for AHR-mediated toxic effects in the beluga, the tissue-specific expression of AHR was examined. Several tissues were collected from 5 male beluga from the Alaskan Arctic. Three methods were used to measure AHR expression: 1) ligand binding in cytosols, 2) presence of immunodetectable AHR protein in cytosols, and 3) messenger RNA expression. These studies show that the AHR is ubiquitously expressed at the level of mRNA in the tissues examined. Protein levels are relatively high in thymus, spleen, lymph node, liver, and lung, implying that these may be targets for toxicity of coplanar HAH as well as other AHR ligands.

The observation that the beluga possesses a high affinity AHR, together with the demonstration of high expression of AHR in lymphoid organs relative to other tissues are consistent with a role for planar HAH in cetacean disease. As mechanisms for AHRdependent immunosuppression are discovered in rodent models, the potential for direct examination for bona fide toxic responses in marine mammals increases.

There are several directions for future research that can immediately enhance these studies. The first is to determine the inter- and intra-specific variability in AHR ligand binding affinities among cetaceans and other highly exposed marine species. Another need is to derive relative potencies for AHR-dependent responses that are downstream from ligand-binding, such as nuclear translocation, DNA binding, and gene induction. For example, DNA binding and/or gene induction might be measured in 
whole cells either by an endogenous enzyme such as CYP1A, or a reporter construct that is driven by binding to dioxin-responsive elements.

This work is a part of efforts to address more general questions about the role of the AHR in cetacean, mammalian, and overall environmental health. Some of these include: What are the most critical toxic endpoints caused by HAH? What is the likelihood of toxic effects to occur at doses observed in the environment? What are the synergistic and antagonistic effects among different structure classes of $\mathrm{HAH}$, or between HAH with other contaminant types? What is the endogenous role of the AHR? Because top-feeding marine mammals occupy a niche in the marine environment that is comparable to the human niche in the terrestrial environment, understanding impacts in marine mammals is critical for understanding the potential impacts on our own health. Thus, it is important that these questions continue to be addressed with innovative approaches and state-of-the art techniques.

In conclusion, this thesis provides critical evidence that cetaceans might be among the most sensitive organisms to the effects of persistent planar halogenated aromatic hydrocarbons and other AHR ligands. Future studies will continue to examine the relevance of these in vitro relationships and toxic effects in the whole animal. Finally, cloning and in vitro characterization of a key protein involved in toxicity is a promising approach for obtaining species-specific mechanistic data from protected species. 
Bibliography 
Aarts, J.M., Denison, M.S., Cox, M.A., Schalk, M.A., Garrison, P.M., Tullis, K., de Haan, L.H. \& Brouwer, A. (1995). Species-specific antagonism of Ah receptor action by 2,2',5,5'- tetrachloro- and 2,2',3,3'4,4'-hexachlorobiphenyl. Eur $J$ Pharmacol, 293, 463-74.

Abnet, C.C., Tanguay, R.L., Hahn, M.E., Heideman, W. \& Peterson, R.E. (1999). Two forms of aryl hydrocarbon receptor type 2 in rainbow trout (Oncorhynchus mykiss): Evidence for differential expression and enhancer specificity. Journal of Biological Chemistry, 274, 15159-15166.

Aguilar, A. \& Borrell, A. (1994). Abnormally high polychlorinated biphenyl levels in striped dolphins (Stenella coeruleoalba) effected by the 1990-1992 Mediterranean epizootic. Science of the Total Environment, 154, 237-247.

Ahlborg, U.G., Becking, G.C., Birnbaum, L.S., Brouwer, A., Derks, H.J.G.M., Feeley, M., Golor, G., Hanberg, A., Larsen, J.C., Liem, A.K.D., Safe, S.H., Schlatter, C., Waern, F., Younes, M. \& Yrjanheikki, E. (1994). Toxic equivalency factors for dioxin-like PCBs. Chemosphere, 28, 1049-1067.

Alberts, B., Bray, D., Lewis, J., Raff, M., Roberts, K. \& Watson, J.D. (1994). Molecular biology of the cell. New York: Garland Publishing, Inc.

Alonso, S., Minty, A., Bourlet, Y. \& Buckingham, M. (1986). Comparison of three actincoding sequences in the mouse; evolutionary relationships between the actin genes of warm-blooded vertebrates. J. Mol. Evol., 23, 11-22.

AMAP (1998). AMAP Assessment Report: Arctic Pollution Issues. Oslo, Norway: Arctic Monitoring and Assessment Programme (AMAP).

Bailey, R. \& Singer, N. (1995). St. Lawrence beluga recovery plan. pp. 75. Mont Joli, Quebec: Department of Fisheries and Oceans.

Bandiera, S., Safe, S. \& Okey, A.B. (1982). Binding of polychlorinated biphenyls classified as either phenobarbitone-, 3-methylcholanthrene- or mixed-type inducers to cytosolic Ah receptor. Chem.-Biol. Inter., 39, 259-277.

Beland, P., DeGuise, S., Girard, C., Lagace, A., Martineau, D., Michaud, R., Muir, D.C.G., Norstrom, R.J., Pelletier, E., Ray, S. \& Shugart, L.R. (1993). Toxic compounds an health and reproductive effects in St. Lawrence beluga whales. $J$. Great Lakes Res., 19, 766-775.

Bennett, P., Ramsden, D.B. \& Williams, A.C. (1996). Complete structural characterisation of the human aryl hydrocarbon receptor gene. J. Clin. Pathol. Mol. Pathol., 49, M12-M16.

Berggrena, P., Ishaq, R., Zebuhr, Y., Naf, C., Bandh, C. \& Broman, D. (1999). Patterns and levels of organochlorines (DDTs, PCBs, non-ortho CBs and PCDD/Fs) in male harbour porpoises (Phocoena phocoena) from the Baltic Sea, the KattegatSkagerrak Seas and the West Coast of Norway. Marine Pollution Bulletin, 38, 1070-1084.

Birnbaum, L.S., McDonald, M.M., Blair, P.C., Clark, A.M. \& Harris, M.W. (1990). Differential toxicity of 2,3,7,8-tetrachlorodibenzo-p-dioxin (TCDD) in C57BL/6J mice congenic at the Ah locus. Fund. Appl. Toxicol., 15, 186-200. 
Blank, J.A., Tucker, A.N., Sweatlock, J., Gasiewicz, T.A. \& Luster, M.I. (1987). $\alpha-$ Naphthoflavone antagonism of 2,3,7,8-tetrachlorodibenzo-p-dioxin-induced murine lymphocyte ethoxyrèsorufin O-deethylase activity and immunosuppression. Mol. Pharmacol., 32, 168-172.

Boon, J.P., Vandermeer, J., Allchin, C.R., Law, R.J., Klunsoyr, J., Leonards, P.E.G., Spliid, H., Storrhansen, E., Mckenzie, C. \& Wells, D.E. (1997). Concentrationdependent changes of PCB patterns in fish-eating mammals: Structural evidence for induction of cytochrome P450. Arch Environ Contam Toxicol, 33, 298-311.

Borrell, A., Aguilar, A., Corsolini, S. \& Focardi, S. (1996). Evaluation of toxicity and sex-related variation of PCB levels in Mediterranean striped dolphins affected by an epizootic. Chemosphere, 32, 2359-2369.

Bradfield, C.A., Kende, A.S. \& Poland, A. (1988). Kinetic and equilibrium studies of Ah receptor-ligand binding: use of [125I]2-iodo-7,8-dibromodibenzo-p-dioxin. $M o l$ Pharmacol, 34, 229-37.

Burbach, K.M., Poland, A. \& Bradfield, C.A. (1992). Cloning of the Ah-receptor cDNA reveals a distinctive ligand-activated transcription factor. Proc Natl Acad Sci US $A, 89,8185-9$.

Burczynski, M.E. \& Penning, T.M. (2000). Genotoxic polycyclic aromatic hydrocarbon ortho-quinones generated by aldo-keto reductases induce CYP1A1 via nuclear translocation of the aryl hydrocarbon receptor. Cancer Res, 60, 908-915.

Carrier, F., Owens, R.A., Nebert, D.W. \& Puga, A. (1992). Dioxin-dependent activation of murine Cypla1 gene transcription requires protein kinase C-dependent phosphorylation. Molecular and Cellular Biology, 12, 1856-1863.

Carvan III, M.J., Flood, L.P., Campbell, B.D. \& Busbee, D.L. (1995). Effects of benzo(a)pyrene and tetrachlorodibenzo-p-dioxin on fetal dolphin kidney cells: inhibition of proliferation and initiation of DNA damage. Chemosphere, 30, 187198.

Carver, L.A. \& Bradfield, C.A. (1997). Ligand-dependent interaction of the aryl hydrocarbon receptor with a novel immunophilin homolog in vivo. $J$ Biol Chem, $272,11452-6$.

Carver, L.A., Hogenesch, J.B. \& Bradfield, C.A. (1994). Tissue specific expression of the rat Ah-receptor and ARNT mRNAs. Nucleic Acids Res, 22, 3038-44.

Chen, H.-S. \& Perdew, G.H. (1994). Subunit composition of the heteromeric cytosolic aryl hydrocarbon receptor complex. Journal of Biological Chemistry, 269, 2755427558.

Chen, Y. \& Tukey, R.H. (1996). Protein kinase C modulates regulation of the CYP1A1 gene by the aryl hydrocarbon receptor. J Biol Chem, 271, 26261-26266.

Cheng, Y.-C. \& Prusoff, W.H. (1973). Relationship between the inhibition constant (KI) and the concentration of inhibitor which causes 50 percent inhibition (I50) of an enzymatic reaction. Biochemical Pharmacology, 22, 3099-3108.

Clark, G.C., Blank, J.A., Germolec, D.R. \& Luster, M.I. (1991). 2,3,7,8Tetrachlorodibenzo-p-dioxin stimulation of tyrosine phosphorylation in B lymphocytes: potential role in immunosuppression. Mol Pharm, 39, 495-501. 
Clemens, M.J. (1984). Chapter 8: Purification of Total RNA. In Transcription and Translation. ed. Hames \& Higgins.

Cockcroft, V.G., De Kock, A.C., Ross, G.J.B. \& Lord, D.A. (1989). Organochlorines in bottlenosed dolphins, Tursiops truncatus, from the east coast of South Africa. $S$ African J Mar Sci, 8, 207-217.

Coombs, D.H. \& Watts, N.R.M. (1985). Generating sucrose gradients in three minutes by tilted tube rotation. Analytical Biochemistry, 148, 254-259.

Coumailleau, P., Poellinger, L., Gustafsson, J.A. \& Whitelaw, M.L. (1995). Definition of a minimal domain of the dioxin receptor that is associated with hsp90 and maintains wild type ligand binding affinity and specificity. J Biol Chem, 270, 25291-25300.

Davarinos, N.A. \& Pollenz, R.S. (1999). Ah receptor imported into the nucleus following ligand binding is rapidly degraded via the $26 \mathrm{~S}$ proteosome pathway following nuclear export. Journal of Biological Chemistry, in press.

Davis, D. \& Safe, S. (1990). Immunosuppressive activities of polychlorinated biphenyls in $\mathrm{C} 57 \mathrm{BL} / 6 \mathrm{~N}$ mice: structure-activity relationships as Ah receptor agonists and partial antagonists. Toxicology, 63, 97-111.

Davis, D. \& Safe, S. (1988). Immunosuppressive activities of polychlorinated dibenzofuran congeners: quantitative structure-activity relationships and interactive effects. Tox Appl Pharm, 94, 141-149.

Deguise, S., Martineau, D., Beland, P. \& Fournier, M. (1995). Possible mechanisms of action of environmental contaminants on St. Lawrence beluga whales (Delphinapterus leucas). Environ Health Perspect, 103, 73-77.

Dekrey, G.K. \& Kerkvliet, N.I. (1995). Suppression of cytotoxic T lymphocyte activity by 2,3,7,8-tetrachlorodibenzo-p-dioxin occurs in vivo, but not in vitro, and is independent of corticosterone elevation. Toxicology, 97, 105-112.

Deswart, R.L., Ross, P.S., Timmerman, H.H., Vos, H.W., Reijnders, P.J.H., Vos, J.G. \& Osterhaus, A.D.M.E. (1995). Impaired cellular immune response in harbour seals (Phoca vitulina) feeding on environmentally contaminated herring. Clin Exp Immunol, 101, 480-486.

DeSwart, R.L., Ross, P.S., Vetter, L.J., Timmerman, H.H., Heisterkamp, S., Loveren, H.V., Vos, J.G., Reijnders, P.J.H. \& Osterhaus, A.D.M.E. (1994). Impairment of immune function in harbor seals (Phoca vitulina) feeding on fish from polluted waters. Ambio, 23, 155-1159.

Devito, M.J., Ma, X.F., Babish, J.G., Menache, M. \& Birnbaum, L.S. (1994). DoseResponse Relationships in Mice Following Subchronic Exposure to 2,3,7,8Tetrachlorodibenzo-P-Dioxin - Cyp1A1, Cyp1A2, Estrogen Receptor, and Protein Tyrosine Phosphorylation. Toxicol Appl Pharmacol, 124, 82-90.

Dickerson, R., Howie, L., Davis, D. \& Safe, S. (1990). The structure-dependent effects of heptachlorodibenzofuran isomers in male C57BL/6 mice: immunotoxicity and monooxygenase enzyme induction. Fund Appl Tox, 15, 298-307.

Dolwick, K.M., Schmidt, J.V., Carver, L.A., Swanson, H.I. \& Bradfield, C.A. (1993). Cloning and expression of a human Ah receptor cDNA. Mol Pharmacol, 44, 9117. 
Dolwick, K.M., Swanson, H.I. \& Bradfield, C.A. (1993). In vitro analysis of Ah receptor domains involved in ligand-activated DNA recognition. Proc Natl Acad Sci US A, 90, 8566-70.

Dottavio-Martin, D. \& Ravel, J.M. (1978). Radiolabeling of proteins by reductive alkylation with $\left[{ }^{14} \mathrm{C}\right]$ formaldehyde and sodium cyanoborohydride. Analytical Biochemistry, 87, 562-565.

Ema, M., Ohe, N., Suzuki, M., Mimura, J., Sogawa, K., Ikawa, S. \& Fujii-Kuriyama, Y. (1994). Dioxin binding activities of polymorphic forms of mouse and human aryl hydrocarbon receptors. Joumal of Biological Chemistry, 269, 27337-27343.

Ema, M., Sogawa, K., Watanabe, N., Chujoh, Y., Matsushita, N., Gotoh, O., Funae, Y. \& Fuji-Kuriyama, Y. (1992). cDNA cloning and structure of mouse putative Ah receptor. Biochemical and Biophysical Research Communications, 184, 246-253.

Enan, E. \& Matsumura, F. (1995). Evidence for a second pathway in the action mechanism of 2,3,7,8-Tetrachlorodibenzo-p-dioxin (TCDD) - Significance of Ahreceptor mediated activation of protein kinase under cell-free conditions. Biochem Pharmacol, 49, 249-261.

Enan, E. \& Matsumura, F. (1996). Identification of c-Src as the integral component of the cytosolic Ah receptor complex, transducing the signal of 2,3,7,8-

Tetrachlorodibenzo-p-dioxin (TCDD) through the protein phosphorylation pathway. Biochem Pharmacol, 52, 1599-1612.

Fan, C.-M., Kuwana, E., Bulfone, A., Fletcher, C.F., Copeland, N.G., Jenkins, N.A., Crews, S., Martinez, S., Puelles, L., Rubenstein, J.J.R. \& Tessier-Lavigne, M. (1996). Expression patterns of two murine homologs of Drosophila SingleMinded suggest possible roles in embryonic patterning and in the pathogenesis of Down Syndrome. Mol. Cell. Neurosci., 7, 1-16.

Fernandez-Salguero, P., Pineau, T., Hilbert, D.M., McPhail, T., Lee, S.S.T., Kimura, S., Nebert, D.W., Rudikoff, S., Ward, J.M. \& Gonzalez, F.J. (1995). Immune system impairment and hepatic fibrosis in mice lacking the dioxin-binding Ah receptor. Science, 268, 722-726.

Fernandez-Salguero, P.M., Hilbert, D.M., Rudikoff, S., Ward, J.M. \& Gonzalez, F.J. (1996). Aryl-hydrocarbon receptor-deficient mice are resistant to 2,3,7,8tetrachlorodibenzo-p-dioxin-induced toxicity. Toxicol Appl Pharm, 140, 173-179.

Finklea, B., Miller, G. \& Busbee, D. (2000). Polychlorinated biphenyl residues in blubber of male Atlantic bottlenose dolphins (Tursiops truncatus) that stranded and died at Matagorda Bay. Bull Environ Contam Toxicol, 64, 323-32.

Fukunaga, B.N., Probst, M.R., Reiszporszasz, S. \& Hankinson, O. (1995). Identification of functional domains of the aryl hydrocarbon receptor. J Biol Chem, 270, 2927029278.

Gasiewicz, T.A. \& Bauman, P.A. (1987). Heterogeneity of the rat hepatic Ah receptor and evidence for its transformation in vitro and in vivo. J. Biol. Chem., 262, 2116-2120. 
Gasiewicz, T.A. \& Neal, R.A. (1979). 2,3,7,8-tetrachlorodibenzo-p-dioxin tissue distribution, excretion, and effects on clinical chemical parameters in guinea pigs. Toxicol. Appl. Pharmacol., 51, 329-339.

Gasiewicz, T.A. \& Neal, R.A. (1982). The examination and quantitation of tissue cytosolic receptors for 2,3,7,8-tetrachlorodibenzo-p-dioxin using hydroxylapatite. Anal. Biochem., 124, 1-11.

Gasiewicz, T.A. \& Rucci, G. (1984). Cytosolic receptor for 2,3,7,8-tetrachlorodibenzo-pdioxin. Evidence for a homologous nature among various mammalian species. Mol. Pharmacol., 26, 90-98.

Gauthier, J.M., Pelletier, E., Brochu, C., Moore, S., Metcalfe, C.D. \& Beland, P. (1998). Environmental contaminants in tissues of a neonate St Lawrence beluga whale (Delphinapterus leucas). Mar Pollut Bull, 36, 102-108.

Ghosh, S., May, M.J. \& Kopp, E.B. (1998). NF-kB AND REL PROTEINS: Evolutionarily Conserved Mediators of Immune Responses. Annu. Rev. Immunol., $16,225-260$.

Goks $\varnothing y r$, A., Andersson, T., Forlin, L., Stenersen, J., Snowberger, E.A., Woodin, B.R. \& Stegeman, J.J. (1988). Xenobiotic and steroid metabolism in adult and foetal piked (minke) whales, Balaenoptera acutorostrata. Mar. Environ. Res., 24, 9-13.

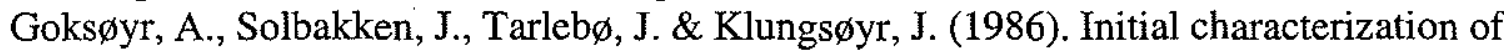
the hepatic microsomal cytochrome P-450-system of the piked whale (minke) Balaenoptera acutorostrata. Mar. Environ. Res, 19, 185-203.

Golas, C.L., Prokipcak, R.D., Okey, A.B., Manchester, D.K., Safe, S. \& Fujita, T. (1990). Competitive binding of 7-substituted-2,3-dichlorodibenzo-p-dioxins with human placental Ah receptor--a QSAR analysis. Biochem. Pharmacol., 40, 737-741.

Goldstein, J.A. \& Safe, S. (1989). Mechanism of action and structure-activity relationships for the chlorinated dibenzo-p-dioxins and related compounds. In Halogenated biphenyls, terphenyls, naphthalenes, dibenzodioxins and related products. ed. Kimbrough, R.D. \& Jensen, A.A. pp. 239-293. Amsterdam: Elsevier Science Publishers, Biomedical Division.

Gradin, K., Whitelaw, M.L., Toftgard, R., Poellinger, L. \& Berghard, A. (1994). A tyrosine kinase-dependent pathway regulates ligand-dependent activation of the dioxin receptor in human keratinocytes. J Biol Chem, 269, 23800-23807.

Gu, Y.-Z., Hogenesch, J.B. \& Bradfield, C.A. (2000). The PAS Superfamily: Sensors of Environmental and Developmental Signals. Annual Review of Pharmacology and Toxicology, 40, 519-561.

Hahn, M.E. \& Karchner, S.I. (1995). Evolutionary conservation of the vertebrate Ah (dioxin) receptor: amplification and sequencing of the PAS domain of a teleost Ah receptor cDNA. Biochem J, 310, 383-7.

Hahn, M.E., Karchner, S.I., Shapiro, M.A. \& Perera, S.A. (1997). Molecular evolution of two vertebrate aryl hydrocarbon (dioxin) receptors (AHR1 and AHR2) and the PAS family. Proc Natl Acad Sci U S A, 94, 13743-8.

Hahn, M.E., Poland, A., Glover, E. \& Stegeman, J.J. (1994). Photoaffinity labeling of the Ah receptor: phylogenetic survey of diverse vertebrate and invertebrate species. Arch Biochem Biophys, 310, 218-28. 
Hahn, M.E., Woodward, B.L., Stegeman, J.J. \& Kennedy, S.W. (1996). Rapid assessment of induced cytochrome P4501A (CYP1A) protein and catalytic activity in fish hepatoma cells grown in multi-well plates. Environmental Toxicology and Chemistry, 15, 582-591.

Hall, A.J., Law, R.J., Wells, D.E., Harwood, J., Ross, H.M., Kennedy, S., Allchin, C.R., Campbell, L.A. \& Pomeroy, P.P. (1992). Organochlorine levels in common seals (Phoca vitulina) which were victims and survivors of the 1988 phocine distemper epizootic. Sci Total Environ, 115, 145-62.

Heid, S.E., Pollenz, R.S. \& Swanson, H.I. (2000). Role of heat shock protein 90 dissociation in mediating agonist-induced activation of the aryl hydrocarbon receptor. Mol Pharmacol, 57, 82-92.

Heidel, S.M., Holston, K., Buters, J.T.M., Gonzalez, F.J., Jefcoate, C.R. \& Czupyrynski, C.J. (1999). Bone marrow stromal cell cytochrome P4501B1 is required for pre-B cell apoptosis induced by 7,12-dimethylbenz[a] anthracene. Mol Pharmacol, 56, 1317-1323.

Hestermann, E.V., Stegeman, J.J. \& Hahn, M.E. (2000). Relative contributions of affinity and intrinsic efficacy to aryl hydrocarbon receptor ligand potency. Toxicology and Applied Pharmacology, submitted.

Hochstein, J.R., Bursian, S.J. \& Aulerich, R.J. (1998). Effects of dietary exposure to 2,3,7,8-tetrachlorodibenzo-p-dioxin in adult female mink (Mustela vison). Arch Environ Contam Toxicol, 35, 348-53.

Hoffman, E.C., Reyes, H., Chu, F.-F., Sander, F., Conley, L.H., Brooks, B.A. \& Hankinson, O. (1991). Cloning of a factor required for activity of the Ah (dioxin) receptor. Science, 252, 954-958.

Hornung, M.W., Zabel, E.W. \& Peterson, R.E. (1996). Toxic equivalency factors of polybrominated dibenzo-p-dioxin, dibenzofuran, biphenyl, and polyhalogenated diphenyl ether congeners based on rainbow trout early life stage mortality. Tox Appl Pharm, 140.

Huff, J., Lucier, G. \& Tritscher, A. (1994). Carcinogenicity of TCDD - Experimental, Mechanistic, and Epidemiologic Evidence. Annu Rev Pharmacol Toxicol, 34, 343-372.

Hundeiker, C., Pineau, T., Cassar, G., Betensky, R.A., Gleichmann, E. \& Esser, C. (1999). Thymocyte development in Ah-receptor-deficient mice is refractory to TCDD-inducible changes. Int J Immunopharmacol, 21, 841-859.

Hushka, L.J., Williams, J.S. \& Greenlee, W.F. (1998). Characterization of 2,3,7,8tetrachlorodibenzofuran-dependent suppression and $\mathrm{AH}$ receptor pathway gene expression in the developing mouse mammary gland. Toxicol Appl Pharmacol, 152, 200-210.

Jackson, F.R., Bargiello, T.A., Yun, S.H. \& Young, M.W. (1986). The product of the per locus of Drosophila shares homology with proteoglycans. Nature, 320, 185-188.

Jepson, P.D., Bennett, P.M., Allchin, C.R., Law, R.J., Kuiken, T., Baker, J.R., Rogan, E. \& Kirkwood, J.K. (1999). Investigating potential associations between chronic exposure to polychlorinated biphenyls and infectious disease mortality in harbour porpoises from England and Wales. Sci Total Envir, 244, 339-348. 
Kannan, K., Tanabe, S., Borrell, A., Aguilar, A., Focardi, S. \& Tatsukawa, R. (1993). Isomer-specific analysis and toxic evaluation of polychlorinated biphenyls in striped dolphins affected by an epizootic in the western Mediterranean Sea. Arch. Environ. Contam. Toxicol., 25, 227-233.

Kannan, N., Tanabe, S., Ono, M. \& Tatsukawa, R. (1989). Critical evaluation of polychlorinated biphenyl toxicity in terrestrial and marine mammals: Increasing impact of non-ortho and mono-ortho coplanar polychlorinated biphenyls from land to ocean. Arch. Environ. Contam. Toxicol., 18, 850-857.

Karchner, S.I., Powell, W.H. \& Hahn, M.E. (1999). Identification and functional characterization of two highly divergent aryl hydrocarbon receptors (AHR1 and AHR2) in the teleost Fundulus heteroclitus - Evidence for a novel subfamily of ligand-binding basic helix loop helix-Per-ARNT-Sim (BHLH-PAS) factors. $J$ Biol Chem, 274, 33814-33824.

Karchner, S.I., Powell, W.H. \& Hahn, M.E. (1999). Structural and Functional Characterization of Two Highly Divergent Aryl Hydrocarbon Receptors (AHR1 and AHR2) in the teleost Fundulus heteroclitus. Evidence for a novel class of ligand-binding basic helix-loop-helix Per-ARNT-Sim (bHLH-PAS) factors. Journal of Biological Chemistry, 274, 33814-33824.

Kawajiri, K., Watanabe, J., Eguchi, H., Nakachi, K., Kiyohara, C. \& Hayashi, S.-i. (1995). Polymorphisms of human Ah receptor gene are not involved in lung cancer. Pharmacogenetics, 5, 151-158.

Kawamoto, T., Matsumura, F., Madhukar, B.V. \& Bombick, D.W. (1989). Effects of TCDD on the EGF receptor of XB mouse keratinizing epithelial cells. $J$ Biochem Tox, 4, 173-182.

Kenakin, T. (1999). Pharmacologic Analysis of Drug-Receptor Interactions. New York: CRC/Raven Press.

Kerkvliet, N.I., Baecher-Steppan, L., Smith, B.B., Youngberg, J.A., Henderson, M.C. \& Buhler, D.R. (1990). Role of the Ah locus in suppression of cytotoxic T lymphocyte activity by halogenated aromatic hydrocarbons (PCBs and TCDD): structure-activity relationships and effects in C57BV/6 mice congenic at the Ah locus. Fund Appl Toxicol, 14, 532-541.

Kerkvliet, N.I., Steppan, L.B., Brauner, J.A., Deyo, J.A., Henderson, M.C., Tomar, R.S. \& Buhler, D.R. (1990). Influence of the Ah locus on the humoral immunotoxicity of 2,3,7,8-tetrachlorodibenzo-p-dioxin: evidence for Ah-receptor-dependent and Ah-receptor-independent mechanisms of immunosuppression. Toxicology and Applied Pharmacology, 105, 26-36.

Kester, J.E. \& Gasiewicz, T.A. (1987). Characterization of the in vitro stability of the rat hepatic receptor for 2,3,7,8-tetrachlorodibenzo-p-dioxin. Arch. Biochem. Biophys., 252, 606-625.

Kingsley, M.C.S. (1998). Population index estimates for the St. Lawrence belugas, 19731995. Mar Mammal Sci, 14, 508-530.

Kuby, J. (1998). Immunology, Third Edition. New York: W. H. Freeman and Company. Lahvis, G.P., Wells, R.S., Kuehl, D.W., Stewart, J.L., Rhinehart, H.L. \& Via, C.S. (1995). Decreased lymphocyte responses in free-ranging bottlenose dolphins ( 
Tursiops truncatus) are associated with increased concentrations of PCBs and DDT in peripheral blood. Environ Health Perspect, 103, 67-72.

Lai, Z.W., Hundeiker, C., Gleichmann, E. \& Esser, C. (1997). Cytokine gene expression during ontogeny in murine thymus on activation of the aryl hydrocarbon receptor by 2,3,7,8-tetrachlorodibenzo-p-dioxin. Mol Pharmacol, 52, 30-37.

Lai, Z.W., Pineau, T. \& Esser, C. (1996). Identification of dioxin-responsive elements (DREs) in the $5^{\prime}$ regions of putative dioxin-inducible genes. Chem Biol Interact, $100,97-112$.

Lawrence, B.P. \& Kerkvliet, N.I. (1997). Role of PGE2 and cyclooxygenase in TCDDinduced immunosuppression. Fund Appl Toxicol, 36, 290.

Lawrence, B.P., Leid, M. \& Kerkvliet, N.I. (1996). Distribution and behavior of the Ah receptor in murine T lymphocytes. Toxicol Appl Pharmacol, 138, 275-284.

Lees, M.J. \& Whitelaw, M.L. (1999). Multiple roles of ligand in transforming the dioxin receptor to an active basic helix-loop-helix/PAS transcription factor complex with the nuclear protein Arnt. Mol Cell Biol, 19, 5811-5822.

Li, H., Ko, H.P. \& Whitlock, J.P. (1996). Induction of phosphoglycerate kinase 1 gene expression by hypoxia - Roles of Arnt and HIF1 alpha. J Biol Chem, 271, 2126221267.

Li, W., Donat, S., Dohr, O., Unfried, K. \& Abel, J. (1994). Ah receptor in different tissues of $\mathrm{C} 57 \mathrm{BL} / 6 \mathrm{~J}$ and $\mathrm{DBA} / 2 \mathrm{~J}$ mice: Use of competitive polymerase chain reaction to measure Ah-receptor mRNA expression. Arch Biochem Biophys, 315, 279-284.

Long, W.P., Praygrant, M., Tsai, J.C. \& Perdew, G.H. (1998). Protein kinase c activity is required for aryl hydrocarbon receptor pathway-mediated signal transduction. $\mathrm{Mol}$ Pharmacol, 53, 691-700.

Lorenzen, A. \& Kennedy, S.W. (1993). A fluorescence-based protein assay for use with a microplate reader. Anal. Biochem., 214, 346-348.

Lorenzen, A. \& Okey, A.B. (1990). Detection and characterization of $\left[{ }^{3} \mathrm{H}\right] 2,3,7,8-$ tetrachlorodibenzo- $p$-dioxin binding to $\mathrm{Ah}$ receptor in a rainbow trout hepatoma cell line. Toxicol. Appl. Pharmacol., 106, 53-62.

Luster, M.I., Holladay, S.D., Blaylock, B.L., Germolec, D.R., Clark, G.C., Comment, C.E., Heindel, J.J. \& Rosenthal, G.J. (1992). TCDD inhibits murine thymocyte and B lymphocyte maturation. Chemosphere, 25, 115-118.

Ma, Q. \& Whitlock, J.P. (1997). A novel cytoplasmic protein that inteacts with the Ah receptor, contains tetratricopeptide repeat motifs, and augments the transcriptional response to 2,3,7,8-tetrachrodibenzo-p-dioxin. J Biol Chem, 272, 8878-8884.

Ma, X.F. \& Babish, J.G. (1993). Acute 2,3,7,8-Tetrachlorodibenzo-p-dioxin Exposure Results in Enhanced Tyrosylphosphorylation and Expression of Murine Hepatic Cyclin Dependent Kinases. Biochem Biophys Res Commun, 197, 1070-1077.

Manchester, D.K., Gordon, S.K., Golas, C.L., Roberts, E.A. \& Okey, A.B. (1987). Ah receptor in human placenta: stabilization by molybdate and characterization of binding of 2,3,7,8-tetrachlorodibenzo-p-dioxin, 3-methylcholanthrene, and benzo[a]pyrene. Cancer Res., 47, 4861-4868. 
Maniatis, T., Fritsch, E.F. \& Sambrook, J. (1982). Selection of poly A+ RNA by Oligo $\mathrm{d}(\mathrm{T})$ cellulose chromatography. In Molecular cloning, a laboratory manual. Cold Spring Harbor: Cold Spring Harbor Laboratory.

Mann, K.K., Matulka, R.A., Hahn, M.E., Trombino, A.F., Lawrence, B.P., Kerkvliet, N.I. \& Sherr, D.H. (1999). The role of polycyclic aromatic hydrocarbon metabolism in dimethylbenz[a]anthracene-induced pre-B lymphocyte apoptosis. Toxicol Appl Pharmacol, 161, 10-22.

Martin, R.G. \& Ames, B.N. (1961). A method for determining the sedimentation behavior of enzymes: application to protein mixtures. Journal of Biological Chemistry, 236, 1372-1379.

Martineau, D., Beland, P., Desjardins, C. \& Lagace, A. (1987). Levels of organochlorine chemicals in tissues of beluga whales (Delphinapterus leucas) from the St. Lawrence estuary, Quebec, Canada. Arch. Environ. Contam. Toxicol., 16, 137147.

Martineau, D., Deguise, S., Girard, C., Lagace, A. \& Beland, P. (1994). Pathology and toxicology of beluga whales from the St. Lawrence estuary. Science of the Total Environment, 154, ???-???

Martineau, D., Lagace, A., Beland, P., Higgins, R., Armstrong, D. \& Shugart, L.R. (1988). Pathology of stranded beluga whales (Delphinapterus leucas) from the St. Lawrence Estuary, Quebec, Canada. J. Comp. Pathol., 98, 287-311.

Mason, M.E. \& Okey, A.B. (1982). Cytosolic and nuclear binding of 2,3,7,8- . tetrachlorodibenzo-p-dioxin to the Ah receptor in extra-hepatic tissues of rats and mice. Eur. J. Biochem., 123, 209-215.

Matsumura, F. (1994). How important is the protein phosphorylation pathway in the toxic expression of dioxin-type chemicals? Commentary. Biochem Pharmacol, 48, 215224.

McClure, V.E. (1976). Transport of heavy chlorinated hydrocarbons in the atmosphere. Envir Sci Tech, 10, 1223-1228.

Meyer, B.K., Praygrant, M.G., Vandenheuvel, J.P. \& Perdew, G.H. (1998). Hepatitis B virus $\mathrm{X}$-associated protein 2 is a subunit of the unliganded aryl hydrocarbon receptor core complex and exhibits transcriptional enhancer activity. Mol Cell Biol, 18, 978-988.

Mimura, J., Ema, M., Sogawa, K. \& Fujii-Kuriyama, Y. (1999). Identification of a novel mechanism of regulation of Ah (dioxin) receptor function. Genes Dev, 13, 20-25.

Mimura, J., Yamashita, K., Nakamura, K., Morita, M., Takagi, T., Nakao, K., Ema, M., Sogawa, K., Yasuda, M., Katsuki, M. \& Fujii-Kuriyama, Y. (1997). Loss of teratogenic response to 2,3,7,8-tetrachlorodibenzo-p-dioxin (TCDD) in mice lacking the $\mathrm{Ah}$ (dioxin) receptor. Genes Cells, 2, 645-654.

Mizell, M., Stegeman, J.J., Romig, E., Smolowitz, R., Schlezinger, J., Katayani, R., Woodin, B. \& Mortensen, M. (1996). Chemically induced cardiovascular defects in developmental stages of vertebrates: Dose-response and phenotypic comparisons in medaka and zebrafish exposed to aryl hydrocarbon receptor agonists. Biol Bull, 191, 294-295. 
MMC (1999). Marine Mammals and Persistent Ocean Contaminants: Proceedings of the Marine Mammal Commission Workshop, Keystone, Colorado, 12-15 October 1998. In Marine Mammal Commission Workshop. ed. O'Shea, T.J., Reeves, R.R. \& Kirk Long, A. pp. 150 pp. Keystone, CO: Marine Mammal Commission.

Motulsky, H. (1999). Analyzing radioligand binding data. In Graph Pad Prism, Version 2 Manual. ed. Motulsky, H. \& Searle, P. pp. 385. San Diego: Graph Pad Prism Software.

Muir, D. (1990). Level and possible effects of PCBs and other organochlorine contaminants in Arctic and St. Lawrence belugas. In Pour L'Avenir du Beluga (For the Future of the Beluga, Proceedings of the International Forum for the Future of the Beluga, Tadoussac, Quebec, Canada, 29 September - 1 October, 1988). ed. Prescott, J. \& Gauquelin, M. pp. 171-183. Sillery, Quebec: Presses de l'Universite du Quebec.

Nakai, J.S. \& Bunce, N.J. (1995). Characterization of the Ah receptor from human placental tissue. J Biochem Toxicol, 10, 151-159.

Nakajima-Iijima, S., Hamada, H., Reddy, P. \& Kakunaga, T. (1985). Molecular structure of the human cytoplasmic B-actin gene: interspecies homology of sequences in introns. Proc. Natl. Acad. Sci., USA, 82, 6133-6137.

Nambu, J.R., Lewis, J.O., Wharton, K.A. \& Crews, S.T. (1991). The Drosophila singleminded gene encodes a helix-loop-helix protein that acts as a master regulator of CNS midline development. Cell, 67, 1157-1167.

Norstrom, R.J., Muir, D.C.G., Ford, C.A., Simon, M., Macdonald, C.R. \& Beland, P. (1992). Indications of P450 monooxygenase activities in beluga (Delphinapterus leucas) and narwhal (Monodon monoceros) from patterns of PCB, PCDD and PCDF accumulation. Mar. Environ. Res., 34, 267-272.

O'Shea, T.J. (1999). Environmental contaminants and marine mammals. In Biology of Marine Mammals. ed. Reynolds, J.E. \& Rommel, S.A. Washington, D. C.: Smithsonian Institution Press.

Okey, A.B., Vella, L.M. \& Harper, P.A. (1989). Detection and characterization of a low affinity form of cytosolic Ah receptor in livers of mice nonresponsive to induction of cytochrome $\mathrm{P}_{1}-450$ by 3-methylcholanthrene. Mol. Pharmacol., 35, 823-830.

Petrulis, J.R. \& Bunce, N.J. (2000). Competitive behavior in the interactive toxicology of halogenated aromatic compounds. J Biochem Mol Toxicol, 14, 73-81.

Phillips, D.H. (1983). Fifty years of benzo(a)pyrene. Nature, 303, 468-72.

Pitot, H.C., Goldsworthy, T., Campbell, H.A. \& A.Poland (1980). Quantitative evaluation of promotion by TCDD of hepatocarcinogenesis from diethylnitrosamine. Cancer Res., 40, 3616-3620.

Pohjanvirta, R., Viluksela, M., Tuomisto, J.T., Unkila, M., Karasinska, J., Franc, M.A., Holowenko, M., Giannone, J.V., Harper, P.A., Tuomisto, J. \& Okey, A.B. (1999). Physicochemical differences in the AH receptors of the most TCDD-susceptible and the most TCDD-resistant rat strains. Toxicol Appl Pharmacol, 155, 82-95.

Pohjanvirta, R., Wong, J.M.Y., Li, W., Harper, P.A., Tuomisto, J. \& Okey, A.B. (1998). Point mutation in intron sequence causes altered carboxyl-terminal structure in the 
aryl hydrocarbon receptor of the most 2,3,7,8-tetrachlorodibenzo-p-dioxinresistant rat strain. Mol Pharmacol, 54, 86-93.

Poland, A. \& Glover, E. (1988). Ca2+-dependent proteolysis of the Ah receptor. Arch Biochem Biophys, 261, 103-11.

Poland, A. \& Glover, E. (1990). Characterization and strain distribution pattern of the murine Ah receptor specified by the Ahd and Ahb-3 alleles. Mol Pharmacol, 38, 306-12.

Poland, A. \& Glover, E. (1975). Genetic expression of aryl hydrocarbon hydroxylase by 2,3,7,8-tetrachlorodibenzo-p-dioxin: evidence for a receptor mutation in genetically non-responsive mice. Molecular Pharmacology, 11, 389-398.

Poland, A. \& Glover, E. (1976). Studies on the mechanism of induction of aryl hydrocarbon hydroxylase activity: evidence for an induction receptor. pp. 277-91. In: de Serres FJ, et al., ed. In vitro metabolic activation in mutagenesis testing. Amsterdam, North-Holland Publ,.

Poland, A. \& Glover, E. (1987). Variation in the molecular mass of the Ah receptor among vertebrate species and strains of rats. Biochem Biophys Res Commun, 146, 1439-49.

Poland, A., Glover, E., Ebetino, H. \& Kende, A. (1986). Photoaffinity labelling of the Ah receptor. Food Chem Toxicol, 24, 781-7.

Poland, A., Glover, E. \& Kende, A.S. (1976). Stereospecific, high affinity binding of 2,3,7,8-tetrachlorodibenzo-p-dioxin by hepatic cytosol. Evidence that the binding species is receptor for induction of aryl hydrocarbon hydroxylase. J Biol Chem, 251, 4936-46.

Poland, A. \& Knutson, J.C. (1982). 2,3,7,8-tetrachlorodibenzo-p-dioxin and related halogenated aromatic hydrocarbons: examination of the mechanism of toxicity. Annu Rev Pharmacol Toxicol, 22, 517-54.

Poland, A., Palen, D. \& Glover, E. (1994). Analysis of the four alleles of the murine aryl hydrocarbon receptor. Molecular Pharmacology, 46, 915-921.

Pollenz, R.S. (1996). The aryl hydrocarbon receptor, but not the aryl hydrocarbon receptor nuclear translocator protein, is rapidly depleted in hepatic and nonhepatic culture cells exposed to 2,3,7,8-tetrachlorodibenzo-p-dioxin. Molecular Pharmacology, 49, 391-398.

Pollenz, R.S., Santostefano, M.J., Klett, E., Richardson, V.M., Necela, B. \& Birnbaum, L.S. (1998). Female Sprague-Dawley rats exposed to a single oral dose of 2,3,7,8tetrachlorodibenzo-p-dioxin exhibit sustained depletion of aryl hydrocarbon receptor protein in liver, spleen, thymus, and lung. Toxicol Sci, 42, 117-128.

Pollenz, R.S., Sullivan, H.R., Holmes, J., Necela, B. \& Peterson, R.E. (1996). Isolation and expression of cDNAs from rainbow trout (Oncorhynchus mykiss) that encode two novel basic helix-loop-helix/PER-ARNT-SIM (bHLH/PAS) proteins with distinct functions in the presence of the aryl hydrocarbon receptor. Evidence for alternative mRNA splicing and dominant negative activity in the bHLH/PAS family. Journal of Biological Chemistry, 271, 30886-30896.

Probst, M.R., Fan, C.M., Tessierlavigne, M. \& Hankinson, O. (1997). Two murine homologs of the Drosophila single-minded protein that interact with the mouse 
aryl hydrocarbon receptor nuclear translocator protein. $J$ Biol Chem, 272, 44514457.

Puga, A., Barnes, S.J., Chang, C.Y., Zhu, H., Nephew, K.P., Khan, S.A. \& Shertzer, H.G. (2000). Activation of transcription factors activator protein-1 and nuclear factorkappa B by 2,3,7,8-tetrachlorodibenzo-p-dioxin. Biochem Pharmacol, 59, 9971005 .

Roberts, B.J. \& Whitelaw, M.L. (1999). Degradation of the basic helix-loop-helix/PerARNT-Sim homology domain dioxin receptor via the ubiquitin/proteasome pathway. J Biol Chem, 274, 36351-36356.

Roberts, E.A., Johnson, K.C., Harper, P.A. \& Okey, A.B. (1990). Characterization of the Ah receptor mediating aryl hydrocarbon hydroxylase induction in the human liver cell line Hep G2. Arch. Biochem. Biophys., 276, 442-450.

Ross, P.S. (2000). Marine mammals as sentinels in ecological risk assessment. Human and Ecological Risk Assessment, 6, 29-46.

Ross, P.S., Deswart, R.L., Reijnders, P.J.H., Vanloveren, H., Vos, J.G. \& Osterhaus, A.D.M.E. (1995). Contaminant related suppression of delayed-type hypersensitivity and antibody responses in harbor seals fed herring from the Baltic Sea. Environ Health Perspect, 103, 162-167.

Ross, P.S., Ellis, G.M., Ikonomou, M.G., Barrett-Lennard, L.G. \& Addison, R.F. (2000). High PCB concentrations in free-ranging Pacific killer whales, Orcinus orca: effects of age, sex and dietary preference. Mar Poll Bull, 40, 504-515.

Safe, S. (1990). Polychlorinated biphenyls (PCBs), dibenzo-p-dioxins (PCDDs), dibenzofurans (PCDFs), and related compounds: environmental and mechanistic considerations which support the development of toxic equivalency factors (TEFs). CRC Crit. Rev. Toxicol., 21, 51-88.

Safe, S.H. (1994). Polychlorinated Biphenyls (PCBs) - Environmental Impact, Biochemical and Toxic Responses, and Implications for Risk Assessment. CRC Critical Reviews in Toxicology, 24, 87-149.

Sanderson, J.T. \& Bellward, G.D. (1995). Hepatic microsomal ethoxyresorufin Odeethylase-inducing potency in ovo and cytosolic Ah receptor binding affinity of 2,3,7,8-tetrachlorodibenzo-p-dioxin: Comparison of four avian species. Toxicol Appl Pharmacol, 132, 131-145.

Sanderson, J.T., Elliott, J.E., Norstrom, R.J., Whitehead, P.E., Hart, L.E., Cheng, K.M. \& Bellward, G.D. (1994). Monitoring Biological Effects of Polychlorinated Dibenzo-P-Dioxins, Dibenzofurans, and Biphenyls in Great Blue Heron Chicks (Ardea herodias) in British-Columbia. J Toxicol Environ Health, 41, 435-450.

Sanderson, J.T., Norstrom, R.J., Elliott, J.E., Hart, L.E., Cheng, K.M. \& Bellward, G.D. (1994). Biological Effects of Polychlorinated Dibenzo-P-Dioxins, Dibenzofurans, and Biphenyls in Double-Crested Cormorant Chicks (Phalacrocorax Auritus). $J$ Toxicol Environ Health, 41, 247-265.

Schmidt, J.V. \& Bradfield, C.A. (1996). Ah receptor signaling pathways. Annu Rev Cell Dev Biol, 12, 55-89. 
Schmidt, J.V., Su, G.H., Reddy, J.K., Simon, M.C. \& Bradfield, C.A. (1996). Characterization of a murine Ahr null allele: involvement of the Ah receptor in hepatic growth and development. Proc Natl Acad Sci U S A, 93, 6731-6.

Schneider, U.A., Brown, M.M., Logan, R.A., Millar, L.C. \& Bunce, N.J. (1995). Screening assay for dioxin-like compounds based on competitive binding to the murine hepatic Ah receptor. 1. Assay development. Environmental Science and Technology, 29, 2595-2602.

Schwarz, M., Buchmann, A., Stinchcombe, S., Kalkuhl, A. \& Bock, K.W. (2000). Ah receptor ligands and tumor promotion: survival of neoplastic cells. Toxicol Lett, 112, 69-77.

Shimizu, Y., Nakatsuru, Y., Ichinose, M., Takahashi, Y., Kume, H., Mimura, J., FujiiKuriyama, Y. \& Ishikawa, T. (2000). Benzo[a]pyrene carcinogenicity is lost in mice lacking the aryl hydrocarbon receptor. Proc Natl Acad Sci U S A, 97, 779782.

Silkworth, J.B. \& Grabstein, E.M. (1982). Polychlorinated biphenyl immunotoxicity: dependence on isomer planarity and the Ah gene complex. Toxicol Appl Pharm, 65, 109-115.

Smart, J. \& Daly, A.K. (2000). Variation in induced CYP1A1 levels: relationship to CYP1A1, Ah receptor and GSTM1 polymorphisms. Pharmacogenetics, 10, 1124.

Staples, J.E., Murante, F.G., Fiore, N.C., Gasiewicz, T.A. \& Silverstone, A.E. (1998). Thymic alterations induced by 2,3,7,8-tetrachlorodibenzo-p-dioxin are strictly dependent on aryl hydrocarbon receptor activation in hemopoietic cells. $J$ Immunol, 160, 3844-3854.

Starr, T.B., Greenlee, W.F., Neal, R.A., Poland, A. \& Sutter, T.R. (1999). The trouble with TEFs [letter; comment]. Environ Health Perspect, 107, A492-3.

Sun, W., Zhang, J. \& Hankinson, O. (1997). A mutation in the aryl hydrocarbon receptor (AHR) in a cultured mammalian cell line identifies a novel region of AHR that affects DNA binding. Journal of Biological Chemistry, 272, 31845-31854.

Swanson, H.I., Chan, W.K. \& Bradfield, C.A. (1995). DNA binding specificities and pairing rules of the Ah receptor, ARNT, and SIM proteins. J Biol Chem, 270, 26292-302.

Takahashi, Y., Nakayama, K., Shimojima, T., Itoh, S. \& Kamataki, T. (1996). Expression of aryl hydrocarbon receptor (AhR) and aryl hydrocarbon receptor nuclear translocator (Arnt) in adult rabbits known to be non-responsive to cytochrome P450 1A1 (CYP1A1) inducers. Eur J Biochem, 242, 512-518.

Tanabe, S. \& Tatsukawa, R. (1992). Chemical Modernization and vulnerability of cetaceans: increasing toxic threat of organochlorine contaminants. In Persistent Pollutants in Marine Ecosystems. ed. Walker, C.H. \& Livingstone, D.R. pp. 161177: Pergamon.

Tanabe, S., Watanabe, S., Kan, H. \& Tatsukawa, R. (1988). Capacity and mode of PCB metabolism in small cetaceans. Mar. Mam. Sci., 4, 103-124. 
Tanguay, R.L., Abnet, C.C., Heideman, W. \& Peterson, R.E. (1999). Cloning and characterization of the zebrafish (Danio rerio) aryl hydrocarbon receptor. Biochim Biophys Acta (Gene Struct Express), 1444, 35-48.

Thomas, P.E., Kouri, R.E. \& Hutton, J.J. (1972). The genetics of aryl hydrocarbon hydroxylase induction in mice: a single gene difference between $\mathrm{C} 57 \mathrm{BL} / 6 \mathrm{~J}$ and DBA/2J. Biochem. Genet., 6, 157-168.

Thurmond, T.S., Silverstone, A.E., Baggs, R.B., Quimby, F.W., Staples, J.E. \& Gasiewicz, T.A. (1999). A chimeric aryl hydrocarbon receptor knockout mouse model indicates that aryl hydrocarbon receptor activation in hematopoietic cells contributes to the hepatic lesions induced by 2,3,7,8-tetrachlorodibenzo-p-dioxin. Toxicol Appl Pharmacol, 158, 33-40.

Thurmond, T.S., Staples, J.E., Silverstone, A.E. \& Gasiewicz, T.A. (2000). The aryl hydrocarbon receptor has a role in the in vivo maturation of murine bone marrow B lymphocytes and their response to 2,3,7, 8- tetrachlorodibenzo-p-dioxin [In Process Citation]. Toxicol Appl Pharmacol, 165, 227-36.

Tian, Y., Ke, S., Denison, M.S., Rabson, A.B. \& Gallo, M.A. (1999). Ah receptor and NF-kappa B interactions, a potential mechanism for dioxin toxicity. Journal of Biological Chemistry, 274, 510-515.

Tsui, H.W. \& Okey, A.B. (1981). Rapid vertical tube rotor gradient assay for binding of 2,3,7,8-tetrachlorodibenzo-p-dioxin to the Ah receptor. Can. J. Physiol. Pharmacol., 59, 927-931.

Tucker, A.N., Vore, S.J. \& Luster, M.I. (1986). Suppression of B cell differentiation by 2,3,7,8-tetrachlorodibenzo-p-dioxin. Mol. Pharmacol., 29, 372-377.

van den Berg, M., Birnbaum, L., Bosveld, B.T.C., Brunström, B., Cook, P., Feeley, M., Giesy, J.P., Hanberg, A., Hasegawa, R., Kennedy, S.W., Kubiak, T., Larsen, J.C., Leeuwen, F.X.R.v., Liem, A.K.D., Nolt, C., Peterson, R.E., Poellinger, L., Safe, S., Schrenk, D., Tillitt, D., Tysklind, M., Younes, M., Waern, F. \& Zacharewski, T. (1998). Toxic Equivalency Factors (TEFs) for PCBs, PCDDs, and PCDFs for humans and wildlife. Environmental Health Perspectives, 106, 775-792.

Vandekerckhove, J. \& Weber, K. (1978). Mammalian cytoplasmic actins are the products of at least two genes and differ in primary structure in at least 25 identified positions from skeletal muscle actins. Proc Natl Acad Sci U S A, 75, 1106-10.

Wade, T.L., Chambers, L., Gardinali, P.R., Sericano, J.L., Jackson, T.J., Tarpley, R.J. \& Suydam, R. (1997). Toxaphene, PCB, DDT, and chlordane analyses of Beluga Whale blubber. Chemosphere, 34, 1351-1357.

Watanabe, S., Shimada, T., Nakamura, S., Nishiyama, N., Yamashita, N., Tanabe, S. \& Tatsukawa, R. (1989). Specific profile of liver microsomal cytochrome P-450 in dolphin and whales. Mar. Environ. Res., 27, 51-65.

Wenger, R.H., Rolfs, A., Kvietikova, I., Spielmann, P., Zimmerman, D.R. \& Gassmann, M. (1997). The mouse gene for the hypoxia-inducible factor-alpha. Eur. $J$. Biochem, 246, 155-165.

White, R.D., Hahn, M.E., Lockhart, W.L. \& Stegeman, J.J. (1994). Catalytic and immunochemical characterization of hepatic microsomal cytochromes P450 in 